\title{
CARBON DIOXIDE CAPTURE FROM FLUE GAS USING DRY REGENERABLE SORBENTS
}

\author{
TOPICAL REPORT
}

DOE Cooperative Agreement No. DE-FC26-00NT40923

Reporting Period: July 1, 2004 to September 30, 2004

For

U.S. Department of Energy

National Energy Technology Laboratory

Pittsburgh, PA 15236

\author{
by \\ David A. Green \\ Brian S. Turk \\ Jeffrey W. Portzer \\ Raghubir P. Gupta \\ William J. McMichael \\ Thomas Nelson \\ Santosh Gangwal \\ Ya Liang* \\ Tyler Moore* \\ Margaret Williams* \\ Douglas P. Harrison* \\ Submitted by: \\ Research Triangle Institute \\ Post Office Box 12194 \\ Research Triangle Park, NC 27709-2194 \\ * Louisiana State University \\ Department of Chemical Engineering \\ Baton Rouge, LA 70803
}

November 2004 


\section{DISCLAIMER}

This report was prepared as an account of work sponsored by an agency of the United States Government. Neither the United States Government nor any agency thereof, nor any of their employees, makes any warranty, express or implied, or assumes any legal liability or responsibility for the accuracy, completeness, or usefulness of any information, apparatus, product, or process disclosed, or represents that its use would not infringe privately owned rights. Reference herein to any specific commercial product, process, or service by trade name, trademark, manufacturer, or otherwise does not necessarily constitute or imply its endorsement, recommendation, or favoring by the United States Government or any agency thereof. The views and opinions of authors expressed therein do not necessarily state or reflect those of the United States Government or any agency thereof. 


\begin{abstract}
Laboratory studies were conducted to investigate dry, regenerable, alkali carbonate-based sorbents for the capture of $\mathrm{CO}_{2}$ from power plant flue gas. Electrobalance, fixed-bed and fluidbed reactors were used to examine both the $\mathrm{CO}_{2}$ capture and sorbent regeneration phases of the process. Sodium carbonate-based sorbents (calcined sodium bicarbonate and calcined trona) were the primary focus of the testing. Supported sodium carbonate and potassium carbonate sorbents were also tested.
\end{abstract}

Sodium carbonate reacts with $\mathrm{CO}_{2}$ and water vapor contained in flue gas at temperatures between 60 and $80^{\circ} \mathrm{C}$ to form sodium bicarbonate, or an intermediate salt (Wegscheider's salt). Thermal regeneration of this sorbent produces an off-gas containing equal molar quantities of $\mathrm{CO}_{2}$ and $\mathrm{H}_{2} \mathrm{O}$. The low temperature range in which the carbonation reaction takes place is suited to treatment of coal-derived flue gases following wet flue gas desulfurization processes, but limits the concentration of water vapor which is an essential reactant in the carbonation reaction. Sorbent regeneration in an atmosphere of $\mathrm{CO}_{2}$ and water vapor can be carried out at a temperature of $160^{\circ} \mathrm{C}$ or higher. Pure $\mathrm{CO}_{2}$ suitable for use or sequestration is available after condensation of the $\mathrm{H}_{2} \mathrm{O}$. Flue gas contaminants such as $\mathrm{SO}_{2}$ react irreversibly with the sorbent so that upstream desulfurization will be required when sulfur-containing fossil fuels are used.

Approximately $90 \% \mathrm{CO}_{2}$ capture from a simulated flue gas was achieved during the early stages of fixed-bed reactor tests using a nominal carbonation temperature of $60^{\circ} \mathrm{C}$. Effectively complete sorbent carbonation is possible when the fixed-bed test is carried out to completion. No decrease in sorbent activity was noted in a 15-cycle test using the above carbonation conditions coupled with regeneration in pure $\mathrm{CO}_{2}$ at $160^{\circ} \mathrm{C}$.

Fluidized-bed reactor tests of up to five cycles were conducted. Carbonation of sodium carbonate in these tests is initially very rapid and high degrees of removal are possible. The exothermic nature of the carbonation reaction resulted in a rise in bed temperature and subsequent decline in removal rate. Good temperature control, possibly through addition of supplemental water and evaporative cooling, appears to be the key to getting consistent carbon dioxide removal in a full-scale reactor system.

The tendency of the alkali carbonate sorbents to cake on contact with liquid water complicates laboratory investigations as well as the design of larger scale systems. Also their low attrition resistance appears unsuitable for their use in dilute-phase transport reactor systems. Sodium 
and potassium carbonate have been incorporated in ceramic supports to obtain greater surface area and attrition resistance, using a laboratory spray dryer. The caking tendency is reduced and attrition resistance increased by supporting the sorbent. Supported sorbents with loading of up to $40 \mathrm{wt} \%$ sodium and potassium carbonate have been prepared and tested. These materials may improve the feasibility of large-scale $\mathrm{CO}_{2}$ capture systems based on short residence time dilute-phase transport reactor systems. 


\section{TABLE OF CONTENTS}

Chapter

Page

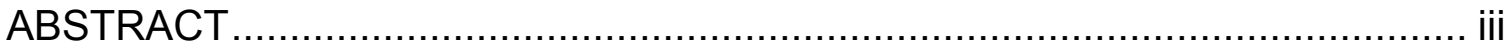

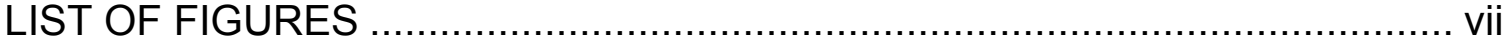

LIST OF FIGURES (continued)..............................................................iii

LIST OF FIGURES (continued)............................................................... ix

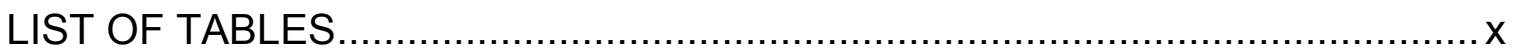

LIST OF ACRONYMS AND ABBREVIATIONS ….......................................

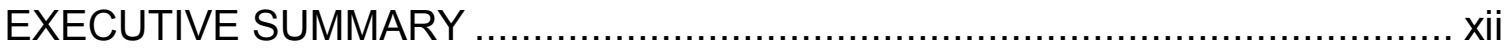

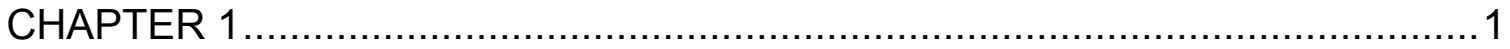

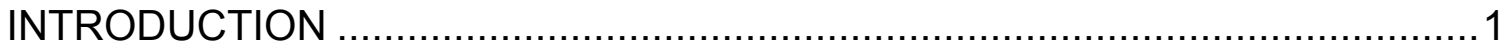

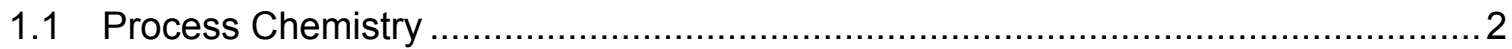

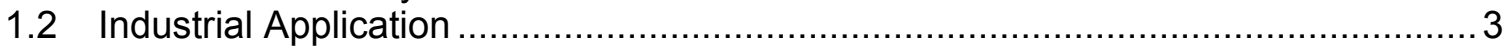

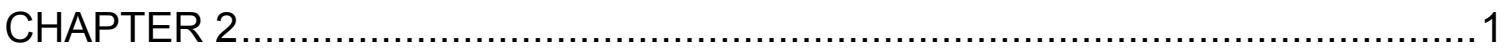

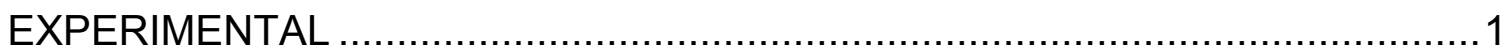

2.1 Electrobalance Experiments Conducted at LSU ………................................ 1

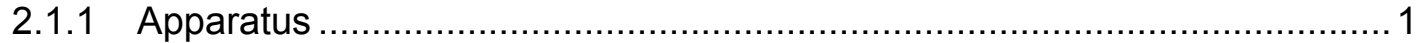

2.1.2 Electrobalance Reaction Conditions.................................................... 1

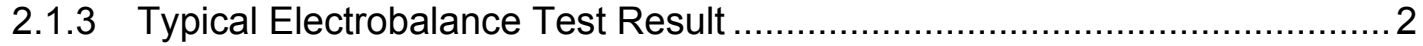

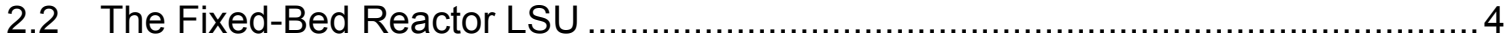

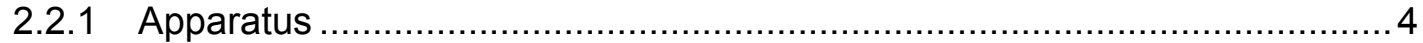

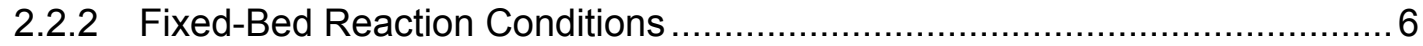

2.2.3 Typical Fixed-Bed Test Result......................................................

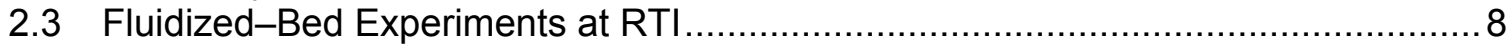

2.4 Determination of Physical Properties of Sorbents ...........................................

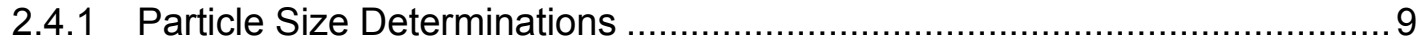

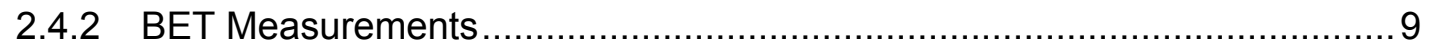

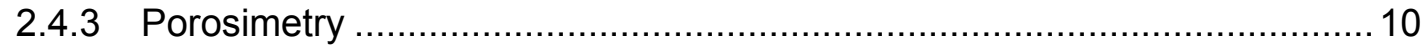

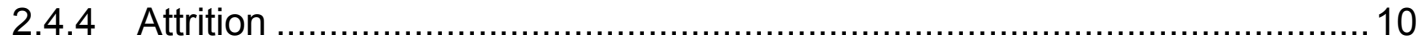

2.5 Preparation of Supported Sorbents ............................................................... 11

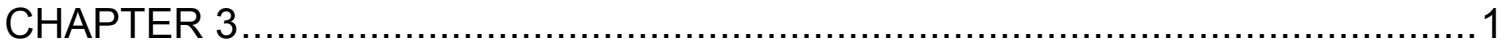

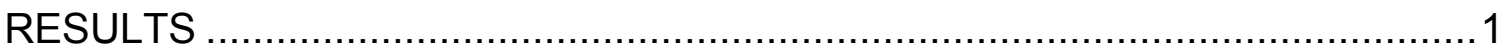

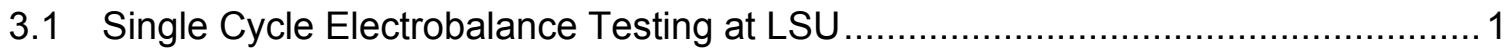

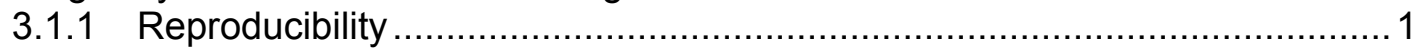

3.1.2 The Effect of Carbonation Temperature .............................................. 3

3.1.3 Effect of $\mathrm{CO}_{2}$ and $\mathrm{H}_{2} \mathrm{O}$ Concentration.............................................. 4

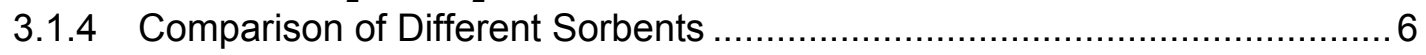

3.1.5 Effect of Calcination Temperature and Atmosphere................................ 7

3.2 Multicycle Electrobalance Testing at LSU ……............................................ 8

3.2.1 Dimensionless Weight Versus Time Results ....................................... 8

3.1.3 Fractional Carbonation Versus Cycle Number Results ............................ 12

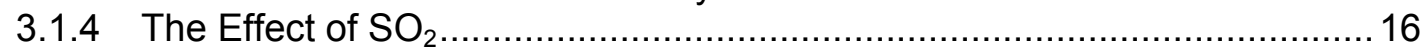


3.3 Fixed-Bed Reactor Testing at LSU............................................................ 19

3.3.1 Five-Cycle Tests With Calcination in $\mathrm{N}_{2}$ at $120^{\circ} \mathrm{C} \ldots \ldots \ldots \ldots \ldots \ldots \ldots \ldots \ldots \ldots \ldots \ldots . .19$

3.3.2 Multicycle Tests With Calcination in $\mathrm{CO}_{2}$ at $160^{\circ} \mathrm{C}$ and $200^{\circ} \mathrm{C} \ldots \ldots \ldots \ldots \ldots . . .24$

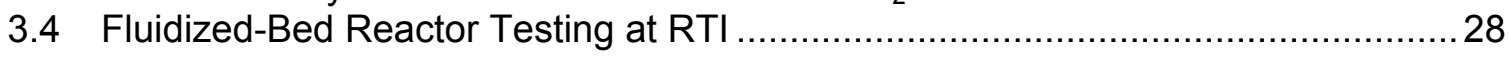

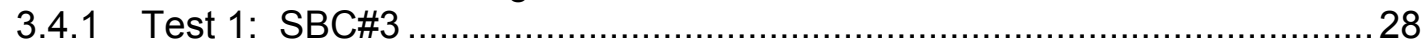

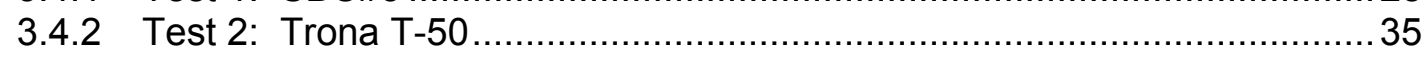

3.4.3 Test 3: Potassium Carbonate: 1 cycle ................................................ 38

3.4.4 Test 4: Trona T-50 (5 cycles) ………………............................... 40

3.4.5 Test 5: Spray-Dried 40\% Supported Potassium Carbonate (5 Cycles) ..... 47

3.4.6 Test 6: 10\% Supported Potassium Carbonate (5-cycles)..........................52

3.5 Properties of Unsupported Sorbents and Sorbent Precursors ............................58

3.6 Characterization and Testing of Supported Materials ……..................................58

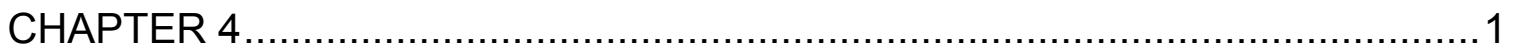

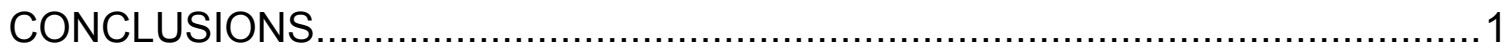

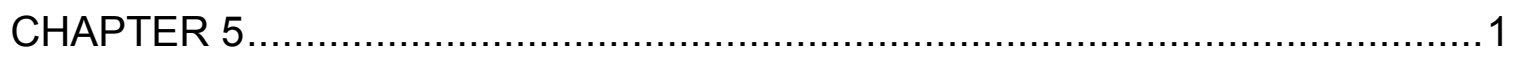

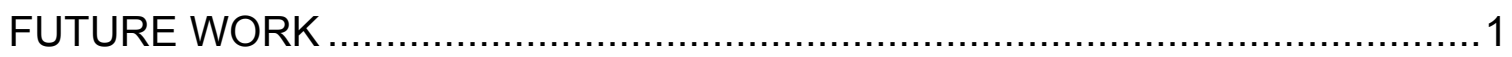

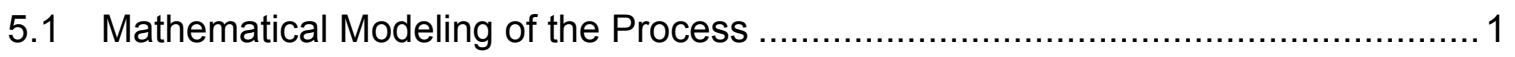

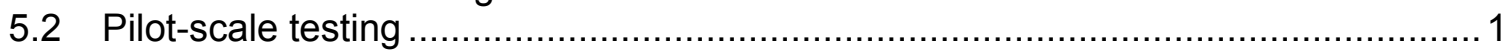

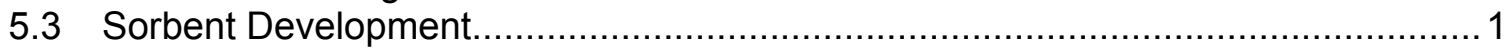

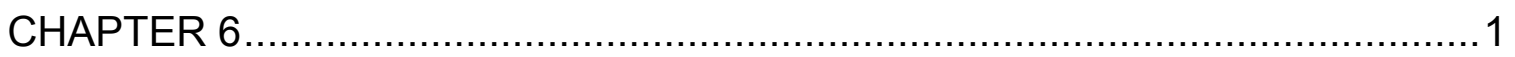

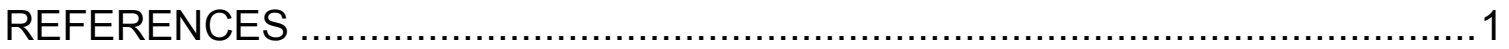




\section{LIST OF FIGURES}

\section{Number}

1 Conceptual carbon dioxide capture process using regenerable sorbent

2 Schematic of the electrobalance reactor system

3 Typical results from a single-cycle electrobalance test (SBC\#3)

4 Schematic of the fixed-bed reactor system

5 Typical results from a two-cycle fixed-bed reactor test (SBC\#3)

6 Fluidized-bed test reactor system

7 NOVA 1000 flow diagram

8 Duplicate carbonation test results using SBR\#3

9 Duplicate Carbonation Test Results Using Trona T-50

10 Effect of Temperature on the carbonation of SBC\#3

11 Effect of temperature on the carbonation of Trona T-50

12 Effect of $\mathrm{CO}_{2}$ concentration on the carbonation of SBC\#3

13 Effect of $\mathrm{H}_{2} \mathrm{O}$ concentration on the carbonation of SBC\#3

14 Comparison of the carbonation of three sorbents at identical carbonation conditions

15 Effect of calcination atmosphere and temperature on carbonation kinetics (SBC\#3)

16 Raw electrobalance result from a five-cycle test using SBC\#3: Calcination in $\mathrm{He}$ at $120^{\circ} \mathrm{C}$

17 Smoothed electrobalance results for five carbonation cycles using SBC\#3: Calcination in He at $120^{\circ} \mathrm{C}$

18 Raw electrobalance results for five-cycle test using SBC\#3: Calcination in $\mathrm{CO}_{2}$ at $200^{\circ} \mathrm{C}$

19 Smoothed electrobalance results for five carbonation cycles using Trona T-200: calcination in $\mathrm{He}$ at $120^{\circ} \mathrm{C}$

$20 f(25)$ and $f(150)$ from three duplicate tests using SBC\#3: Calcination at $120^{\circ} \mathrm{C}$ in $\mathrm{He}$

21 Comparison of $f(25)$ for carbonation of SBC\#3 at four calcination conditions

22 Comparison of $f(150)$ for carbonation of SBC\#3 at four calcination conditions

$23 f(25)$ comparison for four sorbent using $200^{\circ} \mathrm{C}$ calcination in $\mathrm{CO}_{2}$

$24 f(150)$ comparison for four sorbents using $200^{\circ}$ calcination in $\mathrm{CO}_{2}$

25 The effect of $0.2 \% \mathrm{SO}_{2}$ added to the carbonation gas: Three cycles using SBC\#3

26 The effect of $0.1 \% \mathrm{SO}_{2}$ added to the carbonation gas: Five cycles using Trona T-200

$27 \mathrm{CO}_{2}$ concentration for a 5.5-cycle fixed-bed test using $\mathrm{SBC} 33$ at $60^{\circ} \mathrm{C}$ carbonation temperature and $150 \mathrm{sccm}$ carbonation feed rate

$28 \mathrm{CO}_{2}$ concentration during five carbonation cycles using $\mathrm{SBC} 33$ at a nominal carbonation temperature of $60^{\circ} \mathrm{C}$ and feed rate of $150 \mathrm{sccm}$

$29 \mathrm{CO}_{2}$ concentration during five carbonation cycles using SBC\#3 at a nominal carbonation temperature of $70^{\circ} \mathrm{C}$ and feed rate of $150 \mathrm{sccm}$

$30 \mathrm{CO}_{2}$ concentration during five carbonation cycles using SBC\#1 at a nominal carbonation temperature of $60^{\circ} \mathrm{C}$ and feed rate of $150 \mathrm{sccm}$.

31 Percentage $\mathrm{CO}_{2}$ removal as a function of nominal carbonation temperature and cycle number of SBC\#3 and SBC\#1 (based on $\mathrm{CO}_{2}$ concentration in the third sample of each carbonation cycle)

32 Final percentage conversion of $\mathrm{Na}_{2} \mathrm{CO}_{3}$ to Wegscheider's salt as a function of carbonation temperature and cycle number using SBC\#3 and SBC\#1

33 Fractional $\mathrm{CO}_{2}$ removal as a function of time: Five-cycle testing using $\mathrm{SBC \# 3}$ with calcination in $\mathrm{CO}_{2}$ at $160^{\circ} \mathrm{C}$, first test 


\section{LIST OF FIGURES (continued)}

\section{Number}

34 Fractional $\mathrm{CO}_{2}$ removal as a function of time: Five-cycle test using SBC\#3 with calcination at $160^{\circ} \mathrm{C}$ in $\mathrm{CO}_{2}$, second test

35 Fractional $\mathrm{CO}_{2}$ removal as a function of time: Five-cycle test using SBC\#3 with calcination in $\mathrm{CO}_{2}$ at $200^{\circ} \mathrm{C}$

36 Fractional $\mathrm{CO}_{2}$ Removal in the third carbonation sample as a function of cycle number: SBC\#3 with calcination in $\mathrm{CO}_{2}$ at $160^{\circ} \mathrm{C}$ and $200^{\circ} \mathrm{C}$

37 Cycle 1 carbonation test $(9 / 19 / 01)$ - fractional $\mathrm{CO}_{2}$ removal

38 Cycle 2 carbonation test $(9 / 20 / 01)$ - fractional $\mathrm{CO}_{2}$ removal

39 Cycle 3 carbonation test (9/25/01) - fractional $\mathrm{CO}_{2}$ removal

40 Cycle 4 carbonation test (9/26/01) - fractional $\mathrm{CO}_{2}$ removal

41 Cycle 5 carbonation test $(9 / 27 / 01)$ - fractional $\mathrm{CO}_{2}$ removal

42 Temperature profile - Cycle $1(9 / 19 / 01)$

43 Temperature profile - Cycle $2(9 / 20 / 01)$

44 Temperature profile - Cycle $3(9 / 25 / 01)$

45 Temperature profile - Cycle $4(9 / 26 / 01)$

46 Temperature profile - Cycle $5(9 / 27 / 01)$

47 Temperature profile - Cycle 1 with Trona T-50

48 Cycle 1 carbonation test with Trona T-50

49 Temperature profile - Cycle 2 with Trona T-50

50 Cycle 2 carbonation test with Trona T-50

51 Fluidized-bed carbonation of potassium carbonate $(3 / 11 / 02)$

52 Temperature profile for fluidized-bed carbonation of potassium carbonate

53 Carbon dioxide removal and trona Cycle 1 - 5/13/2002

54 Temperature profile - carbonation Cycle 1 - 5/13/2002

55 Carbon dioxide removal with trona - Cycle $2-5 / 14 / 2002$

56 Temperature profile - carbonation Cycle 2 - 5/14/2002

57 Carbon dioxide removal with trona - Cycle 3 - 5/15/2002

58 Temperature profile - carbonation Cycle $3-5 / 15 / 2002$

59 Carbon dioxide removal with trona - Cycle 4 - 5/16/2002

60 Temperature profile - carbonation Cycle 4 - 5/16/2002

61 Carbon dioxide removal with trona - Cycle 5 - 5/20/2002

62 Temperature profile - carbonation Cycle 8 - 5/20/2002

63 Fluidized-bed carbonation of $40 \%$ supported potassium carbonate - Cycle 1

64 Temperature profile - 40\% supported potassum carbonate - Cycle 1

65 Fluidized-bed carbonation of $40 \%$ supported potassium carbonate - Cycle 2

66 Temperature profile - $40 \%$ supported potassium carbonate - Cycle 2

67 Fluidized-bed carbonation of $40 \%$ supported potassium carbonate - Cycle 3

68 Temperature profile - $40 \%$ supported potassium carbonate - Cycle 3

69 Fluidized-bed carbonation of $40 \%$ supported potassium carbonate - Cycle 4

70 Temperature profile - $40 \%$ supported potassium carbonate - Cycle 4

71 Fluidized-bed carbonation of $40 \%$ supported potassium carbonate - Cycle 5

72 Temperature profile - $40 \%$ supported potassium carbonate - Cycle 5

73 Test data from carbonation cycle

74 Test data from carbonation Cycle 2 with $10 \%$ supported potassium carbonate sorbent $\mathrm{CO}_{2}$ removal 


\section{LIST OF FIGURES (continued)}

\section{Number}

75 Test data from carbonation Cycle 2 with $10 \%$ supported potassium carbonate sorbent average bed temperature

76 Test data from carbonation Cycle 4 with $10 \%$ supported potassium carbonate sorbent $\mathrm{CO}_{2}$ concentration in reactor exit gas

77 Test data from carbonation Cycle 4 with $10 \%$ supported potassium carbonate sorbent $\mathrm{CO}_{2}$ removal

78 Test data carbonation Cycle 4 with 10\% supported potassium carbonate sorbent - average bed temperature

79 Test data from carbonation Cycle 5 with 10\% supported potassium carbonate sorbent $\mathrm{CO}_{2}$ concentration in reactor exit gas

80 Test data from carbonation Cycle 5 with $10 \%$ supported potassium carbonate sorbent $\mathrm{CO}_{2}$ removal

81 Test data from carbonation Cycle 5 with 10\% supported potassium carbonate sorbent average bed temperature 


\section{LIST OF TABLES}

\section{Number}

1 Summary of Five-Cycle Carbonation Test Data

2 Summary of Two-Cycle Carbonation Test Data

3 Carbon Dioxide Removal in Test 4 (Five-cycle Fluidized Bed Test Using Trona T-50 as Sorbent Precursor)

$4 \quad$ Carbon Dioxide Removal in Test 5 (Five-cycle Fluidized-Bed Test Using Spray Dried Supported Potassium Carbonate)

5 Physical Properties of Sodium Bicarbonate Materials

6 Physical Properties of Trona

7 Supported Sorbent Characterization 


\section{LIST OF ACRONYMS AND ABBREVIATIONS}

$\begin{array}{ll}\text { AR } & \text { Attrition Ration } \\ \text { BET } & \text { Brunauer-Emmett-Teller } \\ \text { FID } & \text { flame ionization detector } \\ \text { HPLC } & \text { high-pressure liquid chromatography } \\ \text { LSU } & \text { Louisiana State University } \\ \text { MFC } & \text { mass flow controllers } \\ \text { SBC } & \text { sodium bicarbonate } \\ \text { TCD } & \text { thermal conductivity detector } \\ \text { PTFE } & \text { polytetrafluoroethane } \\ \text { PC } & \text { personal computer } \\ \text { Ppm } & \text { parts per million } \\ \text { sccm } & \text { standard cubic centimeters per minute }\end{array}$




\section{EXECUTIVE SUMMARY}

This report contains information relating to research on the capture of $\mathrm{CO}_{2}$ from flue gas using dry, regenerable, alkali carbonate-based sorbents. The research was sponsored by the U.S. Department of Energy, National Energy Technology Laboratory. RTI International ${ }^{1}$ (RTI) was the prime contractor and Louisiana State University (LSU) served as subcontractor. Church and Dwight, Inc. was the industrial partner for the project.

Combustion of fossil fuels since the beginning of the industrial revolution is believed to be a major cause of the increased concentration of $\mathrm{CO}_{2}$ in the atmosphere. It is becoming clear that improved energy efficiency and substitution of low-carbon fuels, while important, will not be sufficient to limit the growth of atmospheric $\mathrm{CO}_{2}$ concentrations. New technologies for the capture and sequestration of $\mathrm{CO}_{2}$ are needed.

The only currently available process for the capture of $\mathrm{CO}_{2}$ from flue gas streams is based on amine scrubbing, a costly and energy-intensive process. The regenerable sorbent-based process being developed in this project provides an alternate to amine scrubbing. This process is applicable to the capture of $\mathrm{CO}_{2}$ from existing fossil fuel-fired power plants and is potentially applicable to $\mathrm{CO}_{2}$ capture from all stationary fossil fuel combustion sources.

The important reactions involved in the capture of $\mathrm{CO}_{2}$ using sodium carbonate $\left(\mathrm{Na}_{2} \mathrm{CO}_{3}\right)$ sorbents result in the reversible formation of sodium bicarbonate $\left(\mathrm{NaHCO}_{3}\right)$ and Wegscheider's salt $\left(\mathrm{Na}_{2} \mathrm{CO}_{3} \cdot 3 \mathrm{NaHCO}_{3}\right)$ :

$$
\begin{gathered}
\mathrm{Na}_{2} \mathrm{CO}_{3}(\mathrm{~s})+\mathrm{CO}_{2}(\mathrm{~g})+\mathrm{H}_{2} \mathrm{O}(\mathrm{g}) \leftrightarrow 2 \mathrm{NaHCO}_{3}(\mathrm{~s}) \\
\text { and } \\
\mathrm{Na}_{2} \mathrm{CO}_{3}(\mathrm{~s})+0.6 \mathrm{CO}_{2}(\mathrm{~g})+0.6 \mathrm{H} \mathrm{O}(\mathrm{g}) \leftrightarrow 0.4\left[\mathrm{Na}_{2} \mathrm{CO}_{3} \cdot 3 \mathrm{NaHCO}_{3}(\mathrm{~s})\right] .
\end{gathered}
$$

Both forward reactions are exothermic. $\mathrm{CO}_{2}$ capture is accomplished by the forward reactions while equal molar quantities of $\mathrm{CO}_{2}$ and $\mathrm{H}_{2} \mathrm{O}$ are produced by the reverse, or sorbent regeneration, reactions. Condensation of $\mathrm{H}_{2} \mathrm{O}$ from the regeneration product gas results in a pure $\mathrm{CO}_{2}$ product suitable for use or sequestration.

Laboratory studies of the $\mathrm{CO}_{2}$ capture and regeneration reactions have been conducted in an electrobalance (thermogravimetric analyzer) and in bench-scale fixed-bed and fluidized-bed

\footnotetext{
${ }^{1} \mathrm{RTI}$ International is a trade name of Research Triangle Institute.
} 
reactor systems. Physical properties of sorbents including several grades of calcined sodium bicarbonate (SBC), calcined trona, and potassium carbonate have been determined.

Multicycle tests have been conducted to provide preliminary information on sorbent durability. The carbonation reaction was studied in the electrobalance between $60^{\circ} \mathrm{C}$ and $80^{\circ} \mathrm{C}$ using, in most cases, a feed gas containing $8 \% \mathrm{CO}_{2}$ and $16 \% \mathrm{H}_{2} \mathrm{O}$, with the balance made up of an inert gas (either $\mathrm{He}$ or $\mathrm{N}_{2}$ ). These $\mathrm{CO}_{2}$ and $\mathrm{H}_{2} \mathrm{O}$ contents simulate the flue gas formed from the complete combustion of $\mathrm{CH}_{4}$ using $10 \%$ excess air. Calcination was studied between $120^{\circ} \mathrm{C}$ and $200^{\circ} \mathrm{C}$ in an atmosphere ranging from $0 \% \mathrm{CO}_{2}\left(100 \%\right.$ inert) to $100 \% \mathrm{CO}_{2}$. Lowtemperature calcination in an inert atmosphere, while not commercially feasible, was chosen to minimize the severity of the sorbent exposure during the calcination phase. If pure $\mathrm{CO}_{2}$ is to be produced in a commercial process, a high- $\mathrm{CO}_{2}$ calcination atmosphere must be used along with a higher calcination temperature. These tests confirmed that the optimal carbonation temperature was in the $60^{\circ} \mathrm{C}$ to $70^{\circ} \mathrm{C}$ range. The minimum temperature is established by the dew point of the feed gas while the maximum temperature is limited by the thermodynamics of the reversible carbonation reaction. The carbonation rate was found to increase with increases in both the $\mathrm{H}_{2} \mathrm{O}$ and $\mathrm{CO}_{2}$ concentrations.

The addition of $\mathrm{SO}_{2}(0.1 \%$ to $0.4 \%)$ to the carbonation feed gas to simulate the flue gas composition from combustion of a sulfur-containing fuel produced a rapid decrease in $\mathrm{CO}_{2}$ removal capacity due to the formation of $\mathrm{Na}_{2} \mathrm{SO}_{3}$. For example, when $0.1 \% \mathrm{SO}_{2}$ was added to the feed gas, the sorbent capacity for $\mathrm{CO}_{2}$ removal decreased by about $76 \%$ during five-cycle tests. The $\mathrm{Na}_{2} \mathrm{SO}_{3}$ was stable in an inert atmosphere at temperatures as high as $200^{\circ} \mathrm{C}$. When sulfur-containing fossil fuels are used, the $\mathrm{CO}_{2}$ sorbent capture step must be downstream of a desulfurization step.

Fixed-bed reactor tests with product gas analysis as a function of time using gas chromatography were used to study the extent of $\mathrm{CO}_{2}$ removal as a function of time. Nominal carbonation temperatures of $60^{\circ} \mathrm{C}$ and $70^{\circ} \mathrm{C}$ were studied, along with calcination in $\mathrm{N}_{2}$ at $120^{\circ} \mathrm{C}$ and in $\mathrm{CO}_{2}$ at both $160^{\circ} \mathrm{C}$ and $200^{\circ} \mathrm{C}$. Five-cycle tests and one 15-cycle test were used to obtain additional information on sorbent durability. When the fixed-bed tests were carried to completion, the final percentage conversion of $\mathrm{Na}_{2} \mathrm{CO}_{3}$ to Wegscheider's salt was approximately $100 \%$ in the $60^{\circ} \mathrm{C}$ tests and about $90 \%$ in the tests at $70^{\circ} \mathrm{C}$. 
Fluidized-bed reactor tests of up to five cycles were conducted. Carbonation of sodium carbonate in these tests was initially very rapid and high degrees of removal were obtained. The exothermic nature of the carbonation reaction resulted in a rise in bed temperature and subsequent decline in removal rate. Good temperature control, possibly through water addition and subsequent evaporative cooling, appears to be the key to getting consistent carbon dioxide removal in a full-scale reactor system.

The tendency of the alkali carbonate sorbents to cake on contact with liquid water complicates laboratory investigations as well as the design of larger scale systems. The low temperature range in which the carbonation reaction takes place is suited to treatment of coal-derived flue gases following wet flue gas desulfurization processes, but limits the concentration of water vapor which is an essential reactant in the carbonation reaction. Also these sorbents have low attrition resistance and cannot be used without modification in dilute-phase transport reactor systems.

Sodium and potassium carbonate have been incorporated in high surface area ceramic supports to obtain greater surface area and attrition resistance, using a laboratory spray dryer. The caking tendency is reduced and attrition resistance increased by supporting the sorbent. Supported sorbents with loadings of up to $40 \mathrm{wt} \%$ sodium and potassium carbonates have been prepared and tested. These materials may improve the feasibility of large-scale $\mathrm{CO}_{2}$ capture systems based on short residence time dilute-phase transport reactor systems. 


\section{CHAPTER 1}

\section{INTRODUCTION}

Global warming, increasingly thought to be associated with the atmospheric emission of greenhouse gases, principally $\mathrm{CO}_{2}$, is emerging as the key environmental issue of the early $21^{\text {st }}$ century. The average atmospheric concentration of $\mathrm{CO}_{2}$ has increased from $280 \mathrm{ppm}$ to 370 $\mathrm{ppm}$ during the last 150 years, or since the beginning of the industrial revolution. During that same period, the average global temperature has increased by as much as $1^{\circ} \mathrm{C}$ (Berger, 2002). Continued uncontrolled emission of greenhouse gases may lead to increases in sea levels and increased frequency and intensity of climatic extremes such as hurricanes and floods.

Fossil fuels used for power generation, transportation, and by industry are the primary sources of anthropogenic $\mathrm{CO}_{2}$ emissions to the atmosphere. While there are many potential approaches to limiting greenhouse gas emissions, including increased energy efficiency and use of carbonfree or low-carbon fuels, it is becoming increasingly clear that $\mathrm{CO}_{2}$ capture and sequestration must play an important role in attacking the global warming problem. Initial $\mathrm{CO}_{2}$ capture effort will no doubt focus on large stationary sources, with fossil fuel-fired power plants being obvious prime targets. New technologies including $\mathrm{O}_{2}$ combustion with $\mathrm{CO}_{2}$ recycle (Douglas et al., 2003), pre-combustion decarbonization (Doctor et al., 2001), and chemical looping combustion (Hurst et al., 2003; Yu et al., 2003) are under development. These technologies, in addition to being expensive and energy intensive, cannot generally be retrofitted to the large number of existing power plants.

The only currently available process for capturing $\mathrm{CO}_{2}$ from flue gas that is also capable of being retrofitted to existing plants is based on amine scrubbing. For example, the Econamine FG Plus process (Reddy et al., 2003), which uses a solvent of monoethanolamine with an oxidation inhibitor, has been used commercially in a number of plants for $\mathrm{CO}_{2}$ recovery. Aminebased scrubbing processes, however, are costly and energy intensive because of the large volume of gas to be treated, the low partial pressure of $\mathrm{CO}_{2}$ in the flue gas, the presence of contaminants that may be detrimental to the solvent, and the energy demand associated with solvent regeneration.

This study is based on the use of a dry, regenerable, alkali carbonate-based sorbent to remove $\mathrm{CO}_{2}$ from flue gases. Sorbent regeneration produces a gas stream containing only $\mathrm{CO}_{2}$ and $\mathrm{H}_{2} \mathrm{O}$. Condensation of $\mathrm{H}_{2} \mathrm{O}$ produces a pure $\mathrm{CO}_{2}$ stream suitable for subsequent use or 
sequestration. The work described in this report primarily involved sodium carbonate as the active component of the sorbent.

This topical report describes work conducted under a cooperative agreement with the U.S. Department of Energy by RTI International, LSU, and Church and Dwight, Inc.

\subsection{PROCESS CHEMISTRY}

The important reactions involved in the capture of $\mathrm{CO}_{2}$ using sodium carbonate $\left(\mathrm{Na}_{2} \mathrm{CO}_{3}\right)$ sorbent result in the reversible formation of sodium bicarbonate $\left(\mathrm{NaHCO}_{3}\right)$ and Wegscheider's salt $\left(\mathrm{Na}_{2} \mathrm{CO}_{3} \cdot 3 \mathrm{NaHCO}_{3}\right)$ :

$$
\begin{gathered}
\mathrm{Na}_{2} \mathrm{CO}_{3}(\mathrm{~s})+\mathrm{CO}_{2}(\mathrm{~g})+\mathrm{H}_{2} \mathrm{O}(\mathrm{g}) \leftrightarrow 2 \mathrm{NaHCO}_{3}(\mathrm{~s}) \\
\Delta \mathrm{H}_{\mathrm{r}}^{\circ}=-32.4 \mathrm{kcal} / \mathrm{mol} \mathrm{CO}{ }_{2} \\
\mathrm{Na}_{2} \mathrm{CO}_{3}(\mathrm{~s})+0.6 \mathrm{CO}_{2}(\mathrm{~g})+0.6 \mathrm{H} \mathrm{O}(\mathrm{g}) \leftrightarrow 0.4\left[\mathrm{Na}_{2} \mathrm{CO}_{3} \cdot 3 \mathrm{NaHCO}_{3}(\mathrm{~s})\right] \\
\Delta \mathrm{H}_{\mathrm{r}}^{\circ}=-32.5 \mathrm{kcal} / \mathrm{mol} \mathrm{CO}{ }_{2}
\end{gathered}
$$

Several patents (Krieg et al., 1984; Sarapata et al., 1987; and Falotico, 1993) describe processes and process improvements to optimize Reaction 1. Both forward reactions are exothermic; energy management will be an important consideration in a commercial system. Other potential reaction products such as sodium sesquicarbonate, $\mathrm{Na}_{2} \mathrm{CO}_{3} \cdot \mathrm{NaHCO}_{3} \cdot 2 \mathrm{H}_{2} \mathrm{O}$, and sodium bicarbonate hydrate, $\mathrm{NaHCO}_{3} \cdot 2 \mathrm{H}_{2} \mathrm{O}$, were found to be of negligible importance at reaction conditions of interest.

Phase diagrams supplied by Church and Dwight, Inc. (Church and Dwight, 2000), indicate that Wegscheider's salt is favored at reaction conditions of $70^{\circ} \mathrm{C}$ and above at the $\mathrm{H}_{2} \mathrm{O}$ and $\mathrm{CO}_{2}$ partial pressures studied. X-ray diffraction analysis of the product from a fixed-bed reactor test at a nominal temperature of $70^{\circ} \mathrm{C}$ confirmed the formation of Wegscheider's salt.

Trona (a naturally occurring mineral used for production of soda ash) may be used to produce a regenerable sorbent for $\mathrm{CO}_{2}$ according to the following reactions:

Trona is initially calcined according to

$$
2\left[\mathrm{Na}_{2} \mathrm{CO}_{3} \cdot \mathrm{NaHCO}_{3} \cdot 2 \mathrm{H}_{2} \mathrm{O}(\mathrm{s})\right] \rightarrow 3 \mathrm{Na}_{2} \mathrm{CO}_{3}(\mathrm{~s})+\mathrm{CO}_{2}(\mathrm{~g})+5 \mathrm{H}_{2} \mathrm{O}(\mathrm{g})
$$

Subsequent carbonation and calcination reactions proceed according to

$$
\mathrm{Na}_{2} \mathrm{CO}_{3}(\mathrm{~s})+\mathrm{CO}_{2}(\mathrm{~g})+\mathrm{H}_{2} \mathrm{O}(\mathrm{g}) \leftrightarrow 2 \mathrm{NaHCO}_{3}(\mathrm{~s})
$$


Potential contaminants in flue gas, such as $\mathrm{SO}_{2}$ and $\mathrm{HCl}$, will react irreversibly with $\mathrm{Na}_{2} \mathrm{CO}_{3}$ and must be reduced to low levels prior to $\mathrm{CO}_{2}$ capture. $\mathrm{HCl}$ and $\mathrm{SO}_{2}$ in the flue gas are also absorbed by $\mathrm{Na}_{2} \mathrm{CO}_{3}$ according to the following reactions:

$$
\begin{aligned}
& \mathrm{Na}_{2} \mathrm{CO}_{3}(\mathrm{~s})+2 \mathrm{HCl}(\mathrm{g}) \rightarrow 2 \mathrm{NaCl}(\mathrm{s})+\mathrm{CO}_{2}(\mathrm{~g})+\mathrm{H}_{2} \mathrm{O}(\mathrm{g}) \\
& \mathrm{Na}_{2} \mathrm{CO}_{3}(\mathrm{~s})+\mathrm{SO}_{2}(\mathrm{~g})+1 / 2 \mathrm{O}_{2}(\mathrm{~g}) \rightarrow \mathrm{Na}_{2} \mathrm{SO}_{4}(\mathrm{~s})+\mathrm{CO}_{2}(\mathrm{~g})
\end{aligned}
$$

Reactions 5 and 6 are not reversible under the conditions expected for regenerable capture of $\mathrm{CO}_{2}$.

\subsection{INDUSTRIAL APPLICATION}

A process based on the chemistry described above could be retrofitted into existing power plants or installed in new plants. A conceptual process employing fast fluidized-bed reactors for carbonation and regeneration of sorbent is shown in Figure 1.

The technical feasibility of such a process depends on rapid reaction rates and long sorbent life. Important economic factors include the use of low-value heat from the power plant for sorbent regeneration and efficient movement of sorbent.

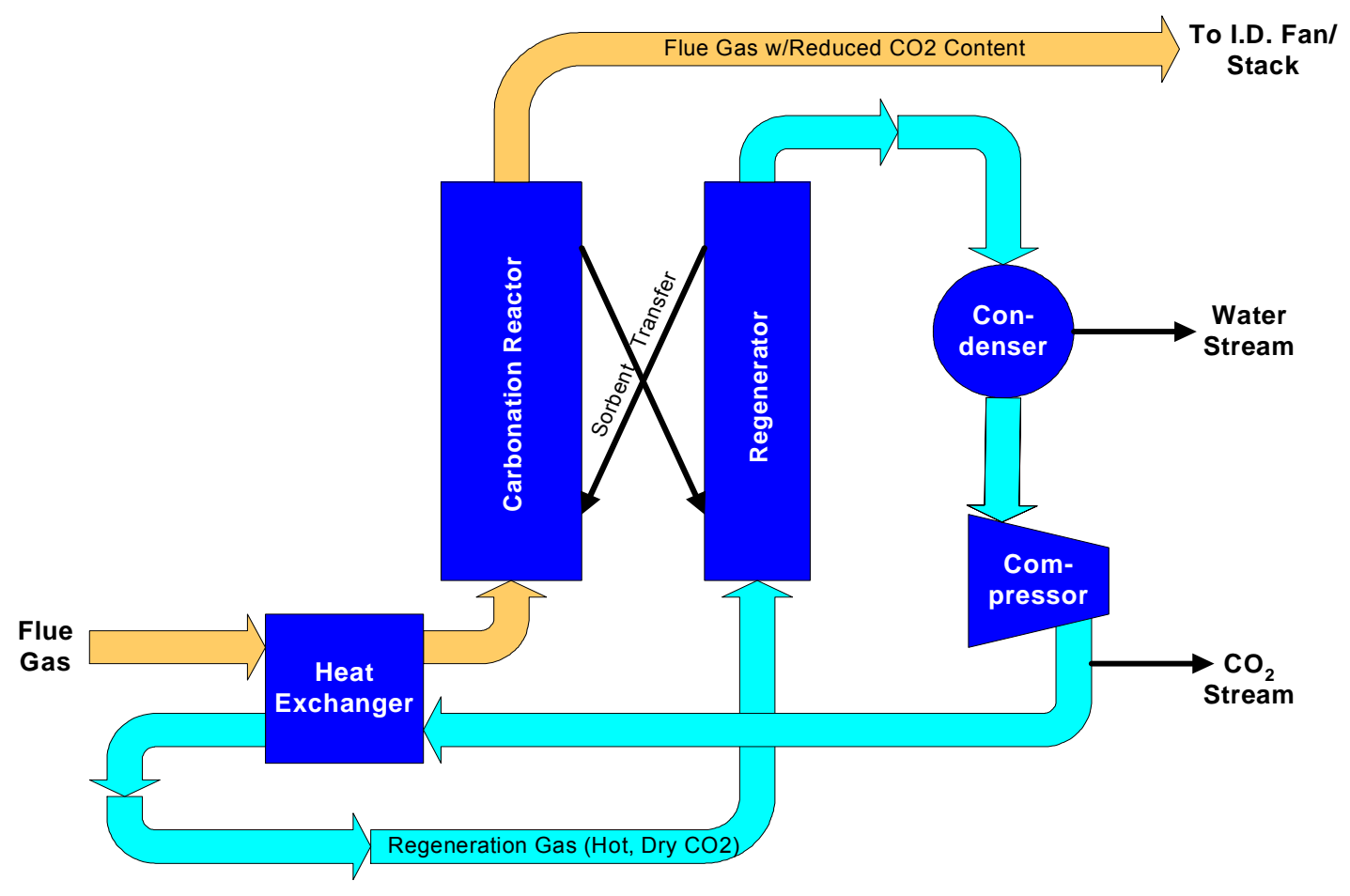

Figure 1. Conceptual carbon dioxide capture process using regenerable sorbent 


\section{CHAPTER 2}

\section{EXPERIMENTAL}

\subsection{ELECTROBALANCE EXPERIMENTS CONDUCTED AT LSU}

\subsubsection{Apparatus}

The electrobalance reactor (or thermogravimetric analyzer [TGA]) monitors the change in weight associated with reaction as a function of time, temperature, and feed gas composition, but provides no information on $\mathrm{CO}_{2}$ removal efficiency. A schematic diagram of the electrobalance reactor system, which consists of a gas flow system, a Cahn model 2000 electrobalance, a MicRICON temperature programmer-controller, and a personal computer $(\mathrm{PC})$ for data acquisition and storage, is shown in Figure 2. Pure $\mathrm{He}$ and $\mathrm{CO}_{2}$ were obtained from highpressure cylinders and their flow rates were monitored using calibrated rotameters equipped with needle valves. Helium was used as the inert gas instead of $\mathrm{N}_{2}$ to reduce aerodynamic noise and increase electrobalance sensitivity. $\mathrm{H}_{2} \mathrm{O}$ was fed as a liquid using a positive displacement syringe pump. Feed lines were heat traced to insure complete vaporization of the $\mathrm{H}_{2} \mathrm{O}$. The He flow was split with a portion introduced at the top of the system to protect the electrobalance mechanism from corrosive reactive gases. The remaining $\mathrm{He}$, mixed with $\mathrm{CO}_{2}$ and steam, was fed to the electrobalance side arm, and the combined gases flowed downward over the reacting solid. The solid was held in a quartz cup and suspended from the electrobalance using a Pt wire. Temperature was monitored and controlled from a chromelalumel thermocouple positioned approximately $1 / 4$-inch below the sample in the isothermal zone.

\subsubsection{Electrobalance Reaction Conditions}

The effects of calcination and carbonation temperature and calcination and carbonation gas composition were examined in the electrobalance tests. In addition, multicycle tests were carried out to obtain preliminary data on sorbent durability. Six sorbents were tested, but the extent of testing varied between the sorbents. Calcination temperature was varied between $120^{\circ} \mathrm{C}$ and $200^{\circ} \mathrm{C}$ while most calcination tests used an atmosphere of pure $\mathrm{He}$. The $\mathrm{He}$ atmosphere is not realistic from a commercial viewpoint, but was chosen to minimize the severity of sorbent exposure during the calcination phase. Additional calcination tests were carried out in more realistic conditions using pure $\mathrm{CO}_{2}$ and in a mixture of $80 \% \mathrm{CO}_{2}-20 \% \mathrm{H}_{2} \mathrm{O}$. However, the increased $\mathrm{CO}_{2}$ partial pressure required a higher calcination temperature. 


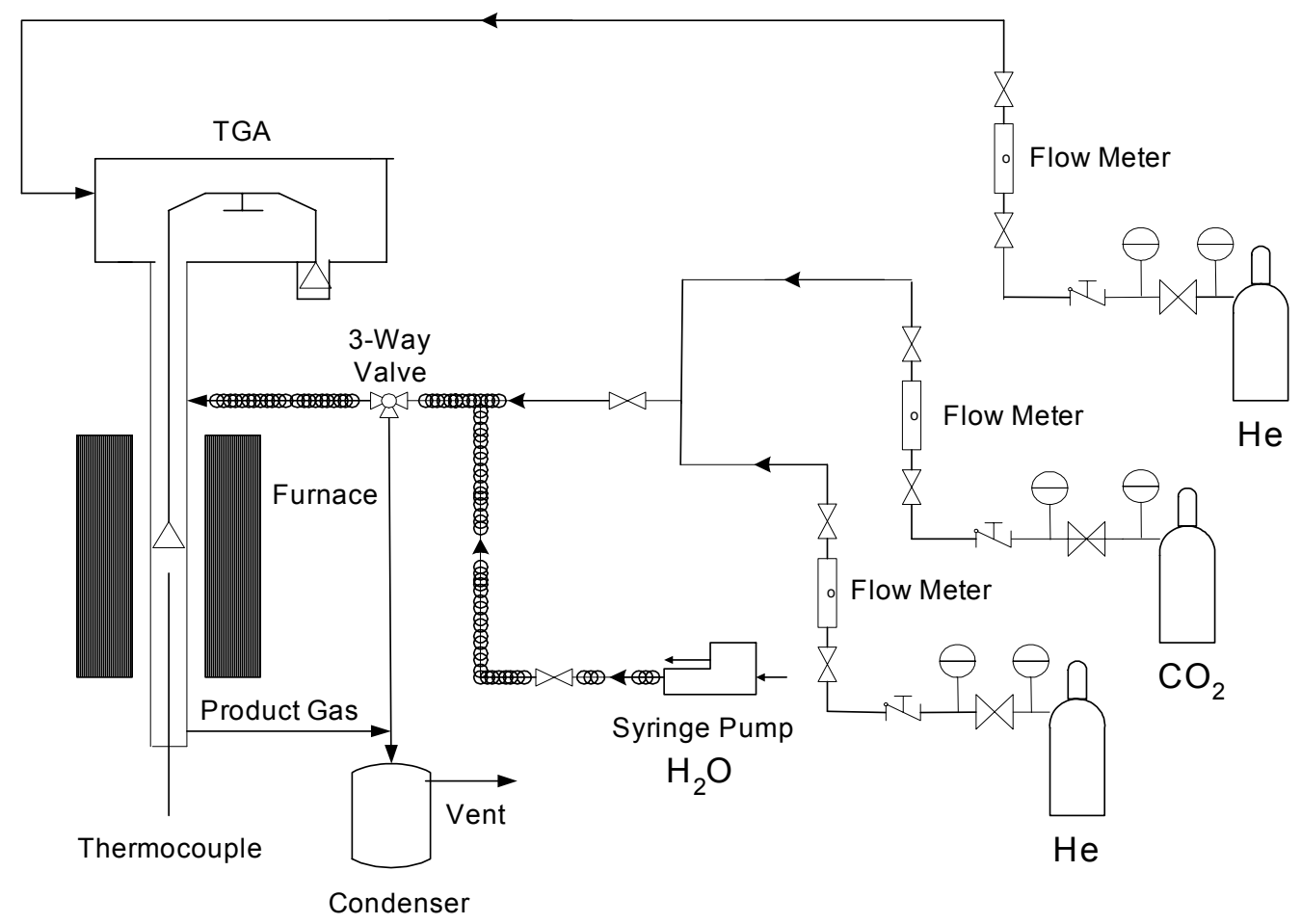

Figure 2. Schematic of the electrobalance reactor system

Carbonation temperature was varied between $60^{\circ} \mathrm{C}$ and $80^{\circ} \mathrm{C}$ and most carbonation tests used a standard feed composition of $8 \% \mathrm{CO}_{2}, 16 \% \mathrm{H}_{2} \mathrm{O}$, and $76 \% \mathrm{He}$ (all mol \%). With the exception of the substitution of $\mathrm{He}$ for $\mathrm{N}_{2}$ and the absence of excess $\mathrm{O}_{2}$, this composition approximates that of flue gas obtained when natural gas is completely combusted in $10 \%$ excess air. In selected tests the $\mathrm{CO}_{2}$ and $\mathrm{H}_{2} \mathrm{O}$ concentrations were varied to determine the effect of these gas concentrations. Carbonation product was considered to be $\mathrm{NaHCO}_{3}$ in tests conducted at $60^{\circ} \mathrm{C}$, and Wegscheider's salt in tests at $70^{\circ} \mathrm{C}$ and $80^{\circ} \mathrm{C}$.

\subsubsection{Typical Electrobalance Test Result}

Results of a typical single-cycle electrobalance test using sorbent SBC\#3 are shown in Figure 3 where dimensionless weight and temperature are plotted versus time. Approximately $70 \mathrm{mg}$ of sorbent precursor was heated from ambient to $100^{\circ} \mathrm{C}$ at a rate of $5^{\circ} \mathrm{C} / \mathrm{min}$, and then to $120^{\circ} \mathrm{C}$ at $1^{\circ} \mathrm{C} /$ min under flowing $\mathrm{He}$. Calcination of $\mathrm{NaHCO}_{3}$ to $\mathrm{Na}_{2} \mathrm{CO}_{3}$ began at about $100^{\circ} \mathrm{C}$ and was complete soon after the temperature reached $120^{\circ} \mathrm{C}$. The final experimental dimensionless weight was quite near the theoretical value of 0.631 that is indicated by the horizontal dashed 
line in the figure. The system was then cooled to the carbonation temperature under flowing $\mathrm{He}$ and, after about $190 \mathrm{~min}$, the gas composition was changed to $8 \% \mathrm{CO}_{2}, 16 \% \mathrm{H}_{2} \mathrm{O}$, and $76 \% \mathrm{He}$ flowing at $600 \mathrm{sccm}$. The subsequent increase in dimensionless weight corresponded to the carbonation of $\mathrm{Na}_{2} \mathrm{CO}_{3}$ and removal of $\mathrm{CO}_{2}$ from the gas phase. The global carbonation rate was rapid initially and decreased as the reaction approached completion. The final dimensionless weight of 0.84 was quite near the theoretical value of 0.85 corresponding to the complete conversion of $\mathrm{Na}_{2} \mathrm{CO}_{3}$ to Wegscheider's salt.

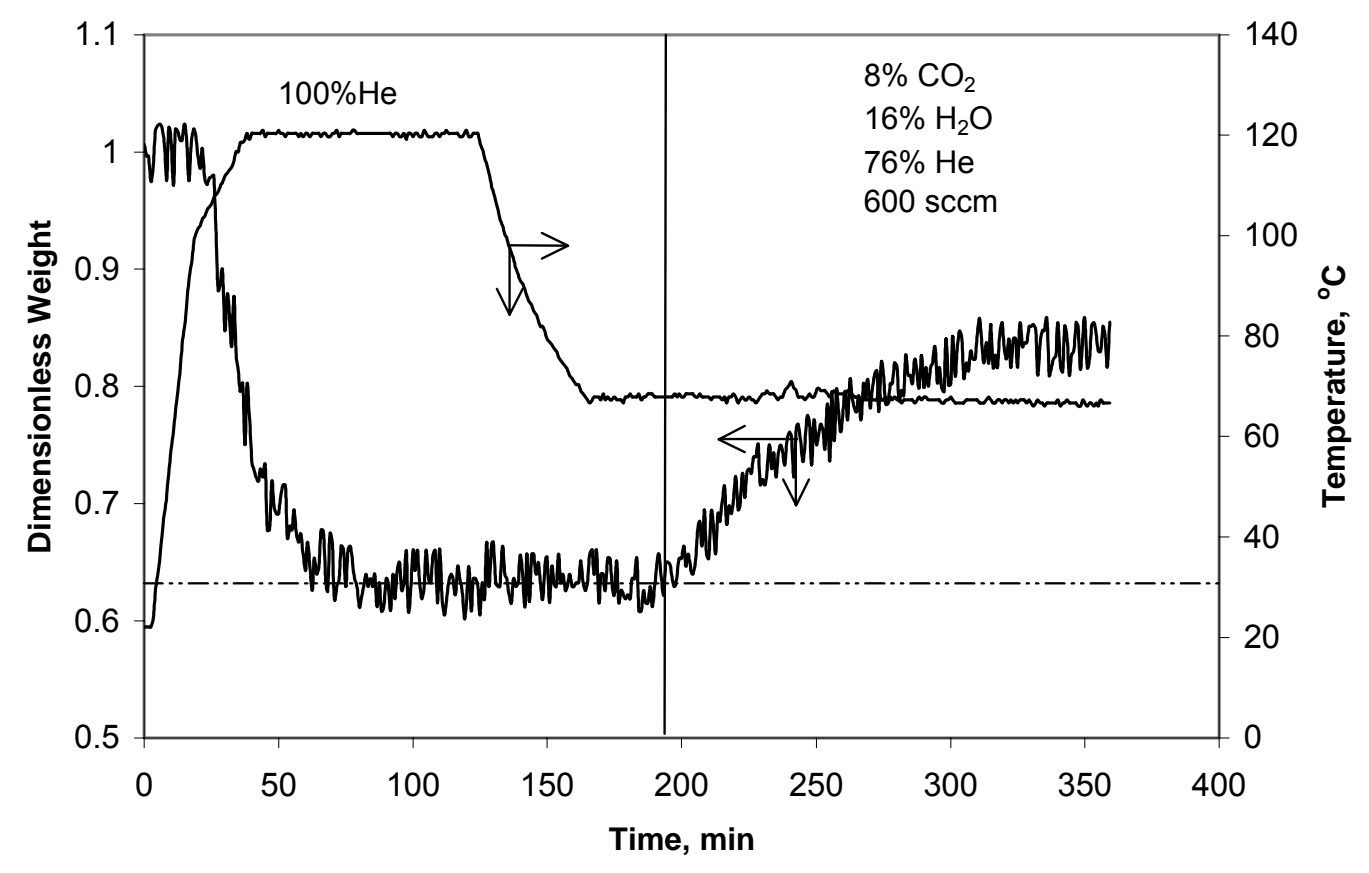

Figure 3. Typical results from a single-cycle electrobalance test (SBC\#3)

Calcination of both the SBC and trona samples was complete in all of the electrobalance tests presented in this report. Many of the carbonation results that follow are presented as fractional carbonation at selected times. The equations for calculating fractional carbonation depend on both the composition of the precursor and whether the carbonation product is $\mathrm{Na}_{2} \mathrm{CO}_{3}$ or Wegscheider's salt. The following equations have been used.

SBC Precursor $-\mathrm{Na}_{2} \mathrm{CO}_{3}$ Product

$$
f(t)=\frac{w(t)-0.631}{0.369}
$$


SBC Precursor - Wegscheider's Salt Product

$$
f(t)=\frac{w(t)-0.631}{0.221}
$$

Trona T-50 Precursor $-\mathrm{Na}_{2} \mathrm{CO}_{3}$ Product

$$
f(t)=\frac{w(t)-0.723}{0.385}
$$

Trona T-50 Precursor - Wegscheider's Salt Product

$$
f(t)=\frac{w(t)-0.723}{0.231}
$$

Trona T-200 Precursor $-\mathrm{Na}_{2} \mathrm{CO}_{3}$ Product

$$
f(t)=\frac{w(t)-0.711}{0.401}
$$

Trona T-200 Precursor - Wegscheider's Salt Product

$$
f(t)=\frac{w(t)-0.711}{0.241}
$$

In equations 4 through $9, f(t)$ is the fractional carbonation at time $t$, and $w(t)$ is the dimensionless weight at time t. $0.631,0.723$, and 0.711 are the dimensionless weights corresponding to complete calcination of the SBC samples, trona T-50, and trona T-200, respectively. 0.369 , 0.385 , and 0.401 are the dimensionless weight increases associated with complete conversion of the calcined product to $\mathrm{NaHCO}_{3}$ for the SBC samples, trona T-50, and trona T-200, respectively. Finally, $0.221,0.231$, and 0.241 are the dimensionless weight increases associated with complete conversion of the calcined product to Wegscheider's salt for the SBC samples, trona $\mathrm{T}-50$, and trona $\mathrm{T}-200$, respectively. These equations are based on the assumption that the inert materials in trona T-50 and trona T-200 are nonvolatile.

\subsection{THE FIXED-BED REACTOR LSU}

\subsubsection{Apparatus}

The fixed-bed reactor system, shown in Figure 4, also consisted of a gas flow system, the fixedbed reactor, a temperature programmer-controller connected to a single-zone split-tube furnace, and a Shimadzu Model GC-14A gas chromatograph. Pure $\mathrm{CO}_{2}$ and, in this case, inert $\mathrm{N}_{2}$ were obtained from high-pressure cylinders, with flow rates controlled by mass flow controllers. In early tests, as shown in Figure $3, \mathrm{H}_{2} \mathrm{O}$ was added as a liquid using a syringe pump, and the feed 
lines were heat traced to insure complete vaporization. In later tests the syringe pump was replaced and $\mathrm{H}_{2} \mathrm{O}$ was added by bubbling $\mathrm{N}_{2}$ and $\mathrm{CO}_{2}$ gases through $\mathrm{H}_{2} \mathrm{O}$ contained in a temperature-controlled wash bottle. The exit gases were assumed to be saturated with $\mathrm{H}_{2} \mathrm{O}$. The narrow window between the temperature needed to vaporize the $\mathrm{H}_{2} \mathrm{O}$ and the desired reaction temperature prompted this change. With too much preheat added to the $\mathrm{H}_{2} \mathrm{O}$ line from the syringe pump, the combined gas temperature exceeded the desired reaction temperature. With too little preheat, not all of the $\mathrm{H}_{2} \mathrm{O}$ vaporized. Control proved to be easier using the gas bubbler and the quality of data improved after the change was made.

Combined gases entered near the bottom of the reactor vessel, and the gases were preheated to reaction temperature as they flowed upward in the annular space between the vessel and reactor insert. The gases then flowed downward through the fixed bed of sorbent, which was supported using a porous stainless disc. Thin layers of quartz wool were placed between the porous disc and sorbent and also above the sorbent. Product gases exited from the bottom of the reactor vessel into a condenser for removal of excess $\mathrm{H}_{2} \mathrm{O}$, and then passed to the gas chromatograph for analysis.

The gas chromatograph, equipped with an automatic 10-port sampling valve, dual columns, methanizer, and both thermal conductivity detectors (TCDs) and flame ionization detectors (FIDs), was used to determine the $\mathrm{CO}_{2}$ concentration in the product gas as a function of time. Product gases from the condenser first entered a HayeSep-N column to trap trace quantities of moisture that escaped the condenser. $\mathrm{CO}_{2}$ was then separated from the dry gases using a Carboxen 1000 column while the HayeSep column was backflushed to vent. The carrier gas was UHP N $N_{2}$. Gases eluted from the Carboxen column flowed first to the TCD, then to the methanizer where $\mathrm{CO}_{2}$ was converted to $\mathrm{CH}_{4}$, and finally to the FID where the $\mathrm{CO}_{2}$ concentration was determined. 


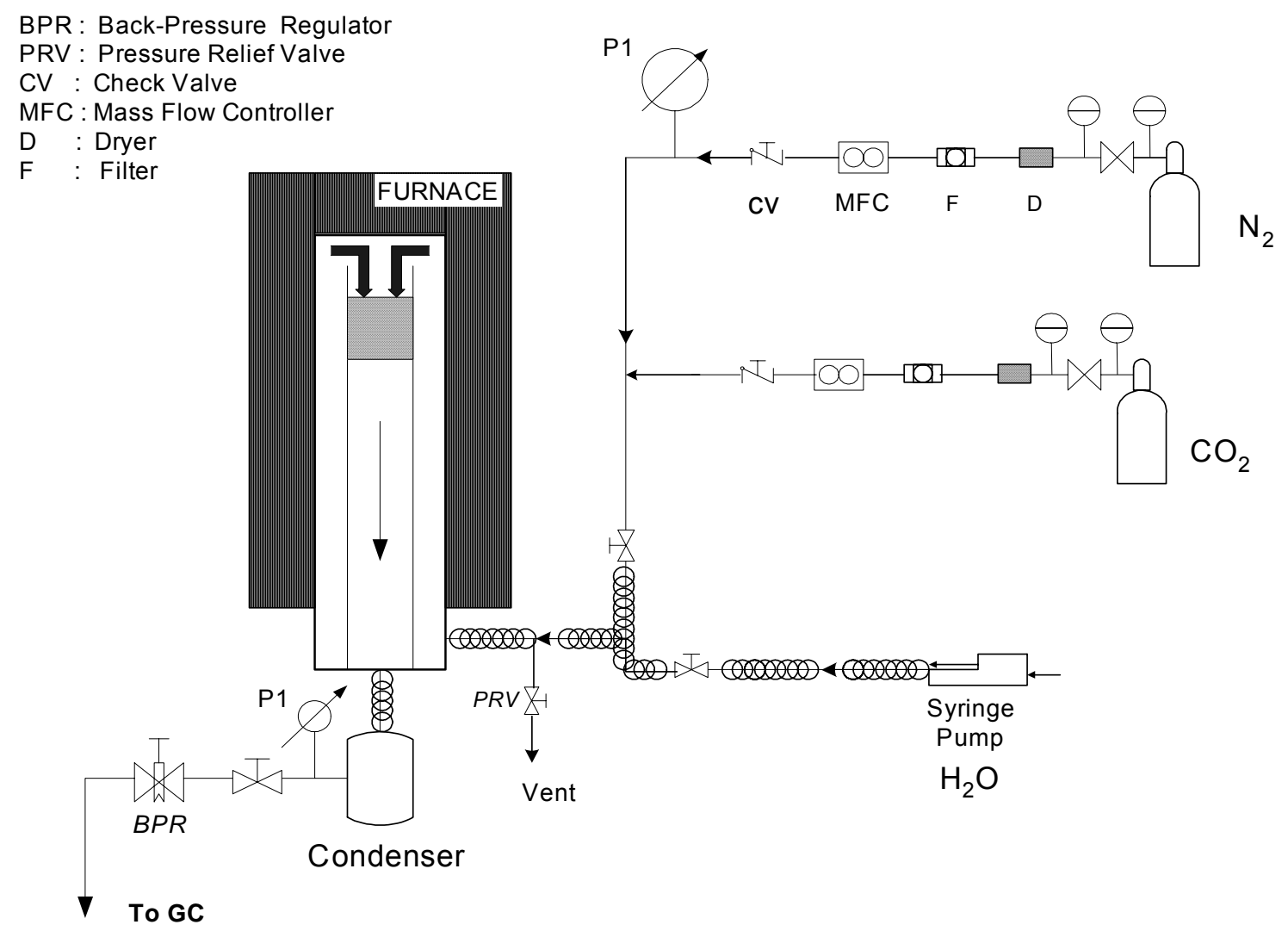

Figure 4. Schematic of the fixed-bed reactor system

\subsubsection{Fixed-Bed Reaction Conditions}

The standard carbonation gas composition of $8 \% \mathrm{CO}_{2}, 16 \% \mathrm{H}_{2} \mathrm{O}$, and $76 \% \mathrm{~N}_{2}$ was used in all tests. $\mathrm{N}_{2}$ was substituted for $\mathrm{He}$ as aerodynamic noise and balance sensitivity were no longer of concern. As with the electrobalance tests, carbonation temperature was varied between nominal temperatures of $60^{\circ} \mathrm{C}$ and $80^{\circ} \mathrm{C}$. Nominal temperatures were reported in all fixed-bed reactor tests, as the energy released by the exothermic carbonation reaction was sufficient to increase the bed temperature above the nominal setting. The carbonation product was considered to be Wegscheider's salt in all fixed-bed tests because of the increase in temperature above the nominal setting. Once again, calcination temperature was varied between $120^{\circ} \mathrm{C}$ and $200^{\circ} \mathrm{C}$ and either pure $\mathrm{He}$ or pure $\mathrm{CO}_{2}$ was used as the calcination atmosphere. Sorbent SBC\#3 was used in most of the fixed-bed tests, and multicycle testing was emphasized. In the fixed-bed reactor tests, product gas composition was analyzed by gas chromatography to determine $\mathrm{CO}_{2}$ removal efficiency. 


\subsubsection{Typical Fixed-Bed Test Result}

Typical results from a two-cycle fixed-bed reactor test using SBC\#3 are shown in Figure 5. $\mathrm{CO}_{2}$ concentration (dry basis) and nominal reaction temperature are plotted as a function of time. In this test, the first calcination was carried out in $\mathrm{N}_{2}$ at $120^{\circ} \mathrm{C}$ during day 1 and the reactor was allowed to cool overnight in flowing $\mathrm{N}_{2}$ to the desired carbonation temperature. The first carbonation and second calcination were completed during day 2. Carbonation occurred at a nominal $60^{\circ} \mathrm{C}$ in a feed gas containing $8 \% \mathrm{CO}_{2}, 16 \% \mathrm{H}_{2}$, and $76 \% \mathrm{~N}_{2}$; second-cycle calcination conditions were the same as in cycle 1 . Finally, the second carbonation was completed during day 3 using the same conditions as in carbonation Cycle 1.
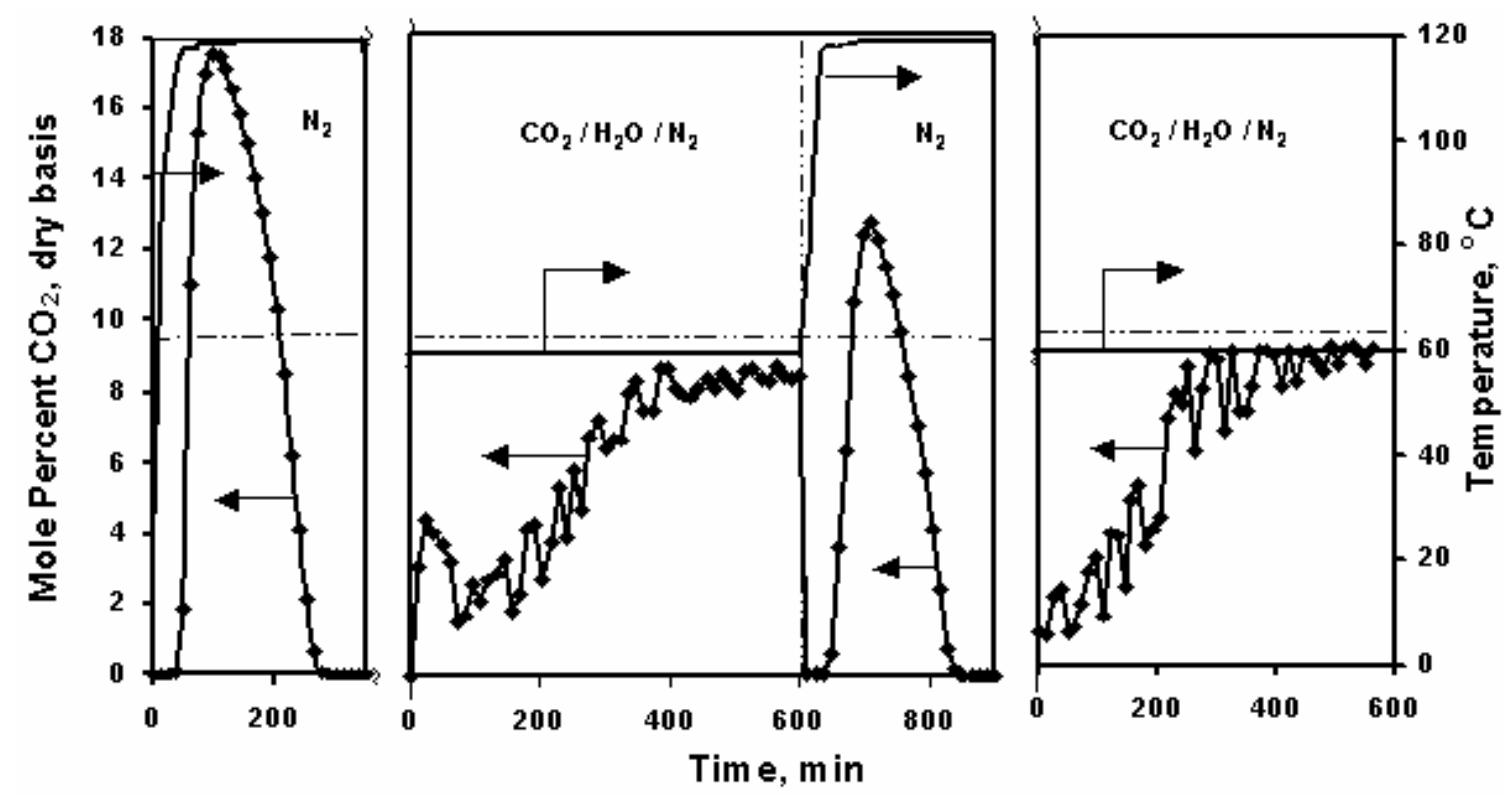

Figure 5. Typical results from a two-cycle fixed-bed reactor test (SBC\#3)

$\mathrm{CO}_{2}$ was first detected in calcination Cycle 1 at about $100^{\circ} \mathrm{C}$, reached a maximum concentration of almost $18 \%$ in just over $100 \mathrm{~min}$, and then decreased to zero by $300 \mathrm{~min}$, indicating that calcination was complete. Good material balance closure was obtained with numerical integration of the area under the concentration-time curve showing that 0.159 mols of $\mathrm{CO}_{2}$ were produced, compared to the stoichiometric amount of 0.159 mols based on the mass of the initial $\mathrm{Na}_{2} \mathrm{CO}_{3}$ charge. Initial $\mathrm{CO}_{2}$ concentration during the first carbonation cycle was almost $5 \%$, corresponding to about $50 \% \mathrm{CO}_{2}$ removal. The $\mathrm{CO}_{2}$ concentration then decreased to just over $1 \%$ before increasing monotonically in a standard breakthrough curve. $1 \% \mathrm{CO}_{2}$ (dry basis) in the product gas corresponds to about $90 \% \mathrm{CO}_{2}$ removal. During the second calcination cycle, the maximum $\mathrm{CO}_{2}$ concentration was about $13 \%$, and the area under the curve corresponded to 
0.089 mols of $\mathrm{CO}_{2}$. While this amount was $58 \%$ less than the amount liberated during the first calcination, it corresponded to greater than $90 \%$ conversion of $\mathrm{Na}_{2} \mathrm{CO}_{3}$ to Wegscheider's salt. Initial $\mathrm{CO}_{2}$ concentration during the second carbonation cycle was about $1 \%$ and the concentration increased monotonically throughout the carbonation test. The $\mathrm{CO}_{2}$ concentration decrease that occurred early in the first carbonation cycle and was not repeated during the second cycle was a general trend noted in several of the multicycle fixed-bed tests. This can be attributed to rearrangement of the packed bed, which minimized gas bypassing.

\subsection{FLUIDIZED-BED EXPERIMENTS AT RTI}

RTI conducted six cyclic fluidized-bed tests in a 2-inch diameter bench-scale system. SBC, trona, potassium carbonate, and two different supported sorbents were tested. The reactor system is shown in Figure 6. The reactant gas supply consists of three electronic mass flow controllers (MFCs) which are used to meter nitrogen, air, and carbon dioxide from compressed gas cylinders. These MFCs were calibrated against a soap bubble flow meter. Deionized water was added to the mixed dry gas stream using a high-pressure liquid chromatography (HPLC) pump. The reactor consists of a 2-inch internal diameter quartz tube, fitted with a 3-mm thick porous quartz plate distributor. The reactor is suspended within a flanged 4-inch stainless steel pipe that is surrounded by a three-zone electric furnace. Inlet gas enters the top flange of the pipe, passes through the annulus, and enters the quartz reactor through the distributor at the bottom. A 6-inch bed of sorbent (or sorbent precursor) is initially charged to the reactor to maintain a length-to-diameter ratio of 3 . Effluent gas passes through a shell and tube heat exchanger for condensation of steam, a Hartmann and a Braun Model URAS-14 nondispersive infrared carbon dioxide monitor. The sorbent bed contains 3 Type- $K$ thermocouples spaced at 1,3 , and 5 inches above the distributor. An electronic differential pressure gauge connected with a digital display indicates the pressure drop across the bed. Total pressure is also monitored.

Information about the process is collected and recorded by the "Lab View" package, an advanced data acquisition software/hardware package from National Instruments. The software has been programmed to facilitate the monitoring of the process providing bed temperatures, inlet gas temperature, reactor pressure, pressure drop, inlet gas flow rates, and outlet carbon dioxide and oxygen concentrations. 


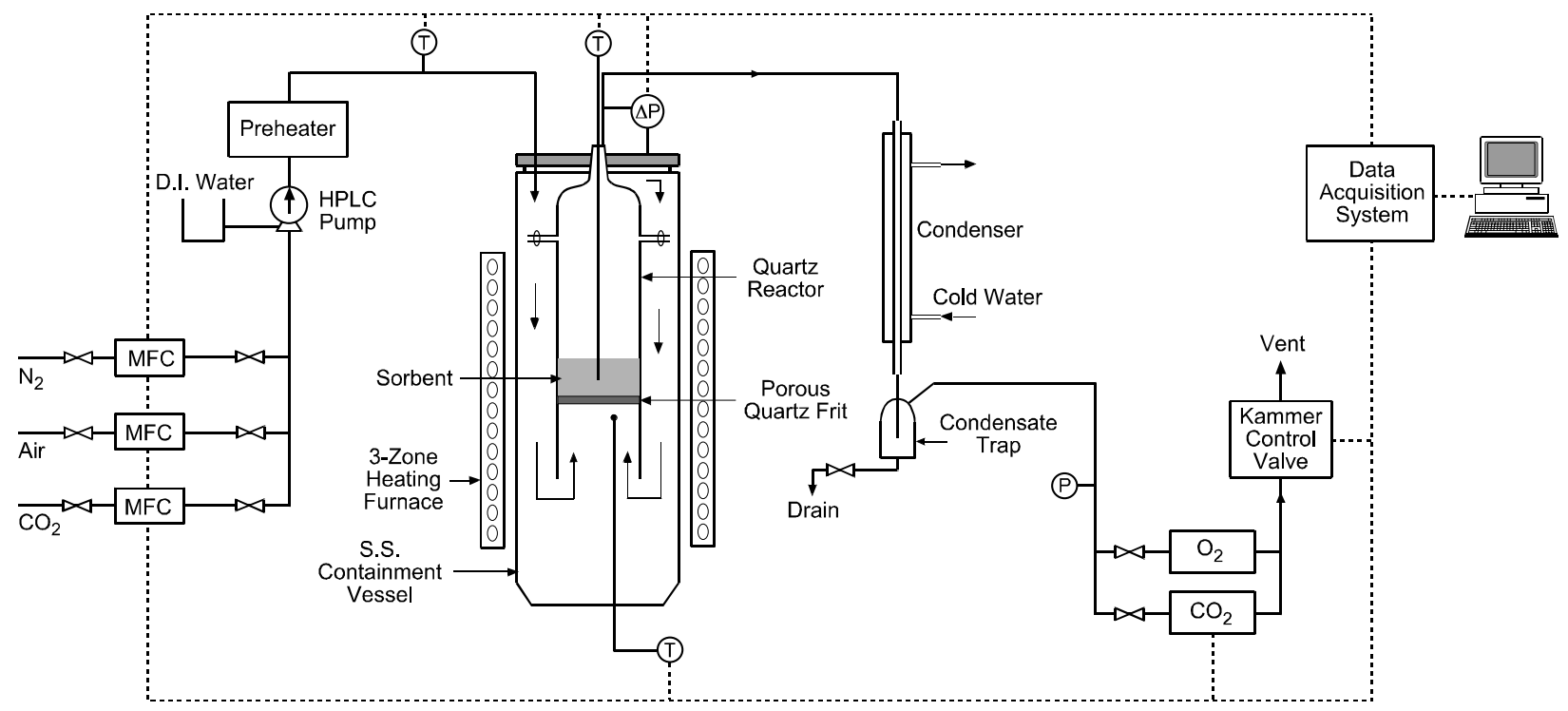

Figure 6. Fluidized-bed test reactor system

Because the carbonation reaction rate is strongly dependent on the concentration of $\mathrm{H}_{2} \mathrm{O}$ in the simulated flue gas, and because the latent heat of vaporization of water can be used to reduce the temperature of the sorbent bed, provisions were made to add liquid water near the top of the fluidized bed. This equipment modification was attempted between the second and third tests. A 1/16-in outside diameter polytetrafluoroethane (PTFE) tube was inserted through the upper reactor flange and extended along the outside of the thermowell, to a height approximately 6-in above the flow distributor. A variable-speed syringe pump was connected to the tube to permit the addition of deionized water. This modification was removed as it proved to be unworkable because the sorbent caked and plugged the bed upon exposure to liquid water.

\subsection{DETERMINATION OF PHYSICAL PROPERTIES OF SORBENTS}

\subsubsection{Particle Size Determinations}

Particle size distributions were measured using a sieve shaker apparatus and a SympatecHelos laser diffraction analyzer.

\subsubsection{BET Measurements}

Brunauer-Emmett-Teller (BET) surface area determinations were conducted with a Quantachrome Nova 1000 instrument. The Nova 1000, shown schematically in Figure 7, has a pore diameter range of 3.5 to $2000 \AA$ and an accuracy of 0.1 percent. The minimum resolvable 
pressure is 0.016 torr. Determinations on various grades of SBC were conducted as received and after overnight calcination at $125^{\circ} \mathrm{C}\left(257^{\circ} \mathrm{F}\right)$. In addition, some samples were tested after shorter calcination periods. The outgassing temperature for all determinations was $250^{\circ} \mathrm{C}$ $\left(482^{\circ} \mathrm{F}\right)$.

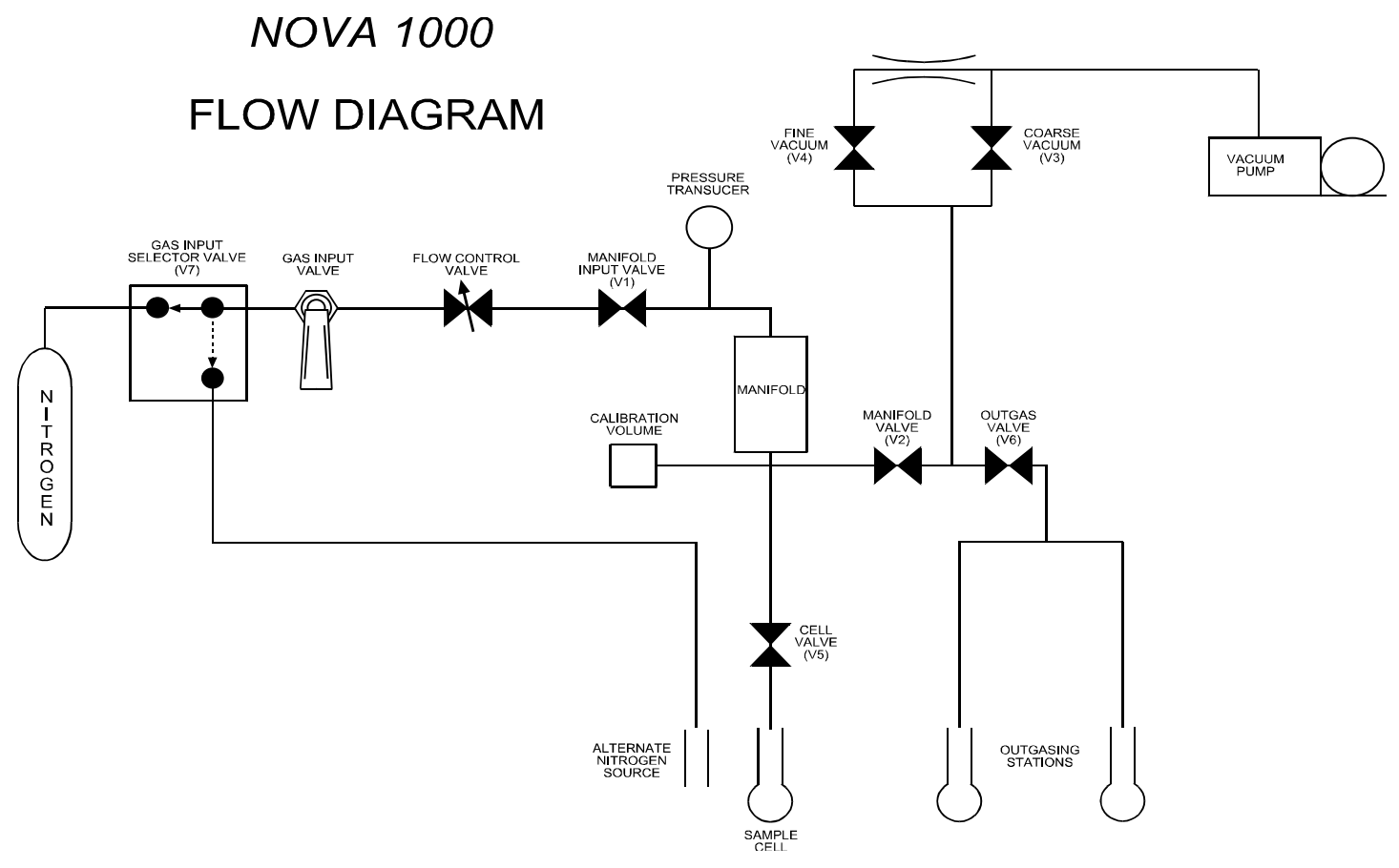

Figure 7. NOVA 1000 flow diagram

\subsubsection{Porosimetry}

Mercury porosimetry determinations were conducted with a Micromeritics AutoPore II 9220 instrument coupled to a PC equipped with AutoPore II software, version 3.01. Triple distilled mercury was used for all determinations. Measurement of pore volume, pore volume distribution, and median pore diameter by mercury intrusion provides a direct indication of diffusional resistance associated with the sorbents. Determinations were conducted on materials as received, and after calcination overnight at $125^{\circ} \mathrm{C}\left(257^{\circ} \mathrm{F}\right)$.

\subsubsection{Attrition}

Attrition measurements of unsupported sorbents were made using a 3-hole air-jet attrition tester using the ASTM D 5757-95 method. Attrition measurements of supported sorbents were made using a "Davison type" jet cup apparatus that is typically used in industry for measuring attrition of a fluidized catalytic cracking (FCC) catalyst. A generic description of the jet cup apparatus 
and the procedure used has been published (Zhao et al., 2000). To remove apparatus-related bias the jet cup attrition values of the samples tested are reported as attrition ratio, where attrition ratio $(A R)$ is defined as:

$$
\mathrm{AR}=\frac{\text { Jet cup attrition index of the sample }}{\text { Jet cup attrition index of a standard }}
$$

The standard chosen for these tests is an equilibrium FCC catalyst, that is known to be a relatively attrition resistant material. Based on the above equation, the higher the $A R$, the higher is the sample likely to undergo attrition in a fluidized-bed or transport reactor.

\subsection{PREPARATION OF SUPPORTED SORBENTS}

RTI prepared sorbents composed of up to $40 \%$ sodium carbonate on alumina-type support materials. The bulk of these materials were prepared using a laboratory-scale spray dryer with a capacity of 1 to $2 \mathrm{~kg} /$ day. One spray-dried sorbent prepared in the laboratory was successfully scaled up to a $200 \mathrm{~kg}$ batch by a commercial catalyst manufacturer. The supported sorbents were subjected to reactivity screening analyses by thermogravimetric analysis at RTI. Selected samples were also subjected to surface area and attrition determinations. 


\section{CHAPTER 3}

\section{RESULTS}

\subsection{SINGLE CYCLE ELECTROBALANCE TESTING AT LSU}

The electrobalance was used to compare performance of the different sorbent precursors and to evaluate the effects of calcination and carbonation temperature and gas composition on sorbent performance. The effect of calcination conditions was evaluated by comparing performance in the subsequent carbonation cycle, particularly in multicycle tests where sorbent durability was studied. While six of the sorbent precursors were tested during early stages of the experimental program, $\mathrm{SBC} 33$ received primary emphasis.

\subsubsection{Reproducibility}

The levels of reproducibility obtained from multiple tests at duplicate reaction conditions for SBC\#3 and trona T-50 are shown in Figures 8 and 9, respectively. Dimensionless weight during the carbonation phase is plotted versus time. Separate samples of sorbent precursor were used in each of the six tests, and calcination occurred at $120^{\circ} \mathrm{C}$ in He. Calcination was complete in each test as indicated by the fact that the initial dimensionless weights were all equal to the theoretical values for calcination of $\mathrm{NaHCO}_{3}$ and trona, respectively, represented by the horizontal dashed lines. Carbonation conditions were identical in each of the six tests and are shown on the figures. The raw electrobalance data were smoothed so that results from individual tests could be identified.

SBC\#3 results in Figure 8 showed a small variation in initial carbonation rate, but the overall results were quite reproducible. Final dimensionless weights in each case were 0.84 , which corresponds to $95 \%$ carbonation to Wegscheider's salt product. Results from two of the trona $\mathrm{T}-50$ tests in Figure 9 were quite similar, but there was a significant difference in the third test. The final dimensionless weights were 0.91 and 0.92 , which correspond to $80 \%$ and $83 \%$ conversion to Wegscheider's salt.

The results shown in these figures were typical in that good reproducibility was normally achieved using all SBC precursors, while scatter even larger than shown in Figure 9 occurred in some of the trona reproducibility tests. The wider range of particle sizes and the possible variation in impurity levels from sample to sample were identified as potential causes of the lack of reproducibility. Indeed, sieving the trona and using narrower particle size ranges improved, 
but did not eliminate, the variation. As a result of the reproducibility studies, the SBC samples received greater emphasis in subsequent experiments.

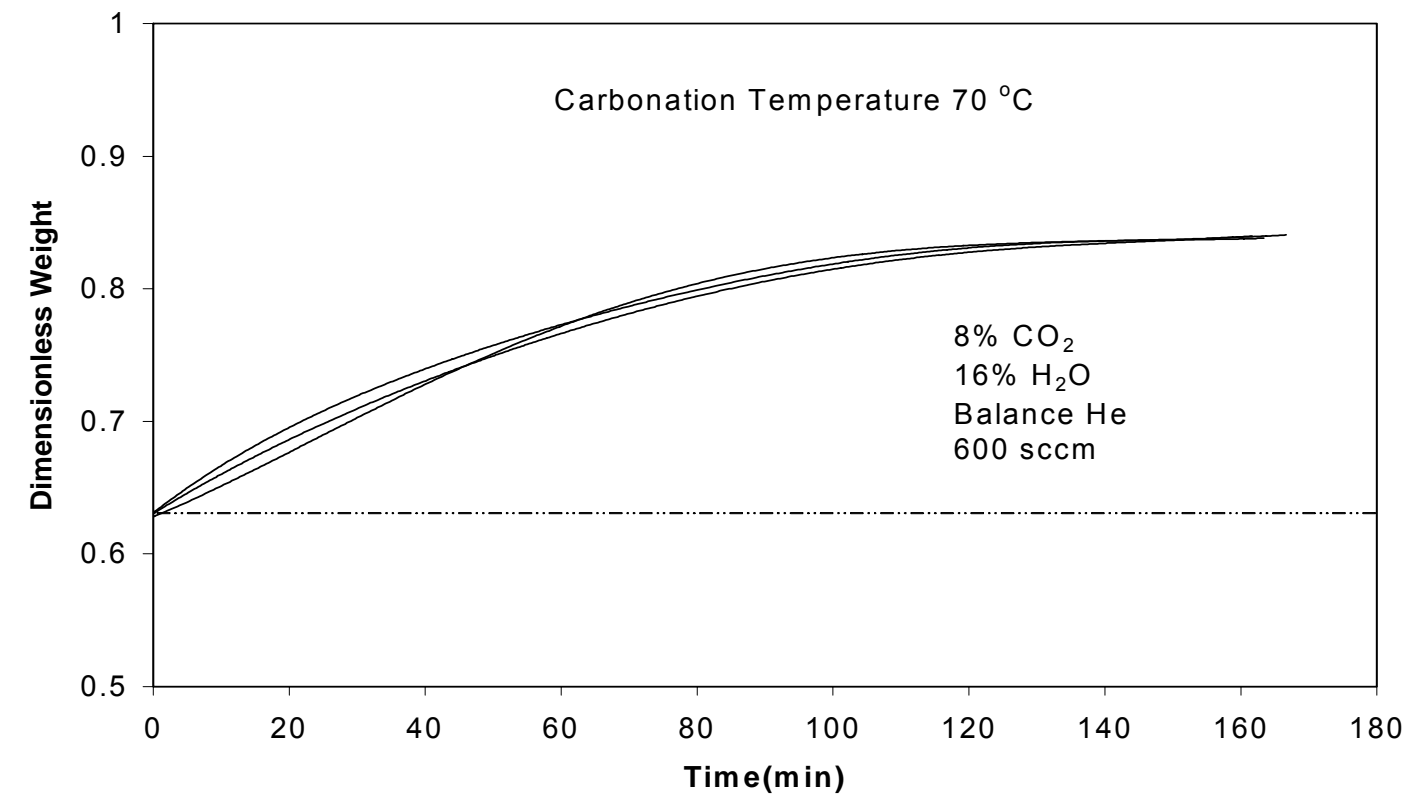

Figure 8. Duplicate carbonation test results using SBR\#3

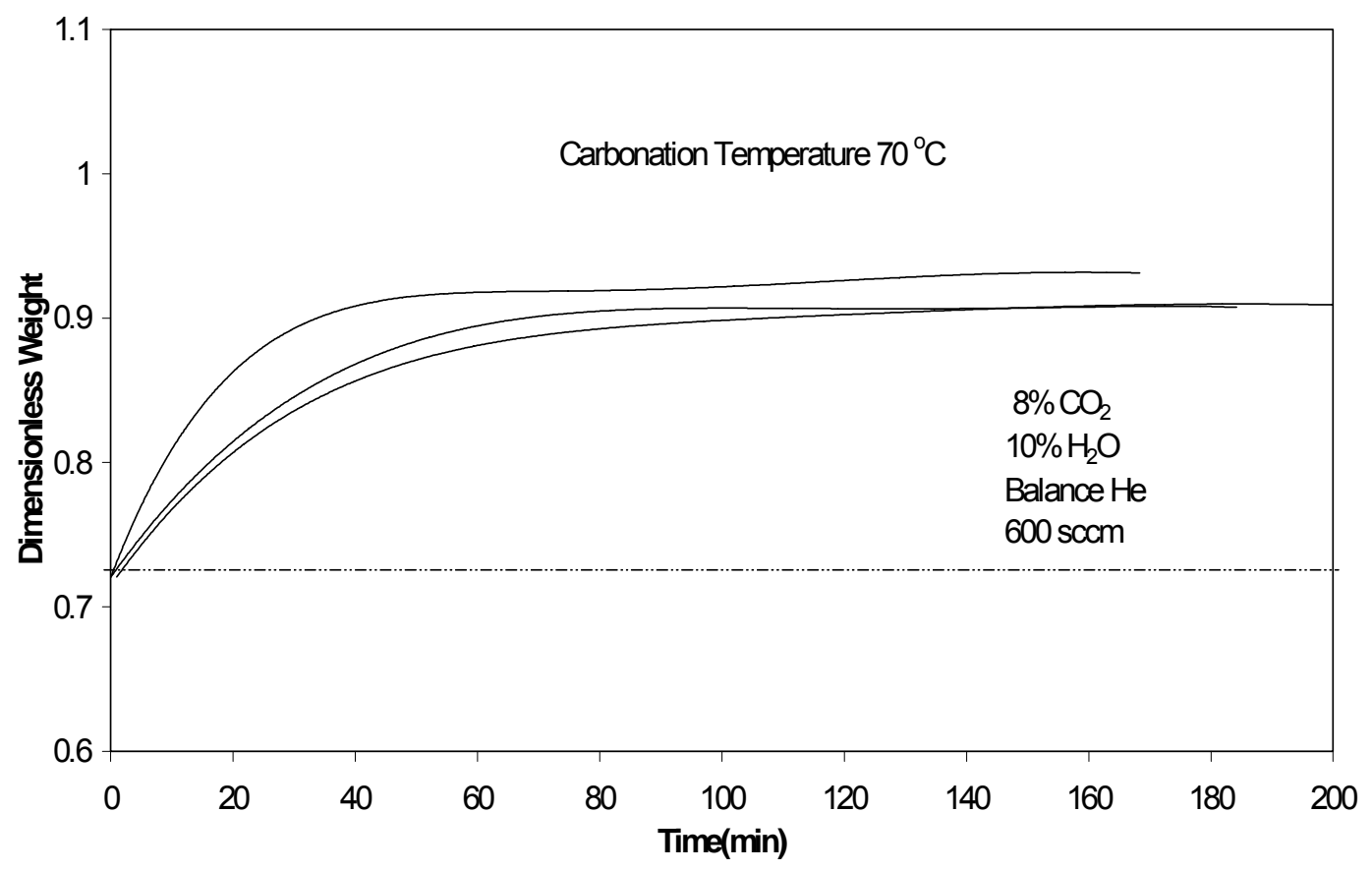

Figure 9. Duplicate Carbonation Test Results Using Trona T-50 


\subsubsection{The Effect of Carbonation Temperature}

Temperature affects both the kinetics and thermodynamics of the carbonation reaction. Figure 10 compares smoothed electrobalance results for three tests using SBC\#3 at carbonation temperatures of $60^{\circ} \mathrm{C}, 70^{\circ} \mathrm{C}$, and $80^{\circ} \mathrm{C}$. Calcination was carried out at $120^{\circ} \mathrm{C}$ in $\mathrm{He}$ and the carbonation gas contained $8 \% \mathrm{CO}_{2}, 16 \% \mathrm{H}_{2} \mathrm{O}$, and $76 \% \mathrm{He}$. Both the initial rate, as measured by the initial slope of the dimensionless weight-time curves, and the final dimensionless weight decreased with increasing temperature. The reaction rate approached zero after about $200 \mathrm{~min}$ at both $60^{\circ} \mathrm{C}$ and $70^{\circ} \mathrm{C}$, but reaction was still occurring slowly at $80^{\circ} \mathrm{C}$ after $400 \mathrm{~min}$.

Carbonation temperatures lower than $60^{\circ} \mathrm{C}$ are not practical, as the dew point of the feed gas is $56^{\circ} \mathrm{C}$.

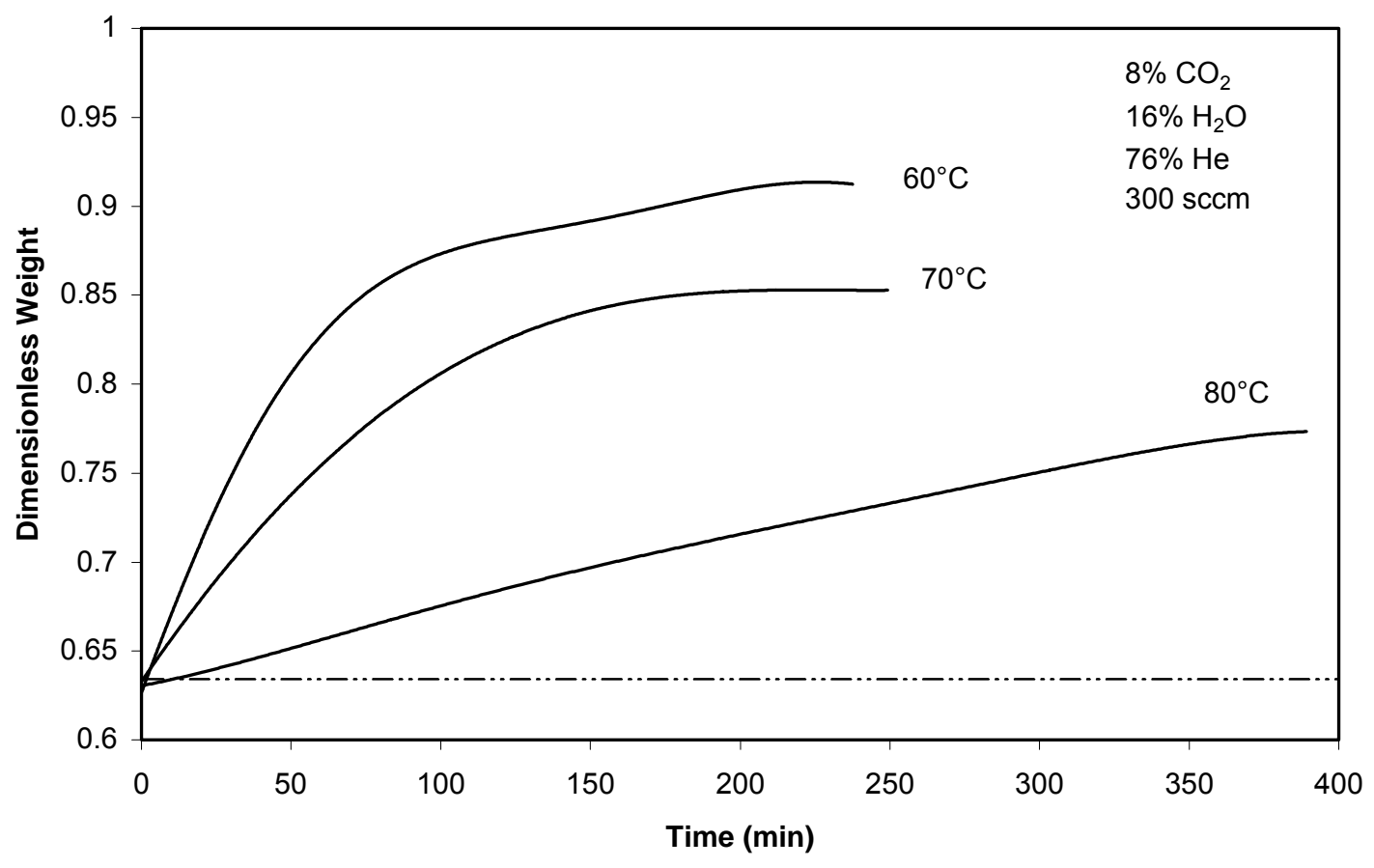

Figure 10. Effect of Temperature on the carbonation of SBC\#3

The decrease in final dimensionless weight between $60^{\circ} \mathrm{C}$ and $70^{\circ} \mathrm{C}$ is attributed to the formation of different products $-\mathrm{NaHCO}_{3}$ at $60^{\circ} \mathrm{C}$ and Wegscheider's salt at $70^{\circ} \mathrm{C}$. The final dimensionless weight of 0.92 at $60^{\circ} \mathrm{C}$ corresponds to $76 \%$ conversion of $\mathrm{Na}_{2} \mathrm{CO}_{3}$ to $\mathrm{NaHCO}_{3}$, while the 0.84 final dimensionless weight at $70^{\circ} \mathrm{C}$ corresponds to about $95 \%$ conversion to Wegscheider's salt. The decrease in rate between $70^{\circ} \mathrm{C}$ and $80^{\circ} \mathrm{C}$ is attributed to a decrease in concentration driving force due to the reversibility of the reaction. No reaction occurred at $80^{\circ} \mathrm{C}$ 
when the $\mathrm{CO}_{2}$ concentration was reduced to $5 \%$, which is in agreement with thermodynamic calculations. These results emphasize the importance of careful temperature control because of the narrow temperature window available for $\mathrm{CO}_{2}$ removal.

Somewhat different results were obtained when trona T-50 was tested at different temperatures as shown in Figure 11. The initial rate showed the exact opposite effect and decreased from $80^{\circ} \mathrm{C}$ to $70^{\circ} \mathrm{C}$ to $60^{\circ} \mathrm{C}$. Final dimensionless weights at $70^{\circ} \mathrm{C}$ and $80^{\circ} \mathrm{C}$ were effectively equal at 0.92 , while at $60^{\circ} \mathrm{C}$ the final weight was 0.98 . These final dimensionless weights correspond to $85 \%$ conversion to Wegscheider's salt at $70^{\circ} \mathrm{C}$ and $80^{\circ} \mathrm{C}$, and to $67 \%$ conversion to $\mathrm{Na}_{2} \mathrm{HCO}_{3}$ at $60^{\circ} \mathrm{C}$. However, since different samples were used in each test, at least part of these effects may be due simply to the lack of reproducibility associated with trona carbonation.

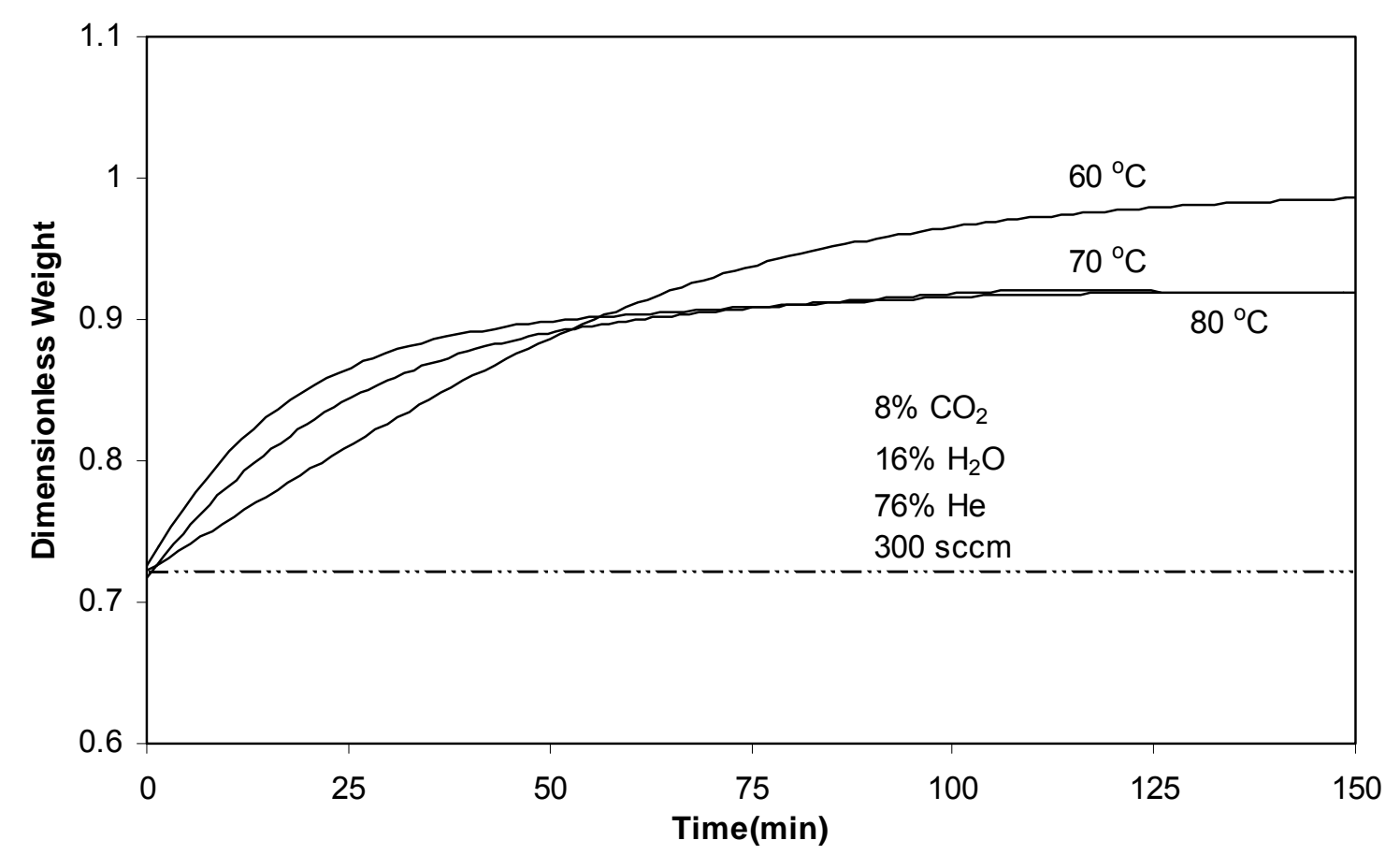

Figure 11. Effect of temperature on the carbonation of Trona T-50

\subsubsection{Effect of $\mathrm{CO}_{2}$ and $\mathrm{H}_{2} \mathrm{O}$ Concentration}

At a fixed carbonation temperature, increases in the concentration of both $\mathrm{CO}_{2}$ and $\mathrm{H}_{2} \mathrm{O}$ produced an increase in the carbonation rate, but little change in the final dimensionless weight. These effects are illustrated for SBC\#3 in Figure 12 for $\mathrm{CO}_{2}$ and Figure 13 for $\mathrm{H}_{2} \mathrm{O}$. When $\mathrm{CO}_{2}$ was removed from the feed gas no reaction occurred, which confirmed that sodium carbonate 
monohydrate, $\mathrm{Na}_{2} \mathrm{CO}_{3} \cdot \mathrm{H}_{2} \mathrm{O}$, would not be formed at this temperature. Although the dimensionless weight after 250 min was slightly less in $5 \% \mathrm{CO}_{2}$ than in $8 \% \mathrm{CO}_{2}$, reaction was still occurring at the lower concentration and extrapolation suggests that the final dimensionless weights would be approximately equal.

Changing the $\mathrm{H}_{2} \mathrm{O}$ concentration had a similar effect as shown in Figure 13. The carbonation rate was clearly faster in $16 \% \mathrm{H}_{2} \mathrm{O}$ and the reaction was effectively complete in less than 200 min. Reaction was still occurring slowly after 400 min in $10 \% \mathrm{H}_{2} \mathrm{O}$, but the final dimensionless weights were approximately equal.

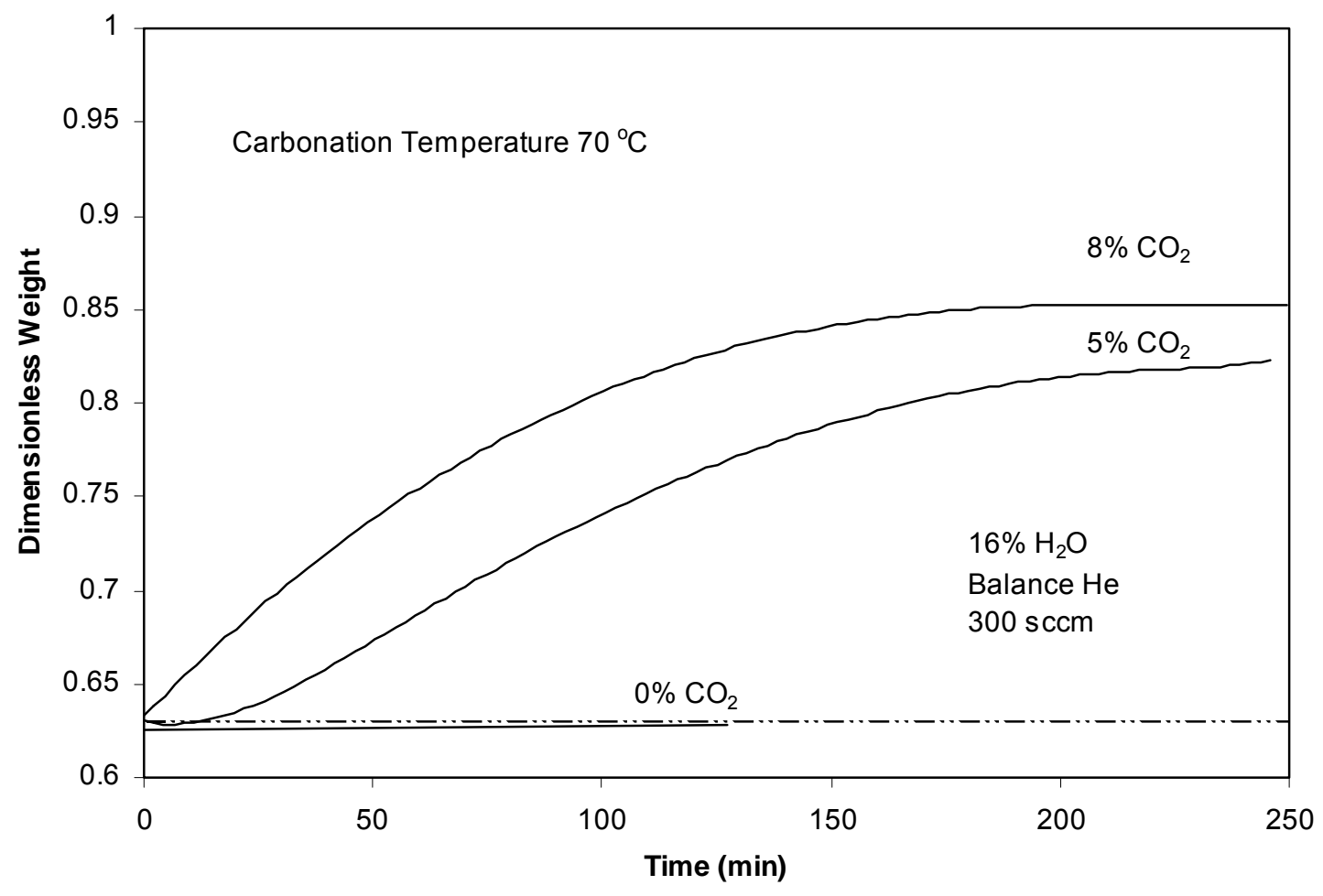

Figure 12. Effect of $\mathrm{CO}_{2}$ concentration on the carbonation of SBC\#3 


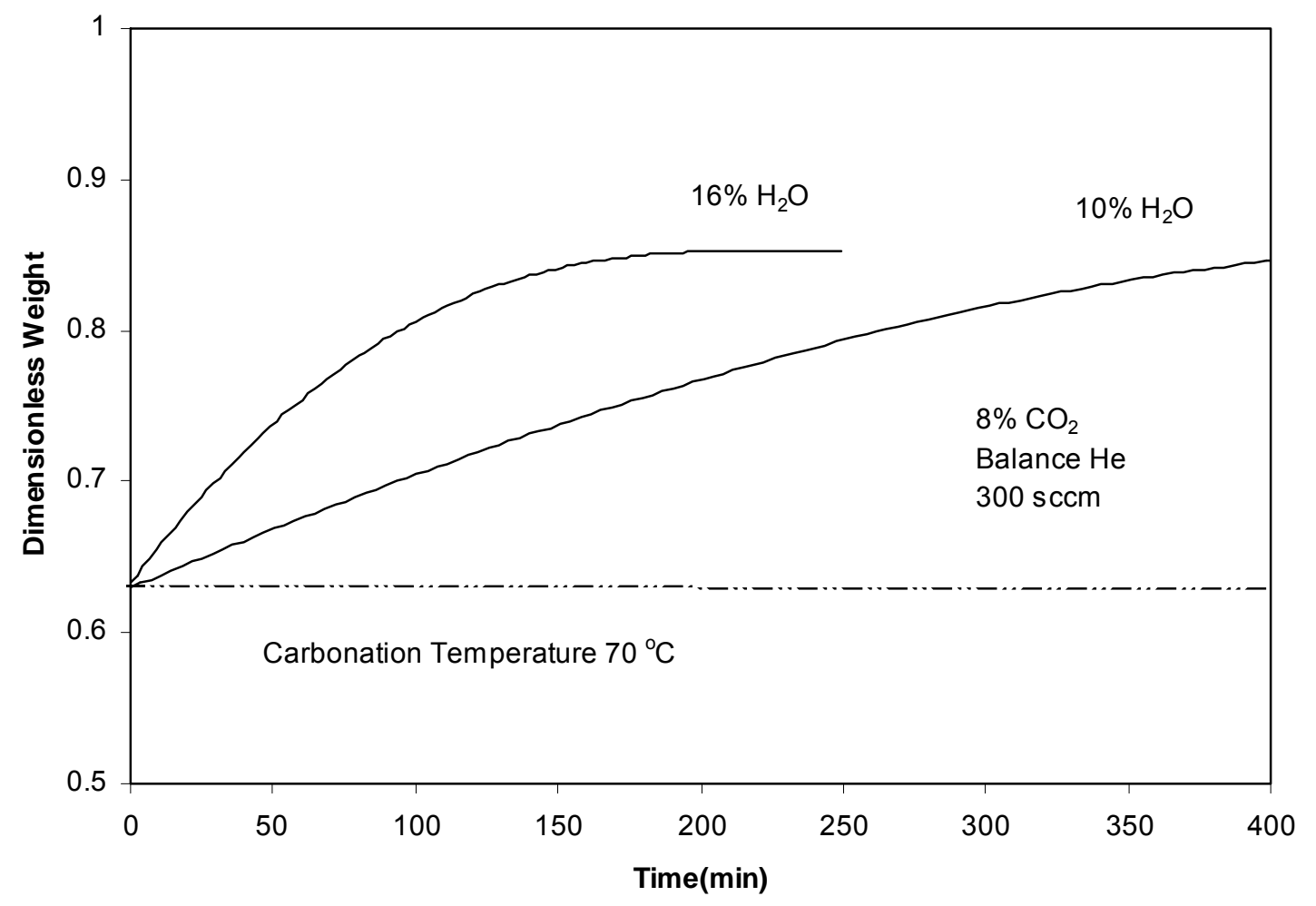

Figure 13. Effect of $\mathrm{H}_{2} \mathrm{O}$ concentration on the carbonation of $\mathrm{SBC} \# 3$

\subsubsection{Comparison of Different Sorbents}

Figure 14 compares the dimensionless weight versus time responses during the carbonation of three sorbents-SBC\#1, SBC\#3, and trona T-50-for a reaction temperature of $60^{\circ} \mathrm{C}$, where the carbonation product should be $\mathrm{NaHCO}_{3}$. The initial dimensionless weights are very close to the theoretical values of 0.631 for both SBC samples, as indicated by the lower horizontal line, and 0.723 for trona T-50, as indicated by the upper horizontal line. The initial reaction rates, which correspond to the initial slopes of the dimensionless weight-time curves, were approximately equal. The final dimensionless weights of the two SBC samples were also reasonably close, although SBC\#1 took considerably longer to reach the final value. The final dimensionless weights of 0.94 for the $\mathrm{SBC}$ samples correspond to $83 \%$ conversion to $\mathrm{NaHCO}_{3}$, while the final dimensionless weight of 0.99 for trona T-50 corresponds to only $69 \%$ conversion to $\mathrm{NaHCO}_{3}$. 


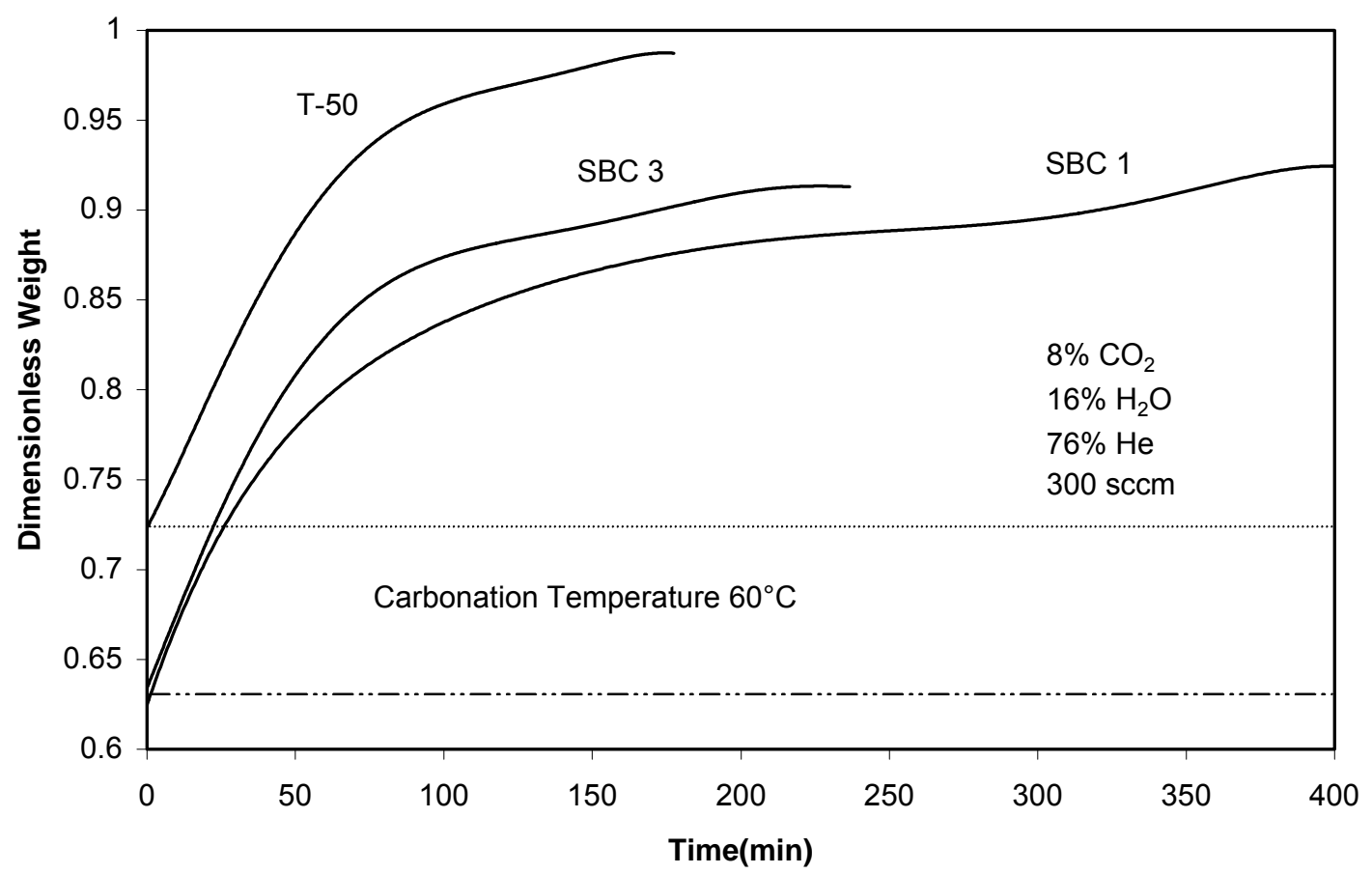

Figure 14. Comparison of the carbonation of three sorbents at identical carbonation conditions

\subsubsection{Effect of Calcination Temperature and Atmosphere}

In all the previous tests reported, the sorbent precursor was calcined at the mildest possible conditions in $\mathrm{He}$ at $120^{\circ} \mathrm{C}$. In order to produce pure $\mathrm{CO}_{2}$ during sorbent calcination, it will be necessary to carry out the calcination in an atmosphere containing a high concentration of $\mathrm{CO}_{2}$, and the calcination temperature must be increased. The higher temperature will increase the possibility of sintering and cumulative loss of activity through many cycles. Results of carbonation tests in which calcination occurred in pure $\mathrm{CO}_{2}$ at temperatures between $120^{\circ} \mathrm{C}$ and $200^{\circ} \mathrm{C}$ are shown in Figure 15; carbonation data following calcination in $\mathrm{He}$ at $120^{\circ} \mathrm{C}$ are included for comparison. Calcination results in pure $\mathrm{CO}_{2}$ at $120^{\circ} \mathrm{C}$ are included, although the calcination rate at these conditions is too small to be of practical interest. On the basis of these single-cycle tests, it is clear that the more severe calcination conditions did not have an adverse impact on the subsequent carbonation. In fact, there was a slight increase in both the carbonation rate and the final dimensionless weight in each of the tests following $\mathrm{CO}_{2}$ calcination compared to He calcination. Evaluation of possible cumulative effects requires multicycle tests. 


\subsection{MULTICYCLE ELECTROBALANCE TESTING AT LSU}

Preliminary information on sorbent durability was acquired through a series of five-cycle tests. Carbonation conditions were constant in all cycles in all tests $-70^{\circ} \mathrm{C}$ in $8 \% \mathrm{CO}_{2}, 16 \% \mathrm{H}_{2} \mathrm{O}$, and $76 \% \mathrm{He}$. Various sorbent precursors were tested and calcination temperature and atmosphere were varied. Durability was evaluated by comparing carbonation performance in each cycle.

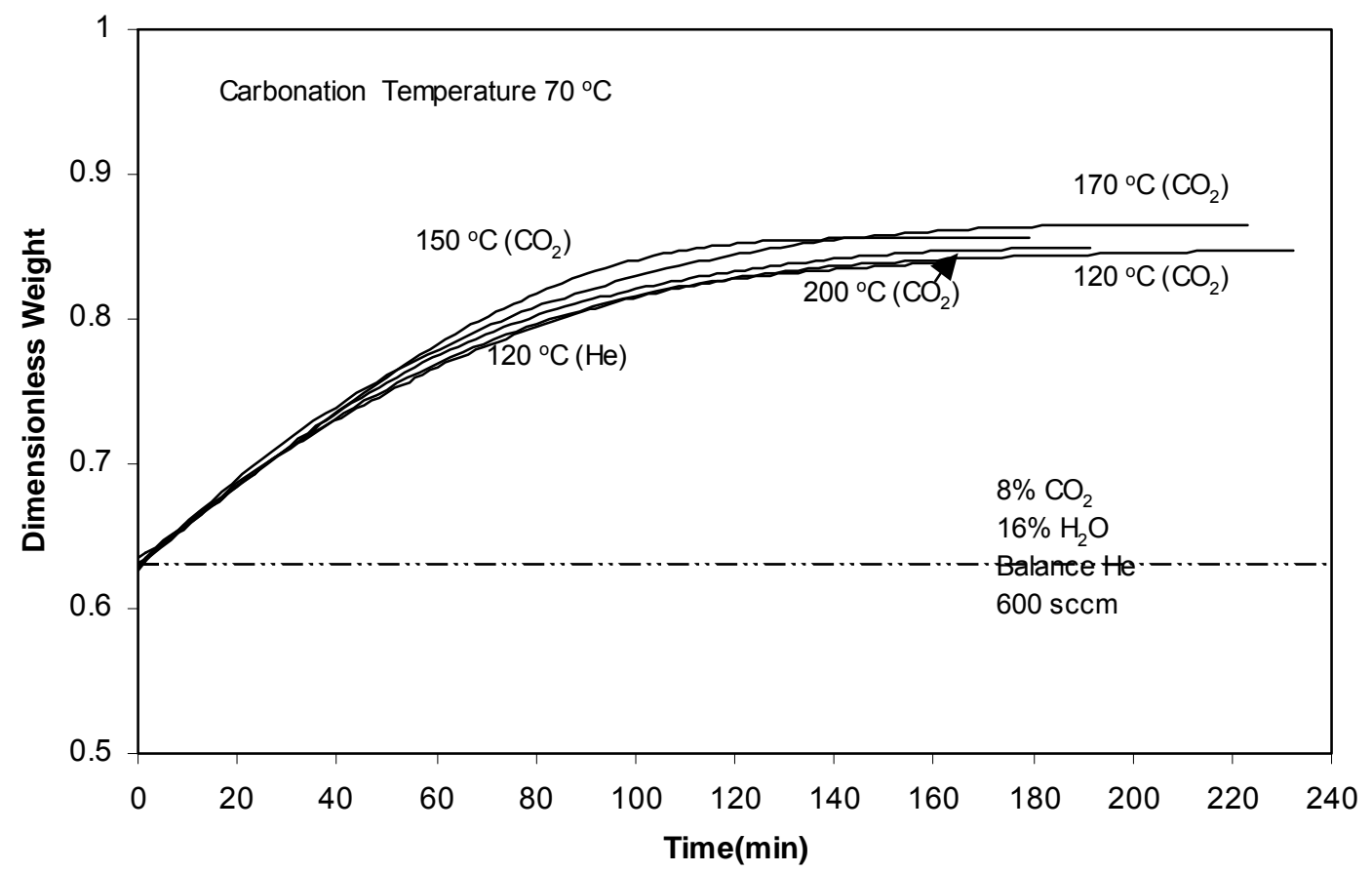

Figure 15. Effect of calcination atmosphere and temperature on carbonation kinetics (SBC\#3)

\subsubsection{Dimensionless Weight Versus Time Results}

Raw electrobalance data from a five-cycle test using SBC\#3 with calcination at $120^{\circ} \mathrm{C}$ in $\mathrm{He}$ are shown in Figure 16. Complete calcination, as indicated by the dimensionless weight of 0.63 , was achieved at the end of all five calcination phases. The first carbonation was initiated after about 200 min and continued until the weight approached a constant value. The second calcination followed immediately. Then the sample was cooled to $70^{\circ} \mathrm{C}$ and left overnight in flowing $\mathrm{He}$, with the second carbonation, third calcination, third carbonation, and fourth calcination carried out the next day. The fourth carbonation, fifth calcination, and fifth carbonation were completed on the third day. Thus, the time scale in Figure 16 is arbitrary following the first cycle. 
Figure 16 clearly shows a decrease in the final dimensionless weight between carbonation Cycles 1 and 2 and again between Cycles 3 and 4 . However, there was an increase in final dimensionless weight between Cycles 2 and 3 and no significant difference between Cycles 4 and 5. In addition, there was a small decrease in the slope of the dimensionless weight-time curves near the beginning of carbonation Cycles 1 and 2. Thereafter, the initial slopes were reasonably constant. These results are indicated more clearly in Figure 17 where smoothed electrobalance data during the five carbonation cycles are overlaid. Note that the maximum cycle time plotted in Figure 17 is 150 min, which is too short to show the larger final dimensionless weight in Cycle 3. However, Figure 14 also shows that carbonation is continuing after 150 min in Cycle 3, but has effectively stopped after $150 \mathrm{~min}$ in the other cycles. Both the reduced initial slope and reduced final dimensionless weight between Cycles 1 and 2 are clear.

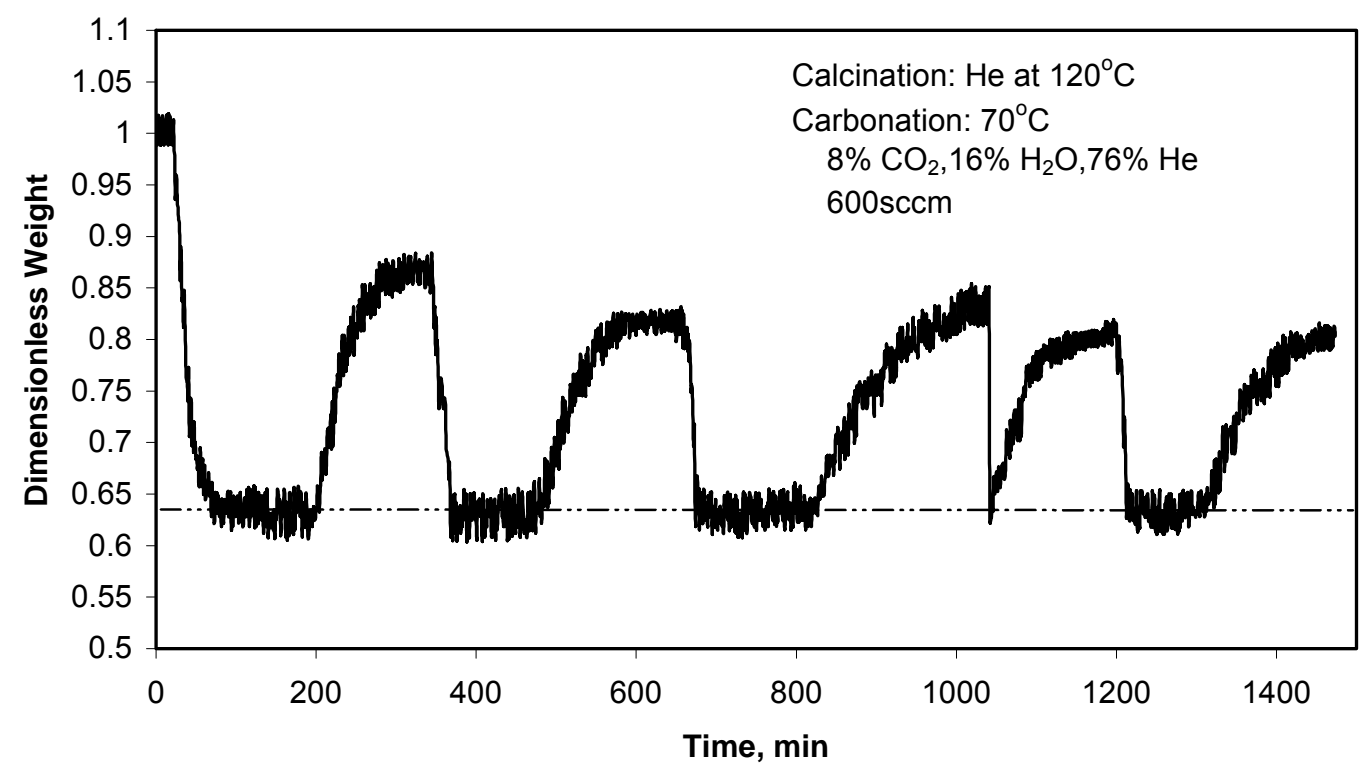

Figure 16. Raw electrobalance result from a five-cycle test using SBC\#3: Calcination in $\mathrm{He}$ at $120^{\circ} \mathrm{C}$ 


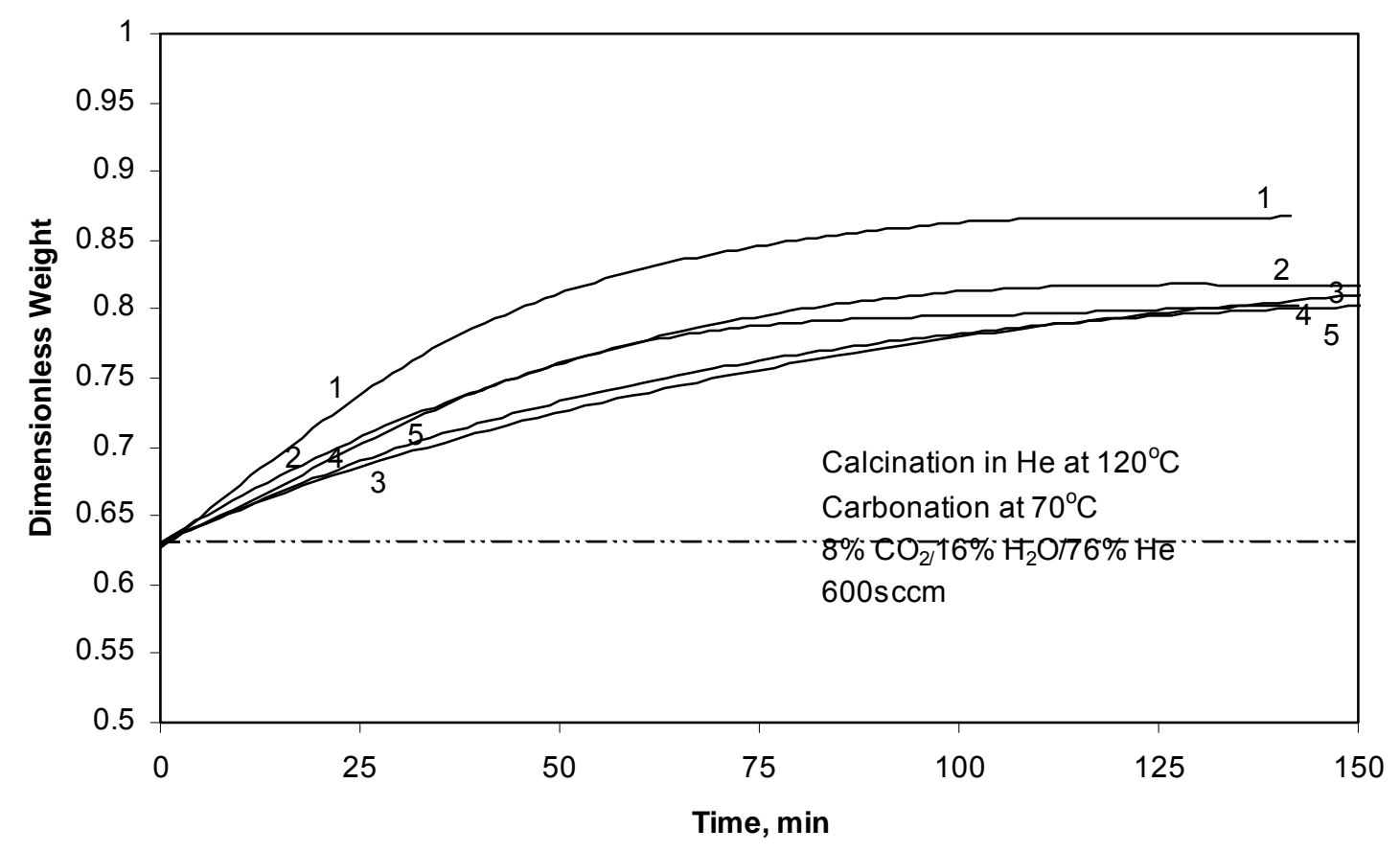

Figure 17. Smoothed electrobalance results for five carbonation cycles using SBC\#3: Calcination in $\mathrm{He}$ at $120^{\circ} \mathrm{C}$

The dimensionless weight of 0.87 after $150 \mathrm{~min}$ in carbonation Cycle 1, which corresponds to $108 \%$ conversion to Wegscheider's salt, is in reasonable agreement with previous single-cycle results. The 150-min dimensionless weights then decreased to $0.82,0.81,0.80$, and 0.80 , in Cycles 2 through 5 , respectively, with the final value of 0.80 corresponding to about $76 \%$ conversion of $\mathrm{Na}_{2} \mathrm{CO}_{3}$ to Wegscheider's salt.

Similar raw electrobalance data from a five-cycle run using SBC\#3, but with calcination at $200^{\circ} \mathrm{C}$ in $\mathrm{CO}_{2}$, are shown in Figure 18. Once again, complete calcination was obtained in each cycle. The final dimensionless weight at the end of the first carbonation cycle was 0.83 , which corresponds to about $90 \%$ conversion to Wegscheider's salt. There were small decreases in the initial slope with increasing cycle number, but the magnitudes of the decreases were smaller than shown in Figure 16. Similarly, there was a small decrease in final dimensionless weight between Cycles 1 and 2, but no further decrease between Cycles 2 and 5. 


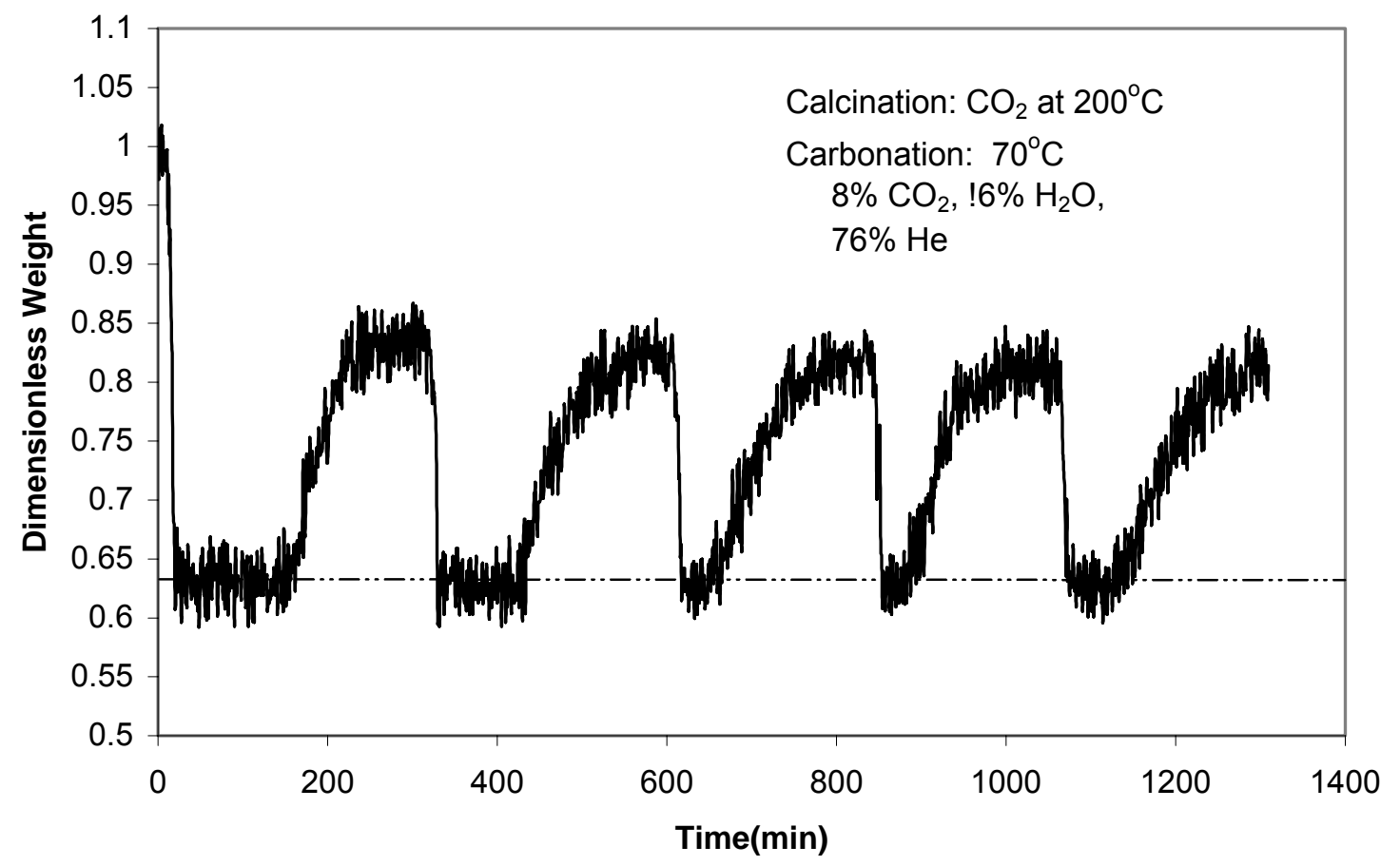

Figure 18. Raw electrobalance results for five-cycle test using SBC\#3: Calcination in $\mathrm{CO}_{2}$ at $200^{\circ} \mathrm{C}$

Smoothed dimensionless weight-time data from a five-cycle test using trona T-200 are shown in Figure 19. Calcination conditions were $120^{\circ} \mathrm{C}$ in $\mathrm{He}$, the same as used in the five-cycle test with SBC\#3 whose results are shown in Figure 17. Note that the reproducibility problems associated with trona samples did not exist in this case because the same sample was used in each cycle. The final dimensionless weights in all cycles were about 0.92 , which corresponds to about $87 \%$

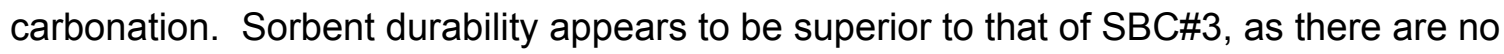
significant decreases in either the initial slopes of the curves or the final dimensionless weights. 


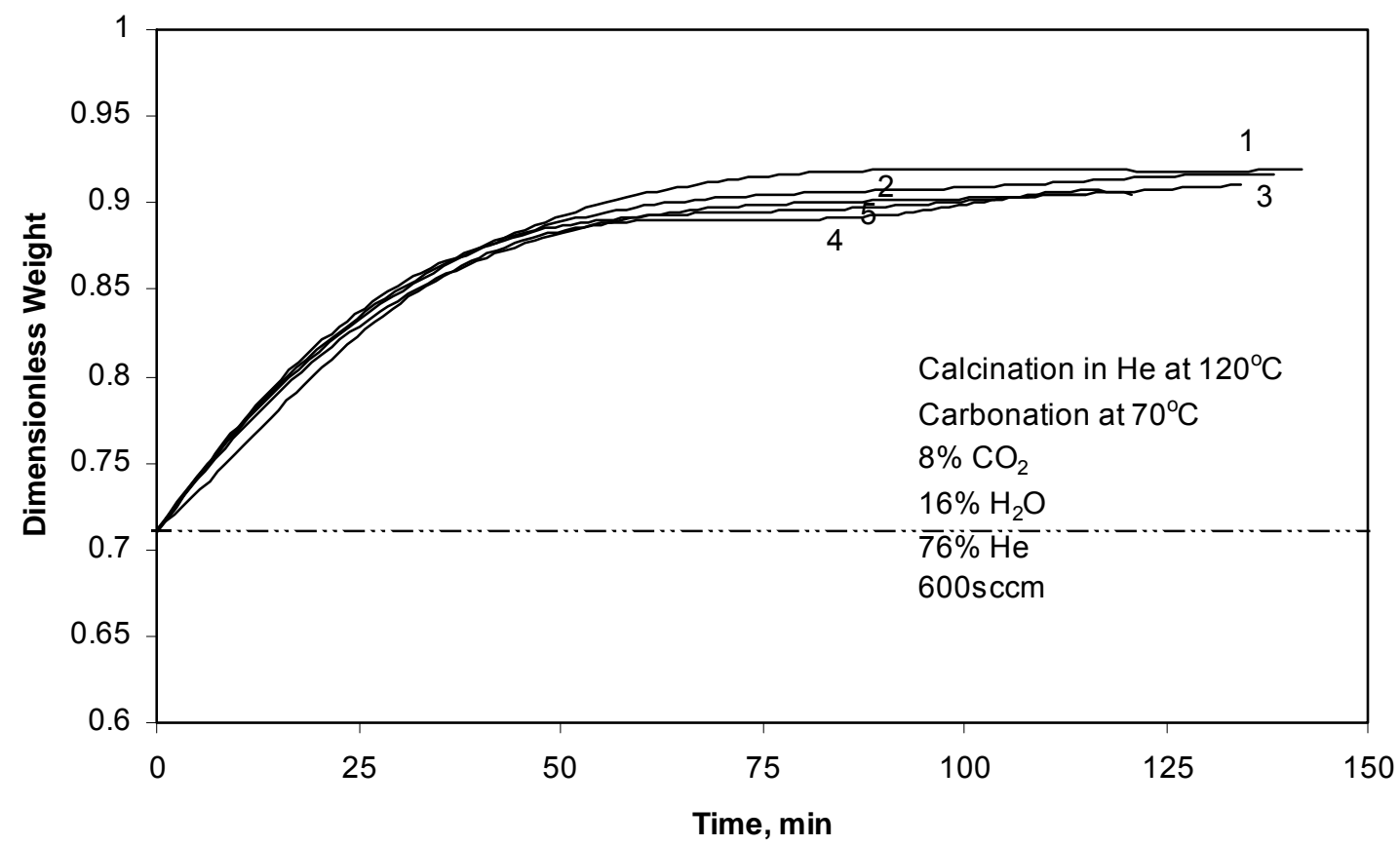

Figure 19. Smoothed electrobalance results for five carbonation cycles using Trona $\mathrm{T}-200$ : calcination in $\mathrm{He}$ at $120^{\circ} \mathrm{C}$

\subsubsection{Fractional Carbonation Versus Cycle Number Results}

In this section, fractional carbonation values at selected reaction times are used instead of the complete dimensionless weight versus time curves presented in the previous section. This facilitates comparison of results from different runs. Fractional conversion as a function of time is given by equations 7 through 12 . Also in this section, $t=25 \min$ was chosen to represent the reaction rate and $t=150 \mathrm{~min}$ was chosen to approximate the final fractional carbonation.

The reproducibility of three five-cycle tests using different samples of SBC\#3 is shown in Figure 20. Calcination was carried out at $120^{\circ} \mathrm{C}$ in $\mathrm{He}$ and the results from the five-cycle test previously presented in Figure 17 are included. The discrete points represent individual test results while the line is drawn through the average from the three tests. The scatter between runs is obvious, particularly in the $f(25)$ data. While there is a general decrease in $f(25)$ with cycle number, there is no consistent trend. The largest single value of $f(25)$ occurred in Cycle 4 of one of the tests, and, probably by coincidence, the $f(25)$ values in Cycle 4 were larger than the Cycle 3 values in each test. There is less scatter in the $f(150)$ results, as well as a clear decrease from Cycles 1 to 2 to 3, followed by reasonably constant values in Cycles 3, 4, and 5 . 
The average values of $f(25)$ and $f(150)$ in Cycle 5 are $29 \%$ and $23 \%$, respectively, smaller than the corresponding values in Cycle 1.

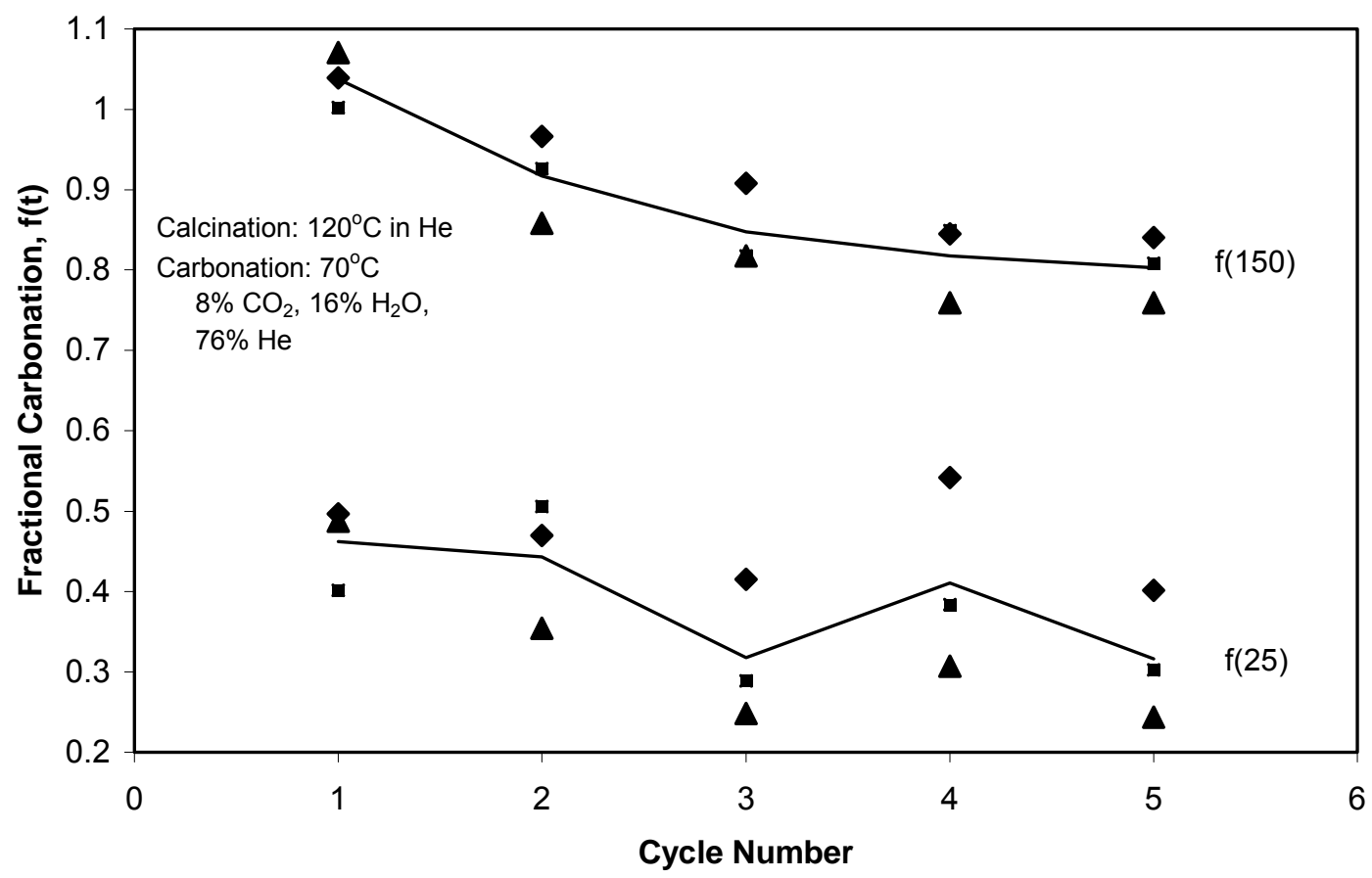

Figure 20. $f(25)$ and $f(150)$ from three duplicate tests using SBC\#3: Calcination at $120^{\circ} \mathrm{C}$ in $\mathrm{He}$

Similar results were obtained from three duplicate five-cycle tests at the same conditions using trona T-200. The average value of $f(150)$ decreased by $12 \%$, from 0.90 in Cycle 1 to 0.79 in Cycle 5, while the average value of $f(25)$ decreased by $27 \%$, from 0.51 in cycle 1 to 0.37 in Cycle 5.

The effects of calcination temperature and atmosphere on reaction rate, $f(25)$, and capacity, $f(150)$, in five-cycle tests using SBC\#3 are shown in Figures 21 and 22, respectively. All carbonations occurred at $70^{\circ} \mathrm{C}$ in $8 \% \mathrm{CO}_{2}, 16 \% \mathrm{H}_{2} \mathrm{O}$, and $76 \% \mathrm{He}$. The average values from Figure 20 are used to represent results at $120^{\circ} \mathrm{C}$ in $\mathrm{He}$, where duplicate tests were made. Calcination at $200^{\circ} \mathrm{C}$ in an atmosphere of $20 \% \mathrm{H}_{2} \mathrm{O}$ and $80 \% \mathrm{CO}_{2}$ was added in this series of tests to simulate possible commercial calcination conditions.

The maximum carbonation reaction rate, represented in Figure 21 by $f(25)$, clearly occurred following calcination at the mildest conditions of $120^{\circ} \mathrm{C}$ in He. Results at the more severe calcination conditions were closely bunched, except for unexpectedly high results in Cycles 2 
and 4 for calcination at $200^{\circ} \mathrm{C}$ in $80 \% \mathrm{CO}_{2}$ and $20 \% \mathrm{H}_{2} \mathrm{O}$. Average slopes of all lines in Figure 21 are approximately equal, suggesting that the rate of decrease in activity was not a strong function of calcination conditions. Sorbent capacity data, shown in Figure 22 and represented by $f(150)$, contained less scatter. In particular, in Cycle 1 all values of $f(150)$ were reasonably close to 1.0. Values of $f(150)$ decreased moderately with increased number of cycles at all calcination conditions, with the only exception being Cycles 4 and 5 following calcination in $\mathrm{He}$ at $160^{\circ} \mathrm{C}$.

The $f(25)$ and $f(150)$ carbonation results for four test sorbents-SBC\#1, SBC\#3, T-50, and T200-are compared in Figures 23 and 24. Calcination occurred under severe conditions of $200^{\circ} \mathrm{C}$ in $\mathrm{CO}_{2}$, while carbonation occurred at $70^{\circ} \mathrm{C}$ in $8 \% \mathrm{CO}_{2}, 16 \% \mathrm{H}_{2} \mathrm{O}$, and $76 \% \mathrm{He}$. SBC\#1 produced the largest values of both $f(25)$ and $f(150)$, and there was relatively little decrease in either value with increasing cycle number. For example, the values of $f(25)$ actually increased between Cycles 1 and 4 before decreasing in Cycle 5. The $f(150)$ value decreased by only 10\%, from 1.02 in Cycle 1 to 0.92 in Cycle 5. SBC\#3 was second to SBC\#1 in both $f(25)$ and $f(150)$, and there was relatively little difference in either of the trona samples.

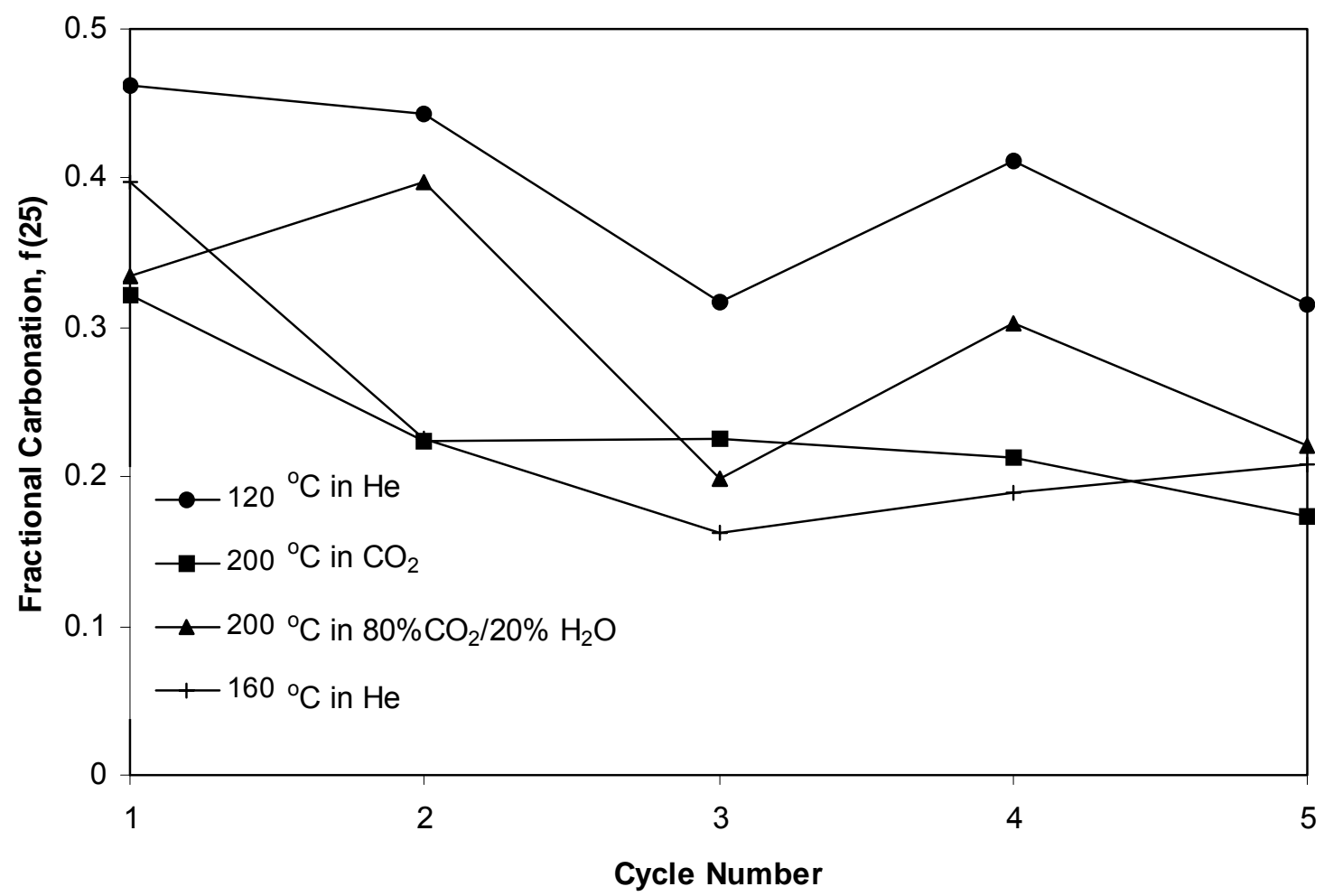

Figure 21. Comparison of $f(25)$ for carbonation of SBC\#3 at four calcination conditions 


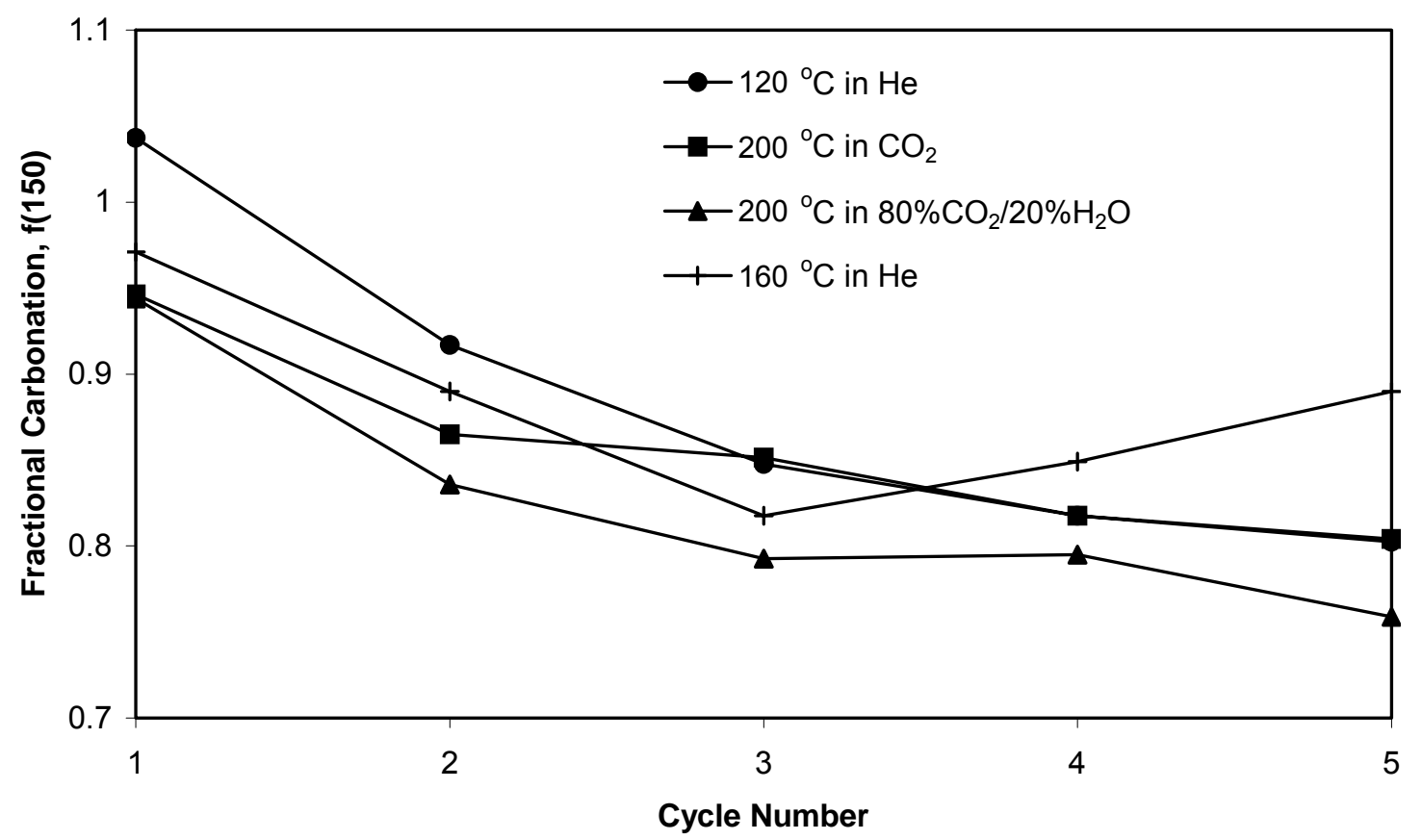

Figure 22. Comparison of $f(150)$ for carbonation of SBC\#3 at four calcination conditions

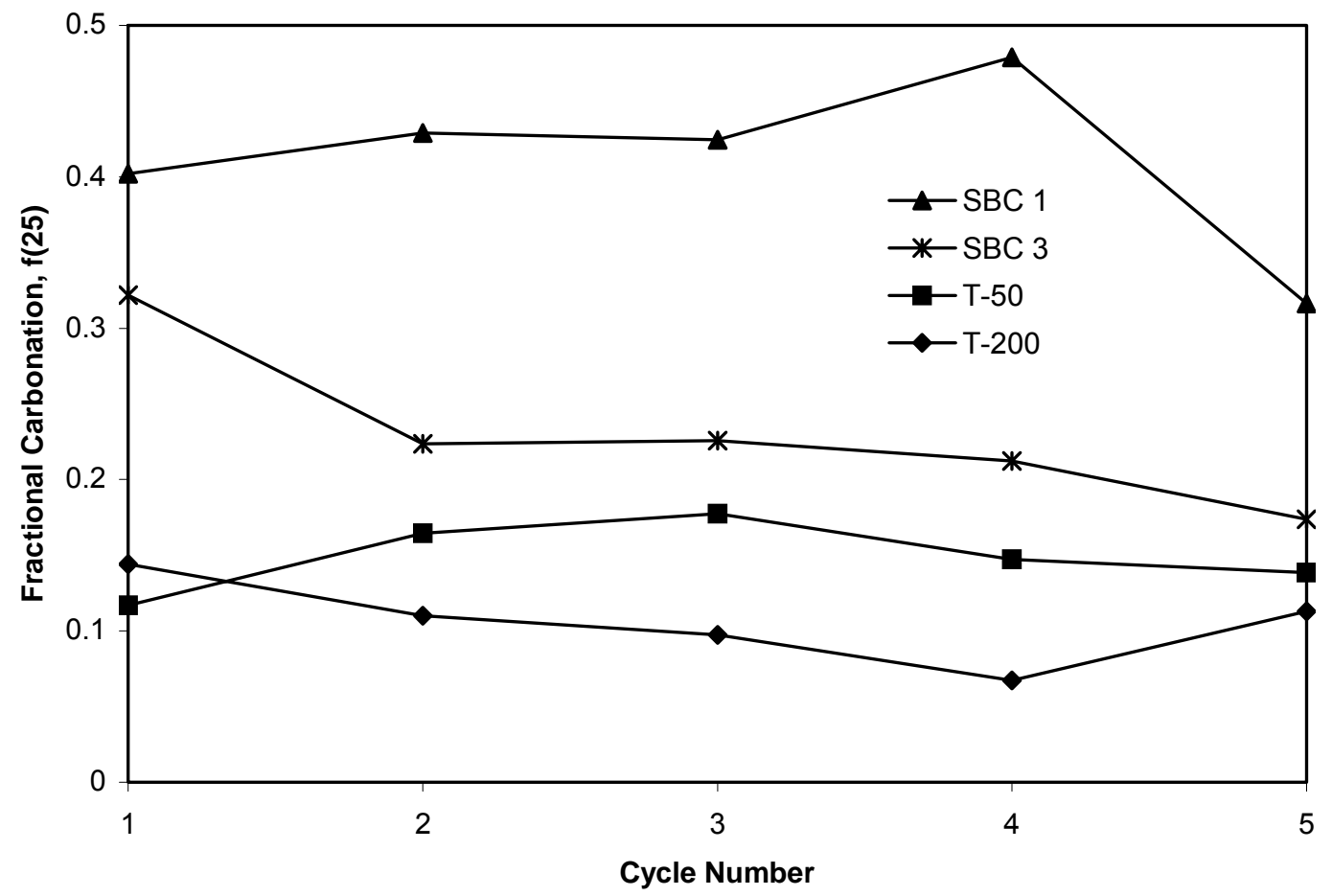

Figure 23. $f(25)$ comparison for four sorbent using $200^{\circ} \mathrm{C}$ calcination in $\mathrm{CO}_{2}$ 


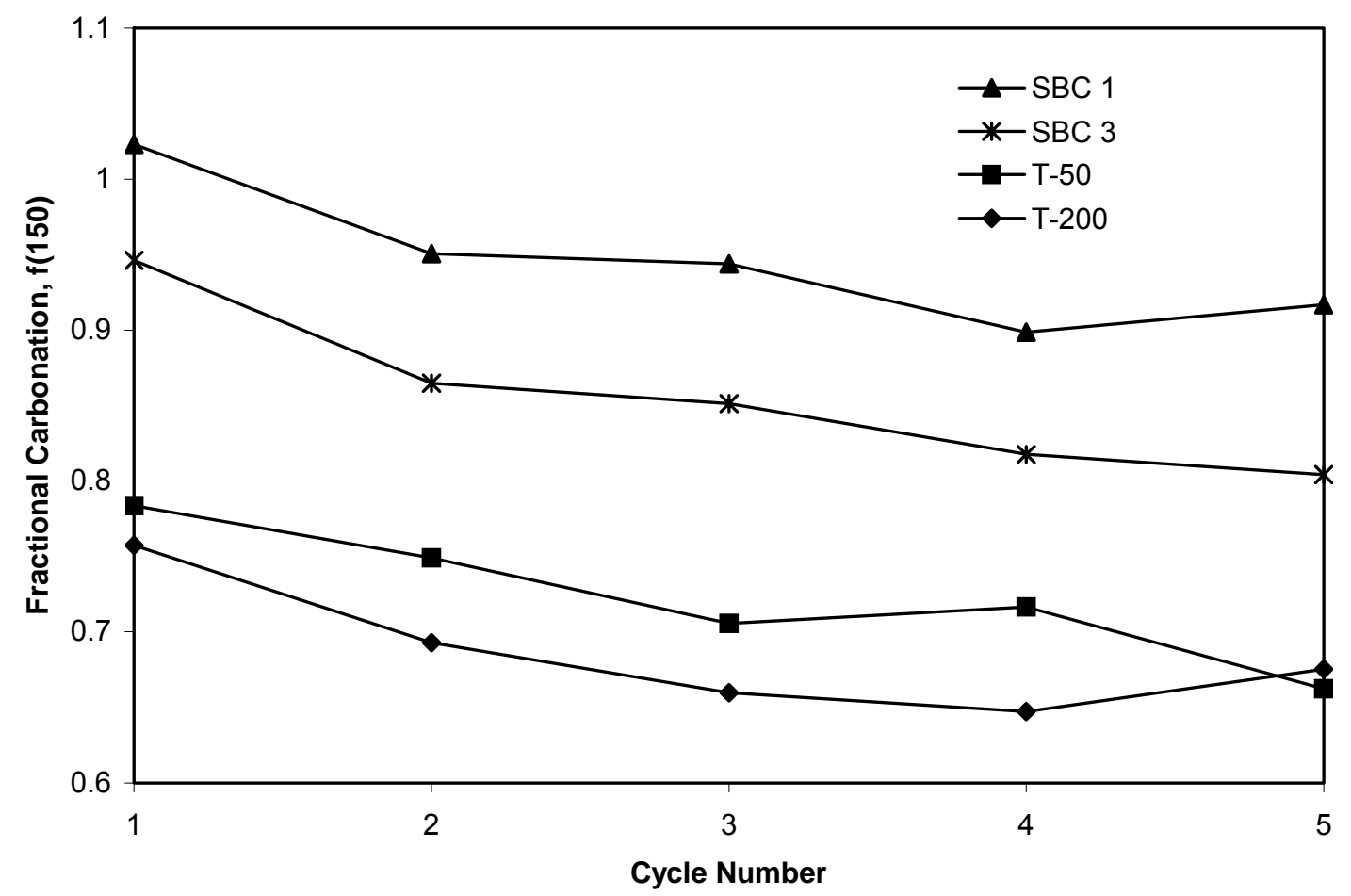

Figure 24. $f(150)$ comparison for four sorbents using $200^{\circ}$ calcination in $\mathrm{CO}_{2}$

\subsubsection{The Effect of $\mathrm{SO}_{2}$}

The presence of $\mathrm{SO}_{2}$ in the flue gas will interfere with $\mathrm{CO}_{2}$ removal through the formation of $\mathrm{Na}_{2} \mathrm{SO}_{3}$ and/or $\mathrm{Na}_{2} \mathrm{SO}_{4}$. The relevant reactions are

$$
\begin{aligned}
& \mathrm{Na}_{2} \mathrm{CO}_{3}(\mathrm{~s})+\mathrm{SO}_{2}(\mathrm{~g}) \rightarrow \mathrm{Na}_{2} \mathrm{SO}_{3}(\mathrm{~g})+\mathrm{CO}_{2}(\mathrm{~g}) \\
& \mathrm{Na}_{2} \mathrm{CO}_{3}(\mathrm{~s})+\mathrm{SO}_{2}(\mathrm{~g})+0.5 \mathrm{O}_{2}(\mathrm{~g}) \rightarrow \mathrm{Na}_{2} \mathrm{SO}_{4}(\mathrm{~s})+\mathrm{CO}_{2}(\mathrm{~g})
\end{aligned}
$$

The effect of $\mathrm{SO}_{2}$ addition, with and without the presence of $\mathrm{O}_{2}$, was examined in a series of multicycle electrobalance tests. When $0.4 \%$ and $0.2 \% \mathrm{SO}_{2}$ were added the tests were terminated after three cycles because little carbonation activity remained. When $0.1 \% \mathrm{SO}_{2}$ was added the test was continued through five cycles with a cumulative loss in $\mathrm{CO}_{2}$ removal in each cycle. Calcination conditions were $120^{\circ} \mathrm{C}$ in $\mathrm{He}$ in all tests, and carbonation occurred at $70^{\circ} \mathrm{C}$ in $8 \% \mathrm{CO}_{2}$ and $16 \% \mathrm{H}_{2} \mathrm{O}$ with the $\mathrm{He}$ concentration decreasing in response to the $\mathrm{SO}_{2}$ that was added.

Figure 25 shows raw electrobalance data for a 3.5-cycle test using SBC\#3 in which $0.2 \% \mathrm{SO}_{2}$ was added to the carbonation gas. The initial calcination progressed as expected with the final 
dimensionless weight very near the theoretical value of 0.631 . The dimensionless weight increased rapidly when the $\mathrm{SO}_{2}$-containing carbonation gas was added and reached a maximum of about 0.88 about 100 min later. The dimensionless weight then began to decrease and was about 0.83 when the first carbonation cycle ended. The final dimensionless weight at the end of the second calcination was 0.68 , instead of 0.63 , presumably due to the irreversible formation of $\mathrm{Na}_{2} \mathrm{SO}_{3}$. The weight changes became progressively smaller thereafter and after the fourth calcination the final dimensionless weight decreased only to 0.74 . At the end of the fourth calcination the temperature was increased incrementally to $200^{\circ} \mathrm{C}$, but there was no additional weight loss. Not only were increasing amounts of $\mathrm{Na}_{2} \mathrm{SO}_{3}$ being formed in each carbonation cycle, the $\mathrm{Na}_{2} \mathrm{SO}_{3}$ was stable in $\mathrm{He}$ at temperatures as high as $200^{\circ} \mathrm{C}$. The cause of the dimensionless weight maximum, which occurred only during the first cycle, is unknown.

The amount of $\mathrm{CO}_{2}$ removed during each carbonation cycle is proportional to the difference in dimensionless weights between the end of a carbonation and subsequent calcination cycle. This difference decreased from 0.15 in Cycle 1 (based on the final dimensionless weight of 0.83 ) to 0.11 in Cycle 2 and to 0.04 in Cycle 3.

Reducing the $\mathrm{SO}_{2}$ concentration to $0.1 \%$ slowed the rate of $\mathrm{Na}_{2} \mathrm{SO}_{3}$ formation enough that five complete cycles could be completed. Results of a five-cycle test using trona T-200 are shown in Figure 26. The results were qualitatively similar to those shown in Figure 25 except that the rate at which $\mathrm{CO}_{2}$ sorption capacity was lost decreased because of the lower $\mathrm{SO}_{2}$ concentration. The dimensionless weight increase was 0.25 during the first carbonation cycle, but was only 0.06 during the fifth carbonation cycle. This represents a loss in $\mathrm{CO}_{2}$ sorption capacity of about $76 \%$ in five cycles.

Results obtained when both $1.7 \% \mathrm{O}_{2}$ and $\mathrm{SO}_{2}$ were added to the carbonation gas were not greatly different from results shown in Figures 22 and 23. $1.7 \% \mathrm{O}_{2}$ was selected as this approximates the $\mathrm{O}_{2}$ concentration in flue gas when natural gas is burned with $10 \%$ excess air. From these results it is clear that when sulfur-containing fossil fuels are burned, the $\mathrm{CO}_{2}$ capture step must be downstream of a desulfurization step. 


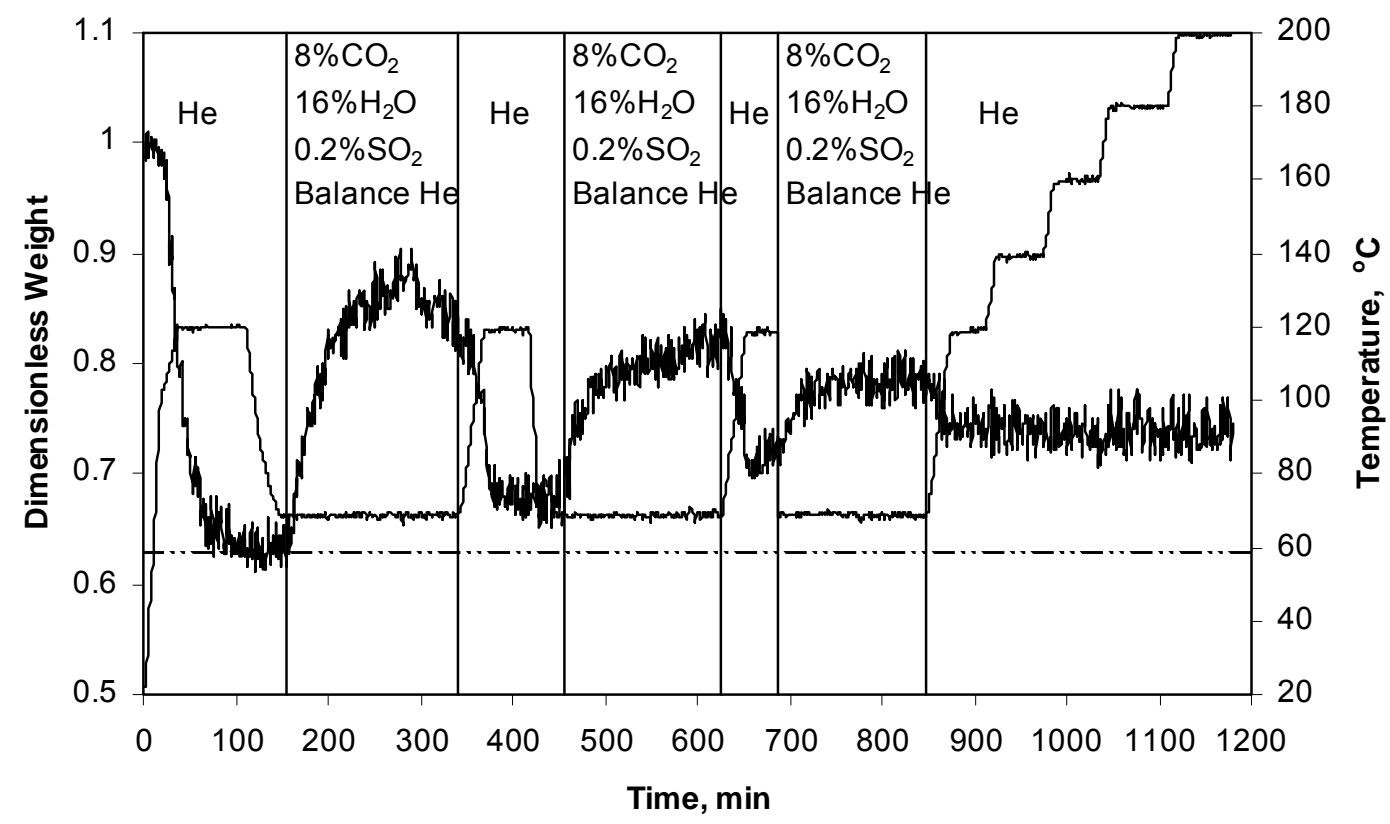

Figure 25. The effect of $0.2 \% \mathrm{SO}_{2}$ added to the carbonation gas: Three cycles using SBC\#3

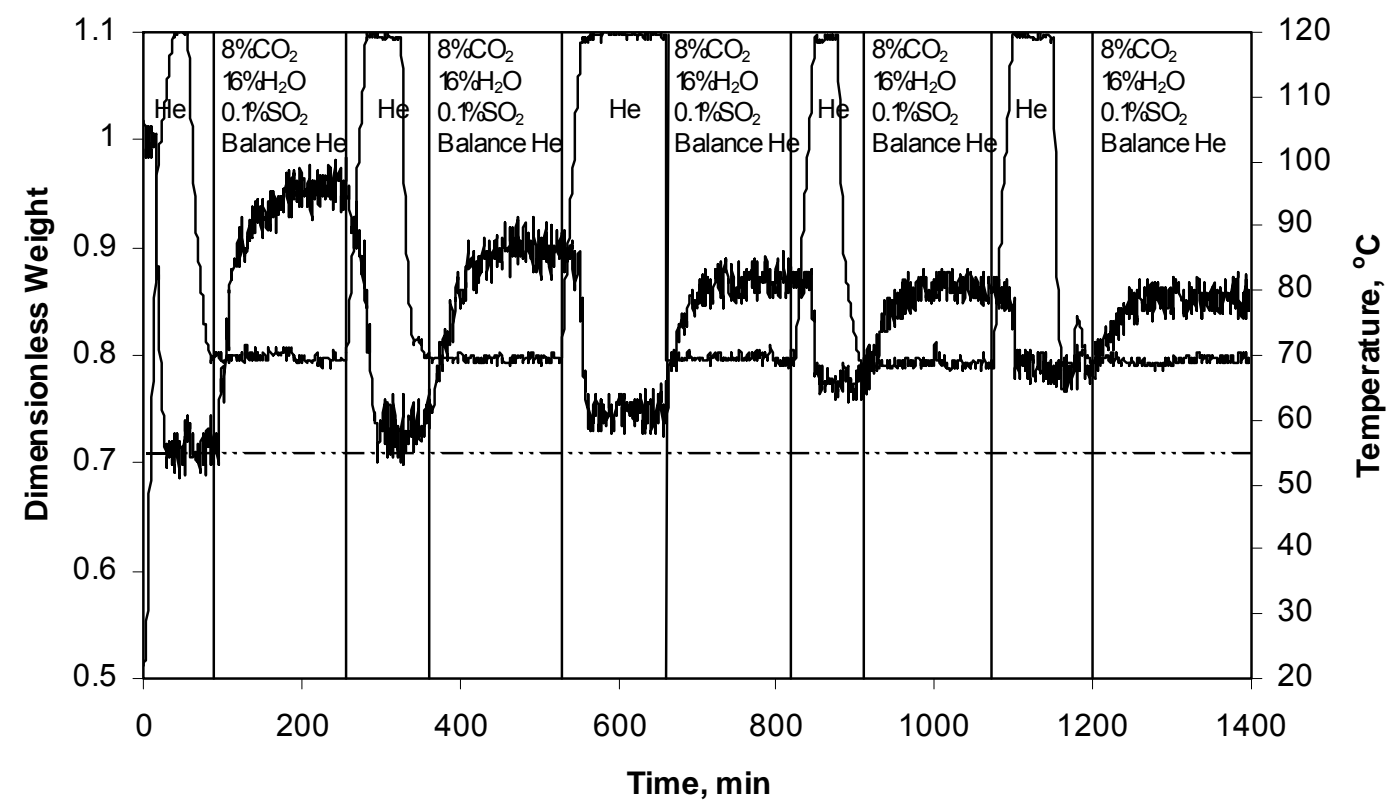

Figure 26. The effect of $0.1 \% \mathrm{SO}_{2}$ added to the carbonation gas: Five cycles using Trona T-200 


\subsection{FIXED-BED REACTOR TESTING AT LSU}

Fixed-bed tests with the product gas analyzed by gas chromatography were used to evaluate $\mathrm{CO}_{2}$ removal. At the beginning, single cycle tests were carried out to confirm the reliability of the reactor and analytical systems; most of the later tests were multicycle to provide additional information on sorbent durability. Calcination was carried out in both pure $\mathrm{N}_{2}$ and $\mathrm{CO}_{2}$ over a temperature range of $120^{\circ} \mathrm{C}$ to $200^{\circ} \mathrm{C}$. The carbonation gas contained $8 \% \mathrm{CO}_{2}, 16 \% \mathrm{H}_{2} \mathrm{O}$, and $76 \% \mathrm{~N}_{2}$, and in most tests $\mathrm{H}_{2} \mathrm{O}$ was added using a gas bubbler system, the gas exiting the bubbler was assumed to be saturated. Nominal carbonation temperatures of $60^{\circ} \mathrm{C}, 70^{\circ} \mathrm{C}$, and $80^{\circ} \mathrm{C}$ were examined, but the actual bed temperature was somewhat higher because of the exothermic nature of the carbonation reaction. SBC\#3 was used as the sorbent in all tests except one, which used SBC\#1.

\subsubsection{Five-Cycle Tests With Calcination in $\mathrm{N}_{2}$ at $120^{\circ} \mathrm{C}$}

$\mathrm{CO}_{2}$ concentration (dry basis) in the product gas as a function of time during both the calcination and carbonation phases of a 5.5-cycle test using SBC\#3 with calcination at $120^{\circ} \mathrm{C}$ in $\mathrm{N}_{2}$ and a nominal carbonation temperature of $60^{\circ} \mathrm{C}$ is shown in Figure 27 . As previously described, the initial calcination was carried out one day with both carbonation and calcination on subsequent days. The sorbent was always left overnight as $\mathrm{Na}_{2} \mathrm{CO}_{3}$ at $60^{\circ} \mathrm{C}$ in flowing $\mathrm{N}_{2}$. First-cycle calcination material balance closure was good with only a $3.5 \%$ difference between the theoretical amount of $\mathrm{CO}_{2}$ liberated and the experimental value determined by numerical integration of the $\mathrm{CO}_{2}$ concentration-time curve. Initial $\mathrm{CO}_{2}$ concentrations were near $1 \%$ in all carbonation cycles except Cycle 1, where the minimum $\mathrm{CO}_{2}$ concentration was about $3 \%$. There is a clear indication of improved performance between carbonation Cycles 1 and 2, similar to that shown in Figure 5, which illustrated typical results. Results from calcination Cycles 2 through 6 are virtually identical, with a maximum $\mathrm{CO}_{2}$ concentration of about $15 \%$ in each cycle.

These results are indicated more clearly in Figure 28 where $\mathrm{CO}_{2}$ concentrations in the carbonation product gas during the five cycles are overlaid. The poorer performance during the early stages of Cycle 1 is obvious. With the exception of the waves in the concentration-time curves in the 200-300 min period of Cycles 2 and 5, performance in Cycles 2 through 5 was basically identical. These waves are thought to be caused by variable feed gas composition due to $\mathrm{H}_{2} \mathrm{O}$ condensation between the gas bubbler and the reactor. The difficulty in controlling the preheat level to prevent condensation without overheating of the feed gas has been 


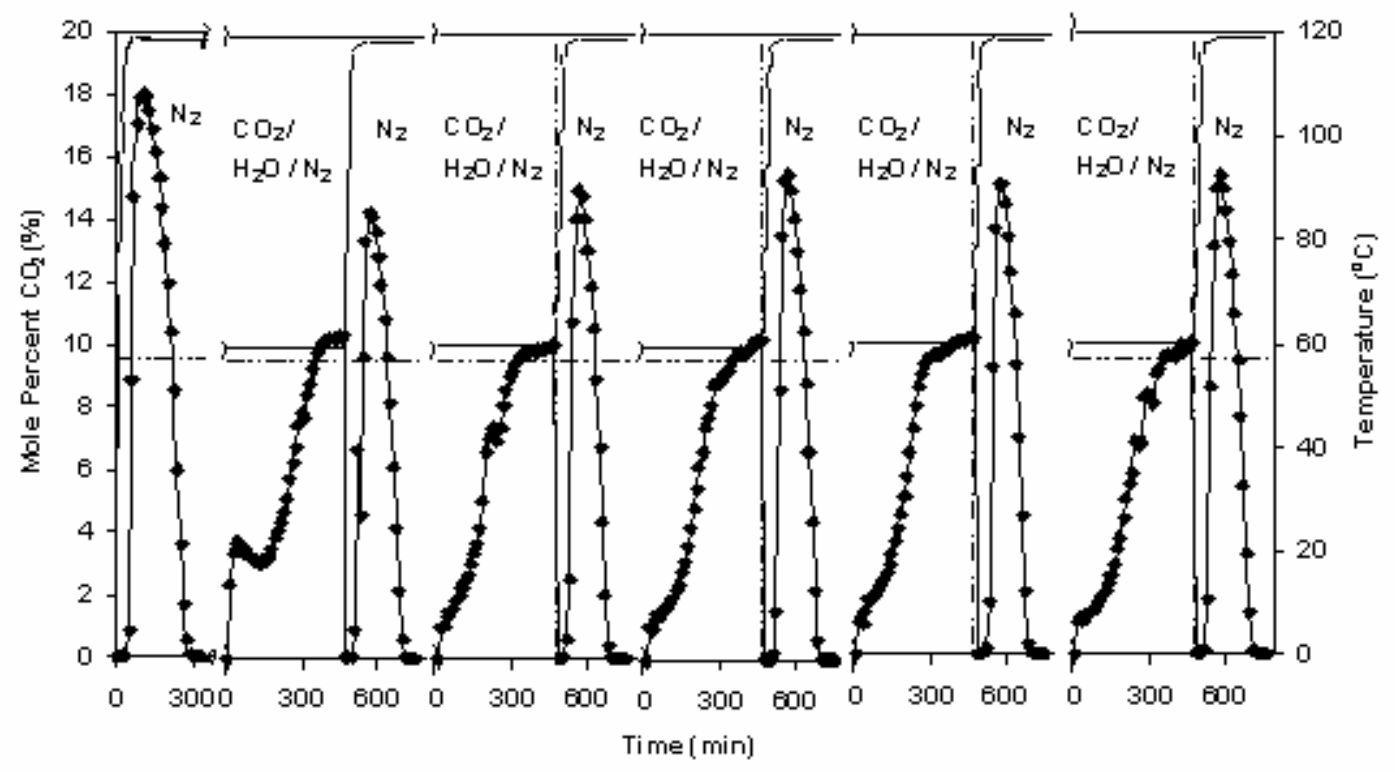

Figure 27. $\mathrm{CO}_{2}$ concentration for a 5.5-cycle fixed-bed test using $\mathrm{SBC} \# 3$ at $60^{\circ} \mathrm{C}$ carbonation temperature and $150 \mathrm{sccm}$ carbonation feed rate

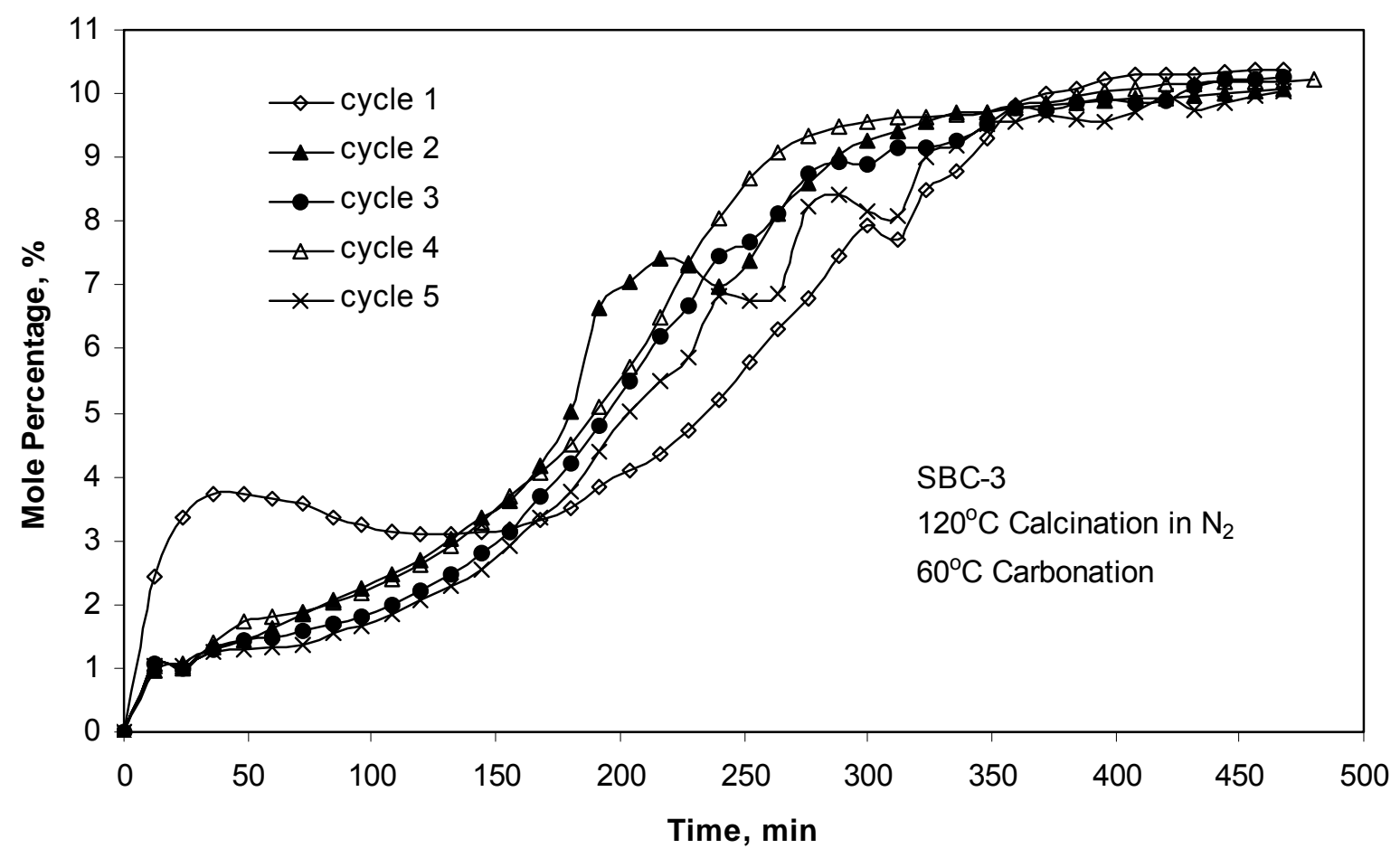

Figure 28. $\mathrm{CO}_{2}$ concentration during five carbonation cycles using SBC\#3 at a nominal carbonation temperature of $60^{\circ} \mathrm{C}$ and feed rate of $150 \mathrm{sccm}$ 
discussed previously. All cycles exhibited the basic shape of a traditional breakthrough curve and all approached almost the same final $\mathrm{CO}_{2}$ concentration.

Results from the carbonation phases of a five-cycle test using a nominal $70^{\circ} \mathrm{C}$ carbonation temperature are shown in Figure 29. Calcination was also at $120^{\circ} \mathrm{C}$ in $\mathrm{He}$ in this test. The results are qualitatively similar to the $60^{\circ} \mathrm{C}$ results shown in Figure 28 . There is an obvious improvement in performance between the early stages of Cycles 1 and 2 with effectively no difference in performance between Cycles 2 and 5 . The concentration waves are absent and Cycles 2 through 5 all exhibit the shape of a traditional breakthrough curve. The most significant difference between the results at $60^{\circ} \mathrm{C}$ and $70^{\circ} \mathrm{C}$ occurred in the early stages of the test. The initial $\mathrm{CO}_{2}$ concentration at $70^{\circ} \mathrm{C}$ was about $3 \%$ compared to about $1 \%$ at $60^{\circ} \mathrm{C}$.

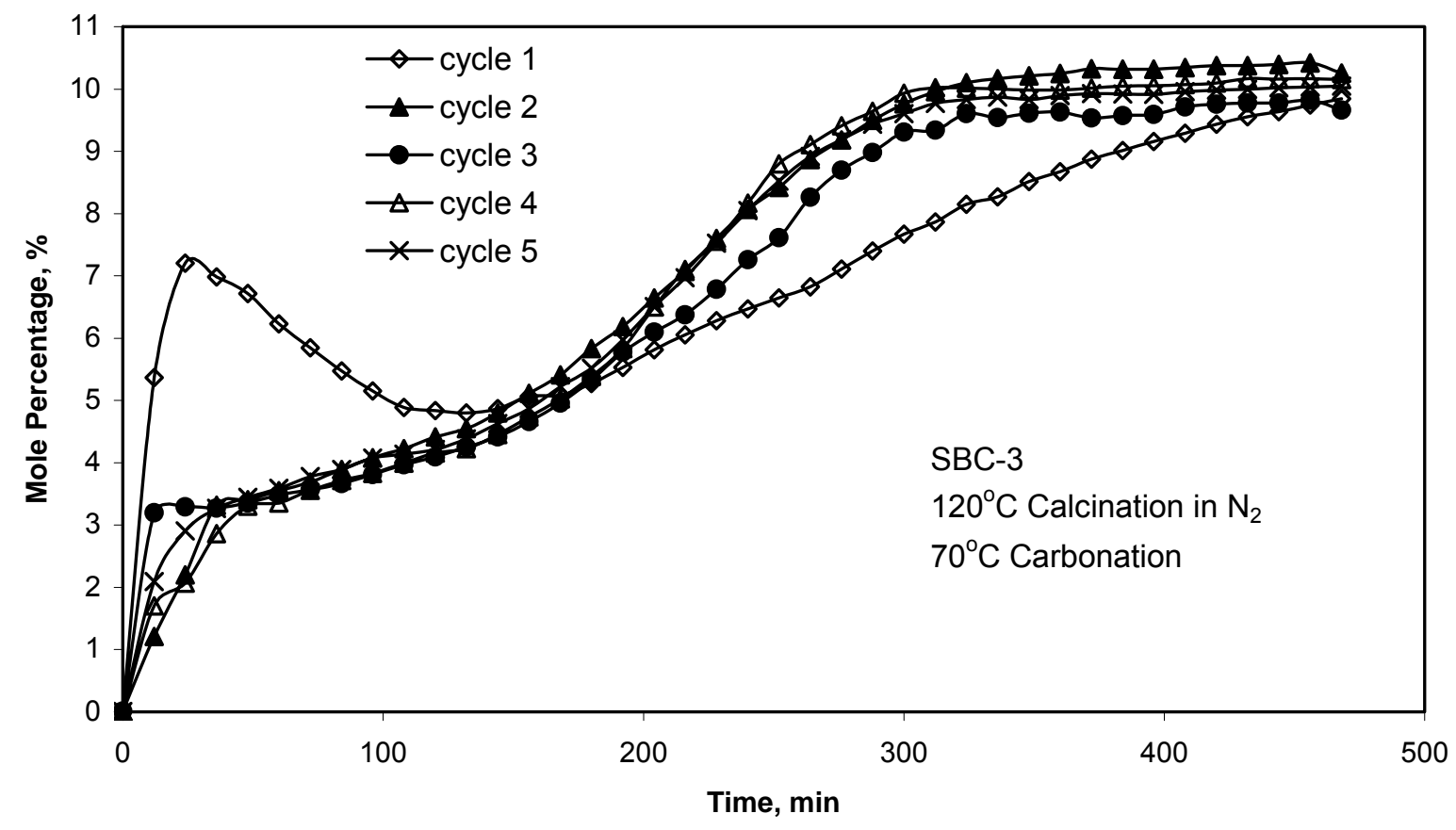

Figure 29. $\mathrm{CO}_{2}$ concentration during five carbonation cycles using $\mathrm{SBC} \# 3$ at a nominal carbonation temperature of $70^{\circ} \mathrm{C}$ and feed rate of $150 \mathrm{sccm}$

Only a small amount of $\mathrm{CO}_{2}$ was removed when the carbonation temperature was increased to a nominal $80^{\circ} \mathrm{C}$, even though carbonation is thermodynamically favored and some $\mathrm{CO}_{2}$ removal occurred in electrobalance tests at this temperature. This is attributed to a temperature increase above the nominal level due to the exothermic heat of reaction, and emphasizes the importance of careful temperature control in any commercial process. 
SBC\#1 was evaluated in a five-cycle test with calcination at $120^{\circ} \mathrm{C}$ in $\mathrm{He}$ and carbonation at a nominal temperature of $60^{\circ} \mathrm{C}$. Results from the five carbonation cycles in terms of $\mathrm{CO}_{2}$ concentration as a function of time are presented in Figure 30. The results are very similar to those shown in Figure 28 for SBC\#3 at the same conditions. Again, there was a noticeable improvement in performance between Cycles 1 and 2 and essentially no difference in performance between Cycles 2 and 5. Initial $\mathrm{CO}_{2}$ concentrations during Cycles 2 through 5 were just over $1 \%$, while the minimum concentration in Cycle 1 was about $2.5 \%$.

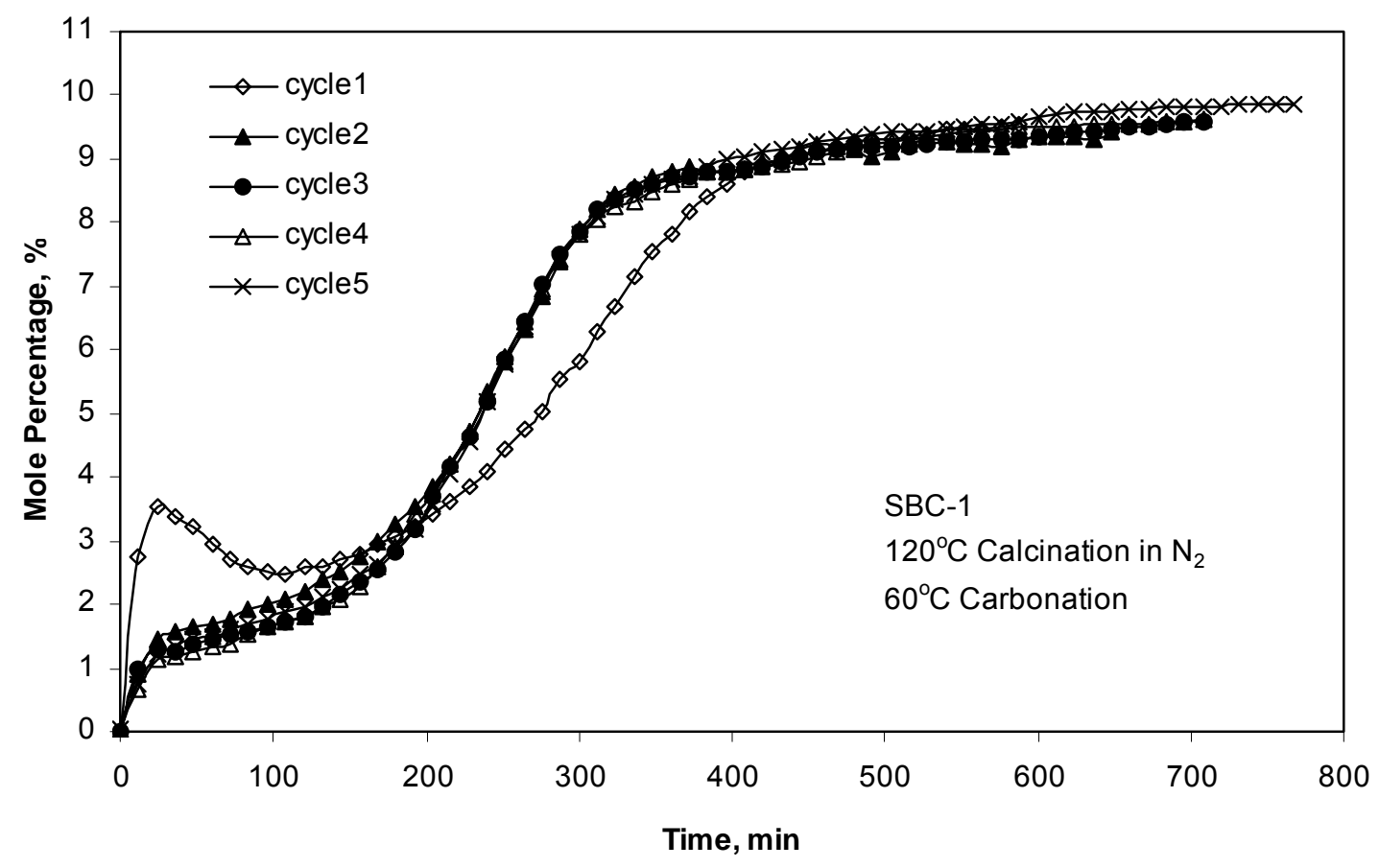

Figure 30. $\mathrm{CO}_{2}$ concentration during five carbonation cycles using SBC\#1 at a nominal carbonation temperature of $60^{\circ} \mathrm{C}$ and feed rate of $150 \mathrm{sccm}$.

The performance of SBC\#3 and SBC\#1 in these five-cycle fixed-bed tests is further compared in Figures 31 and 32 . Figure 31 shows the percentage $\mathrm{CO}_{2}$ removal in the third sample from each carbonation cycle as a function of cycle number. The third sample, which was acquired 36 min after the carbonation reaction was initiated, was chosen for the comparison to provide sufficient time for the carbonation gas feed rate and composition to reach steady-state values. Figure 32 shows the final percentage conversion of $\mathrm{Na}_{2} \mathrm{CO}_{3}$ to Wegscheider's salt as a function of carbonation cycle.

Figure 31 emphasizes the improved performance in all three tests between Cycles 1 and 2, the improved performance associated with the lower nominal temperature of $60^{\circ} \mathrm{C}$, and the close 
correspondence in $60^{\circ} \mathrm{C}$ results between $\mathrm{SBC} \# 3$ and $\mathrm{SBC} \# 1$. At $60^{\circ} \mathrm{C}$, the $\mathrm{CO}_{2}$ removal increased from just above $60 \%$ in Cycle 1 to almost $90 \%$ in the remaining cycles for both sorbents. The comparable numbers for $70^{\circ} \mathrm{C}$ carbonation were almost $30 \% \mathrm{CO}_{2}$ removal in Cycle 1 and about $70 \%$ in the remaining cycles.

The final percentage conversions of $\mathrm{Na}_{2} \mathrm{CO}_{3}$ to Wegscheider's salt shown in Figure 32 are quite consistent during all five cycles of all three tests. $60^{\circ} \mathrm{C}$ carbonation resulted in effectively complete conversion, while the percentage conversion of $\mathrm{SBC} \# 3$ at $70^{\circ} \mathrm{C}$ was near $85 \%$.

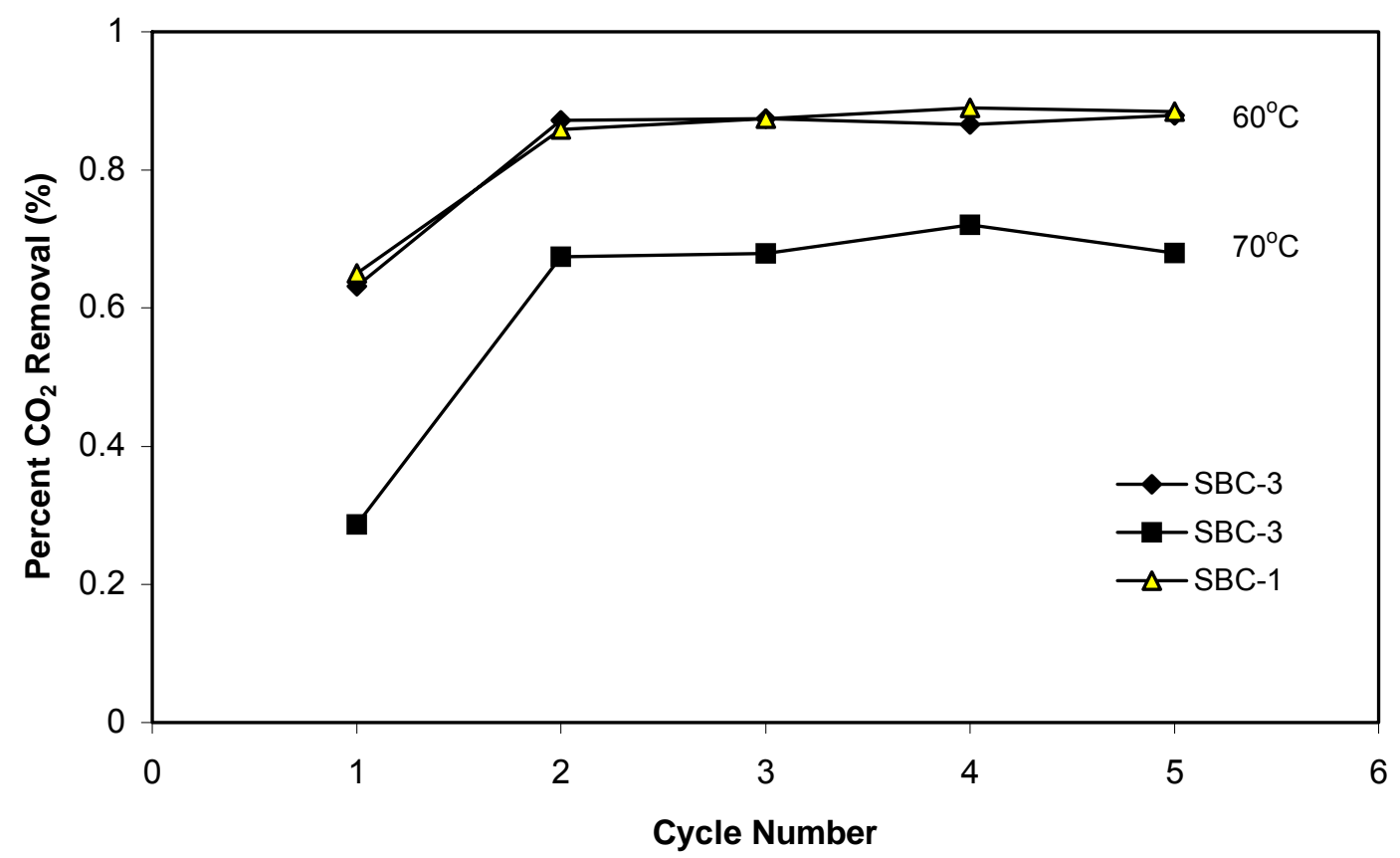

Figure 31. Percentage $\mathrm{CO}_{2}$ removal as a function of nominal carbonation temperature and cycle number of SBC\#3 and SBC\#1 (based on $\mathrm{CO}_{2}$ concentration in the third sample of each carbonation cycle) 


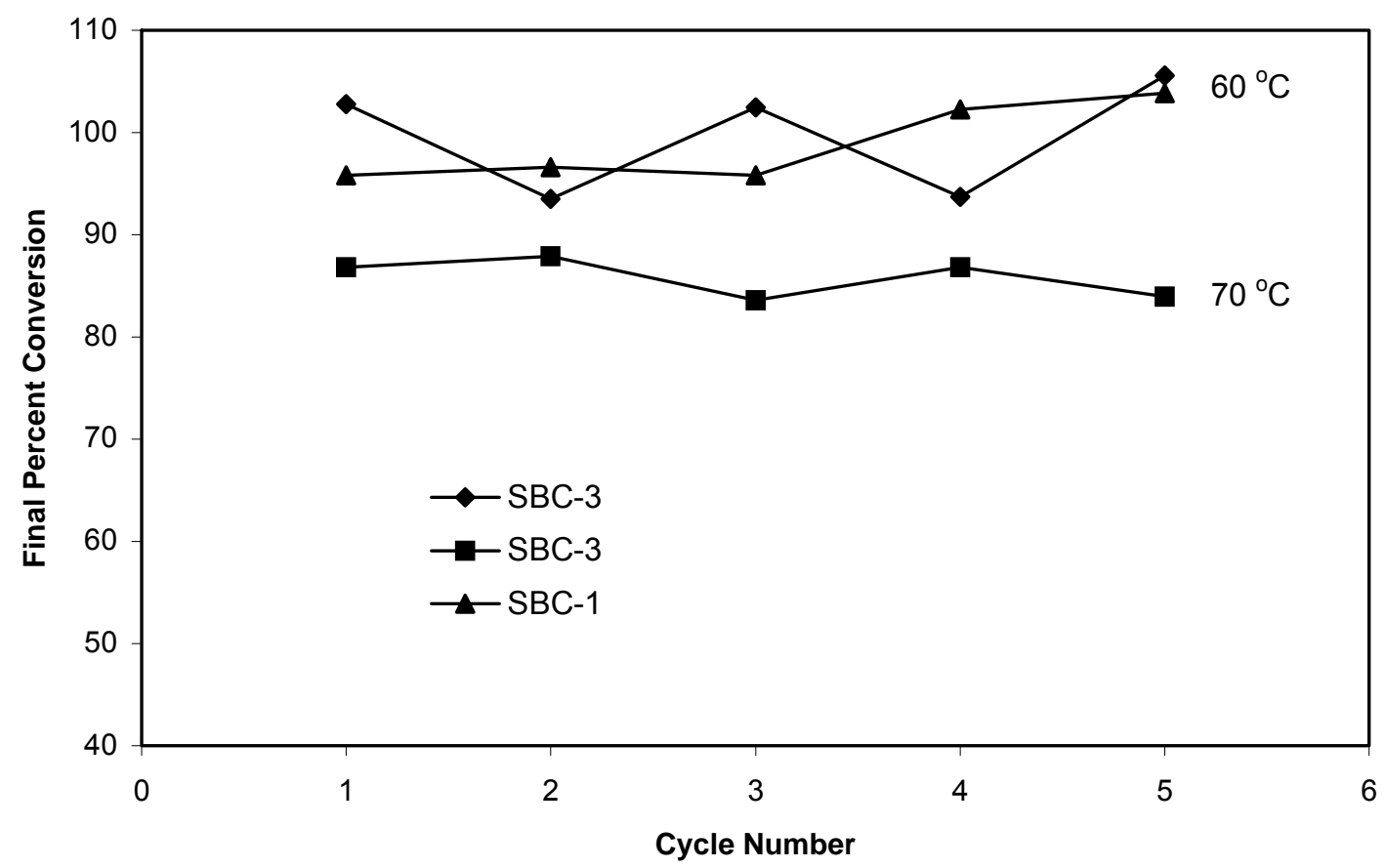

Figure 32. Final percentage conversion of $\mathrm{Na}_{2} \mathrm{CO}_{3}$ to Wegscheider's salt as a function of carbonation temperature and cycle number using SBC\#3 and SBC\#1

\subsubsection{Multicycle Tests With Calcination in $\mathrm{CO}_{2}$ at $160^{\circ} \mathrm{C}$ and $200^{\circ} \mathrm{C}$}

Carbonation results from two five-cycle tests using SBC\#3 with calcination carried out in $\mathrm{CO}_{2}$ at $160^{\circ} \mathrm{C}$ are shown in Figures 33 and 34 . In these figures, fractional $\mathrm{CO}_{2}$ removal is shown as a function of time. Progress of the calcination phase cannot be monitored whenever calcination occurs in a $\mathrm{CO}_{2}$ atmosphere. Consequently, calcination was carried out for a fixed time period of 2 hours. Carbonation was at a nominal temperature of $60^{\circ} \mathrm{C}$ with the feed containing $8 \%$ $\mathrm{CO}_{2}, 16 \% \mathrm{H}_{2} \mathrm{O}$, and $76 \% \mathrm{~N}_{2}$. These figures are, for practical purposes, mirror images of the previous figures, which showed $\mathrm{CO}_{2}$ concentration as a function of time. The only significant difference in the two tests is that in the first (Figure 33), the carbonation cycle lasted about 350 min; in the second test (Figure 34), the carbonation cycle was ended after $225 \mathrm{~min}$. In earlier tests, the carbonation cycle last as long as $700 \mathrm{~min}$ (Figure 30). Figure 33 shows what appears to be a step function increase in $\mathrm{CO}_{2}$ removal after about $100 \mathrm{~min}$ in Cycle 3. This was due, however, to a computer malfunction, which caused the software to incorrectly show $100 \% \mathrm{CO}_{2}$ removal. The carbonation cycle actually continued for the full $350 \mathrm{~min}$ in a normal manner. Figure 34 shows two distinct peaks in $\mathrm{CO}_{2}$ removal during Cycle 1 at about 160 and 190 min. This is attributed to an incorrect level of feed preheat, which allowed partial condensation of $\mathrm{H}_{2} \mathrm{O}$ 
in the feed gas. The level of preheat was increased slightly in subsequent cycles and the peaks were eliminated.

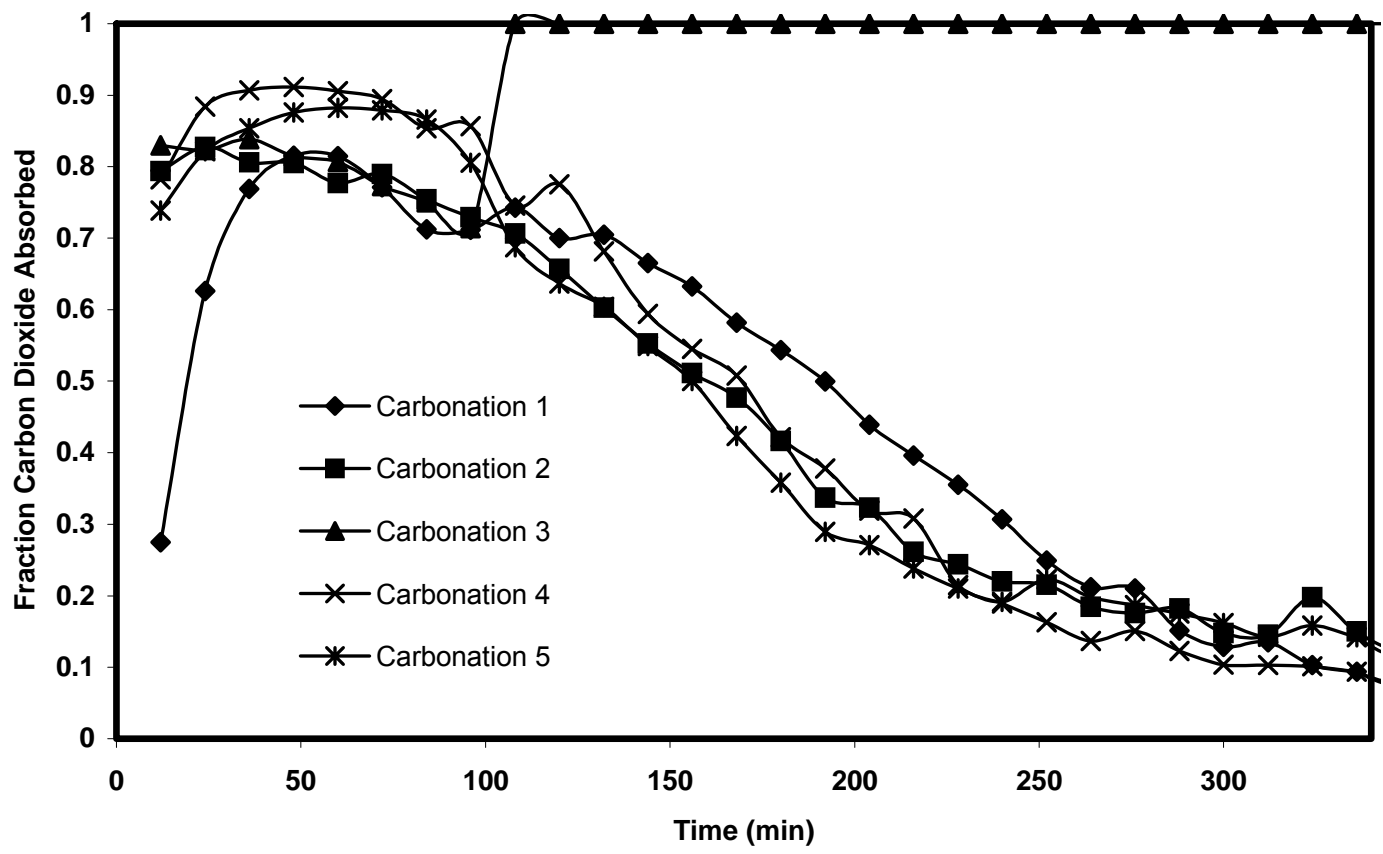

Figure 33. Fractional $\mathrm{CO}_{2}$ removal as a function of time: Five-cycle testing using SBC\#3 with calcination in $\mathrm{CO}_{2}$ at $160^{\circ} \mathrm{C}$, first test

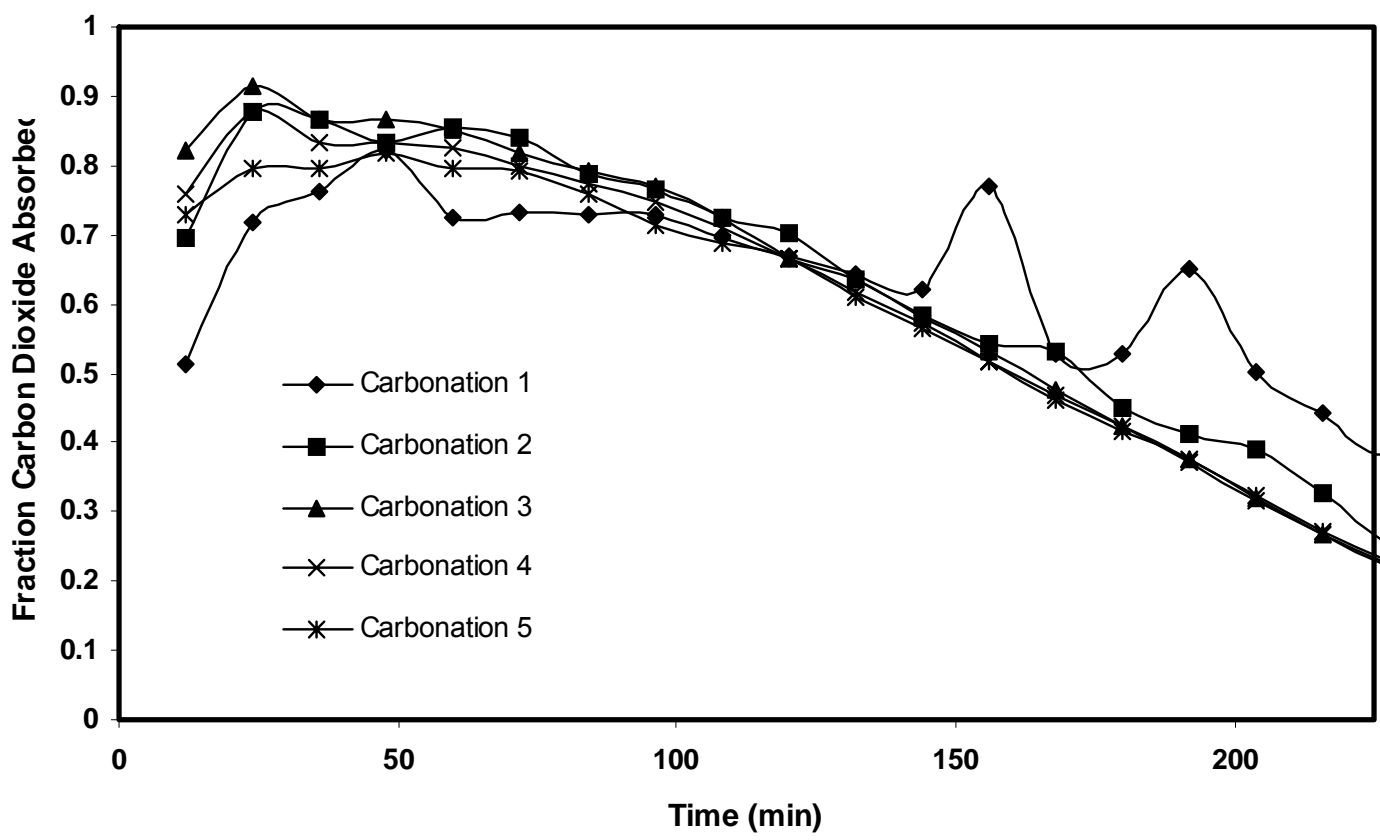

Figure 34. Fractional $\mathrm{CO}_{2}$ removal as a function of time: Five-cycle test using SBC\#3 with calcination at $160^{\circ} \mathrm{C}$ in $\mathrm{CO}_{2}$, second test 
Both figures show an initial minimum in first-cycle $\mathrm{CO}_{2}$ removal, followed by an increase to a maximum value and then a gradual decrease with time. In the first cycle of the first test

(Figure 33) the $\mathrm{CO}_{2}$ removal increased from less than 0.30 in the first sample to a maximum of 0.82 after $48 \mathrm{~min}$ and slowly decreased to 0.09 at the end of the cycle. The first cycle minimum was less pronounced in the second test (Figure 34) where the $\mathrm{CO}_{2}$ removal increased from 0.51 in the first sample to a maximum of 0.82 after $48 \mathrm{~min}$ and a final value of 0.40 after $225 \mathrm{~min}$. However, the final value may be abnormally high because of the earlier peaks in apparent $\mathrm{CO}_{2}$ removal.

Performance improved between Cycles 1 and 2 in both tests and remained relatively constant during Cycles 2 through 5. The initial minima were absent, or at least much less pronounced, in subsequent cycles and the overall maxima in $\mathrm{CO}_{2}$ removal reached 0.91 in both tests. This occurred after $48 \mathrm{~min}$ in Cycle 4 in the first test (Figure 33) and after 24 min in Cycle 3 in the second test (Figure 34). Final $\mathrm{CO}_{2}$ removals ranged from 0.09 to 0.14 when the carbonation cycles were terminated after $350 \mathrm{~min}$ in the first test, and from 0.18 to 0.25 when the carbonation cycles were terminated after $225 \mathrm{~min}$ in the second test (neglecting the final value of 0.40 in Cycle 1 which is attributed to the condensation problem). Overall, there was little difference between cycles in either test and no evidence of performance deterioration as the number of cycles increased.

Fractional $\mathrm{CO}_{2}$ removal as a function of time for a five-cycle test using SBC\#3 with calcination in $\mathrm{CO}_{2}$ at $200^{\circ} \mathrm{C}$ for 2 hours is shown in Figure 35. Once again, the carbonation cycle was at a nominal temperature of $60^{\circ} \mathrm{C}$ with the feed gas containing $8 \% \mathrm{CO}_{2}, 16 \% \mathrm{H}_{2} \mathrm{O}$, and $76 \% \mathrm{~N}_{2}$; the carbonation cycles were again terminated after 225 min. 


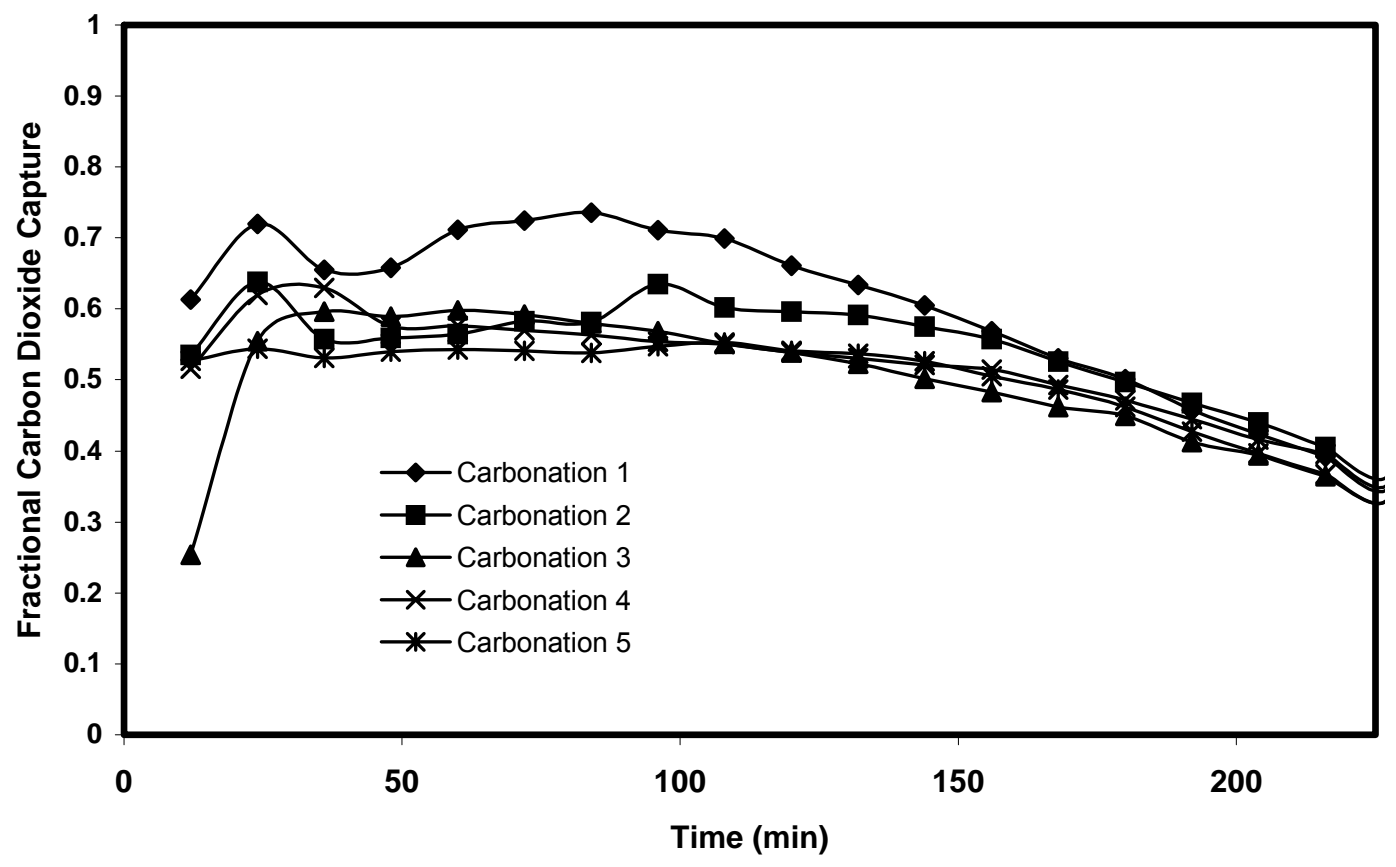

Figure 35. Fractional $\mathrm{CO}_{2}$ removal as a function of time: Five-cycle test using SBC\#3 with calcination in $\mathrm{CO}_{2}$ at $200^{\circ} \mathrm{C}$

While the fractional $\mathrm{CO}_{2}$ removal-time curves in the last three figures are qualitatively similar, there are significant differences. Once again, the initial minima in $\mathrm{CO}_{2}$ removal during the first cycle are evident, and the minima are significantly reduced in subsequent cycles. However, performance was significantly poorer using $200^{\circ} \mathrm{C}$ calcination in $\mathrm{CO}_{2}$. The overall maximum $\mathrm{CO}_{2}$ removal was only 0.74 (after $84 \mathrm{~min}$ in Cycle 1) compared to 0.91 in both tests following calcination in $\mathrm{CO}_{2}$ at $160^{\circ} \mathrm{C}$. The slopes of the curves in Figure 35 are significantly smaller than the slopes in the previous figures, indicating that $\mathrm{CO}_{2}$ removal was still occurring to a greater extent when carbonation was terminated. In fact, final $\mathrm{CO}_{2}$ removals ranged from 0.34 to 0.38 in Figure 35, values that are $50 \%$ to $100 \%$ larger than in the earlier figures.

Results from these three tests plus a final 15-cycle test are further compared in Figure 36, where fractional $\mathrm{CO}_{2}$ removal in the third sample of each carbonation cycle is plotted against cycle number. The 15 -cycle test used calcination at $160^{\circ} \mathrm{C}$ in $\mathrm{CO}_{2}$. As described previously, the third sample was chosen for the comparison to provide sufficient time for feed gas composition and flow rate to reach steady values. The similarity of the results of the three tests using $160^{\circ} \mathrm{C}$ calcination and the superiority of these tests compared to the $200^{\circ} \mathrm{C}$ calcination test is immediately evident. There appears to be no deterioration in performance as the number of 
cycles increased. It is also interesting to note that fractional $\mathrm{CO}_{2}$ removals of about 0.90 associated with $160^{\circ} \mathrm{C}$ calcination in $\mathrm{CO}_{2}$ are quite close to the values shown in Figure 31 for calcination at $120^{\circ} \mathrm{C}$ in $\mathrm{N}_{2}$.

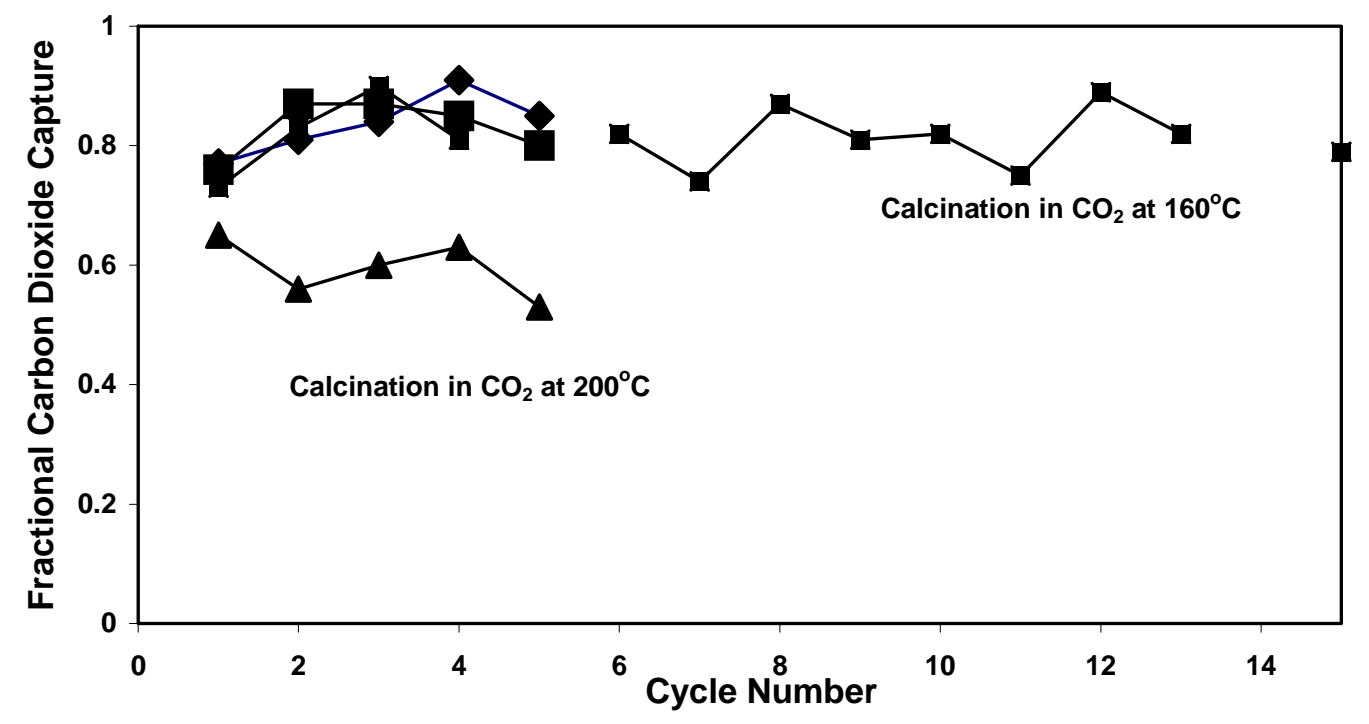

Figure 36. Fractional $\mathrm{CO}_{2}$ Removal in the third carbonation sample as a function of cycle number: $\mathrm{SBC} \# 3$ with calcination in $\mathrm{CO}_{2}$ at $160^{\circ} \mathrm{C}$ and $200^{\circ} \mathrm{C}$

\subsection{FLUIDIZED-BED REACTOR TESTING AT RTI}

\subsubsection{Test 1: SBC\#3}

A five-cycle calcination/carbonation test was conducted using SBC\#3 as a sorbent precursor. Temperatures for the carbonation cycles varied from cycle to cycle, as the range of feasible operating temperatures was determined. While the reactor was preheated prior to carbonation, the exothermic heat of reaction ultimately controlled the reaction temperature, and no additional heat input, beyond the influent gas preheater, was necessary to maintain the bed temperature. Slight variations in temperature across the fluidized sorbent bed occurred. The reactor was initially loaded with $258 \mathrm{~g}$ of SBC\#3, providing an initial bed height of 6 inches, for a height-todiameter ratio of 3 . The material was calcined in situ prior to the first carbonation and between subsequent carbonations. Calcinations were essentially complete, based on, in some cases, 
the carbon dioxide content of the reactor effluent gas and, in all cases, monitored bed temperatures.

Carbon dioxide removal was calculated based on inlet flows (dry basis) of air, nitrogen, and $\mathrm{CO}_{2}$, and $\mathrm{CO}_{2}$ content (dry basis) of the effluent gas. Carbon dioxide removal profiles for each cycle are shown in Figures 37 through 41. Cycle lengths varied from approximately 3 to 6.5 hours. Temperature profiles at 1 in, 3 in, and 5 in above the flow distributor are shown in Figures 42 through 46.

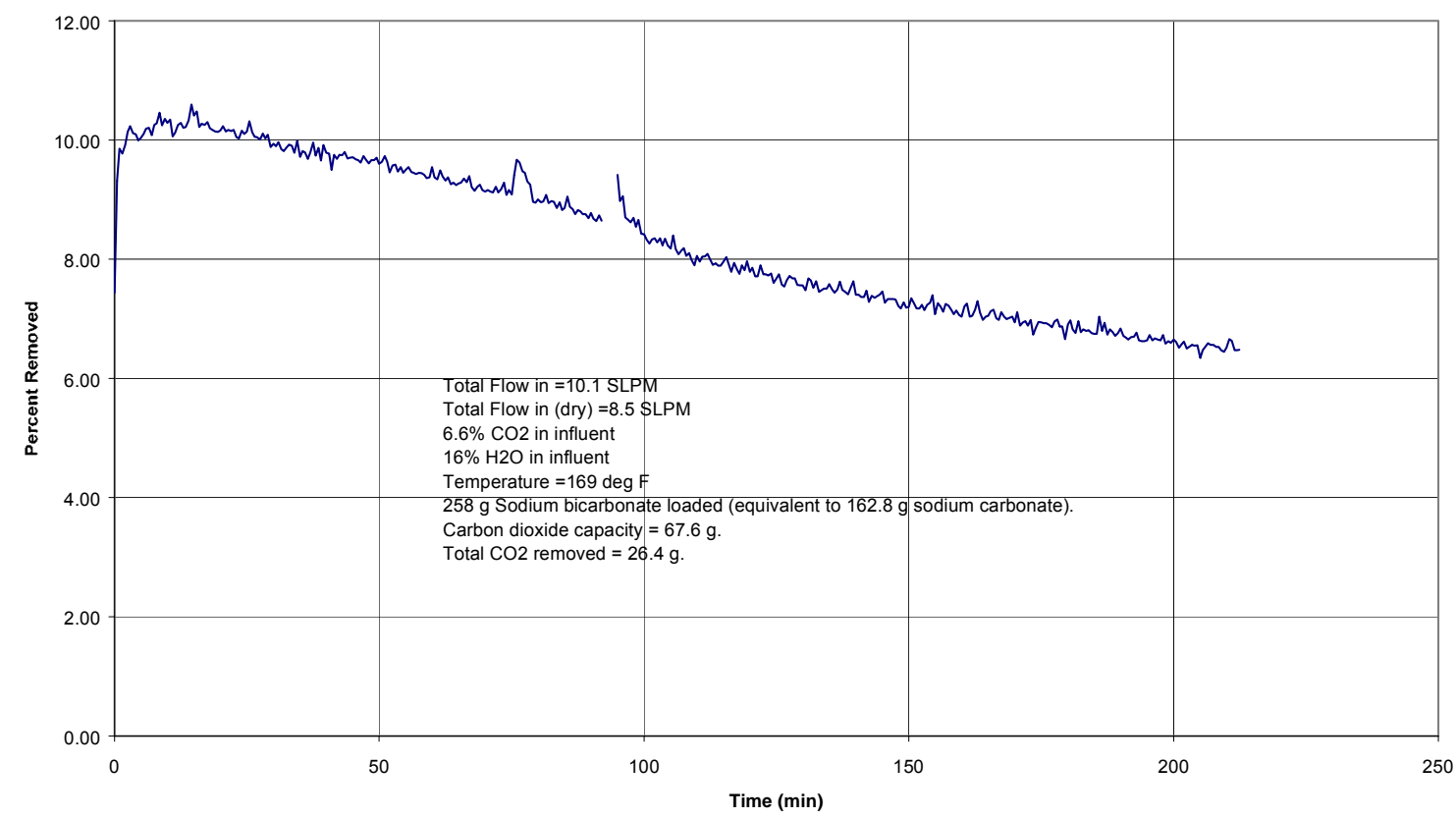

Figure 37. Cycle 1 carbonation test (9/19/01) - fractional $\mathrm{CO}_{2}$ removal 


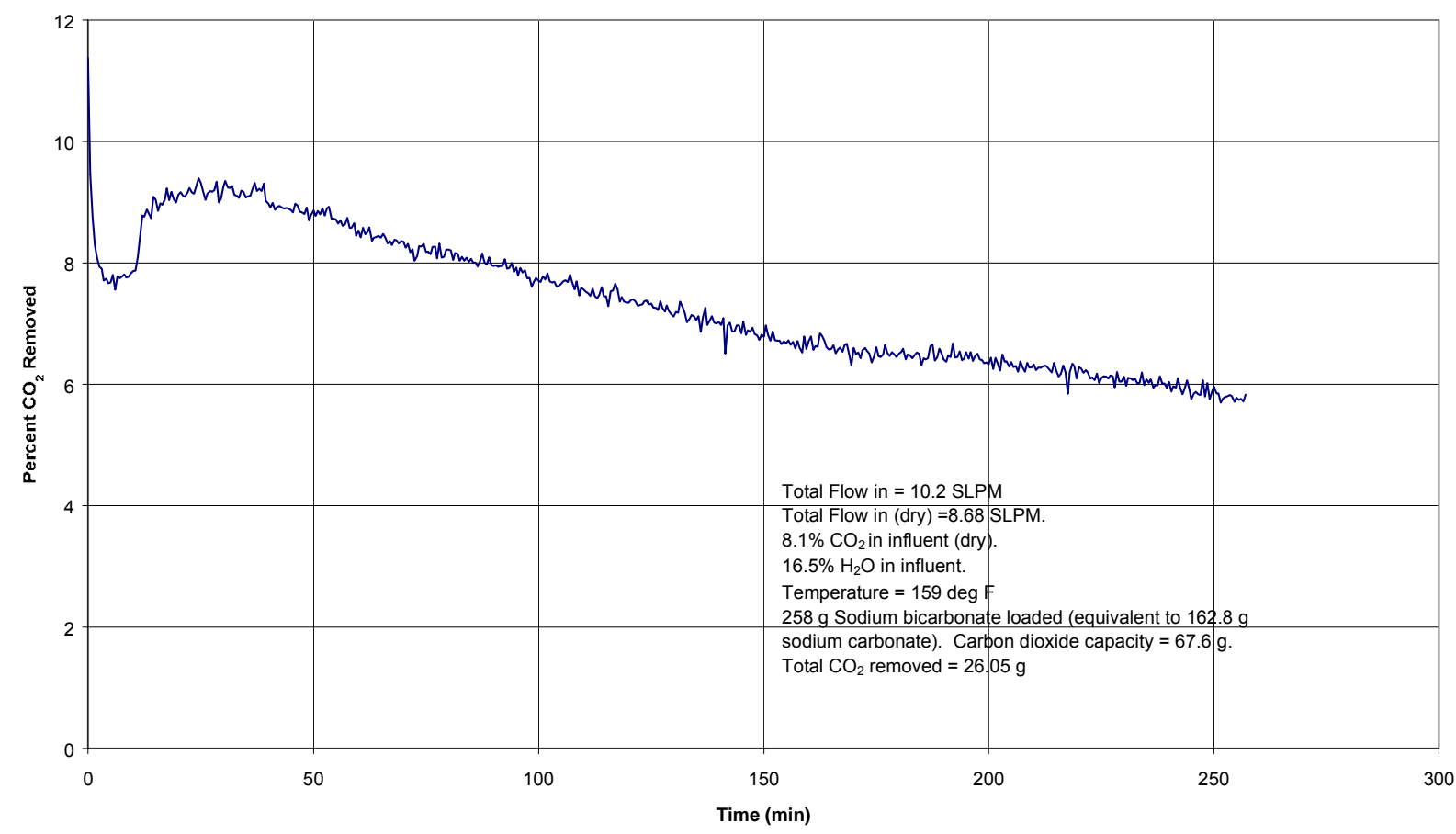

Figure 38. Cycle 2 carbonation test (9/20/01) - fractional $\mathrm{CO}_{2}$ removal

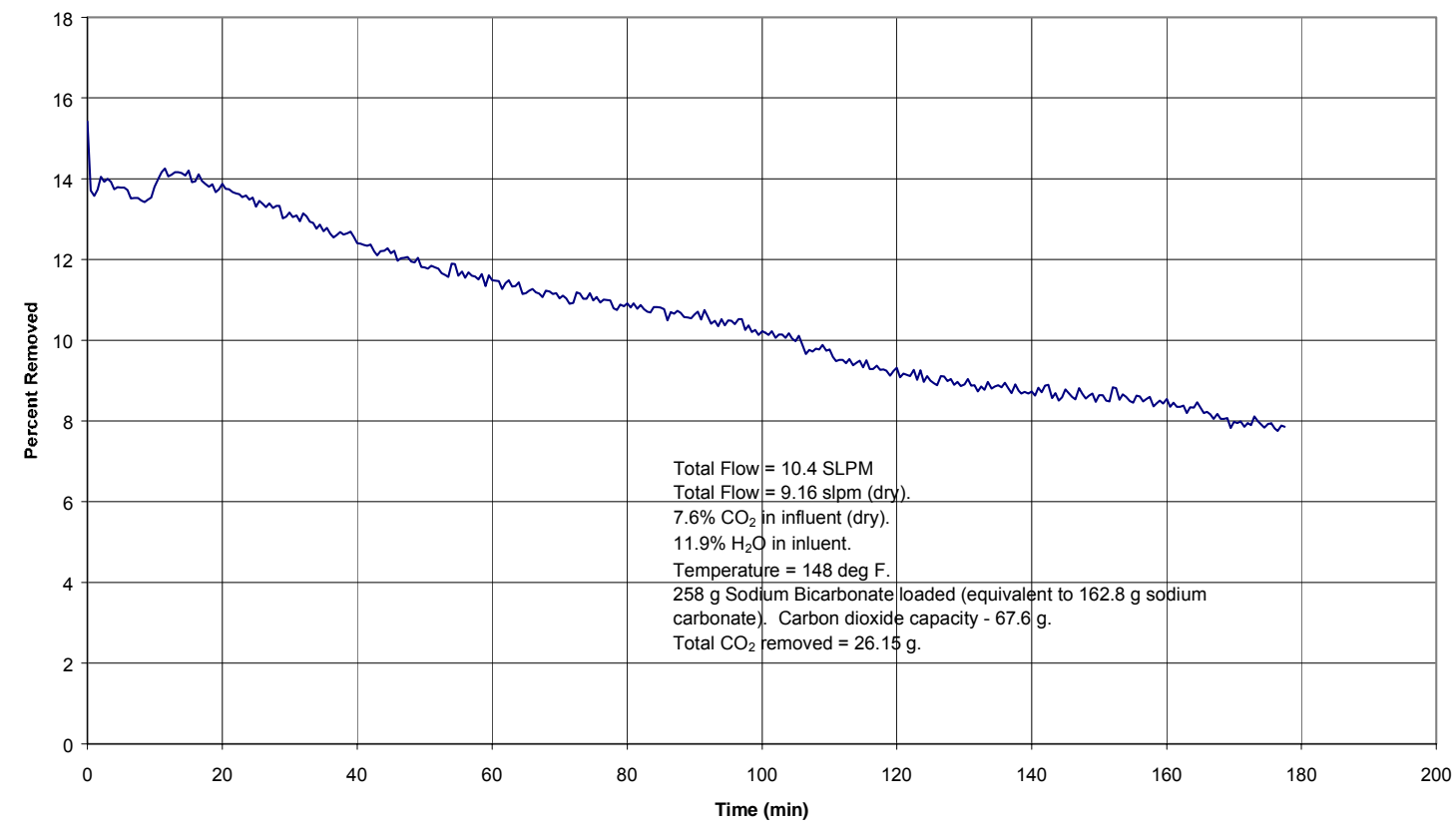

Figure 39. Cycle 3 carbonation test (9/25/01) - fractional $\mathrm{CO}_{2}$ removal 


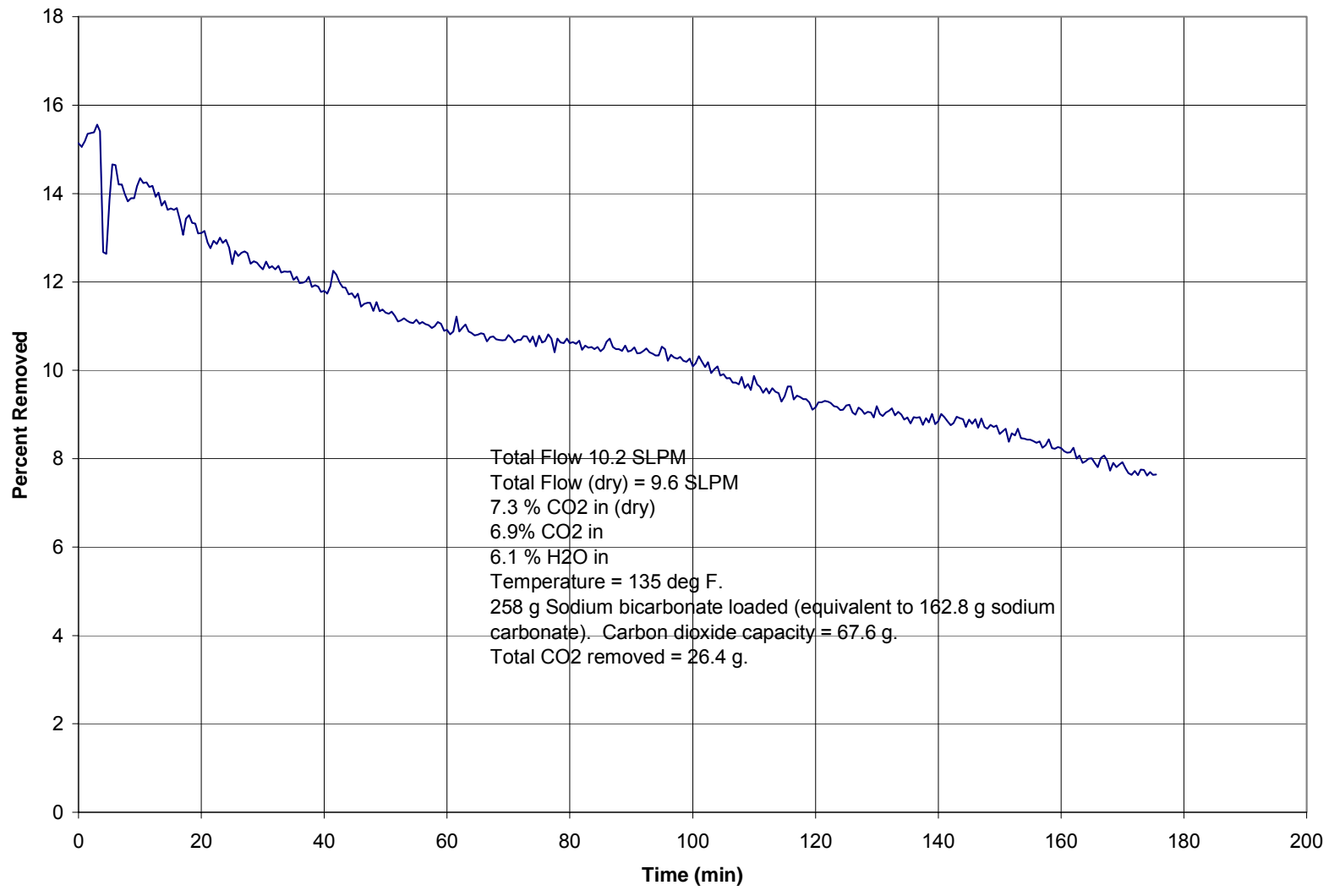

Figure 40. Cycle 4 carbonation test (9/26/01) - fractional $\mathrm{CO}_{2}$ removal

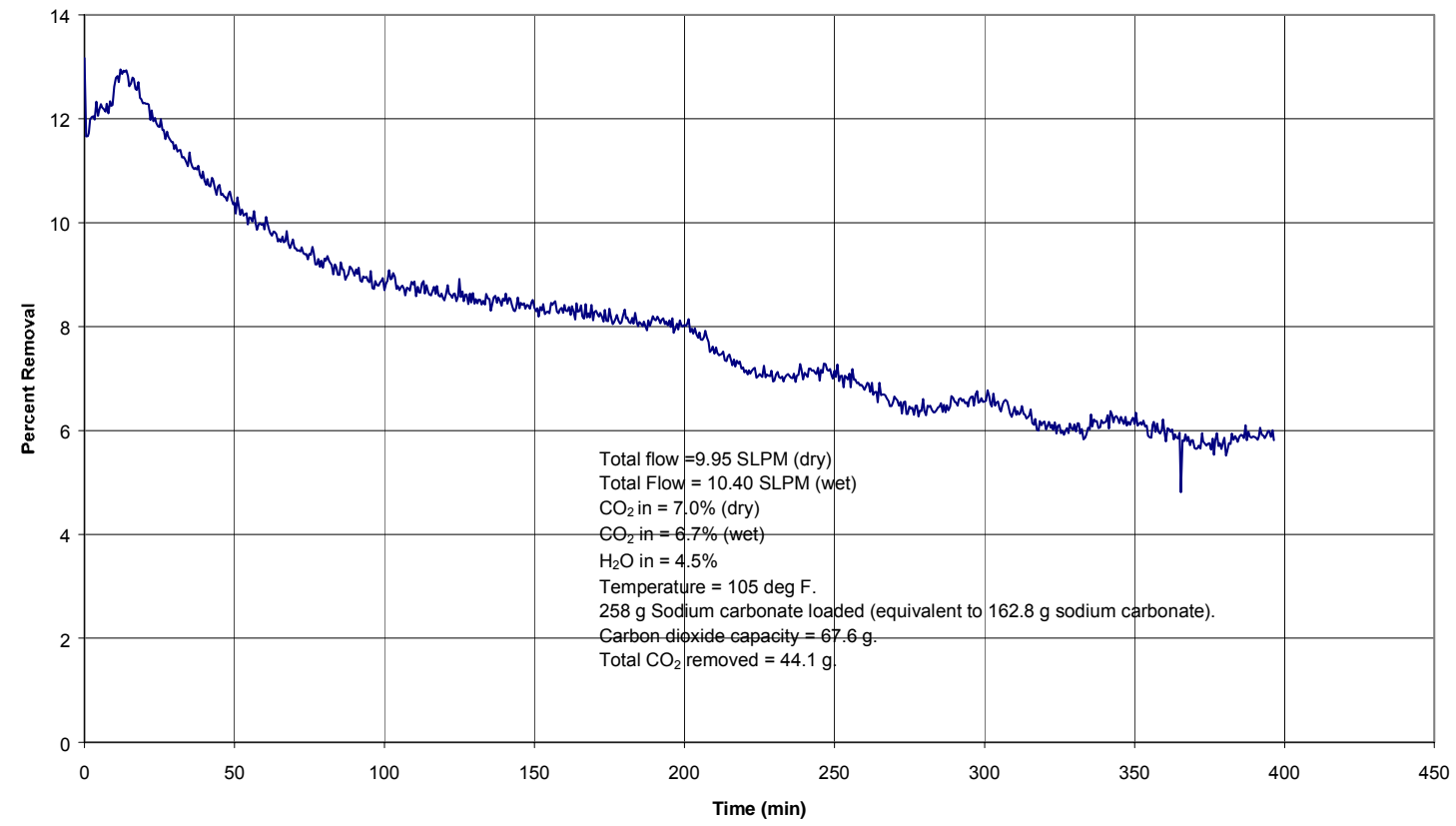

Figure 41. Cycle 5 carbonation test (9/27/01) - fractional $\mathrm{CO}_{2}$ removal 


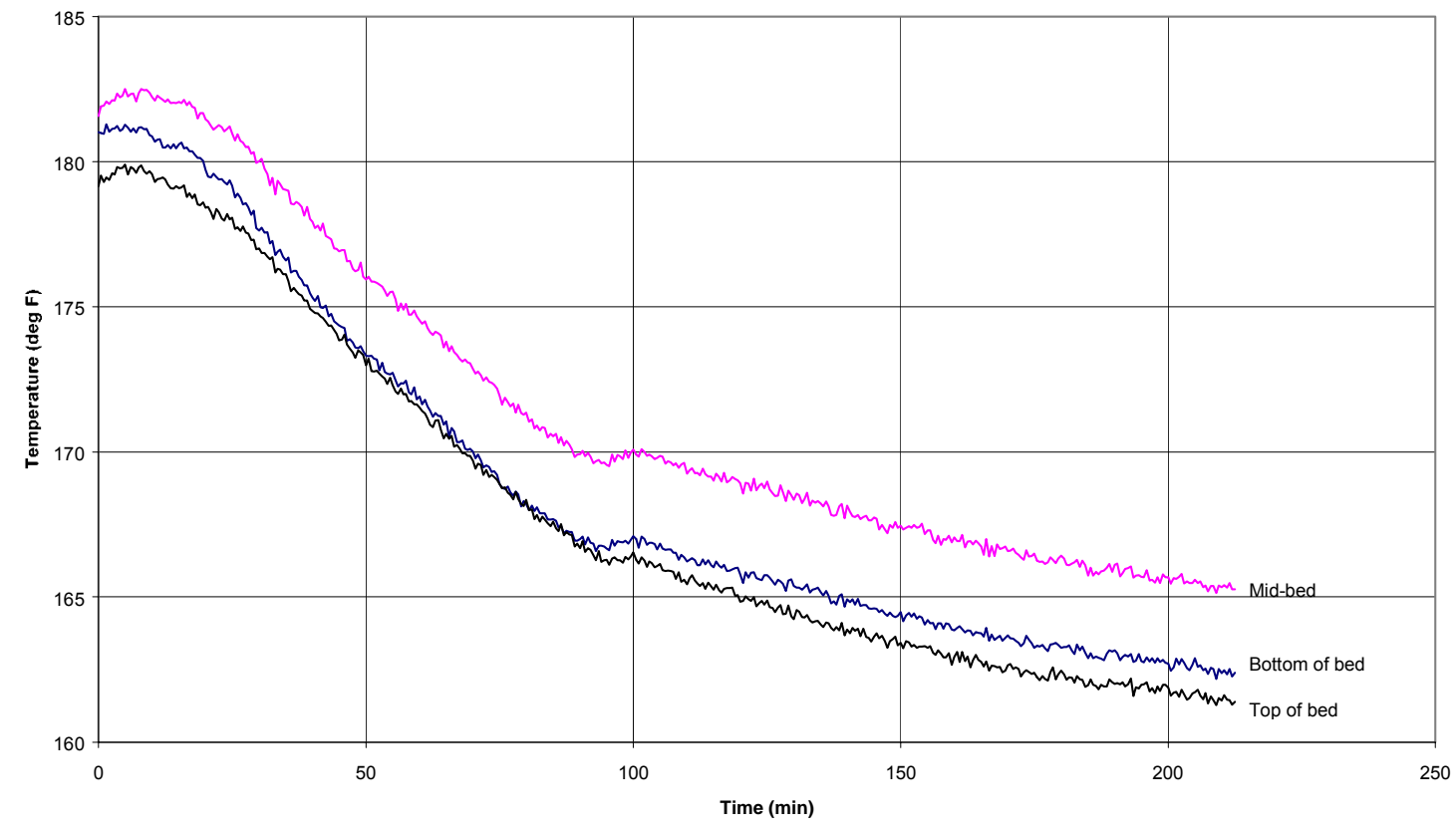

Figure 42. Temperature profile - Cycle $1(9 / 19 / 01)$

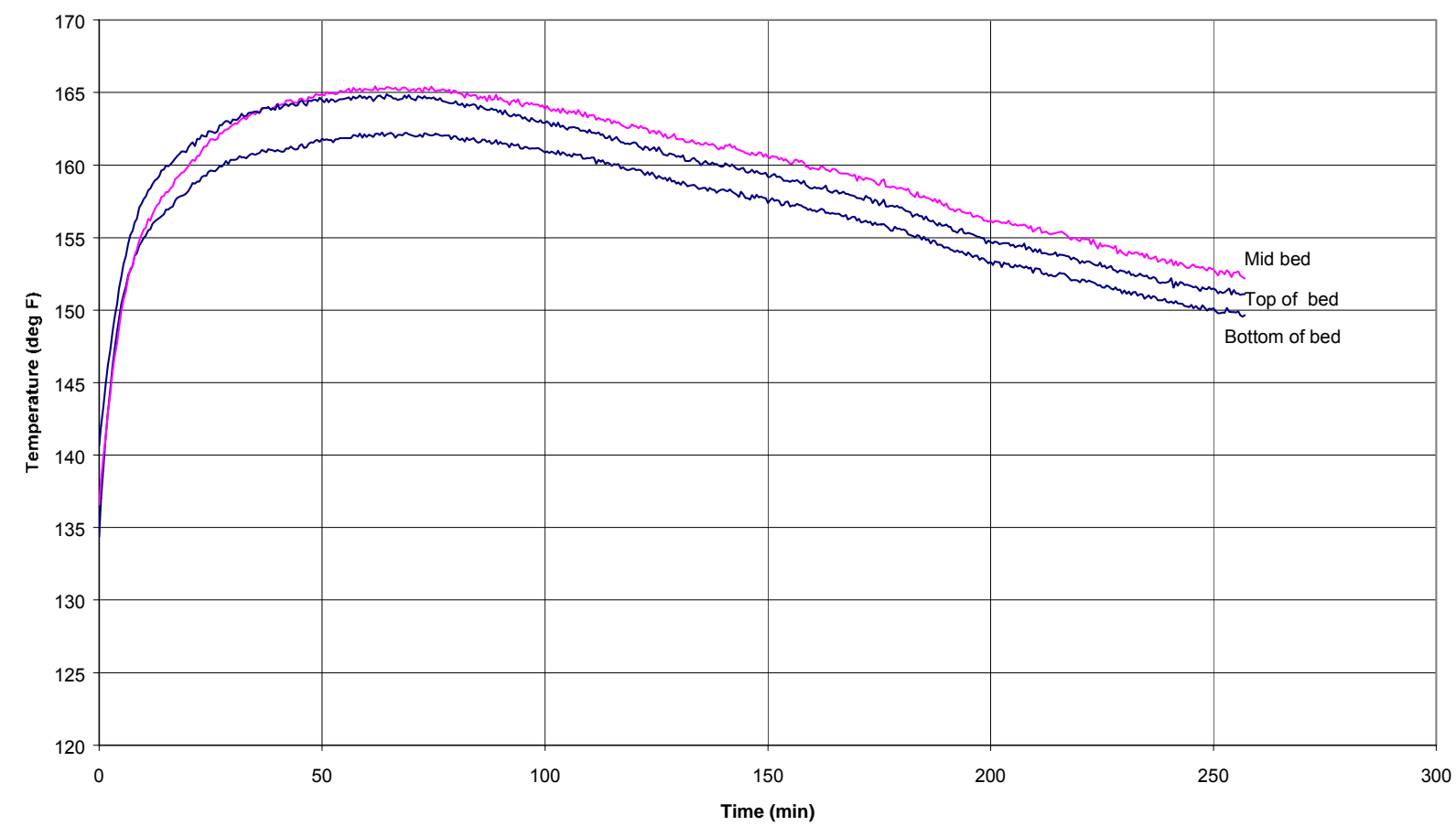

Figure 43. Temperature profile - Cycle 2 (9/20/01) 


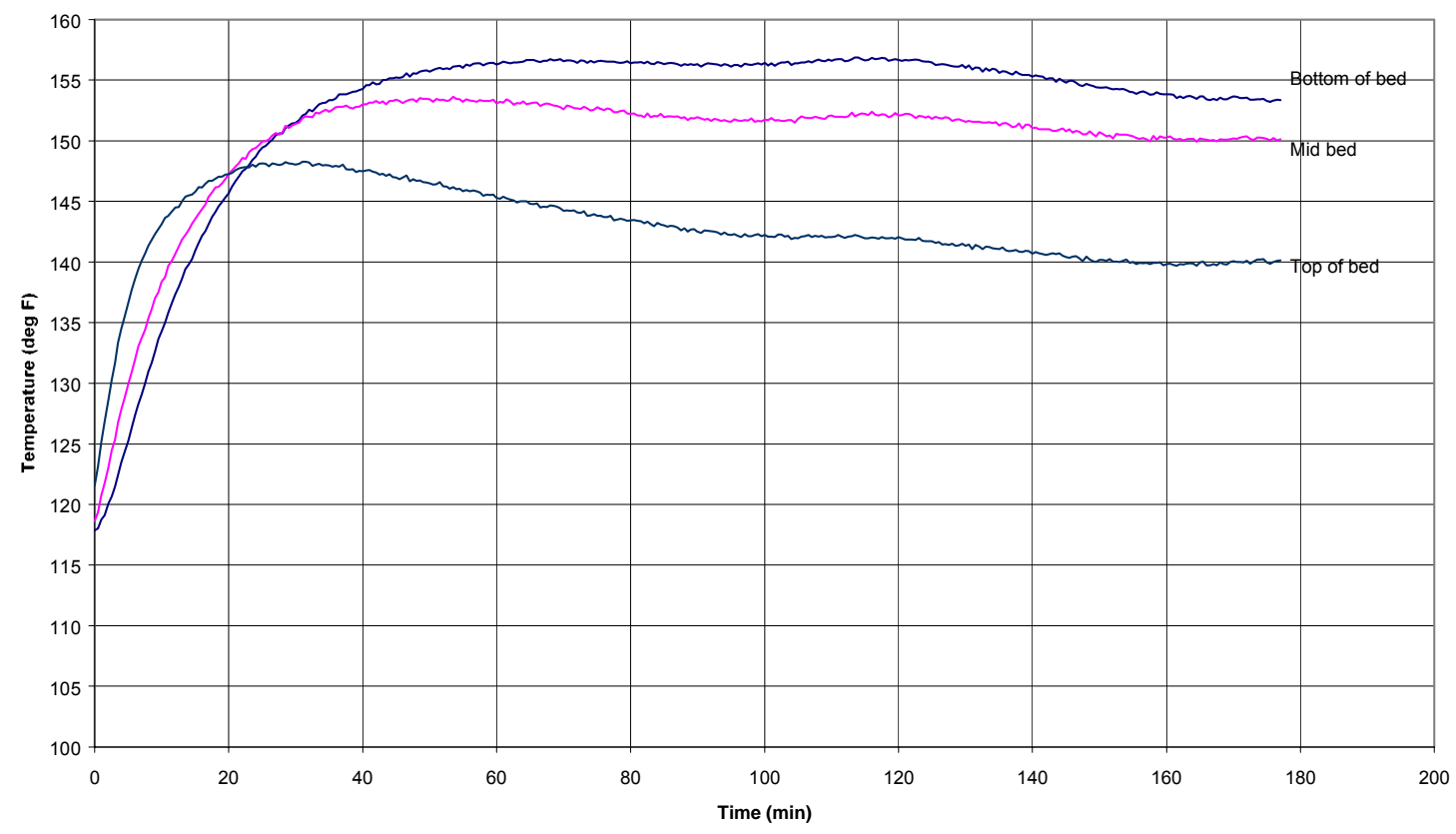

Figure 44. Temperature profile - Cycle 3 (9/25/01)

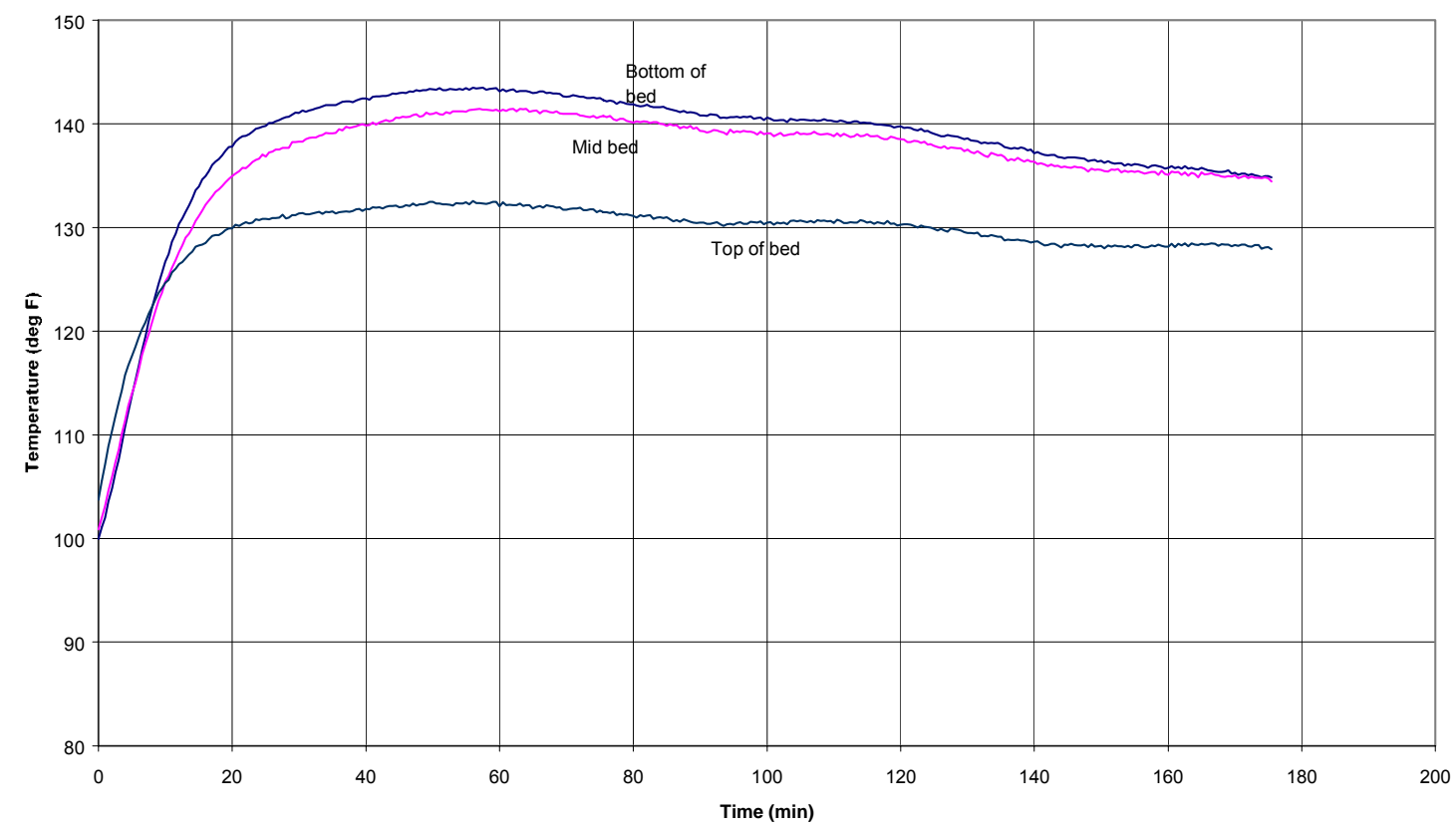

Figure 45. Temperature profile - Cycle 4 (9/26/01) 


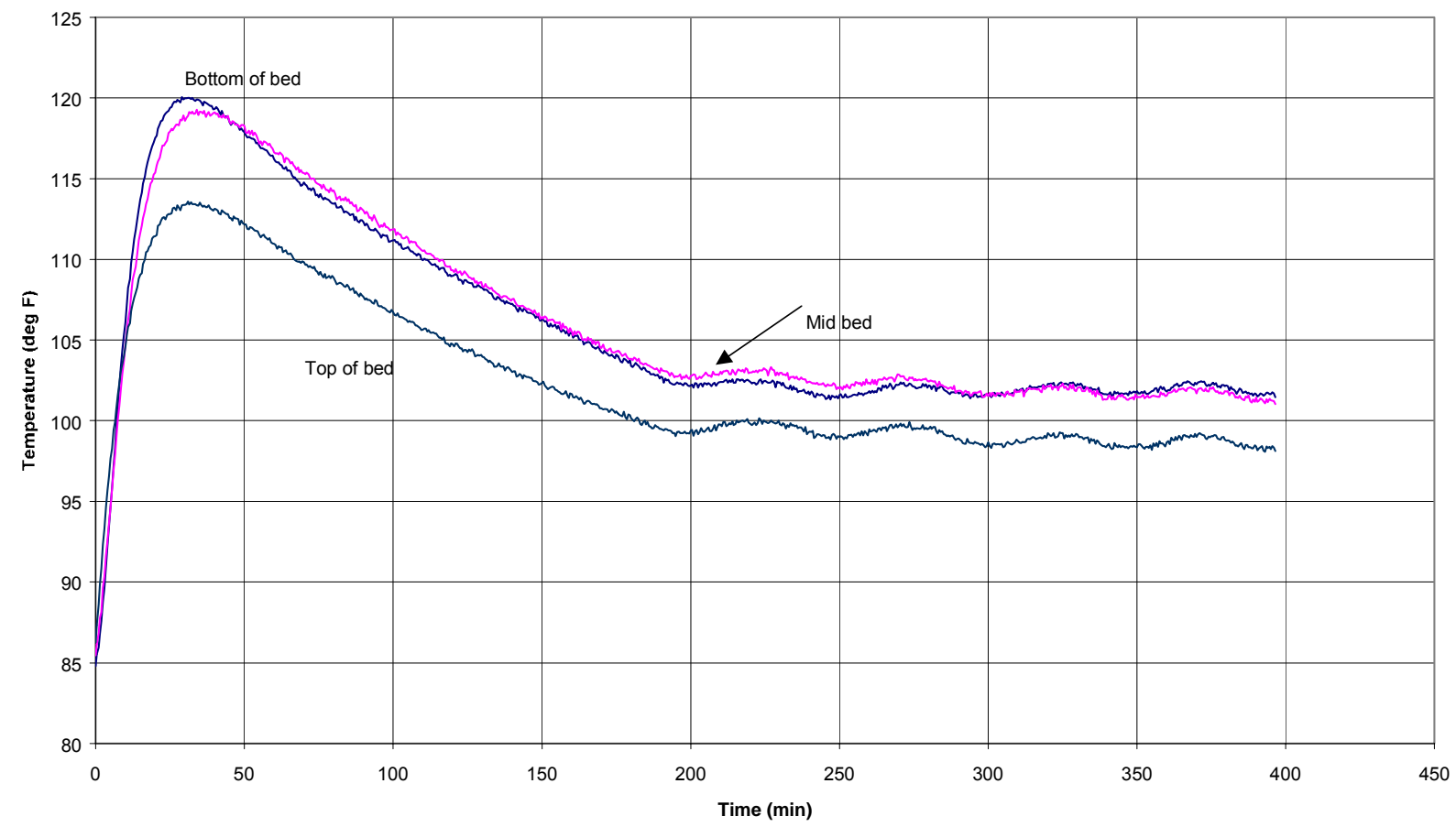

Figure 46. Temperature profile - Cycle 5 (9/27/01)

A summary of test results is given in Table 1. The temperature data in this table are based on the average temperature (for the three measurement locations) during the carbonation cycle, which varied as the exothermic effects of the reaction declined. The water vapor content of the reactant gas was limited in the lower temperature cycles to avoid supersaturation.

Table 1. Summary of Five-Cycle Carbonation Test Data

\begin{tabular}{|c|c|c|c|c|c|}
\hline Cycle & 1 & 2 & 3 & 4 & 5 \\
\hline Total Flow (SLPM) & 10.1 & 10.2 & 10.4 & 10.2 & 10.4 \\
\hline Dry Flow (SLPM) & 8.5 & 8.7 & 9.2 & 9.6 & 10.0 \\
\hline $\mathrm{CO}_{2}$ in (dry \%) & 6.6 & 8.1 & 7.6 & 7.3 & 7.0 \\
\hline $\mathrm{H}_{2} \mathrm{O}$ in $(\%)$ & 16.0 & 16.5 & 11.9 & 6.1 & 4.5 \\
\hline Temperature $\left({ }^{\circ} \mathrm{F}\right)$ & 169 & 159 & 148 & 135 & 105 \\
\hline $\mathrm{CO}_{2}$ removed $(\mathrm{g})$ & 26.4 & 26.1 & 26.2 & 26.4 & 44.1 \\
\hline $\begin{array}{l}\text { Sorbent Capacity Utilization (\%) Based on } \\
\text { conversion to } \mathrm{CO}_{2}\end{array}$ & 39.1 & 38.6 & 38.8 & 39.1 & 65.2 \\
\hline Exposure Time (min) & 210 & 260 & 175 & 175 & 390 \\
\hline
\end{tabular}


Based on these data there was no obvious decline in sorbent activity over five cycles in contaminant-free simulated flue gas. The sorbent was removed from the reactor after the fifth cycle.

\subsubsection{Test 2: Trona T-50}

This cyclic calcination/carbonation test was limited to two cycles due to plugging of the reactant in the bed. Trona T-50 was added to the reactor to a height of 6 in, resulting in an initial heightto-diameter ratio of 3 . The trona was calcined to sodium carbonate by heating to approximately $120^{\circ} \mathrm{C}$ in flowing nitrogen for two hours. Nitrogen flow was maintained until the first carbonation test was started. Temperatures for the first carbonation cycle, as shown in Figure 47, averaged $80^{\circ} \mathrm{C}$, which was higher than optimal, and resulted from preheating the reactor to too high a temperature before beginning the carbonation phase. Carbon dioxide removal (as determined by comparison of the inlet and outlet carbon dioxide mass flow), as shown in Figure 48, declined from about $20 \%$ to about $8 \%$ during a three-hour test. The total mass of carbon dioxide removed was 29.9 grams. The theoretical capacity of the bed based on a sodium bicarbonate endpoint was $103 \mathrm{~g}$ (or $34.3 \mathrm{~g}$ based on a Wegscheider's salt endpoint). The sorbent was then calcined in the reactor in the same manner that it was calcined before the first carbonation cycle.

The second carbonation cycle was conducted at a lower, theoretically more favorable temperature, averaging $65^{\circ} \mathrm{C}$. Bed temperature profiles are shown in Figure 49. Because of the lower feed gas temperature, the water vapor content of the simulated flue gas was decreased from $12.1 \%$ to $5.8 \%$ for the second cycle to avoid condensing water. Carbon dioxide removal for this cycle, as shown in Figure 50, declined from $11 \%$ to $1 \%$ over the course of 160 minutes. 


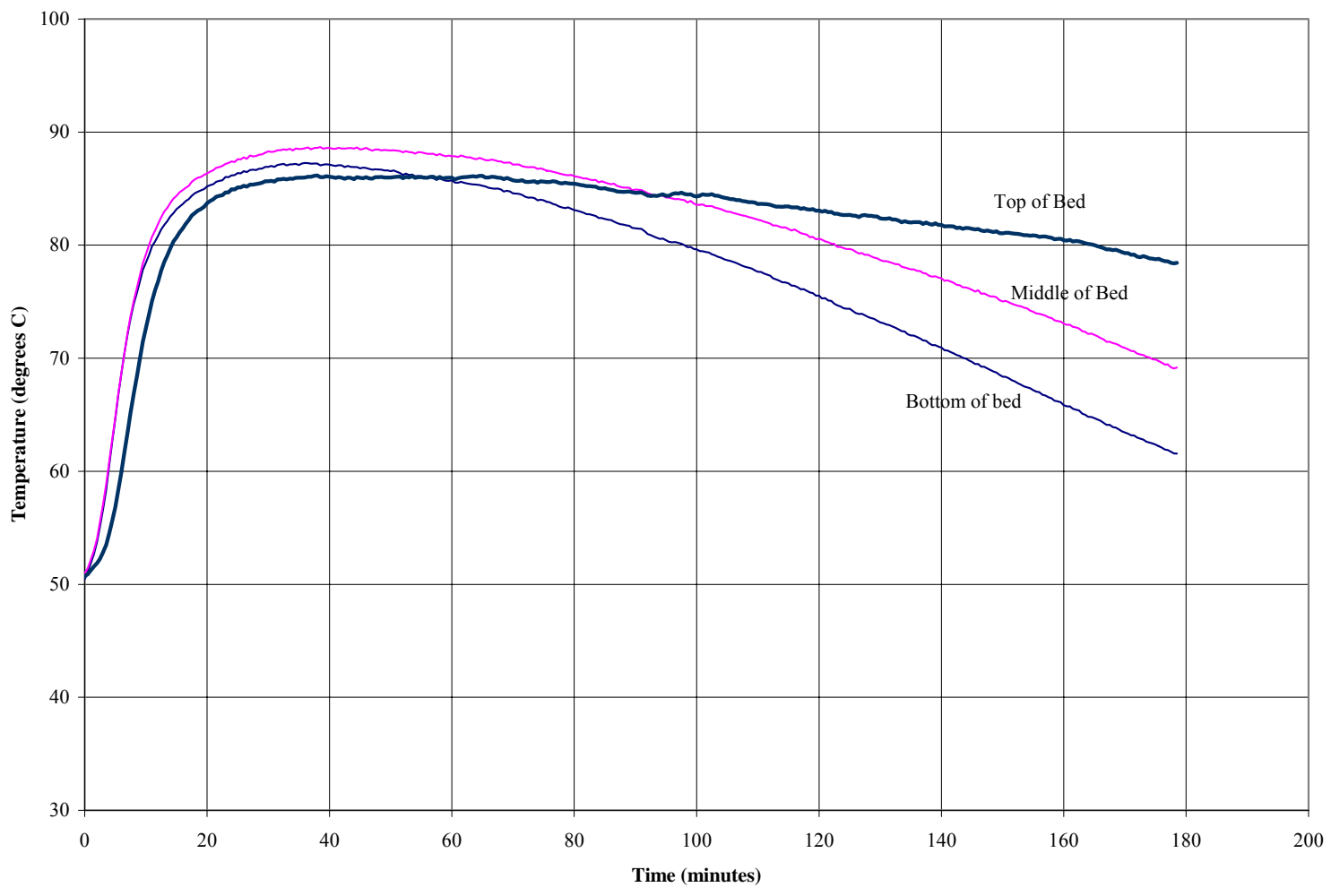

Figure 47. Temperature profile - Cycle 1 with Trona T-50

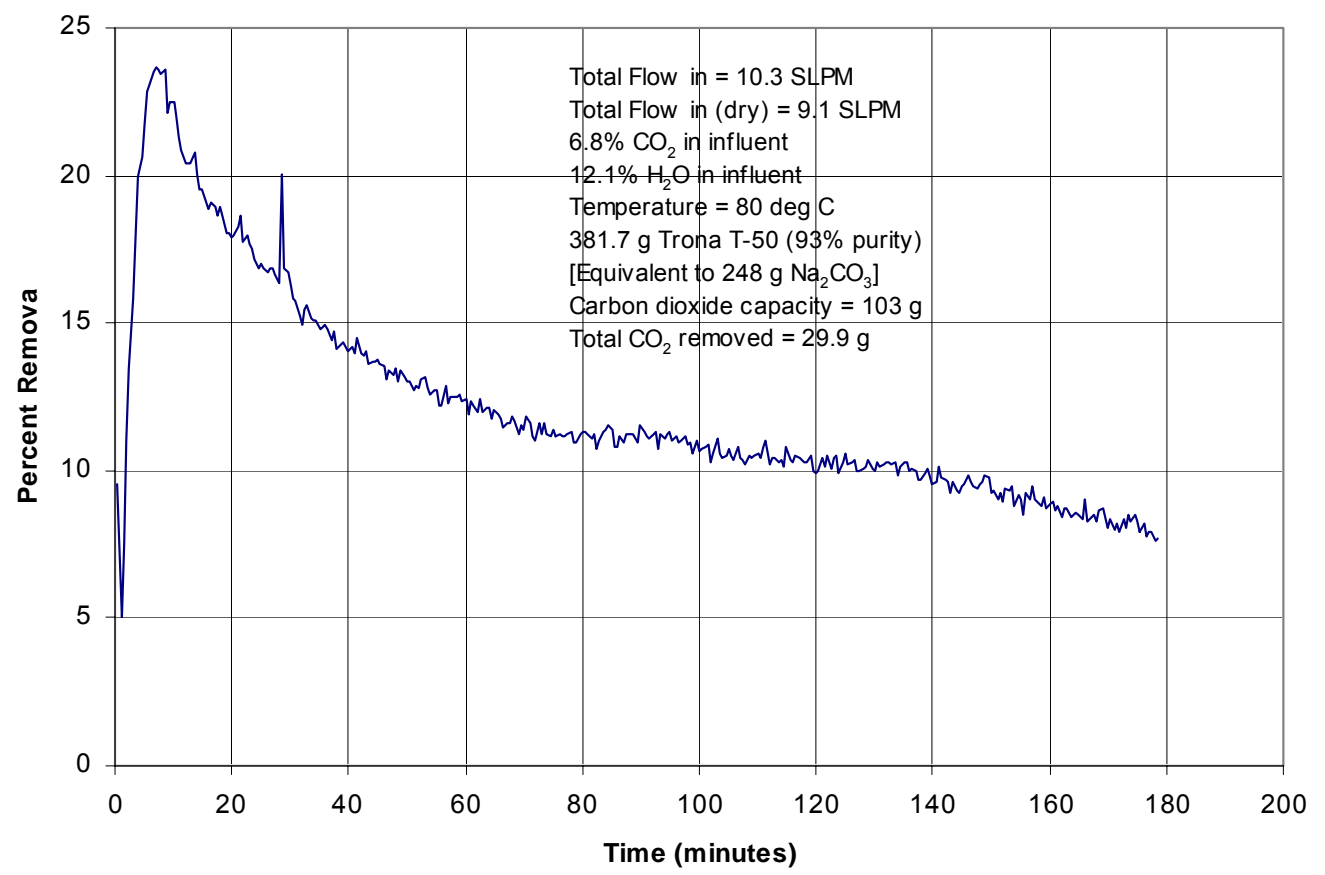

Figure 48. Cycle 1 carbonation test with Trona T-50 


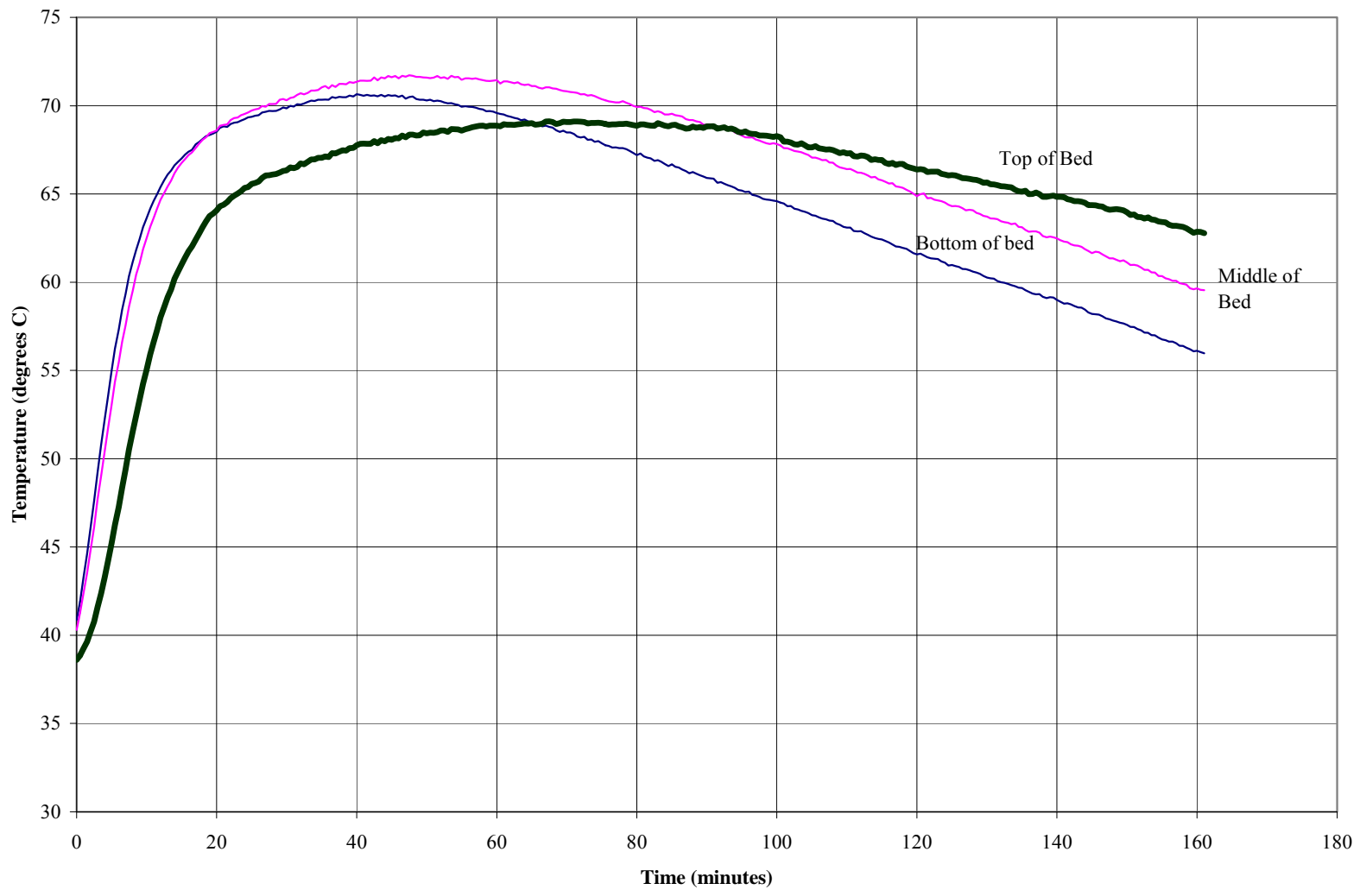

Figure 49. Temperature profile - Cycle 2 with Trona T-50

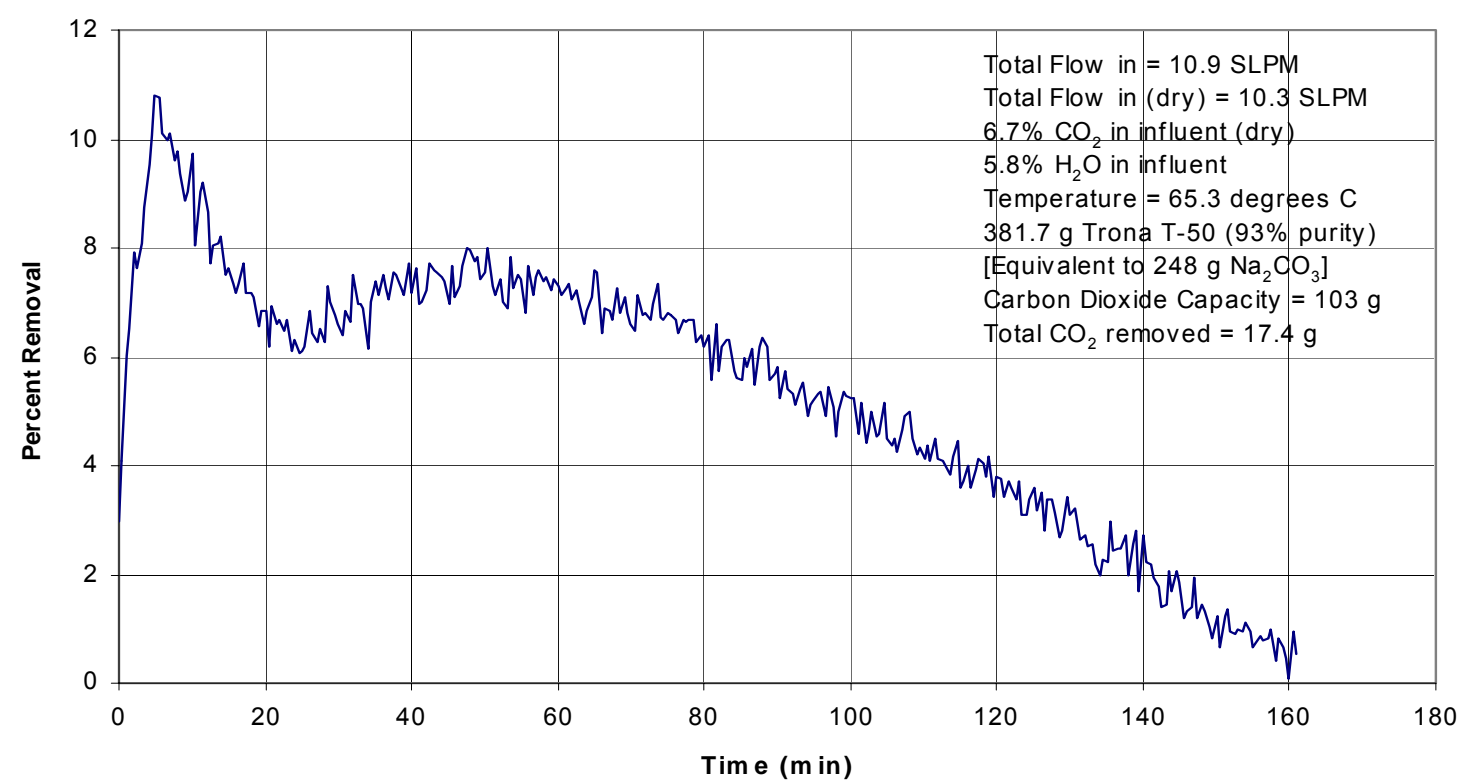

Figure 50. Cycle 2 carbonation test with Trona T-50 
The total mass of carbon dioxide removed was $17.4 \mathrm{~g}$. The theoretical capacity of the bed based on a sodium bicarbonate endpoint was $103 \mathrm{~g}$, same as before. The decline in activity in the second cycle may have been due to the lower water vapor content available for reaction, or a decline in the activity of the sorbent material.

Carbon dioxide removal was calculated based on inlet flows (dry basis) of air, nitrogen and $\mathrm{CO}_{2}$, and $\mathrm{CO}_{2}$ content (dry basis) of the effluent gas. A summary of test results is given in Table 2 .

Table 2. Summary of Two-Cycle Carbonation Test Data

\begin{tabular}{lccc}
\hline \hline & Cycle & $\mathbf{1}$ & $\mathbf{2}$ \\
\hline Total Flow (SLPM) & 10.3 & 10.9 \\
Dry Flow (SLPM) & 9.1 & 10.3 \\
$\mathrm{CO}_{2}$ in (dry \%) & 6.8 & 6.7 \\
$\mathrm{H}_{2} \mathrm{O}$ in (\%) & 12.1 & 5.8 \\
Temperature ( $\left.{ }^{\circ} \mathrm{C}\right)$ & 80 & 65 \\
$\mathrm{CO}_{2}$ removed $(\mathrm{g})$ & 29.9 & 17.4 \\
Sorbent Capacity Utilization (\%) & 29.0 & 16.5 \\
Exposure Time (min) & 180 & 160 \\
\hline \hline
\end{tabular}

The temperature data in this table are based on the average temperature (for the three measurement locations) during the carbonation cycle, which varied as the exothermic effects of the reaction declined. The water vapor content of the reactant gas was limited in the lower temperature cycles to avoid supersaturation.

\subsubsection{Test 3: Potassium Carbonate: 1 cycle}

Several unsuccessful attempts were made to conduct cyclic fluidized-bed tests using potassium carbonate as a sorbent. Problems were encountered with plugging of the bed, as indicated by an increase in differential pressure across the bed. The bed plugged both during pre-drying in dry nitrogen, and during carbonation in nitrogen/oxygen/carbon dioxide/steam mixtures. In general, the material is hygroscopic and tends to agglomerate during storage. A single carbonation cycle was completed during one test. Data are shown in Figure 51. The reactor temperature profile is shown in Figure 52. The reactor plugged up upon calcination following this carbonation cycle. 
The test was conducted with $6.55 \%$ carbon dioxide and $6.14 \%$ water in the inlet gas. Carbon dioxide removal in the early stages of this test peaked at about $35 \%$ and remained above $15 \%$ for the first 30 minutes. The temperature in the bed increased rapidly due to the exothermic nature of the reaction. The fact that $\mathrm{CO}_{2}$ removal continued to take place at these temperatures (peaking at about $110^{\circ} \mathrm{C}$, averaged across the bed) demonstrates a potential advantage of potassium carbonate over sodium carbonate for flue gas operations. Unsupported potassium carbonate would, however, be much more difficult to handle.

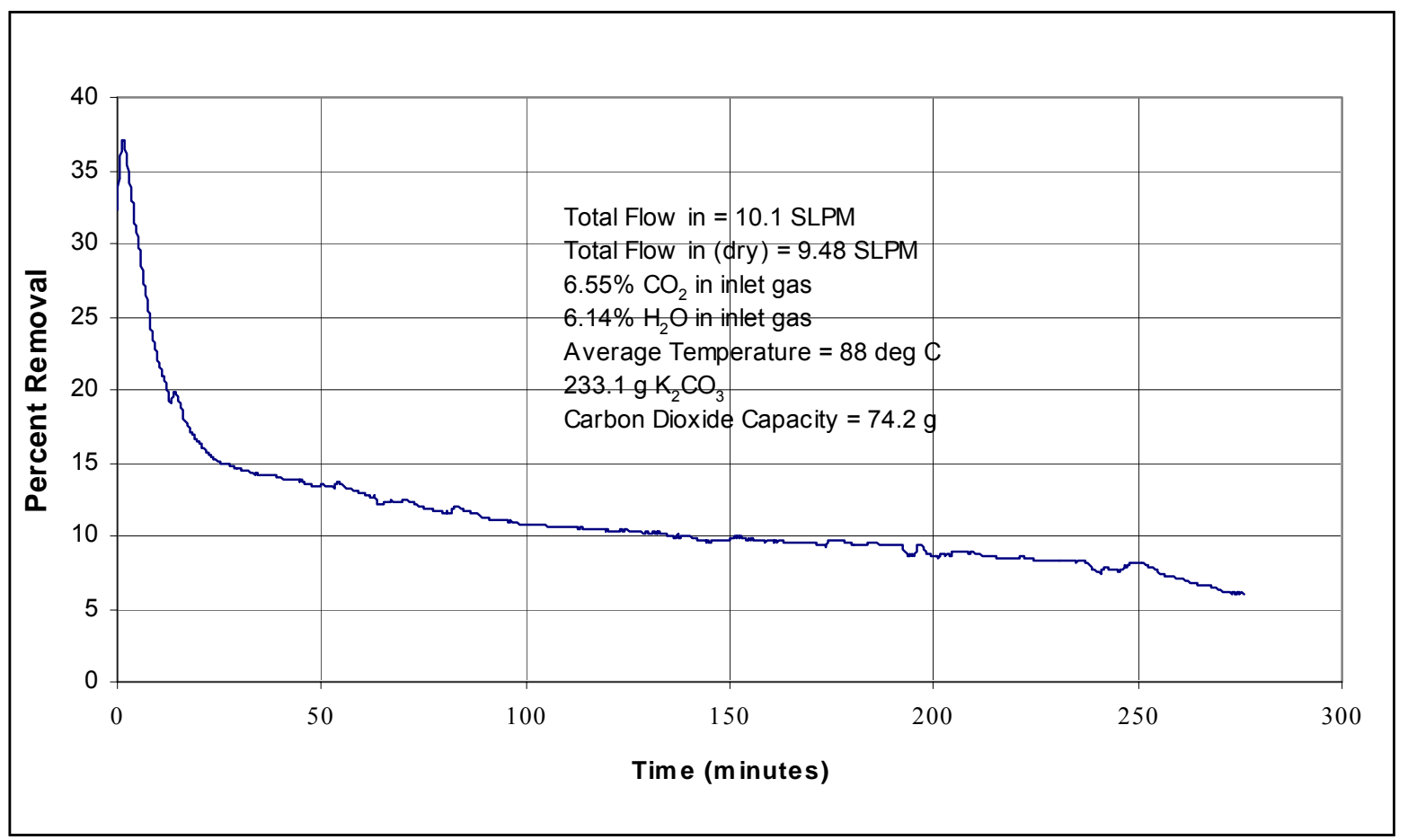

Figure 51. Fluidized-bed carbonation of potassium carbonate (3/11/02) 


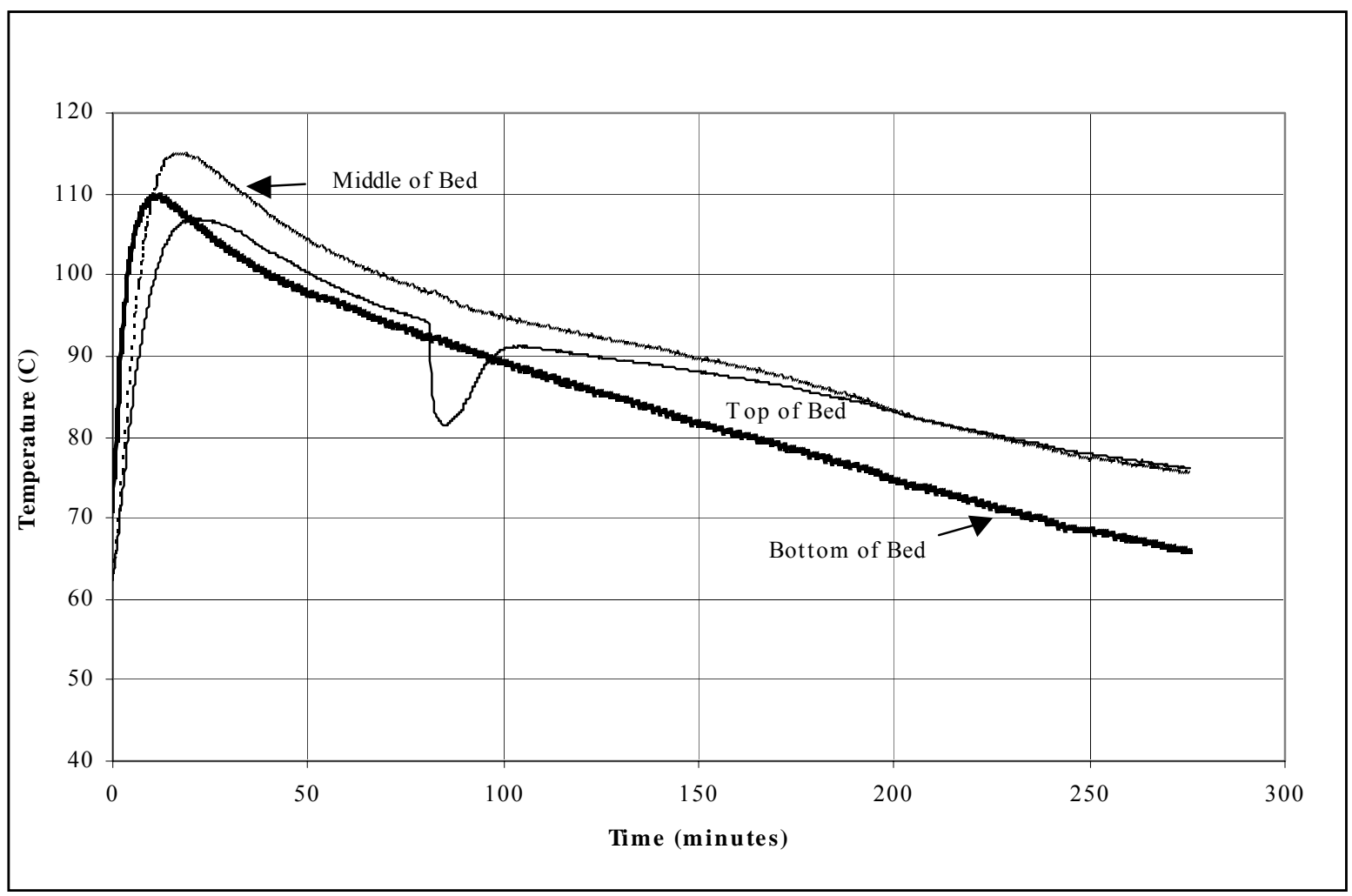

Figure 52. Temperature profile for fluidized-bed carbonation of potassium carbonate

The $\mathrm{CO}_{2}$ removal declined to about $6 \%$ after 280 minutes, at which point the sorbent bed was only $54 \%$ exhausted (based on conversion to potassium bicarbonate). The high initial removals may be indicative of reactivity in short residence time reactor systems such as transport reactors or entrained bed systems. On this basis, potassium carbonate may be a promising sorbent if problems related to agglomeration and attrition can be resolved.

\subsubsection{Test 4: Trona T-50 (5 cycles)}

The reactor was loaded with $406 \mathrm{~g}$ of material, and the material was not removed between cycles. This was equivalent to an initial bed height of 6 inches, resulting in a bed height-todiameter ratio of 3 . This mass of trona, after calcination, has a carbon dioxide capacity of $37 \mathrm{~g}$. All calcinations were carried out in nitrogen at $150^{\circ} \mathrm{C}$. Carbonation reactions were conducted in a simulated flue gas of 4.7 to $6.5 \%$ carbon dioxide and approximately $6.9 \%$ water vapor. Carbonation test temperatures varied within the fluidized bed through the course of the cycles, peaking at approximately $75^{\circ} \mathrm{C}$. The carbonation cycles were stopped after approximately three 
hours, even though most of the stoichiometric capacity of the bed was unused, because the initial rates were of greatest interest. Carbon dioxide removal, and the associated fluidized-bed temperature profiles are shown in Figures 53 through 62. The temperatures at the "bottom," "middle," and "top" of the bed were measured at 1 inch, 3 inches, and 5 inches above the flow distributor. A summary of these data is given in Table 3.

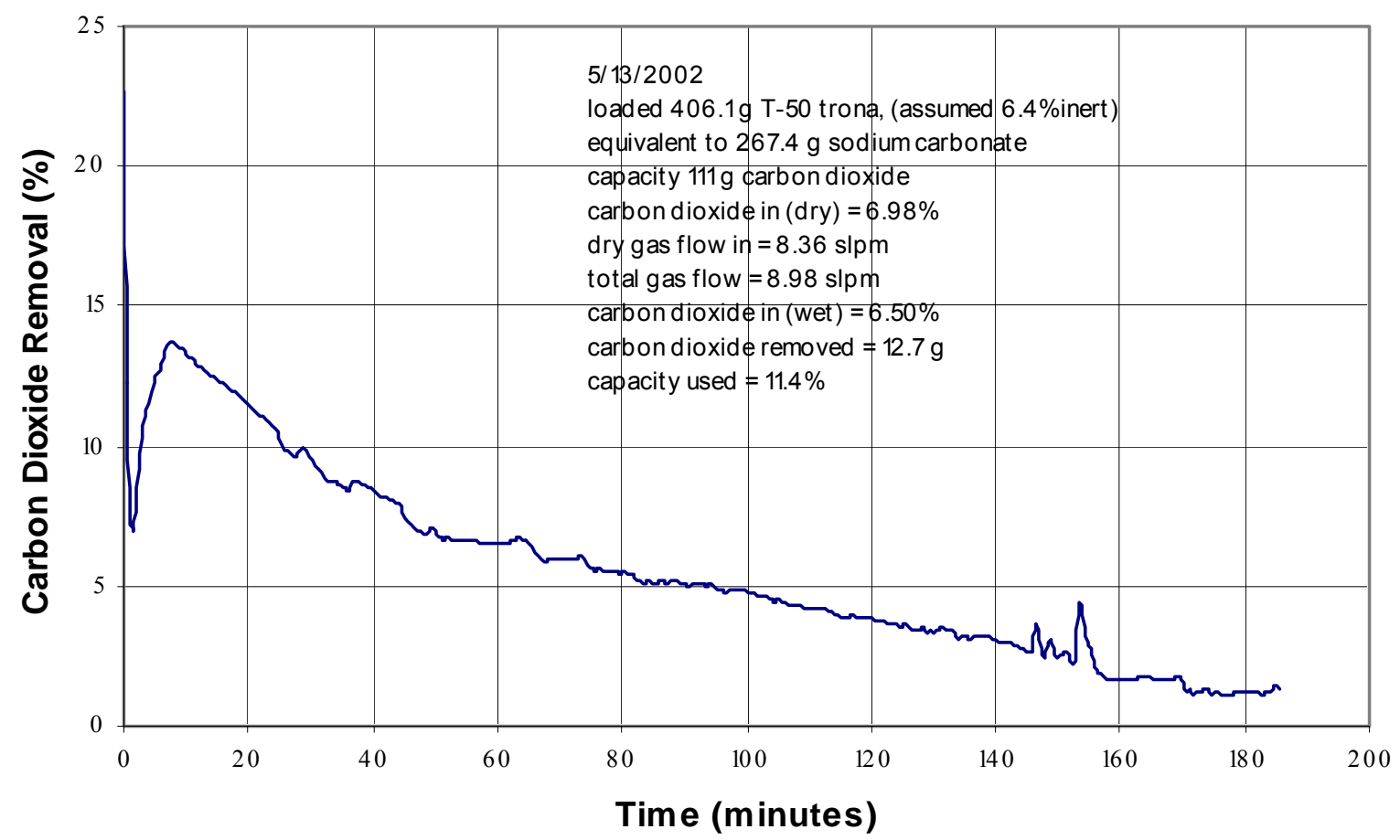

Figure 53. Carbon dioxide removal and trona Cycle 1 - 5/13/2002 


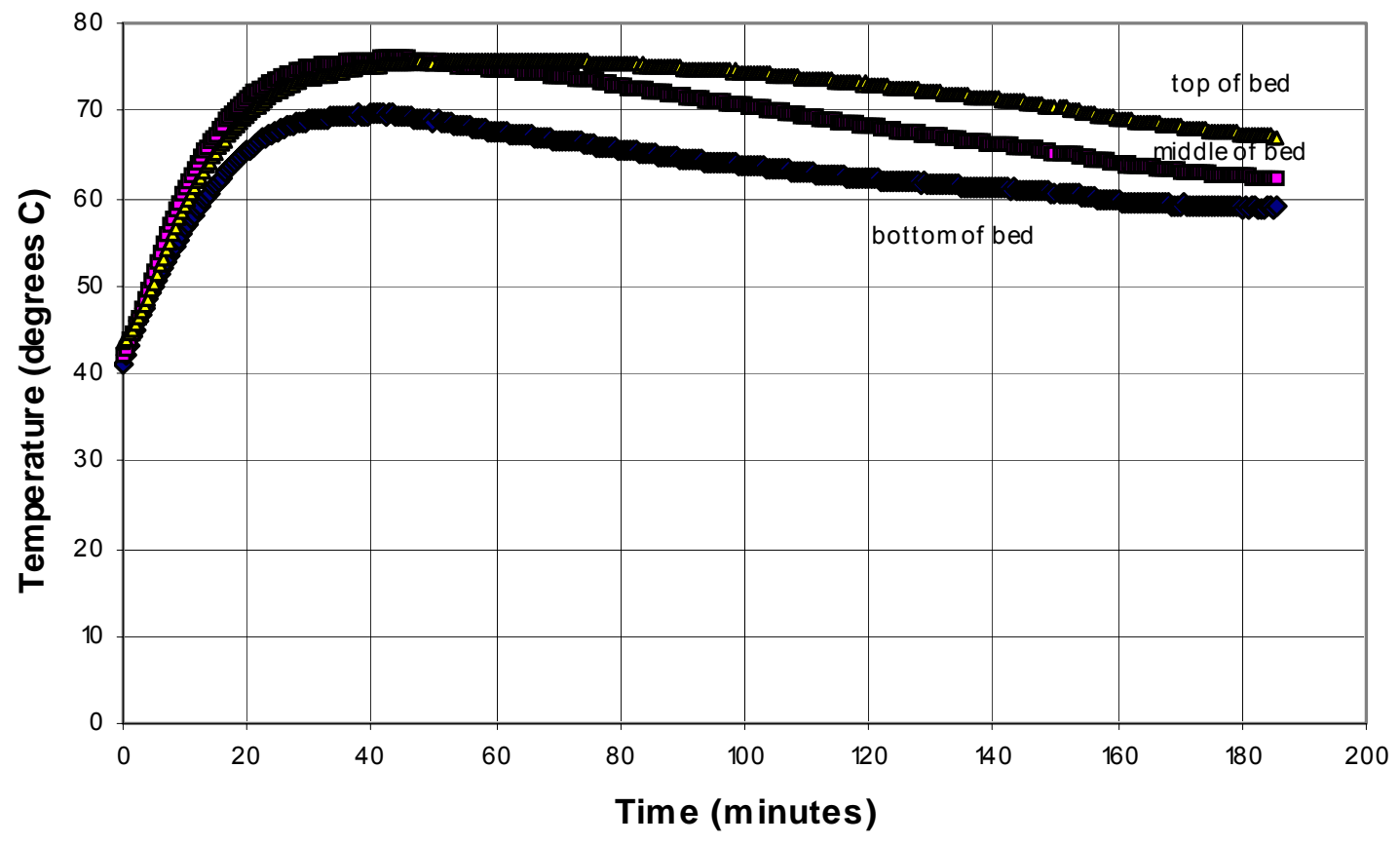

Figure 54. Temperature profile - carbonation Cycle 1 - 5/13/2002

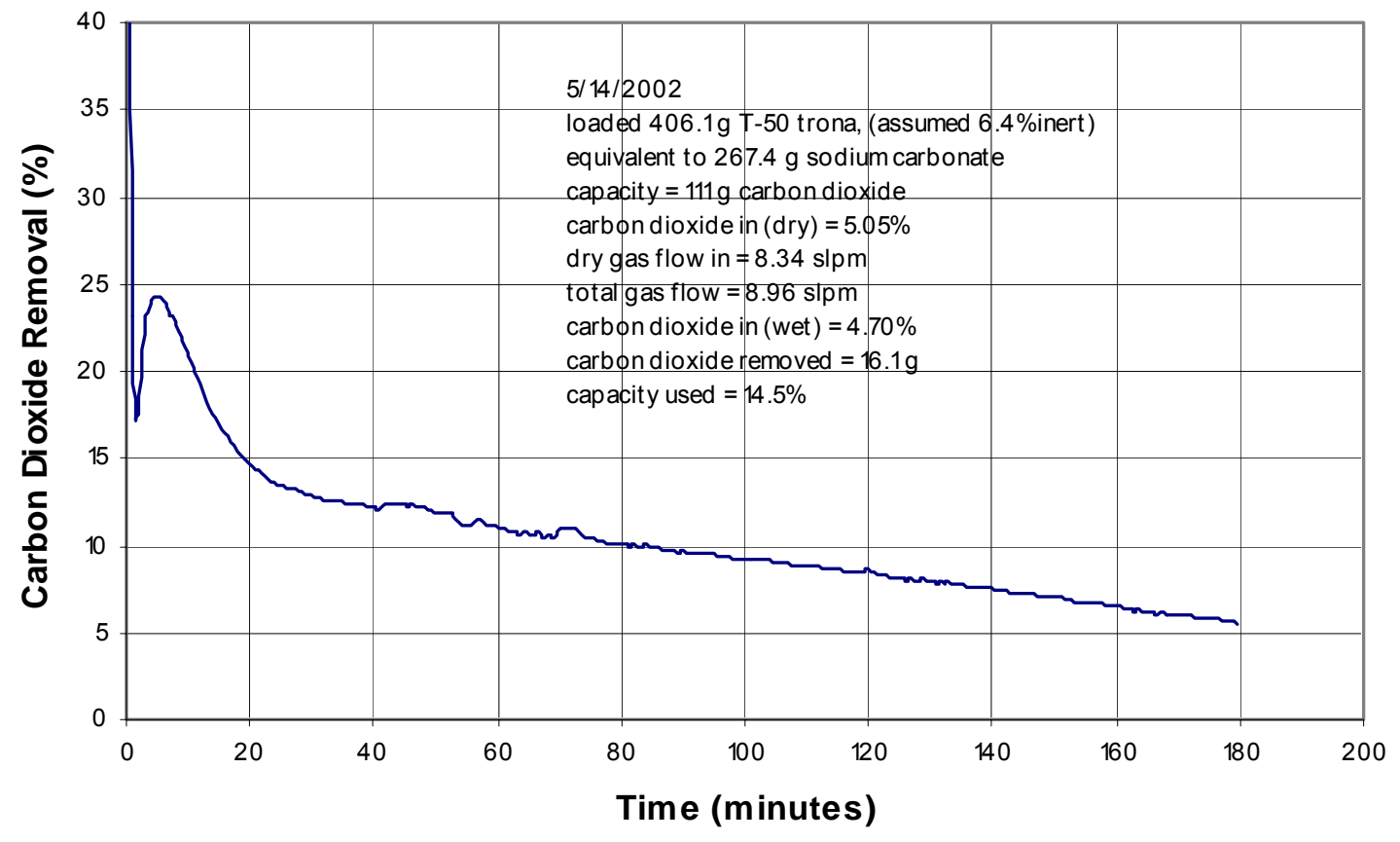

Figure 55. Carbon dioxide removal with trona - Cycle 2 - 5/14/2002 


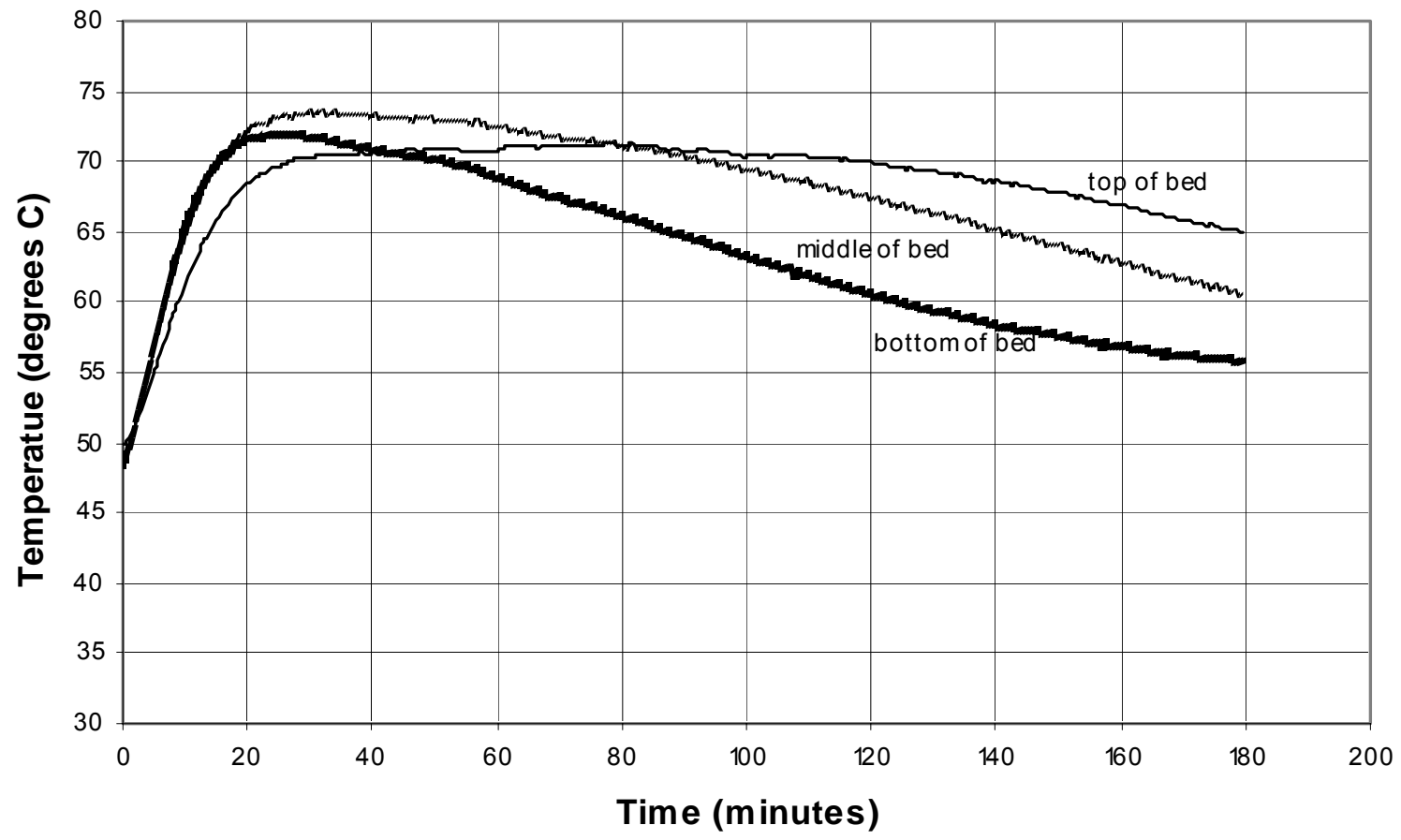

Figure 56. Temperature profile - carbonation Cycle 2 - 5/14/2002

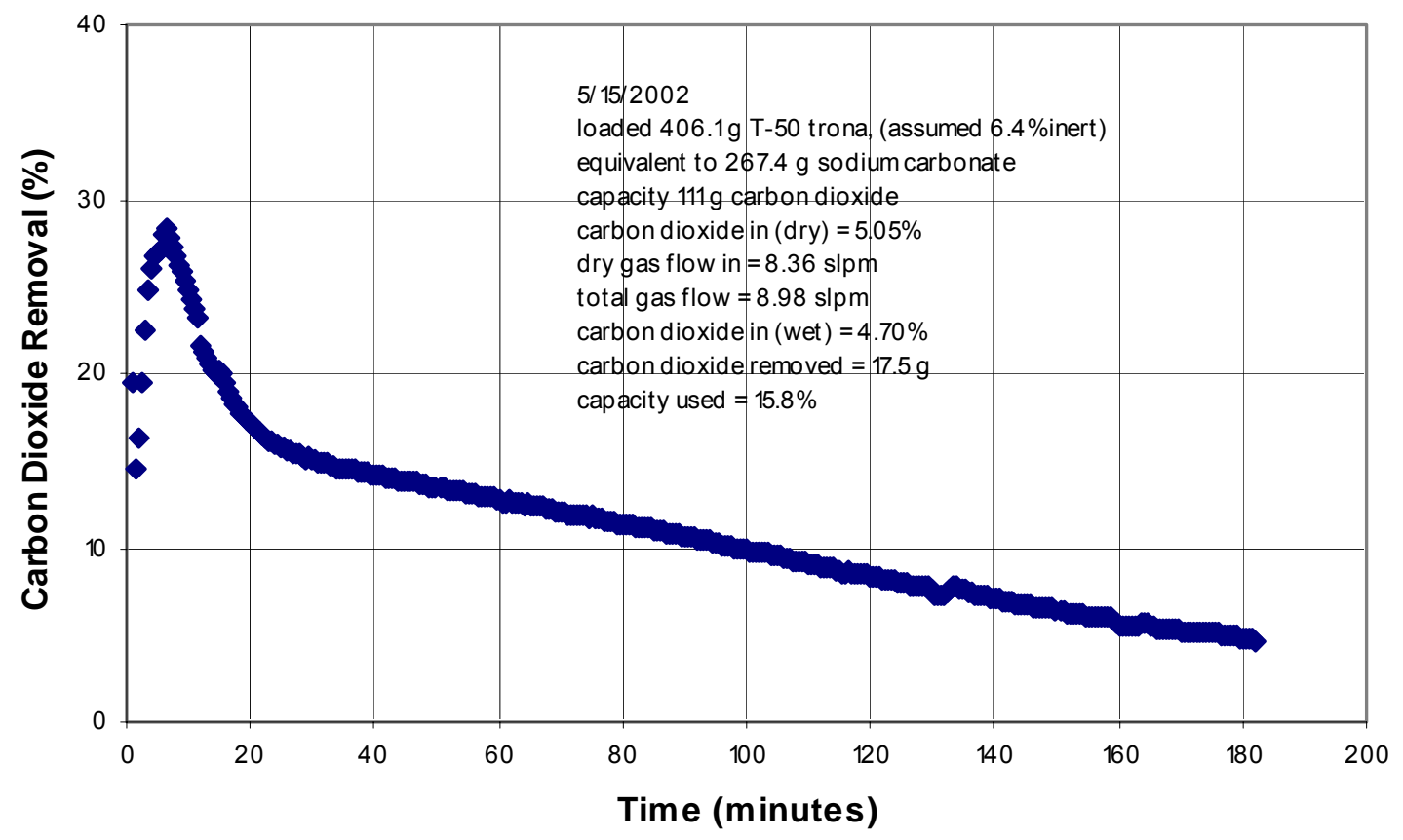

Figure 57. Carbon dioxide removal with trona - Cycle 3 - 5/15/2002 


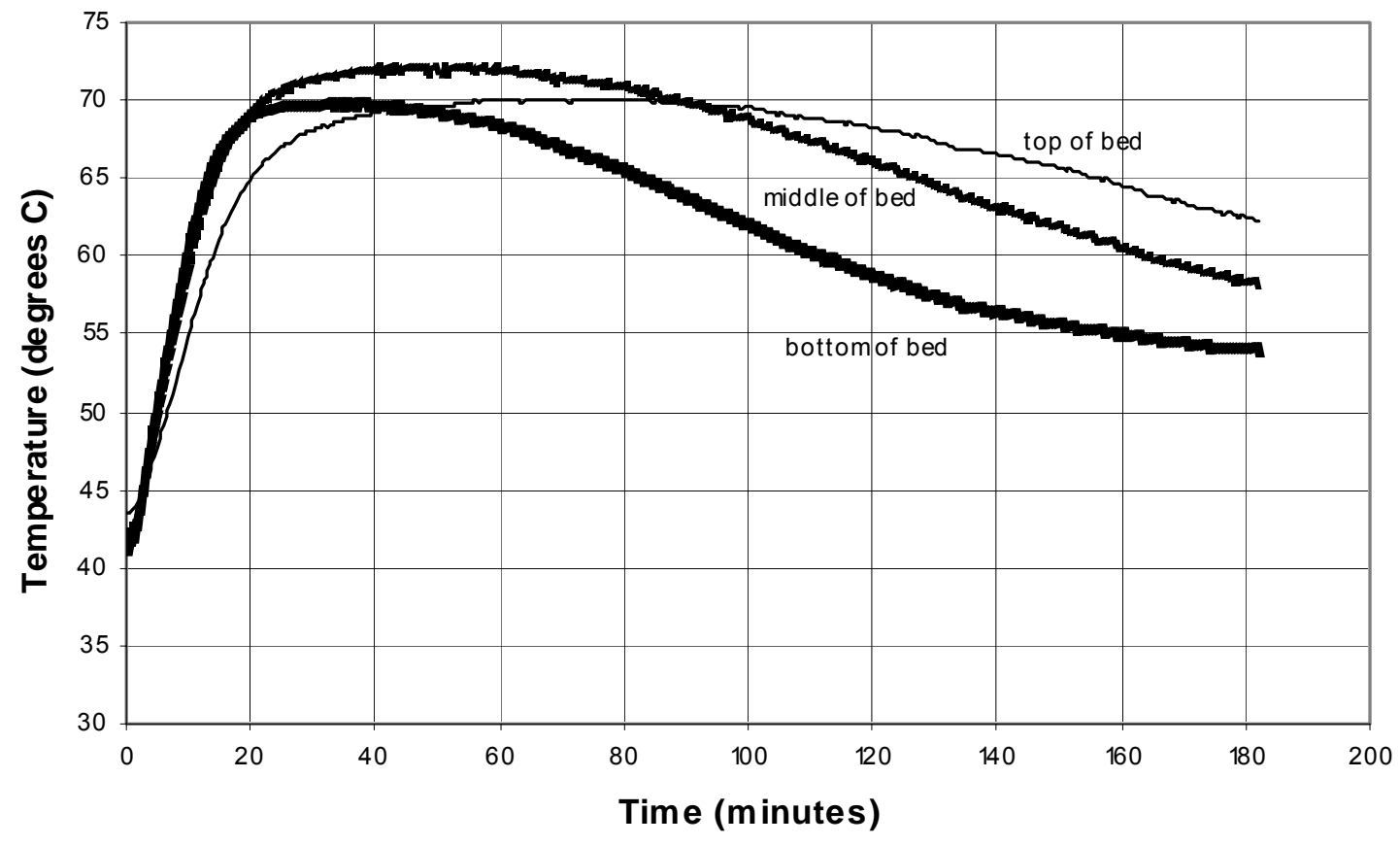

Figure 58. Temperature profile - carbonation Cycle 3 - 5/15/2002

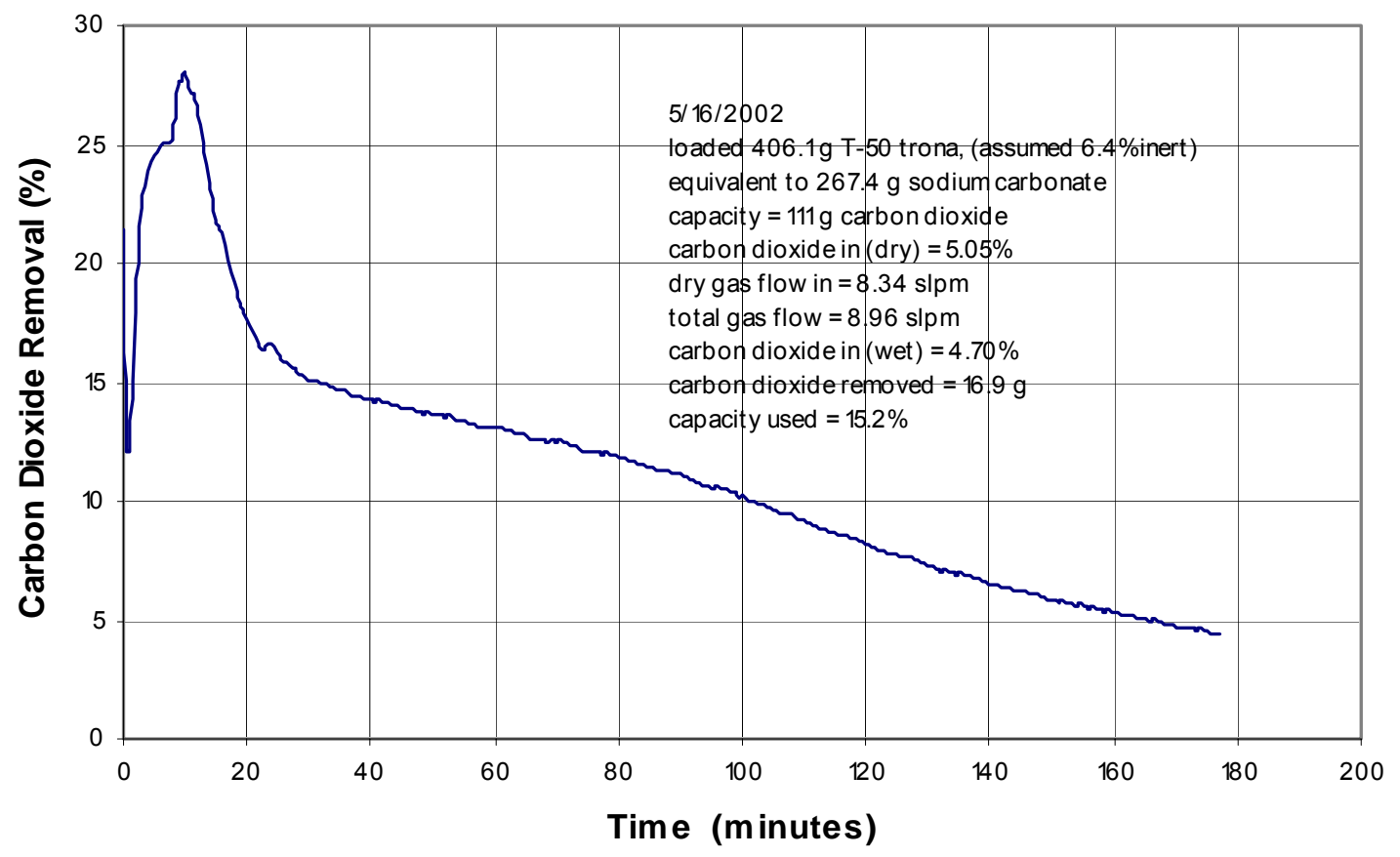

Figure 59. Carbon dioxide removal with trona - Cycle 4 - 5/16/2002 


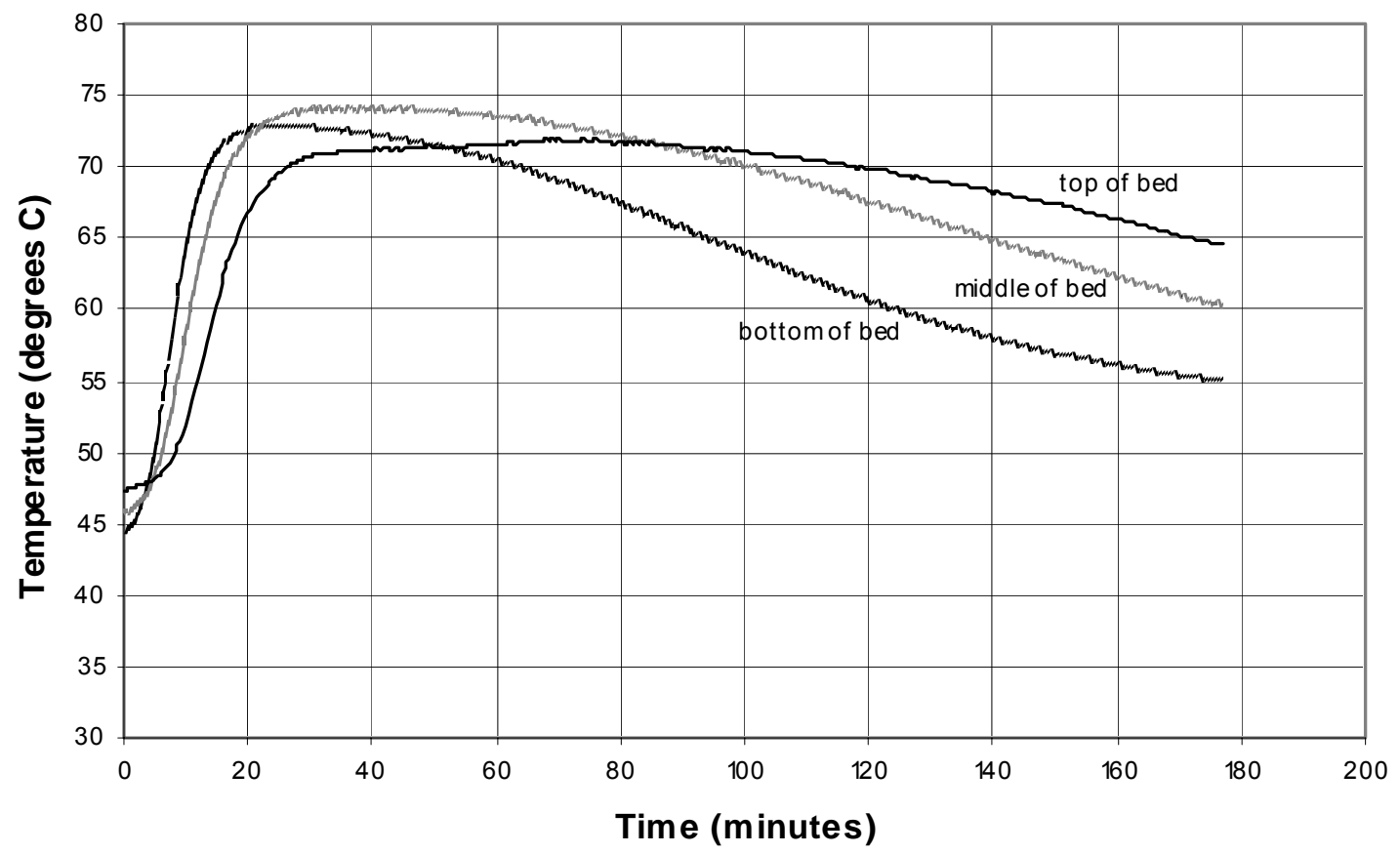

Figure 60. Temperature profile - carbonation Cycle 4 - 5/16/2002

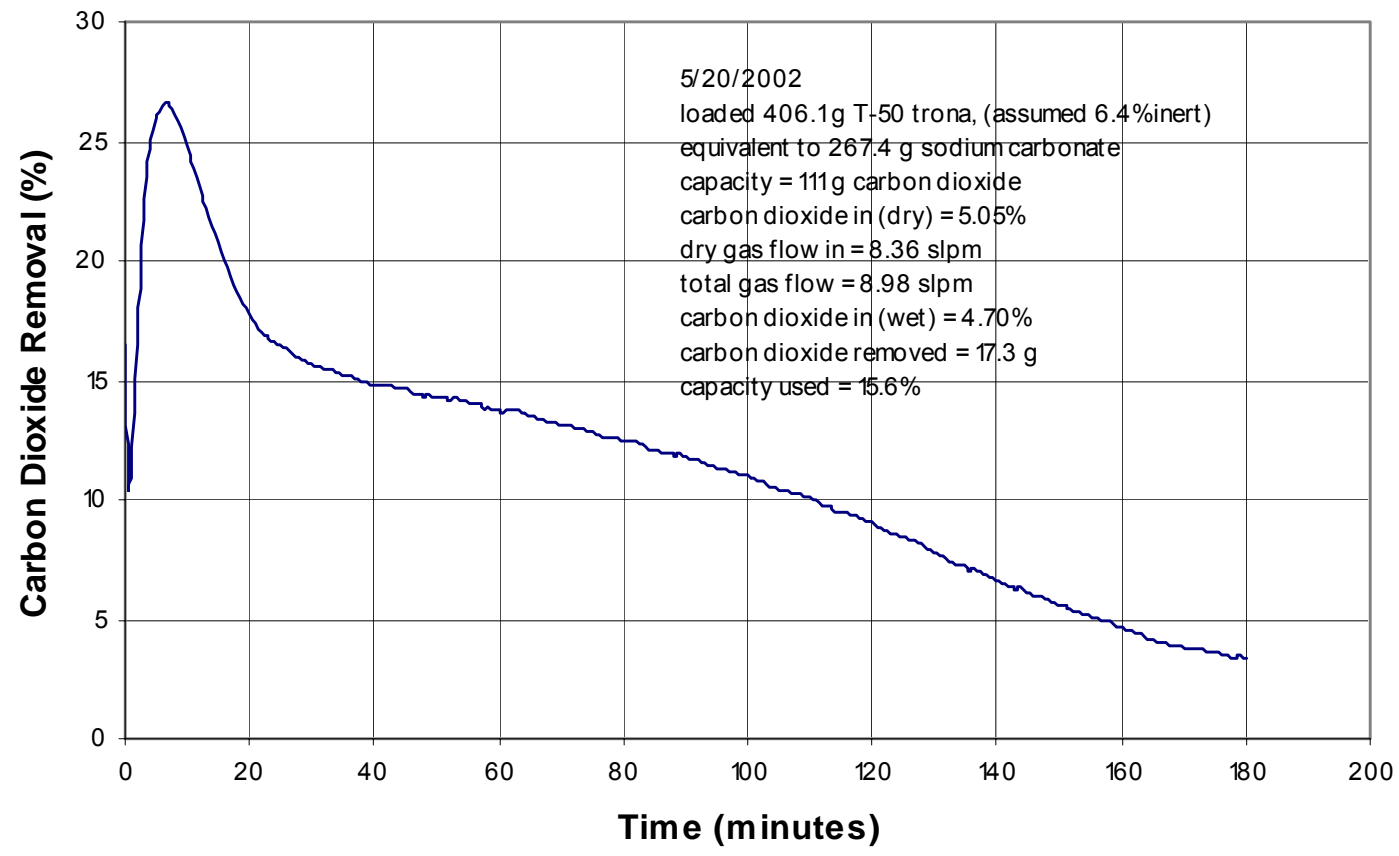

Figure 61. Carbon dioxide removal with trona - Cycle 5 - 5/20/2002 


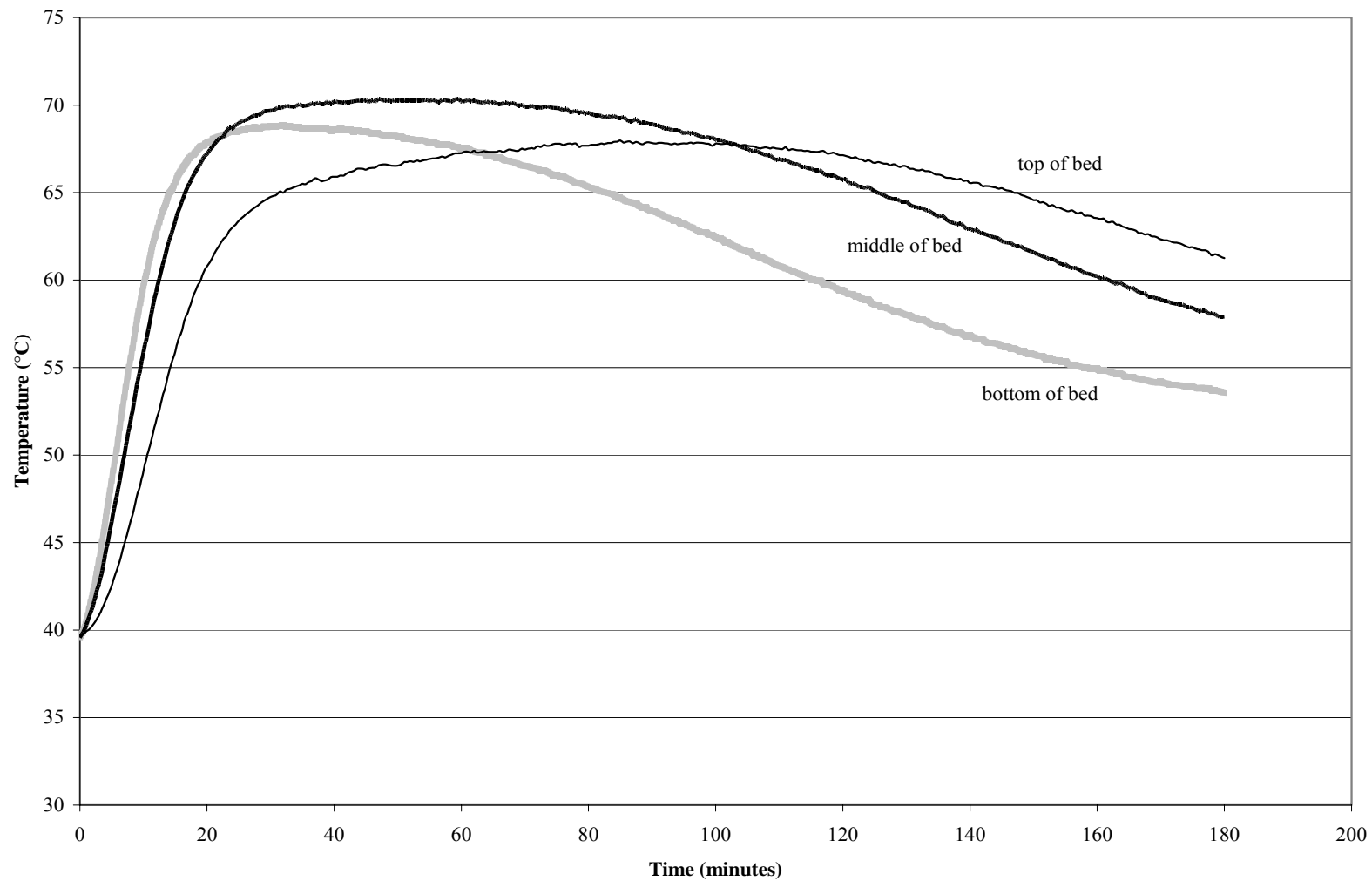

Figure 62. Temperature profile - carbonation Cycle 5 - 5/20/2002

Table 3. Carbon Dioxide Removal in Test 4 (Five-cycle Fluidized Bed Test Using Trona T-50 as Sorbent Precursor)

\begin{tabular}{lccccc}
\hline \hline Cycle & \multicolumn{1}{l}{} & \multicolumn{2}{l}{} & \multicolumn{1}{l}{$\mathbf{3}$} & \multicolumn{1}{l}{$\mathbf{4}$} \\
\hline Total Gas Flow (SLPM) & 8.98 & 8.96 & 8.98 & 8.96 & 8.98 \\
$\mathrm{CO}_{2}$ in (\%) & 6.98 & 4.70 & 4.70 & 4.70 & 4.70 \\
$\mathrm{H}_{2} \mathrm{O}$ in (\%) & 6.90 & 6.90 & 6.90 & 6.91 & 6.90 \\
$\mathrm{CO}_{2}$ removed (g) & 12.7 & 16.1 & 17.5 & 16.9 & 17.3 \\
Capacity used (\%) & 11.4 & 14.5 & 15.8 & 15.2 & 15.6 \\
\hline \hline
\end{tabular}

The results are relatively consistent from cycle to cycle with no indication that the activity of the sorbent declined over the course of the five cycles. Variations in temperature are unavoidable with strongly exothermic reactions in the present well-insulated reactor system. The initial removal rates of 15 to 30 percent, as shown in the data for the first 15 to 30 minutes of the run, are more significant than the overall sorbent capacity usage over the three-hour duration. 


\subsubsection{Test 5: Spray-Dried 40\% Supported Potassium Carbonate (5 Cycles)}

A second five-cycle fluidized-bed test was conducted using a spray-dried $40 \%$ potassium carbonate on alumina support. This material was tested because of its superior attrition resistance to granular potassium carbonate, and because the support provides a heat sink for the energy released by the carbonation reaction. Experimental conditions were similar to the previous test. The reactor was loaded with $379 \mathrm{~g}$ of sorbent, and the material was not removed between cycles. This was equivalent to an initial bed height of 5.5 inches. The potassium carbonate content of this sorbent has a carbon dioxide capacity of $48.2 \mathrm{~g}$ (assuming conversion to bicarbonate). All calcinations were carried out in nitrogen at $150^{\circ} \mathrm{C}$. Carbonation reactions were conducted in a simulated flue gas of $6.28 \%$ carbon dioxide and approximately $6.2 \%$ water vapor. Carbonation test temperatures varied within the fluidized bed through the course of each cycle, peaking at approximately $105^{\circ} \mathrm{C}$. The carbonation cycles were stopped after 3 to 3.5 hours, even though most of the stoichiometric capacity of the bed was unused, because the initial rates are of greatest interest. Carbon dioxide removal, and the associated fluidized-bed temperature profiles are shown in Figures 63 through 72. The temperatures at the "bottom," "middle," and "top" of the bed were measured as in the trona tests. A summary of these data is given in Table 4.

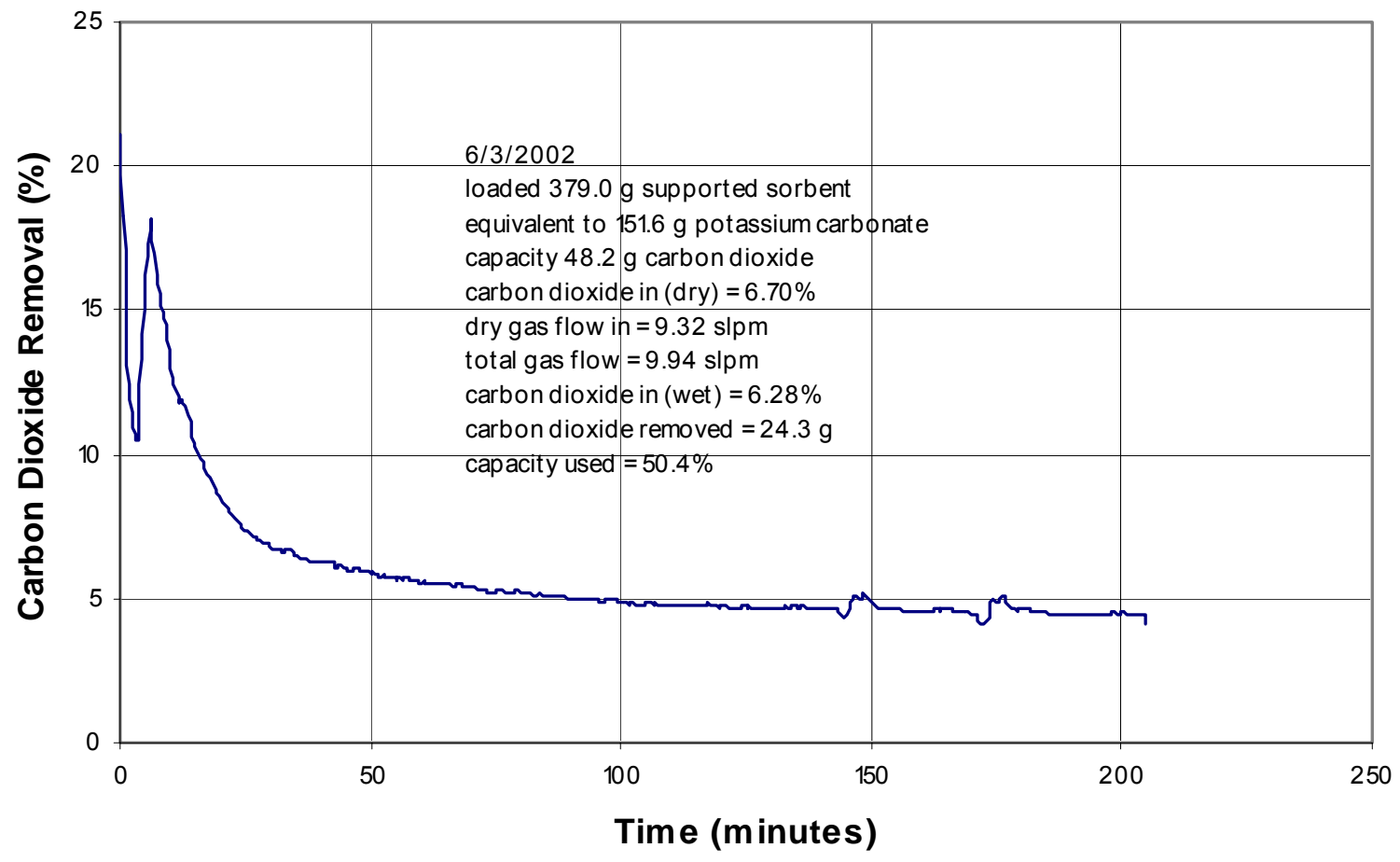

Figure $63 . \quad$ Fluidized-bed carbonation of $40 \%$ supported potassium carbonate - Cycle 1 


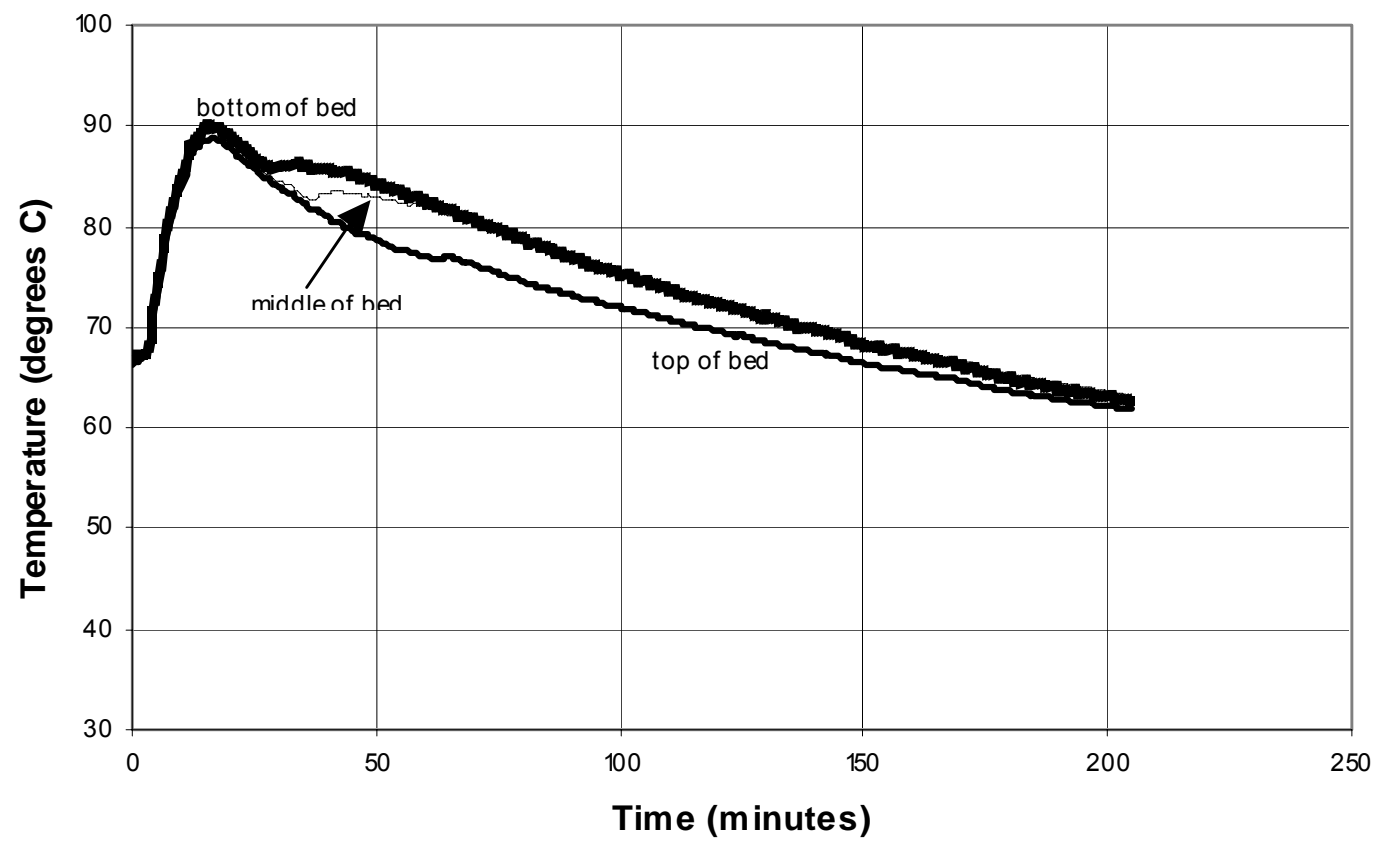

Figure 64 . Temperature profile $-40 \%$ supported potassum carbonate - Cycle 1

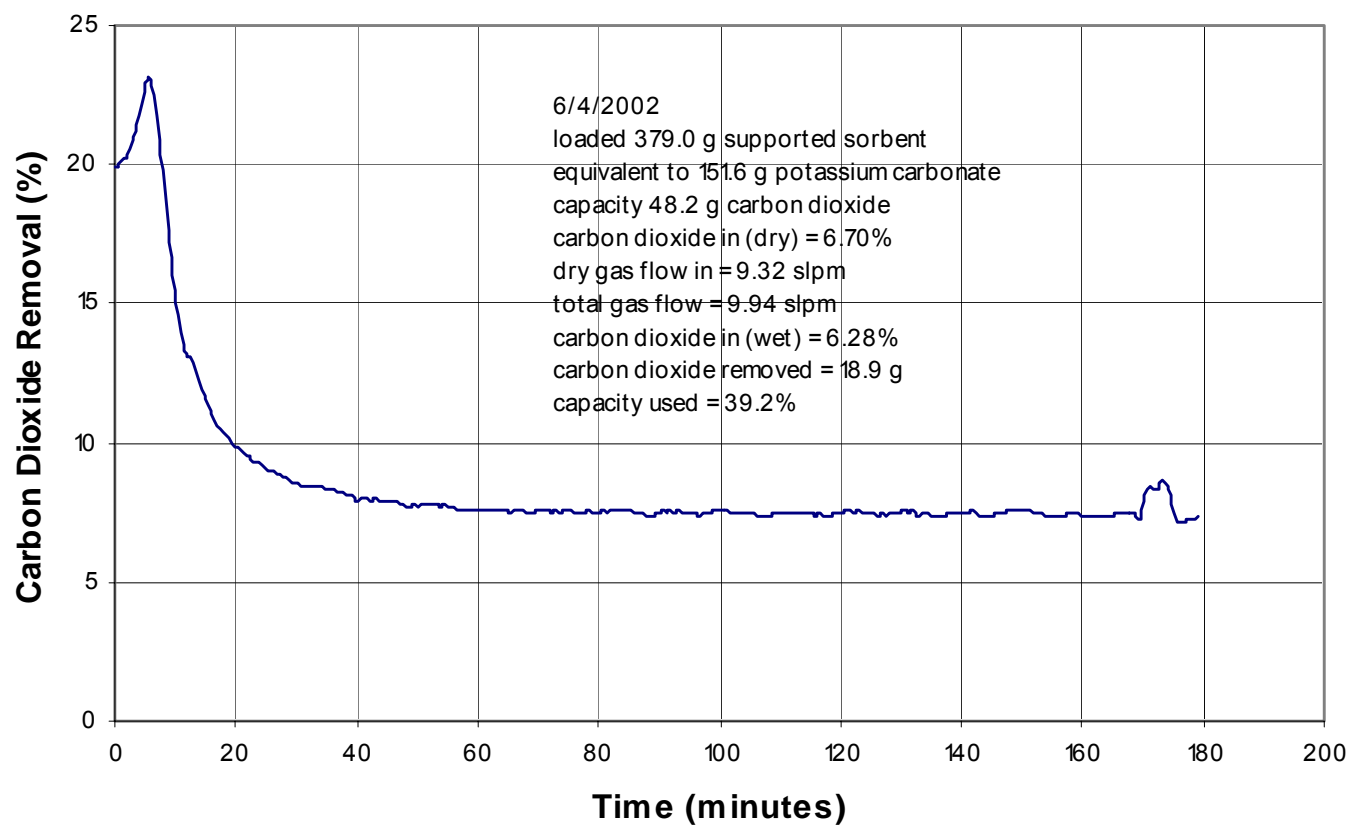

Figure 65 . Fluidized-bed carbonation of $40 \%$ supported potassium carbonate - Cycle 2 


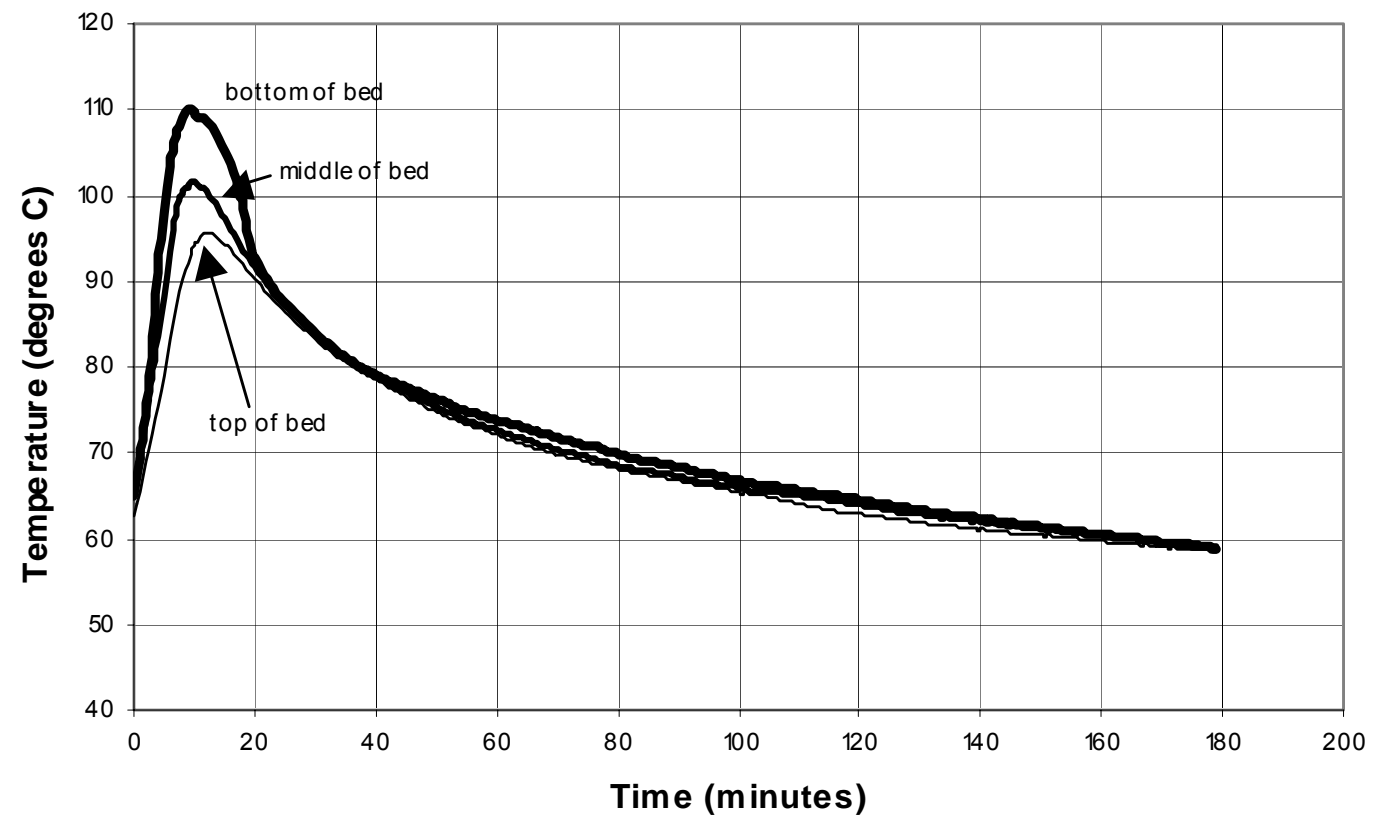

Figure 66 . Temperature profile - 40\% supported potassium carbonate - Cycle 2

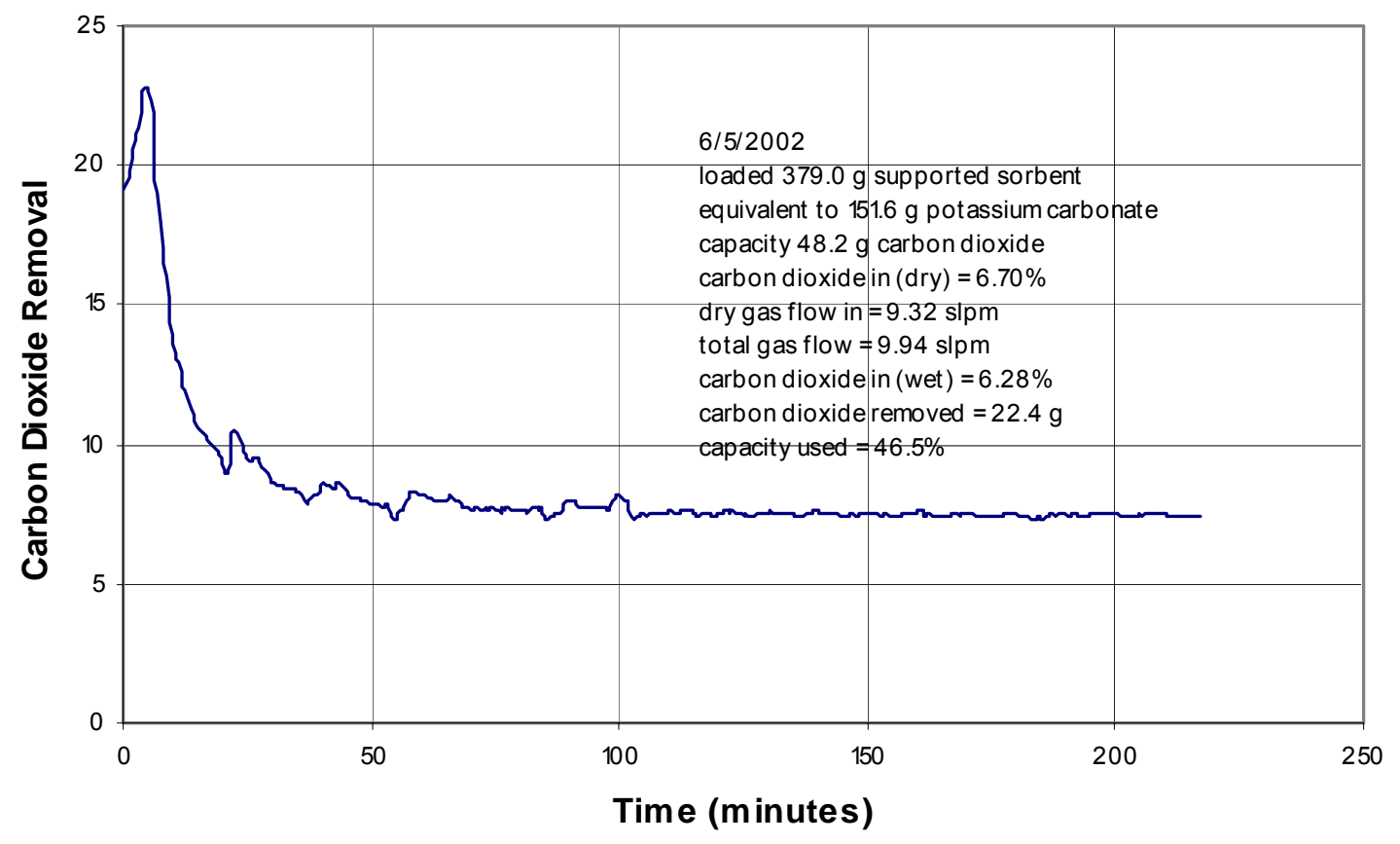

Figure 67 . Fluidized-bed carbonation of $40 \%$ supported potassium carbonate - Cycle 3 


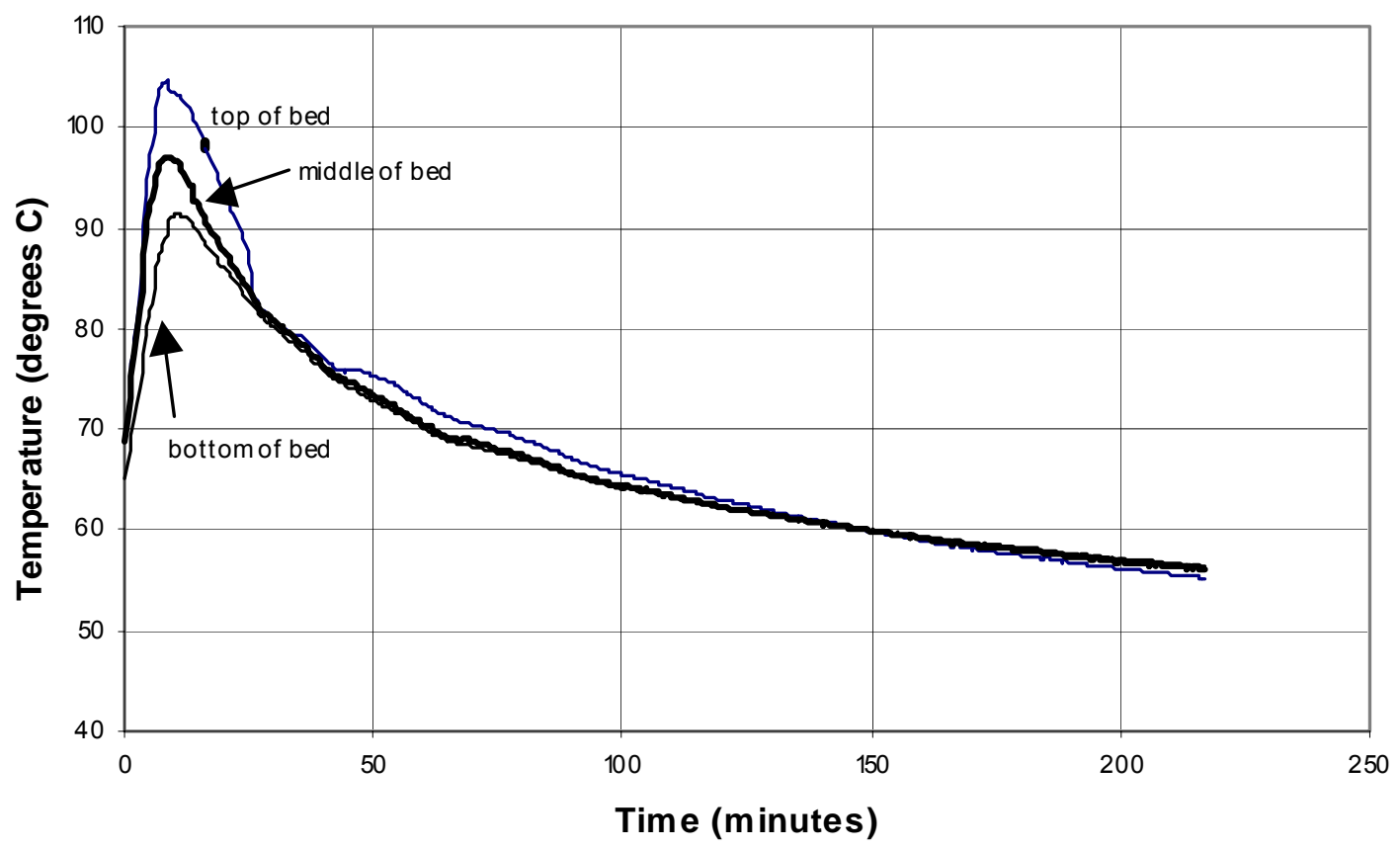

Figure 68. Temperature profile - $40 \%$ supported potassium carbonate - Cycle 3

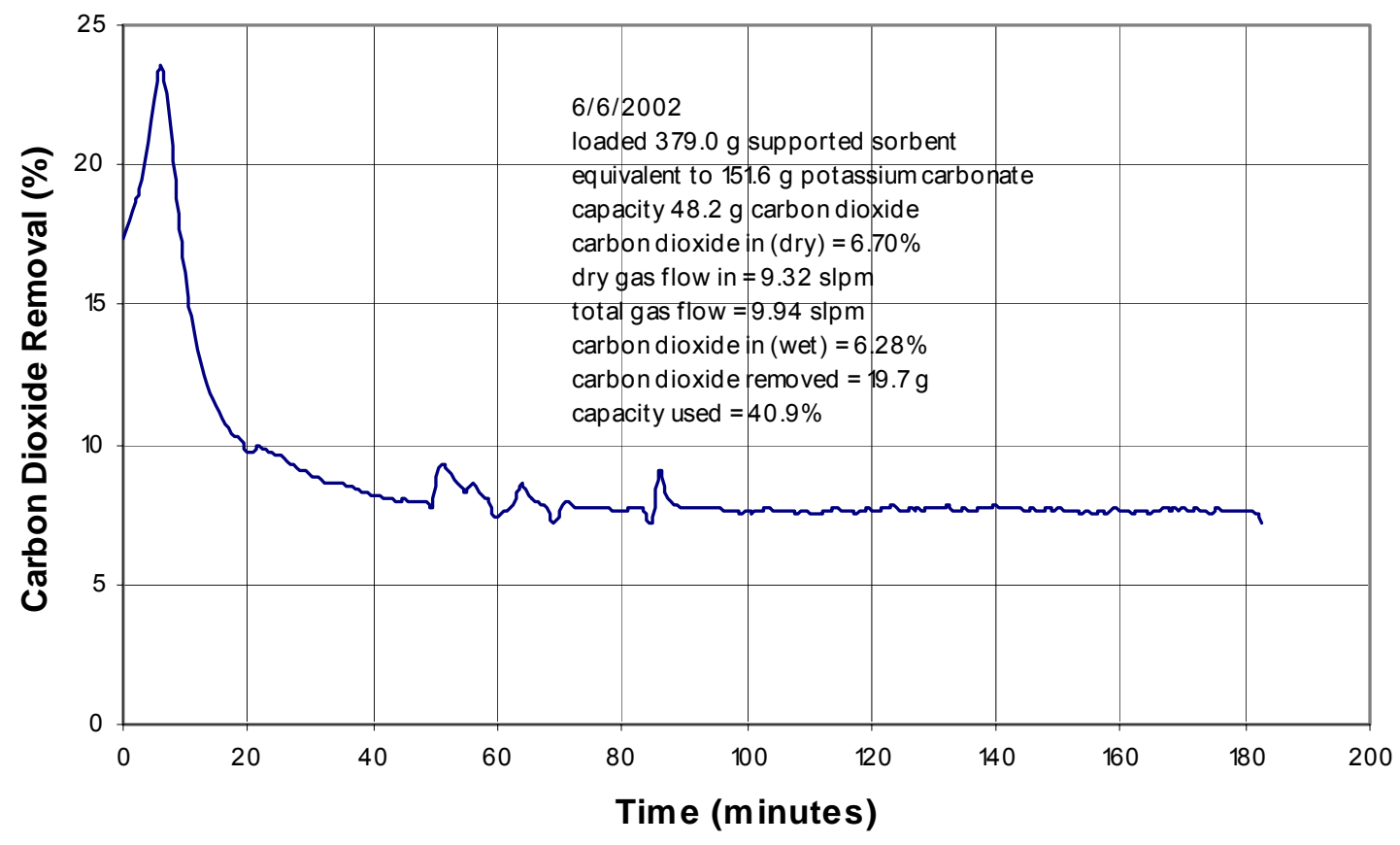

Figure 69 . Fluidized-bed carbonation of $40 \%$ supported potassium carbonate - Cycle 4 


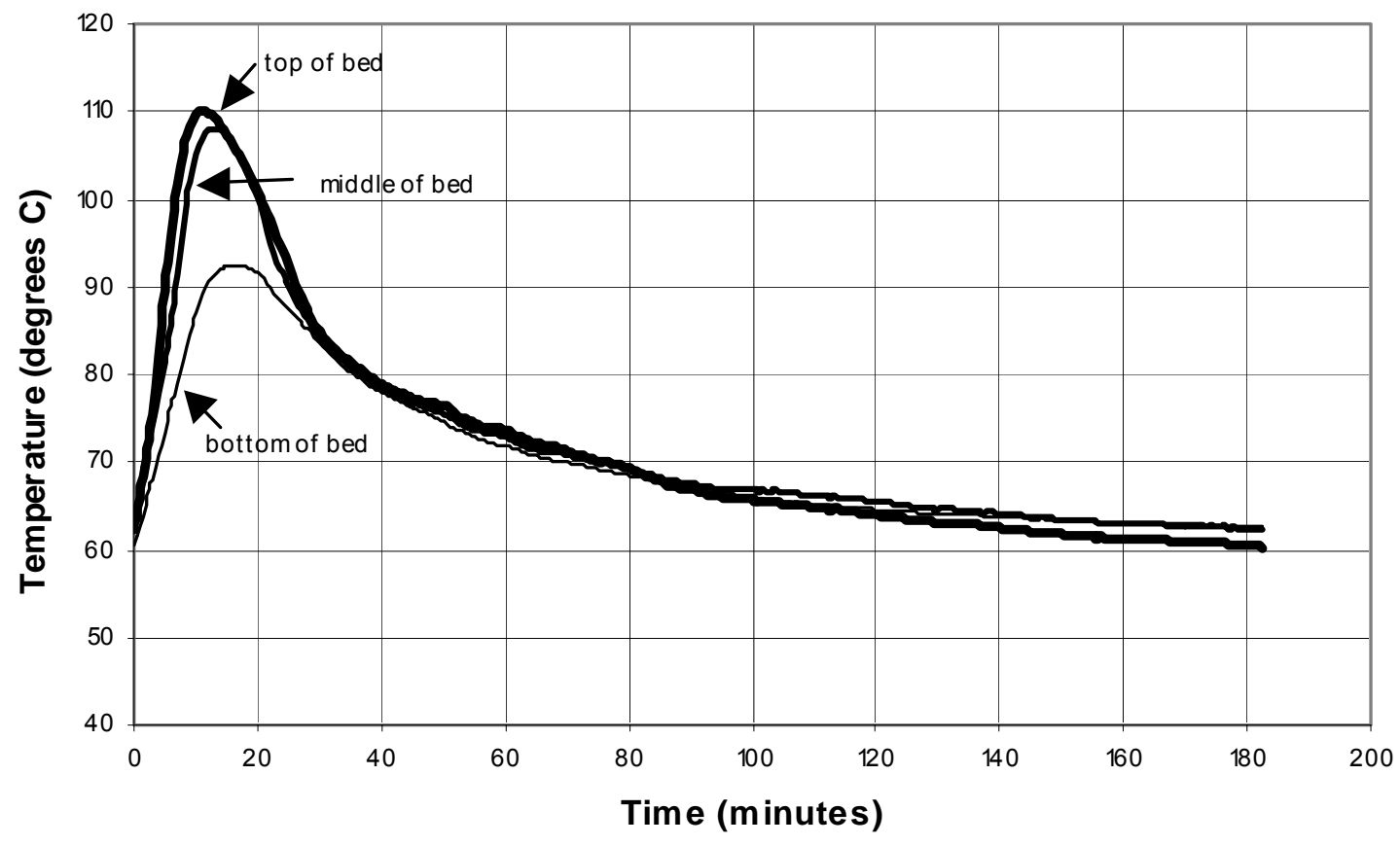

Figure 70. Temperature profile - $40 \%$ supported potassium carbonate - Cycle 4

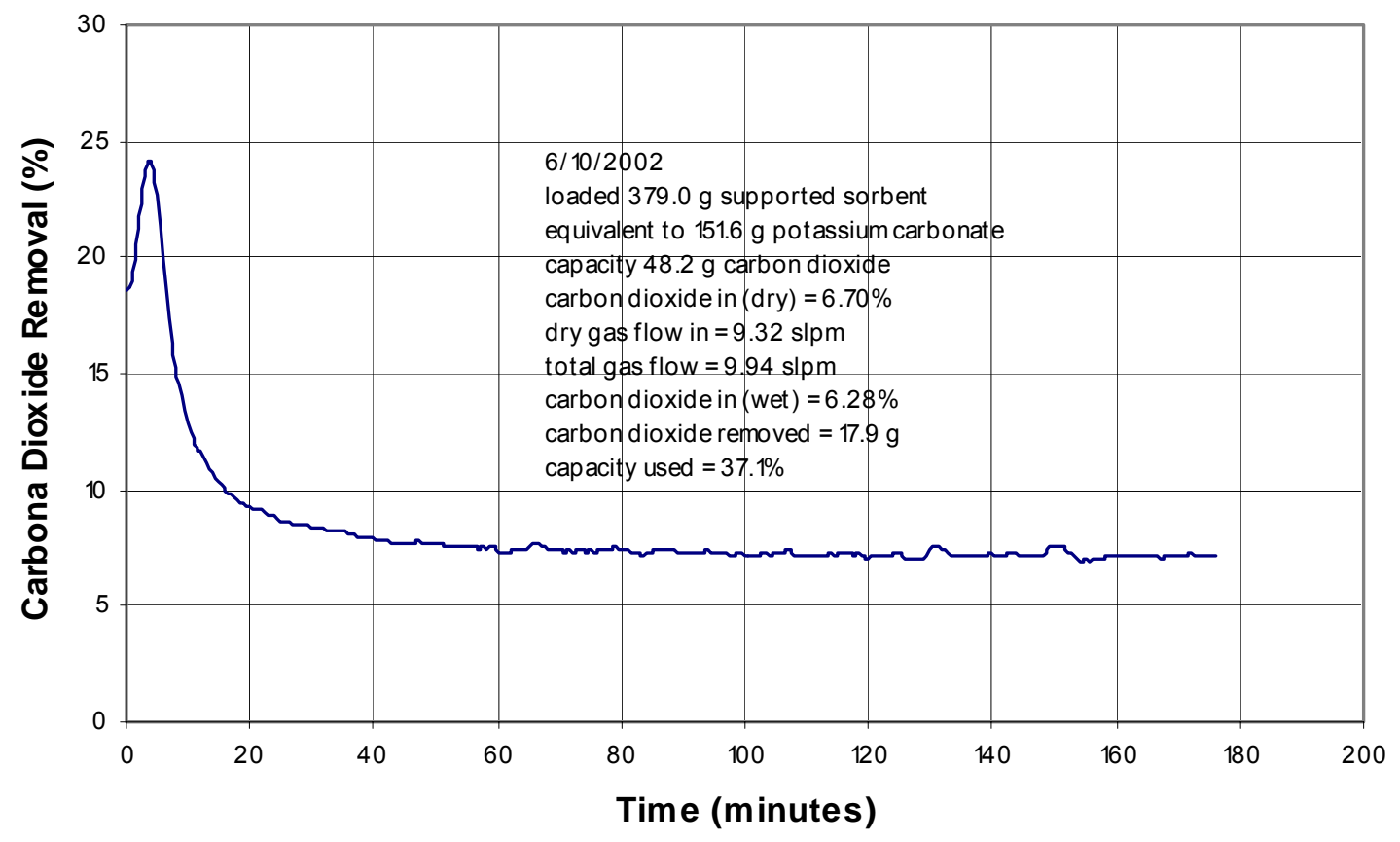

Figure 71. Fluidized-bed carbonation of $40 \%$ supported potassium carbonate - Cycle 5 


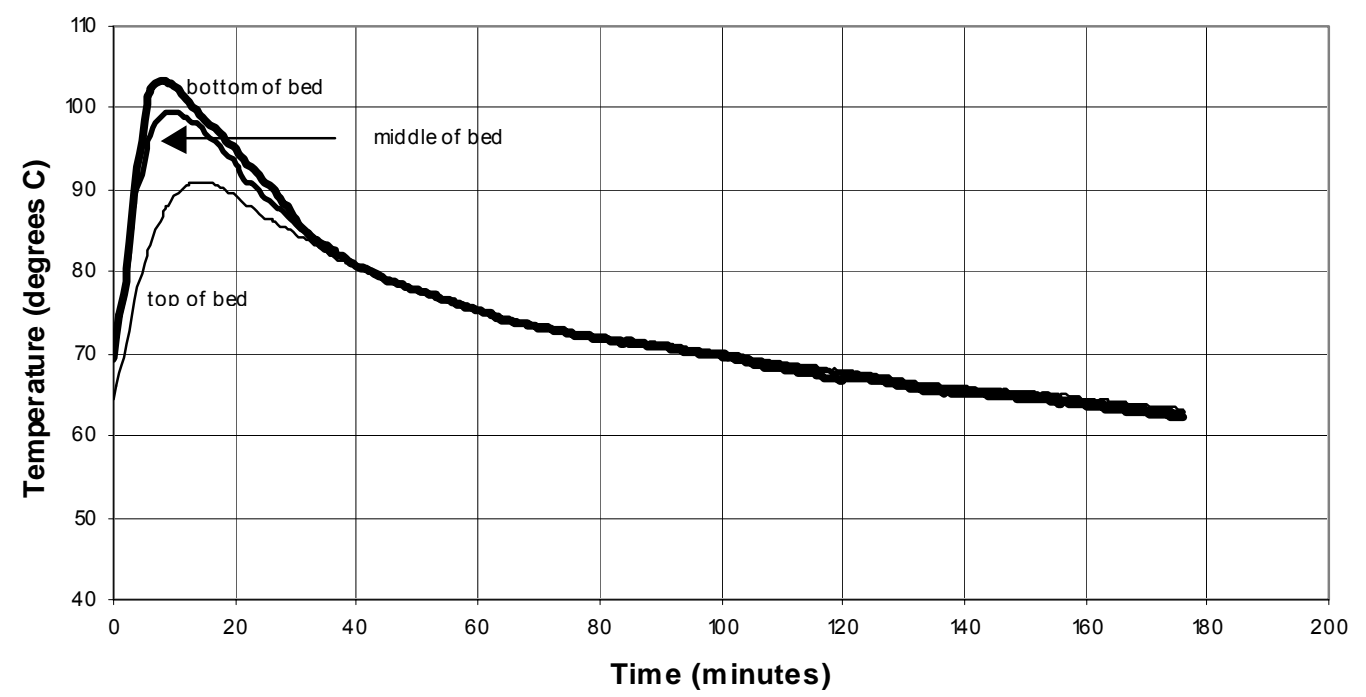

Figure 72. Temperature profile - $40 \%$ supported potassium carbonate - Cycle 5

Table 4. Carbon Dioxide Removal in Test 5 (Five-cycle Fluidized-Bed Test Using Spray Dried Supported Potassium Carbonate)

\begin{tabular}{|c|c|c|c|c|c|}
\hline Cycle & 1 & 2 & 3 & 4 & 5 \\
\hline Total Gas Flow (slpm) & 9.94 & 9.94 & 9.94 & 9.94 & 9.94 \\
\hline $\mathrm{CO}_{2}$ in $(\%)$ & 6.28 & 6.28 & 6.28 & 6.28 & 6.28 \\
\hline $\mathrm{H}_{2} \mathrm{O}$ in $(\%)$ & 6.24 & 6.24 & 6.24 & 6.24 & 6.24 \\
\hline $\mathrm{CO}_{2}$ removed $(\mathrm{g})$ & 24.3 & 18.9 & 22.4 & 19.7 & 17.9 \\
\hline Capacity used (\%) & 50.4 & 39.2 & 46.5 & 40.9 & 37.1 \\
\hline
\end{tabular}

\subsubsection{Test 6: 10\% Supported Potassium Carbonate (5-cycles)}

The reactor was loaded with $190 \mathrm{~g}$ of sorbent material, which contained $19 \mathrm{~g}$ of potassium carbonate and $171 \mathrm{~g}$ of support material. The carbon dioxide capacity of the sorbent, assuming complete conversion of potassium carbonate to potassium bicarbonate (and no activity due to the support material) was $6.0 \mathrm{~g}$. Integration of the carbon dioxide removal data indicated that greater than $100 \%$ of the stoichiometric capacity of the potassium carbonate was used, suggesting that the support was reversibly adsorbing carbon dioxide. Carbonation cycles were extended for 3 hours, as in past tests. Useful data were obtained from three carbonation cycles; experimental problems occurred in the first and third cycles. The carbon dioxide concentration 
at the reactor exit, as well as the sorbent bed temperature rise, suggested that the reaction was essentially complete within the first few minutes of each carbonation cycle. Data for the second, fourth, and fifth cycles are shown in Figures 73 through 81.

The data suggest a rapid reaction rate. While the reactivity of the support, which makes up $90 \%$ of the sorbent material, complicates data analysis (making it impossible to derive a quantitative reaction rate) the temperature rise in the sorbent bed confirms that a rapid exothermic reaction is taking place.

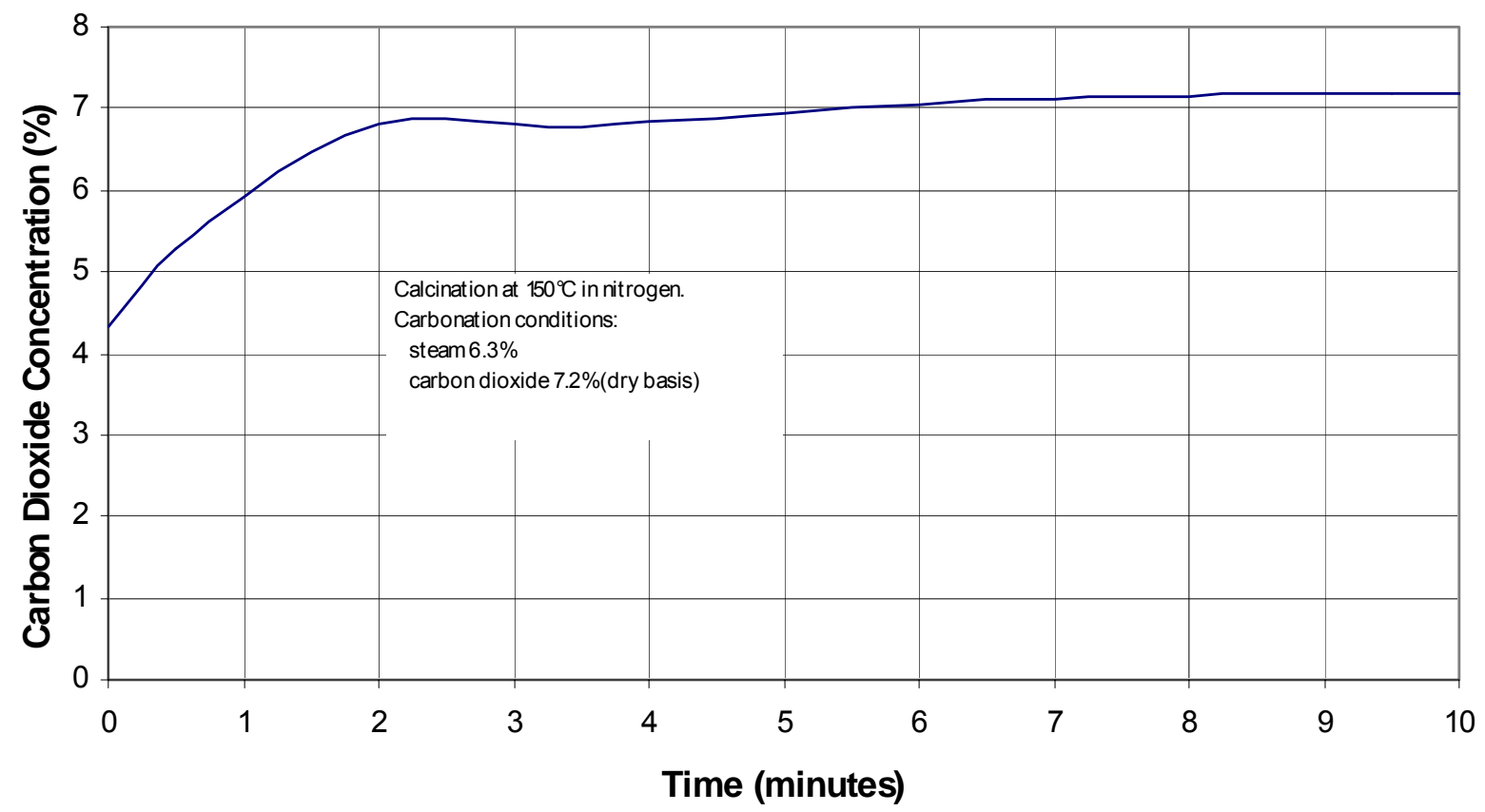

Figure 73. Test data from carbonation cycle 


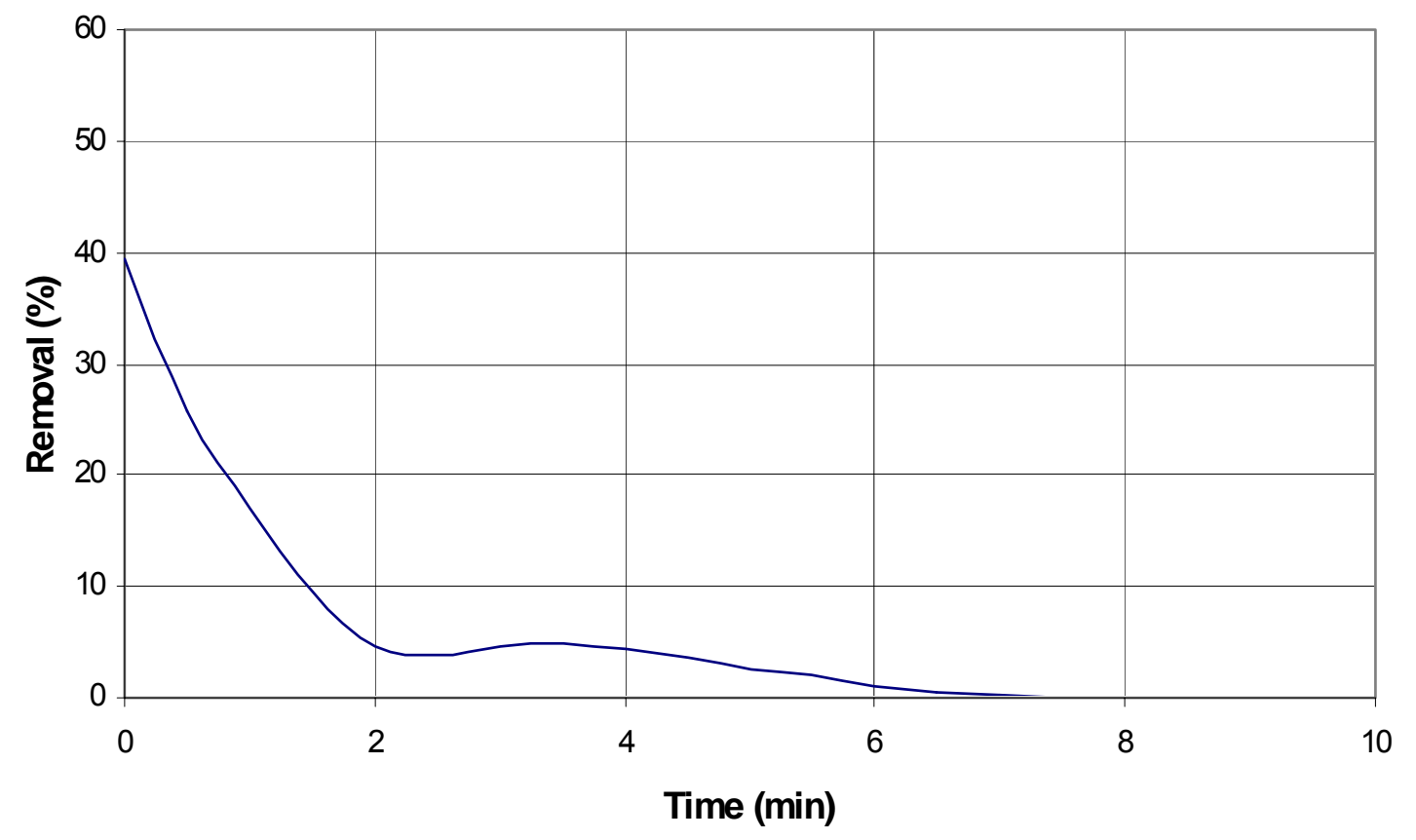

Figure 74. Test data from carbonation Cycle 2 with $10 \%$ supported potassium carbonate sorbent $-\mathrm{CO}_{2}$ removal

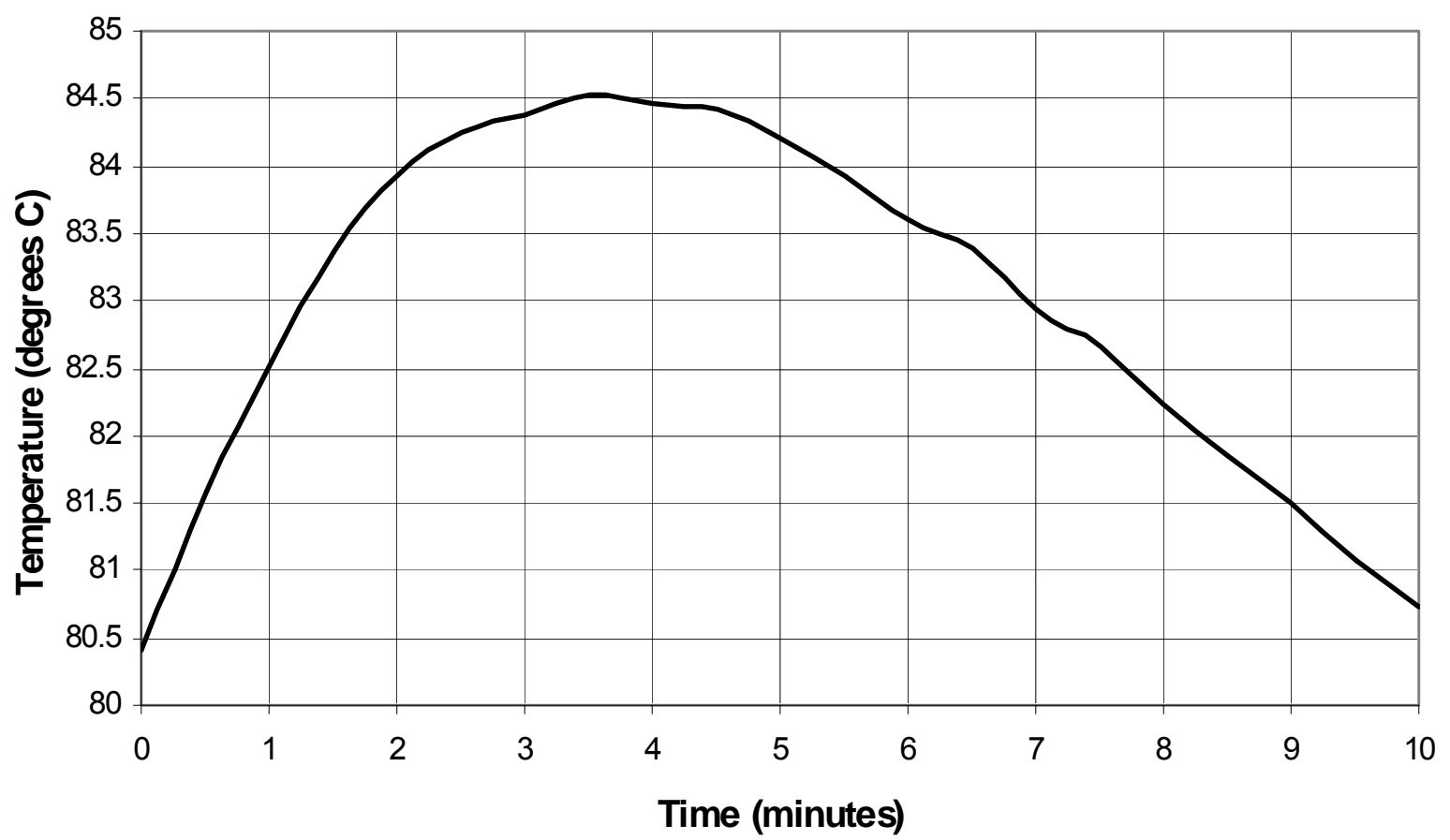

Figure 75. Test data from carbonation Cycle 2 with $10 \%$ supported potassium carbonate sorbent - average bed temperature 


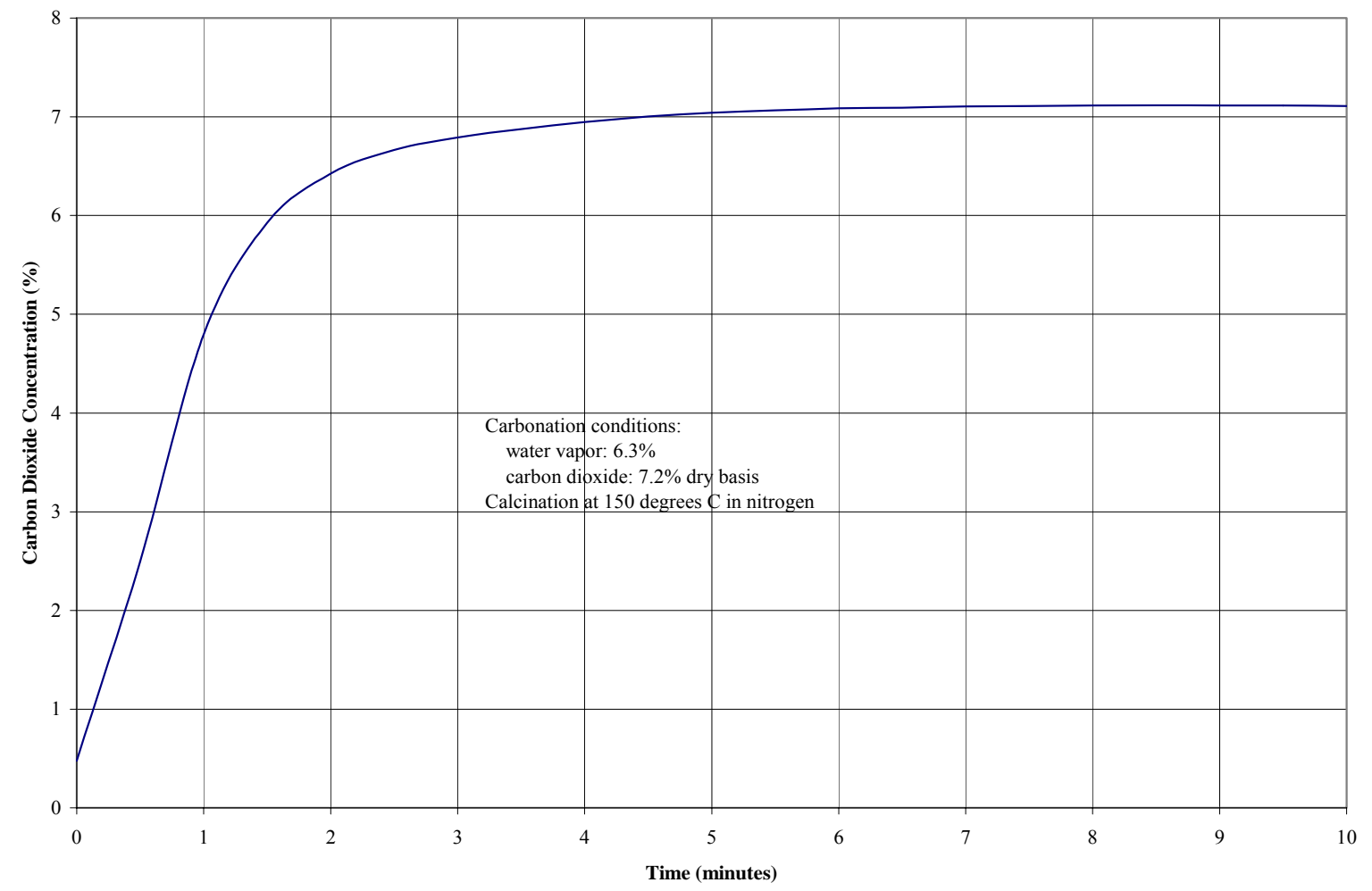

Figure 76. Test data from carbonation Cycle 4 with $10 \%$ supported potassium carbonate sorbent $-\mathrm{CO}_{2}$ concentration in reactor exit gas

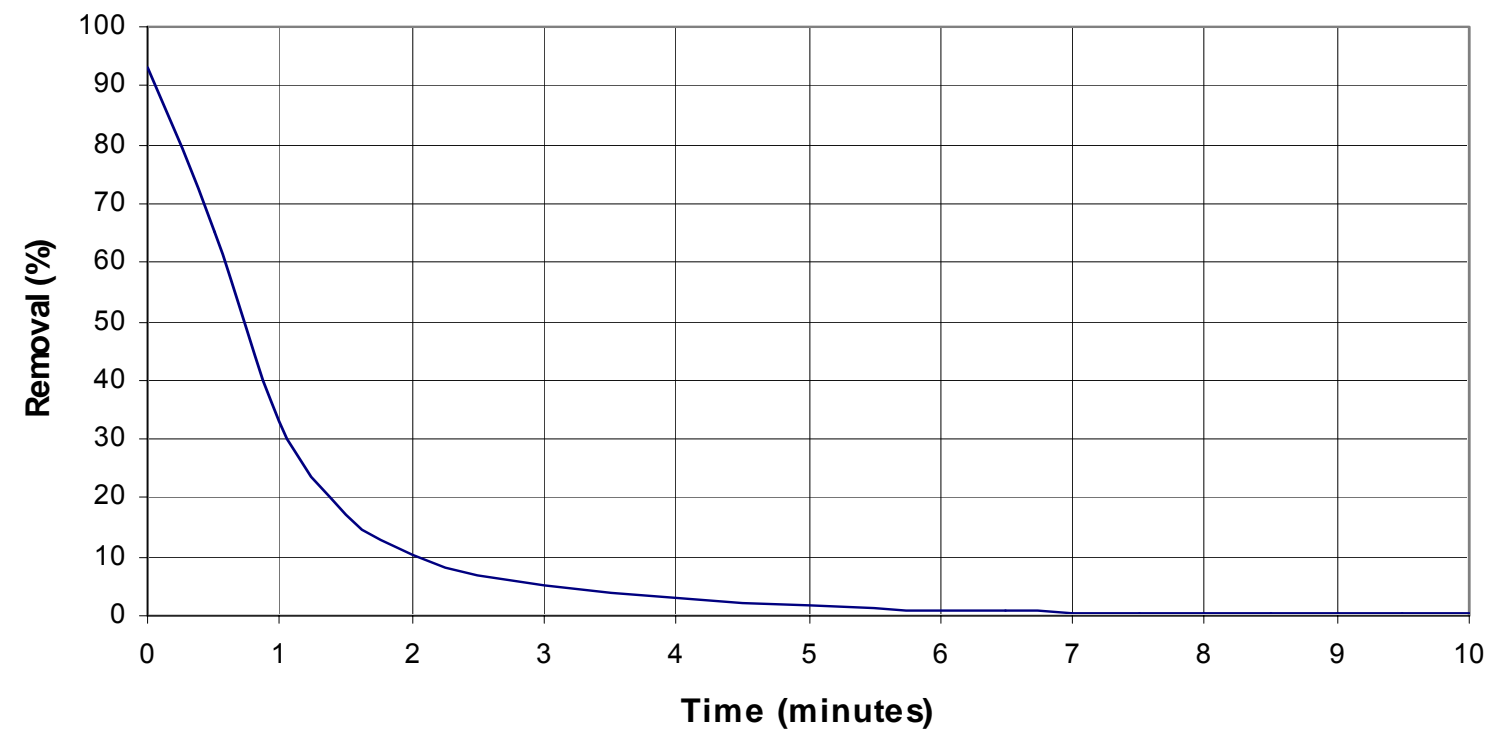

Figure 77. Test data from carbonation Cycle 4 with $10 \%$ supported potassium carbonate sorbent $-\mathrm{CO}_{2}$ removal 


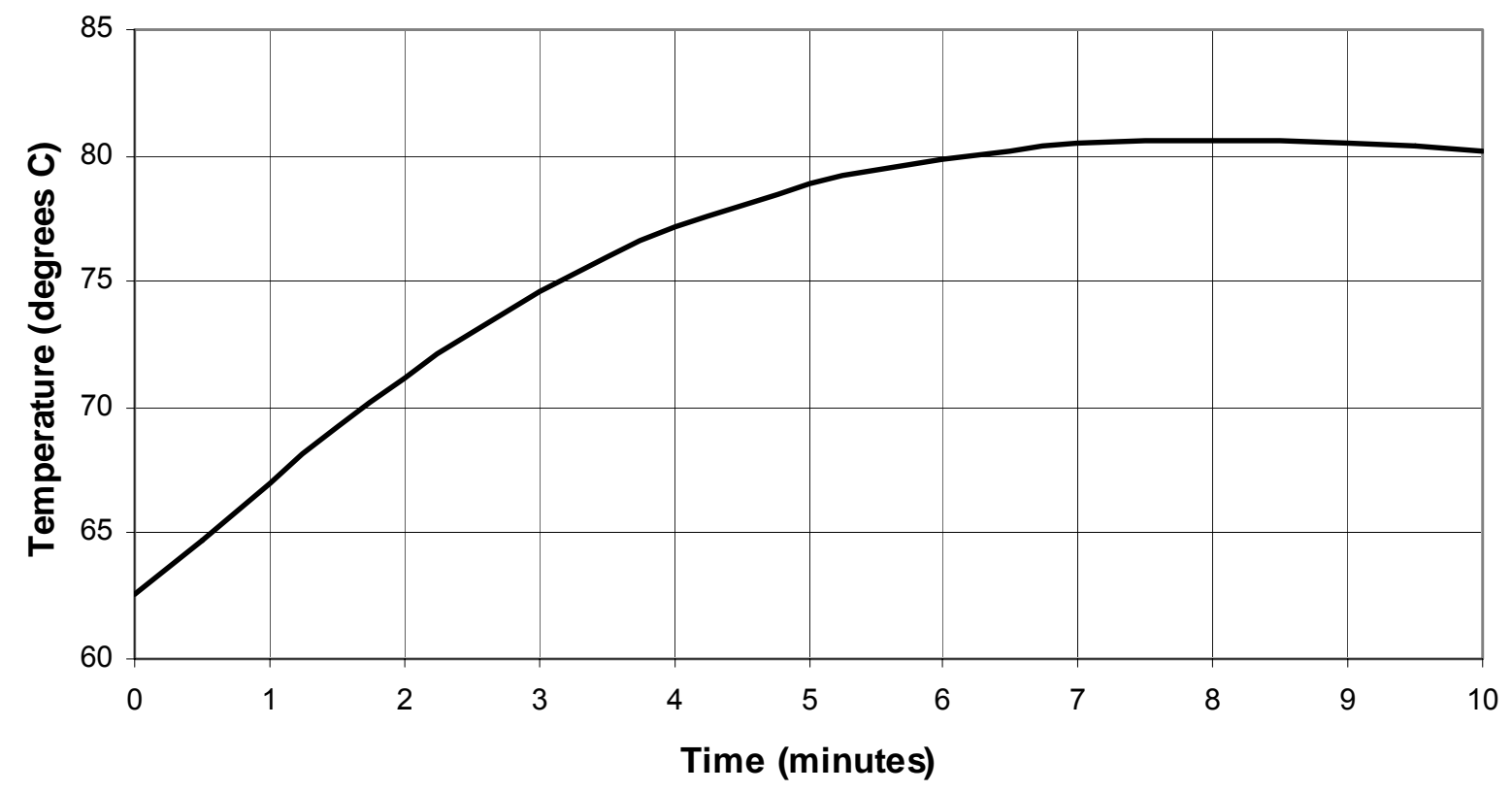

Figure 78. Test data carbonation Cycle 4 with $10 \%$ supported potassium carbonate sorbent - average bed temperature

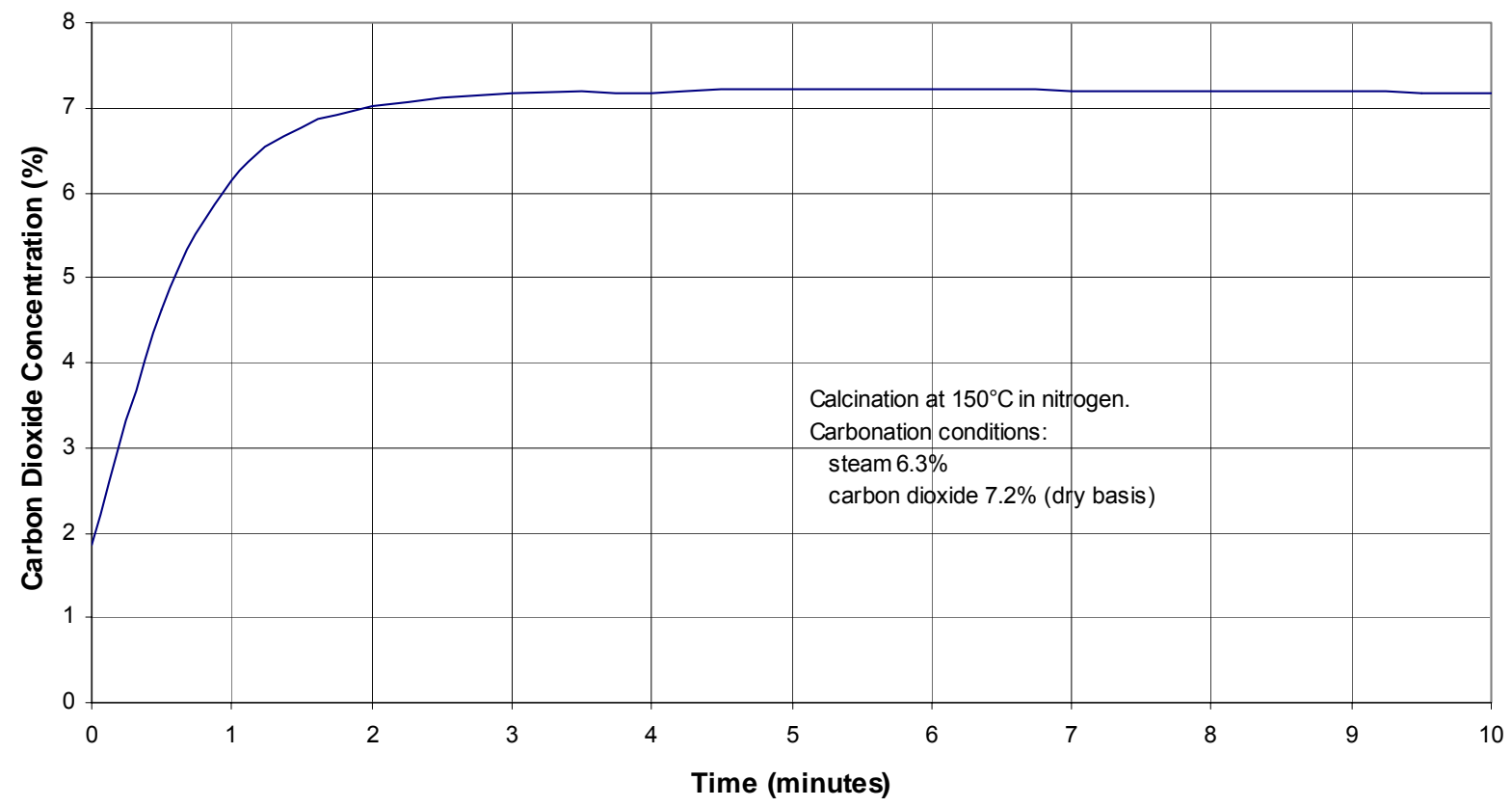

Figure 79. Test data from carbonation Cycle 5 with $10 \%$ supported potassium carbonate sorbent $-\mathrm{CO}_{2}$ concentration in reactor exit gas 


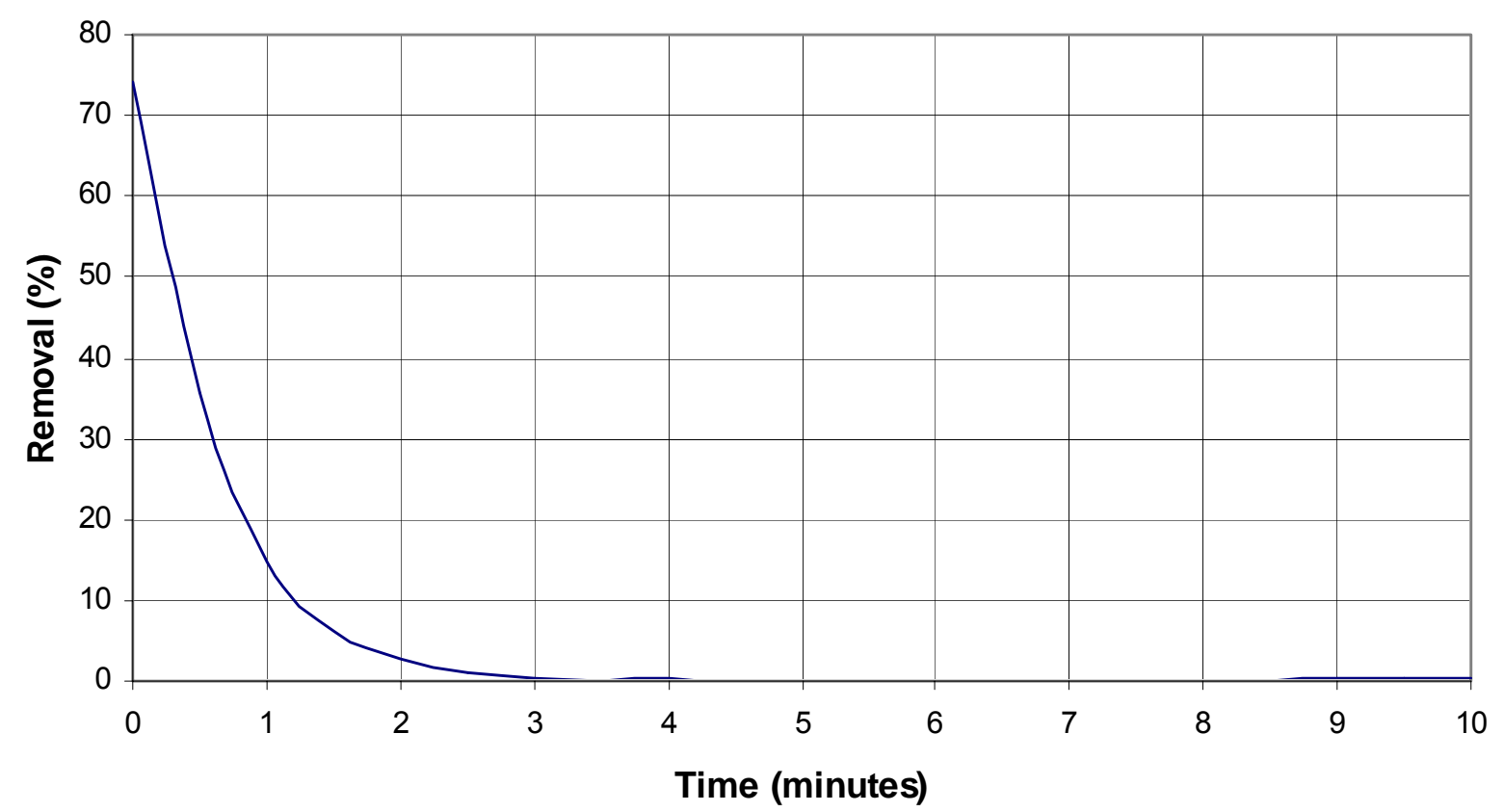

Figure 80. Test data from carbonation Cycle 5 with $10 \%$ supported potassium carbonate sorbent $-\mathrm{CO}_{2}$ removal

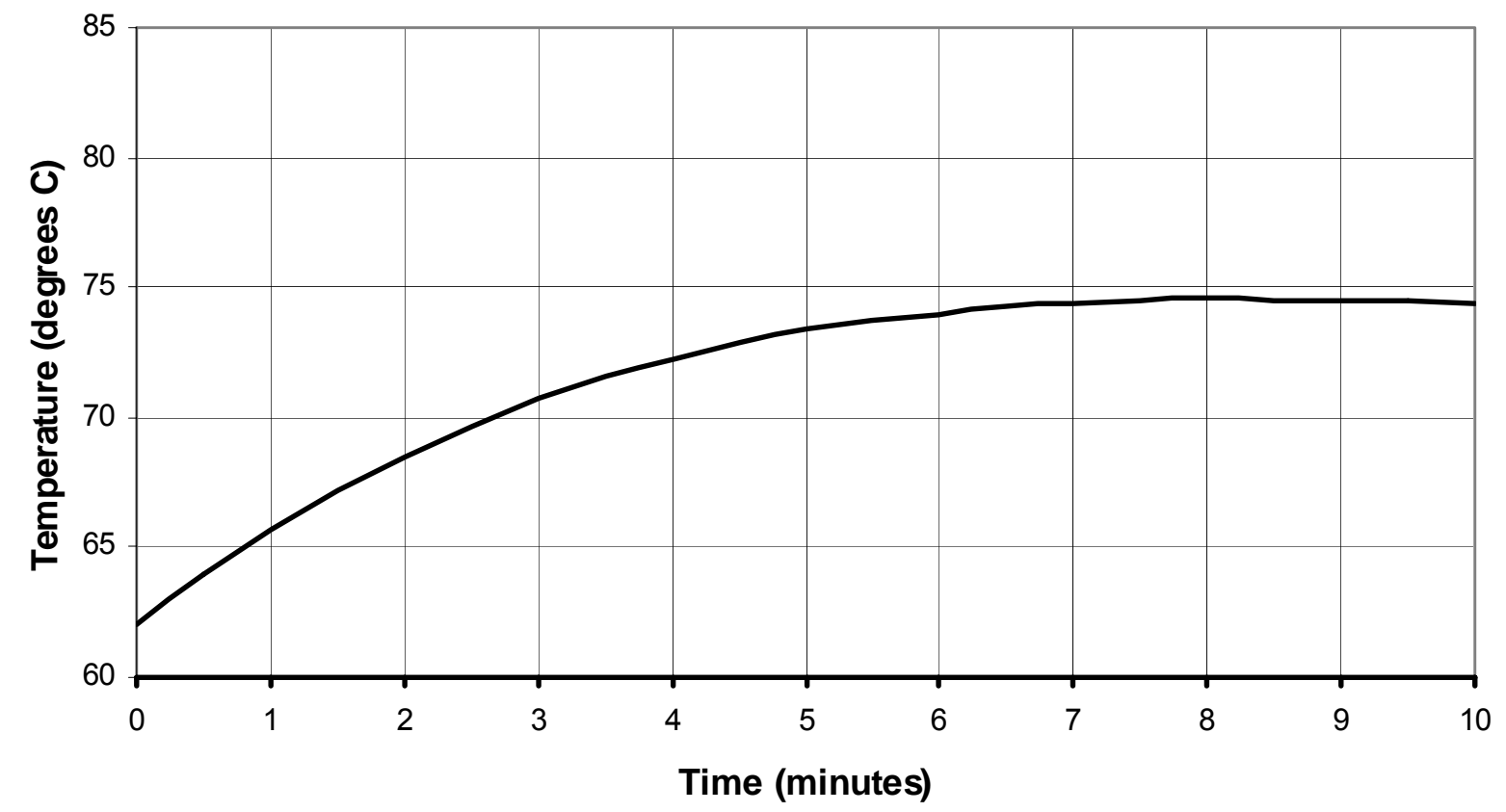

Figure 81. Test data from carbonation Cycle 5 with $10 \%$ supported potassium carbonate sorbent - average bed temperature 


\subsection{PROPERTIES OF UNSUPPORTED SORBENTS AND SORBENT PRECURSORS}

RTI measured particle size, BET surface area, porosity, ASTM attrition index, and bulk density of selected samples of the unsupported sorbents tested. The various grades of SBC and trona were tested before and after laboratory calcination. Properties of sodium bicarbonate (SBC) materials and trona are given in Table 5 and 6 respectively. Structural properties such as pore volume and particle size of these materials appear suitable for use. However, the ASTM attrition index of these materials is very high. Typical ASTM attrition index of an attritionresistant material such as FCC is 0.2-0.5. Except for SBC grade 5, all of the materials tested appear to exhibit poor attrition resistance. However the large particle size and narrow size distribution of the SBC grade 5 is unsuitable for use in a transport reactor.

\subsection{CHARACTERIZATION AND TESTING OF SUPPORTED MATERIALS}

RTI produced a series of sorbents composed of sodium carbonate incorporated in a ceramic support. Two potassium carbonate materials used for fluidized bed testing were also prepared. The objective of the sorbent development work was to produce an active (as indicated by high BET surface area and rapid conversion to Wegscheider's salt) material which is mechanically stable (as indicated by a high value for compact bulk density and a low value for the attrition ration (AR) based on the Davison test). Sorbent composition and spray dryer operation were varied to identify important parameters.

The compositions and selected properties of these materials are shown in Table 7. This table also includes the properties of calcined SBC\#3 and those of plain support materials, without incorporation of $\mathrm{Na}_{2} \mathrm{CO}_{3}$. TGA weight gains based on a 20-minute exposure to an atmosphere of $7.5 \%$ carbon dioxide and $5.9 \%$ water vapor at $60^{\circ} \mathrm{C}$ were used to compare carbonation activity of the different sorbents.

The goal of the supported sorbent development program is to produce a sorbent that is more active than calcined SBC\#3, with attrition resistance comparable to that of commercial FCC materials. These requirements must be satisfied for a transport reactor system to be effectively used for this reaction cycle. A transport reactor process involves a short residence time (on the order of 5-10 seconds) and requires a material which will be mechanically stable over many (typically more than 100) carbonation/calcination cycles. 
Table 5. Physical properties of Sodium Bicarbonate Materials

\begin{tabular}{|c|c|c|c|c|c|c|c|c|c|c|}
\hline & & $\begin{array}{c}\text { SBC } \\
\text { grade } 1 \\
\text { fresh }\end{array}$ & $\begin{array}{c}\text { SBC grade } 1 \\
\text { calcined } \\
\text { overnight } \\
\text { at } 125^{\circ} \mathrm{C} \\
\text { in air }\end{array}$ & $\begin{array}{c}\text { SBC } \\
\text { grade } 2 \\
\text { fresh }\end{array}$ & $\begin{array}{c}\text { SBC grade } \\
2 \\
\text { calcined } \\
\text { overnight } \\
\text { at } 125^{\circ} \mathrm{C} \\
\text { in air } \\
\end{array}$ & $\begin{array}{c}\text { SBC } \\
\text { grade } 3 \\
\text { fresh }\end{array}$ & $\begin{array}{c}\text { SBC grade } 3 \\
\text { calcined } \\
3 \text { hours } \\
\text { at } 125^{\circ} \mathrm{C} \\
\text { in air }\end{array}$ & $\begin{array}{c}\text { SBC grade } 3 \\
\text { calcined } \\
\text { overnight } \\
\text { at } 125^{\circ} \mathrm{C} \\
\text { in air }\end{array}$ & $\begin{array}{c}\text { SBC } \\
\text { grade } 5 \\
\text { fresh }\end{array}$ & $\begin{array}{c}\text { SBC grade } 5 \\
\text { calcined } \\
3 \text { hours } \\
\text { at } 125^{\circ} \mathrm{C} \\
\text { in air } \\
\end{array}$ \\
\hline \multicolumn{11}{|c|}{ Particle Size Distribution (\%) } \\
\hline 297 & microns & 0 & 0 & 0 & 0.65 & 0 & $\mathrm{n} / \mathrm{a}$ & 0 & 0 & $\mathrm{n} / \mathrm{a}$ \\
\hline$-297+177$ & microns & 0 & 0 & 0 & 0.98 & 0 & $\mathrm{n} / \mathrm{a}$ & 0.65 & 27.7 & $\mathrm{n} / \mathrm{a}$ \\
\hline$-177+125$ & microns & 0 & 0 & 8.61 & 8.82 & 0 & $\mathrm{n} / \mathrm{a}$ & 0 & 63.85 & $\mathrm{n} / \mathrm{a}$ \\
\hline$-125+88$ & microns & 8.56 & 8.7 & 65.56 & 64.38 & 1.03 & $\mathrm{n} / \mathrm{a}$ & 0.98 & 5.74 & $\mathrm{n} / \mathrm{a}$ \\
\hline$-88+75$ & microns & 19.86 & 20.4 & 13.58 & 13.07 & 0.69 & $\mathrm{n} / \mathrm{a}$ & 1.31 & 0 & $\mathrm{n} / \mathrm{a}$ \\
\hline$-75+53$ & microns & 43.84 & 41.47 & 8.28 & 9.15 & 10.31 & $\mathrm{n} / \mathrm{a}$ & 10.46 & 1.35 & $\mathrm{n} / \mathrm{a}$ \\
\hline-53 & microns & 27.74 & 29.43 & 3.97 & 2.94 & 87.97 & $\mathrm{n} / \mathrm{a}$ & 86.6 & 1.35 & $\mathrm{n} / \mathrm{a}$ \\
\hline mean particle size & microns & 60.7 & 60.2 & 100.2 & 104.4 & 31.6 & $\mathrm{n} / \mathrm{a}$ & 33.3 & 169.4 & $\mathrm{n} / \mathrm{a}$ \\
\hline harmonic mean & micron & 48.6 & 47.9 & 89.4 & 92.3 & 28.6 & $\mathrm{n} / \mathrm{a}$ & 28.9 & 150.2 & $\mathrm{n} / \mathrm{a}$ \\
\hline BET Surface Area & sq. $\mathrm{m} / \mathrm{g}$ & 1.348 & 2.537 & 5.167 & 2.435 & 3.748 & 3.462 & 2.686 & 4.1 & 2.093 \\
\hline \multicolumn{11}{|c|}{ Mercury Porosimetry Data } \\
\hline Total Intrusion Volume & $\mathrm{ml} / \mathrm{g}$ & 0.0454 & 0.3908 & 0.0295 & 0.3562 & $\mathrm{n} / \mathrm{a}$ & 0.5389 & 0.775 & $\mathrm{n} / \mathrm{a}$ & 0.1138 \\
\hline Total Pore Area & $\mathrm{m} 2 / \mathrm{g}$ & 5.688 & 14.68 & 6.574 & 12.383 & $\mathrm{n} / \mathrm{a}$ & 12.064 & 20.195 & $\mathrm{n} / \mathrm{a}$ & 7.066 \\
\hline Median Pore Diameter & $(\mathrm{vol}) \quad \AA$ & 76426 & 3531 & 10389 & 3320 & $\mathrm{n} / \mathrm{a}$ & 65260 & 51357 & $\mathrm{n} / \mathrm{a}$ & 3425 \\
\hline $\begin{array}{l}\text { Median Pore Diameter } \\
\text { Average Pore }\end{array}$ & (area) $\AA$ & 51 & 72 & 53 & 87 & $\mathrm{n} / \mathrm{a}$ & 62 & 63 & $\mathrm{n} / \mathrm{a}$ & 59 \\
\hline Diameter & $(4 \mathrm{~V} / \mathrm{A}) \AA$ & 320 & 1065 & 179 & 1150 & $\mathrm{n} / \mathrm{a}$ & 1787 & 1532 & $\mathrm{n} / \mathrm{a}$ & 644 \\
\hline Bulk Density & $\mathrm{g} / \mathrm{ml}$ & 1.8389 & 1.185 & 2.0798 & 1.3447 & $\mathrm{n} / \mathrm{a}$ & 0.8359 & 0.7089 & 1.12 & 1.8198 \\
\hline Apparent Density & $\mathrm{g} / \mathrm{ml}$ & 2.0065 & 2.2071 & 2.2157 & 2.5807 & $\mathrm{n} / \mathrm{a}$ & 1.521 & 1.5695 & $\mathrm{n} / \mathrm{a}$ & 2.2954 \\
\hline Porosity & $\%$ & 8.3578 & 46.3107 & 6.1337 & 47.8928 & $\mathrm{n} / \mathrm{a}$ & 45.0432 & 54.8322 & $\mathrm{n} / \mathrm{a}$ & 20.7177 \\
\hline Stem Volume Used & $\%$ & 10 & 42 & 6 & 40 & $\mathrm{n} / \mathrm{a}$ & 54 & 52 & $\mathrm{n} / \mathrm{a}$ & 26 \\
\hline $\begin{array}{l}\text { Attrition Index } \\
\text { (ASTM) }\end{array}$ & & 2.29 & $\mathrm{n} / \mathrm{a}$ & 7.55 & $\mathrm{n} / \mathrm{a}$ & 4.97 & $\mathrm{n} / \mathrm{a}$ & $\mathrm{n} / \mathrm{a}$ & 0.49 & $\mathrm{n} / \mathrm{a}$ \\
\hline Bulk Density & $\mathrm{lb} / \mathrm{ft} 3$ & $\mathrm{n} / \mathrm{a}$ & $\mathrm{n} / \mathrm{a}$ & $\mathrm{n} / \mathrm{a}$ & $\mathrm{n} / \mathrm{a}$ & $\mathrm{n} / \mathrm{a}$ & $\mathrm{n} / \mathrm{a}$ & $\mathrm{n} / \mathrm{a}$ & 69.7 & $\mathrm{n} / \mathrm{a}$ \\
\hline
\end{tabular}

n/a = not tested 
Table 6. Physical Properties of Trona

\begin{tabular}{|c|c|c|c|c|c|c|}
\hline & & $\begin{array}{l}\text { Trona T-50 } \\
\text { fresh }\end{array}$ & $\begin{array}{l}\text { Trona T-50 calcined } \\
\text { overnight at } 125^{\circ} \mathrm{C} \text { in air }\end{array}$ & $\begin{array}{l}\text { Trona T-200 } \\
\text { fresh }\end{array}$ & $\begin{array}{l}\text { Trona T-200 calcined } \\
\text { overnight at } 125^{\circ} \mathrm{C} \text { in air }\end{array}$ & $\begin{array}{l}\text { Sodium Carbonate } \\
\text { (commercial grade) }\end{array}$ \\
\hline \multicolumn{7}{|c|}{ Mercury Porosimetry Data } \\
\hline Total Intrusion Volume & $\mathrm{ml} / \mathrm{g}$ & 0.0294 & 0.2517 & 0.3481 & 0.7056 & $\mathrm{n} / \mathrm{a}$ \\
\hline Total Pore Area & $\mathrm{m} 2 / \mathrm{g}$ & 7.3 & 9.4 & 14.9 & 11.7 & $\mathrm{n} / \mathrm{a}$ \\
\hline Median Pore Diameter & $(\mathrm{vol}) \quad \AA$ & 7410 & 2833 & 68950 & 49258 & $\mathrm{n} / \mathrm{a}$ \\
\hline Median Pore Diameter & (area) $\AA$ & 42 & 100 & 41 & 91 & $\mathrm{n} / \mathrm{a}$ \\
\hline Average Pore Diameter & $(4 \mathrm{~V} / \mathrm{A}) \quad \AA$ & 162 & 1074 & 938 & 2415 & $\mathrm{n} / \mathrm{a}$ \\
\hline Bulk Density & $\mathrm{g} / \mathrm{ml}$ & 2.03 & 1.58 & 1.17 & 0.84 & $\mathrm{n} / \mathrm{a}$ \\
\hline Apparent Density & $\mathrm{g} / \mathrm{ml}$ & 2.16 & 2.63 & 1.97 & 2.08 & $\mathrm{n} / \mathrm{a}$ \\
\hline Porosity & $\%$ & 6 & 39.8 & 40.6 & 59.3 & $\mathrm{n} / \mathrm{a}$ \\
\hline Stem Volume Used & $\%$ & 8 & 44 & 48 & 70 & $\mathrm{n} / \mathrm{a}$ \\
\hline Attrition Index (ASTM) & & 1.79 & $\mathrm{n} / \mathrm{a}$ & 7.95 & $\mathrm{n} / \mathrm{a}$ & 2 \\
\hline
\end{tabular}


Table 7. Supported Sorbent Characterization

\begin{tabular}{|c|c|c|c|c|c|}
\hline Sample \# & $\begin{array}{c}\mathrm{Na}_{2} \mathrm{CO}_{3} \\
\text { content of } \\
\text { sorbent (\%) }\end{array}$ & \begin{tabular}{|c|}
$\begin{array}{c}\text { Compact Bulk } \\
\text { Density } \\
\text { (g/mL) }\end{array}$ \\
\end{tabular} & $\begin{array}{l}\text { BET Surface } \\
\text { Area (sq. m/g) }\end{array}$ & $\begin{array}{c}\text { TGA Weight } \\
\text { Gain, } 20 \text { min. } \\
(\%)\end{array}$ & $\begin{array}{c}\text { Attrition Ratio } \\
\text { (AR) }\end{array}$ \\
\hline 041604-1a & 0 & 0.68 & 96.6 & 3.8 & 3.1 \\
\hline $042004-1 a$ & 0 & 0.74 & 120.8 & 4.6 & 3.0 \\
\hline $040204-1 a$ & 20 & 0.51 & 28.43 & 7 & $\mathrm{Nt}$ \\
\hline $040504-1 a$ & 40 & 0.64 & 12.91 & 10 & $\mathrm{Nt}$ \\
\hline $040804-1 a$ & 20 & 0.5 & 33.7 & 6.2 & $\mathrm{Nt}$ \\
\hline 040904-1a & 40 & 0.64 & 14.29 & 9 & $\mathrm{Nt}$ \\
\hline $041204-1 a$ & 20 & 0.5 & 31.4 & 6.6 & $\mathrm{Nt}$ \\
\hline 041604-2a & 40 & 0.64 & 13.5 & 8.7 & $\mathrm{Nt}$ \\
\hline 041604-3a & 50 & 0.71 & 10.7 & 9.2 & $\mathrm{Nt}$ \\
\hline 042104-1a & 40 & 0.74 & 7.9 & 8.9 & $\mathrm{Nt}$ \\
\hline $042104-2 a$ & 40 & 0.74 & 7.0 & 7.9 & $\mathrm{Nt}$ \\
\hline $042804-1 a$ & 20 & 0.43 & 34.8 & 6.7 & $\mathrm{Nt}$ \\
\hline $042804-2 a$ & 40 & 0.51 & 10.9 & 8.9 & $\mathrm{Nt}$ \\
\hline 042904-1a & 40 & 0.49 & 9.84 & 9.1 & $\mathrm{Nt}$ \\
\hline 050504-3 & 40 & 0.89 & 6.96 & 5.2 & 1.3 \\
\hline $050704-1 a$ & 40 & 0.54 & 14.3 & nt & 2.3 \\
\hline 050704-3a & 40 & 0.54 & 11.4 & nt & 1.3 \\
\hline $110102-1$ & 7.5 & $\mathrm{nt}$ & 178 & 6.0 & 1.0 \\
\hline $\mathrm{K}-1^{+++}$ & 40 & $\mathrm{nt}$ & 4.5 & nt & nt \\
\hline $\mathrm{K}-2^{+++}$ & 10 & $\mathrm{nt}$ & 93 & nt & nt \\
\hline $\begin{array}{l}\text { Calcined } \\
\text { SBC } 3\end{array}$ & --- & 0.99 & 2.41 & 4.2 & nt \\
\hline $\mathrm{FCC}+$ & --- & 0.96 & nt & nt & 1.0 \\
\hline RTI-5 & 40 & 1.61 & 1.85 & 1.5 & 0.51 \\
\hline
\end{tabular}

nt $=$ not tested

$+=$ Commercial fluid cracking catalyst (standard material)

$+++=$ Potassium Carbonate 
As seen in Table 7, sorbents have been developed in the laboratory with substantially greater activity than calcined SBC\#3. The increased activity is even more significant when the reduced fraction of active material (typically $40-50 \%$ for supported sorbents as opposed to $100 \%$ for calcined SBC\#3) is considered. Some of these sorbents also exhibit AR of 1.0 to 1.5 indicating that they are attrition resistant. One promising spray-dried material produced at RTI containing $40 \% \mathrm{Na}_{2} \mathrm{CO}_{3}$ that had relatively high carbonation activity and good attrition resistance was selected for scale-up. A commercial catalyst manufacturer prepared several hundred pounds of this material (RTI-5). The commercially produced material had excellent attrition resistance but had very low reactivity. A review of the procedures used to produce this material suggested that there were significant differences in the production technique between the laboratory and the scale-up facility. Another attempt to scale up this material or a similar formulation is planned. 


\section{CHAPTER 4}

\section{CONCLUSIONS}

This study has demonstrated the technical feasibility of a dry, regenerable, sodium sorbentbased process for the capture of $\mathrm{CO}_{2}$ from flue gas, and the production of pure $\mathrm{CO}_{2}$ suitable for use or sequestration during the sorbent regeneration phase. The process offers a potential alternative to amine-based scrubbing processes for $\mathrm{CO}_{2}$ capture from flue gas.

$\mathrm{CO}_{2}$ capture is accomplished by the reversible reaction with $\mathrm{Na}_{2} \mathrm{CO}_{3}$ to form either $\mathrm{NaHCO}_{3}$ or Wegscheider's salt, depending on reaction conditions. The reaction is reversed at higher temperature to regenerate the sorbent and liberate equal molar quantities of $\mathrm{CO}_{2}$ and $\mathrm{H}_{2} \mathrm{O}$. Pure $\mathrm{CO}_{2}$ for use or sequestration is produced after condensation of the $\mathrm{H}_{2} \mathrm{O}$. The carbonation $\left(\mathrm{CO}_{2}\right.$ capture) reaction is feasible in the temperature range of $60^{\circ} \mathrm{C}$ to $70^{\circ} \mathrm{C}$, with the lower temperature limit established by the dew point of the carbonation feed gas, and the upper temperature limited by the thermodynamics of the exothermic, reversible carbonation reaction. This narrow temperature window coupled with the exothermic nature of the carbonation reaction indicates that careful energy management and temperature control will be required in a commercial process.

A promising means of temperature control of the carbonation reaction is evaporative cooling through the addition of atomized liquid water to the reactor. This is complicated by the tendency of the sorbent materials to cake. Sorbent regeneration in pure $\mathrm{CO}_{2}$ should be carried out at a temperature of about $160^{\circ} \mathrm{C}$. Acid flue gas contaminants such as $\mathrm{SO}_{2}$ and $\mathrm{HCl}$ will react irreversibly with the sorbent to such an extent than an upstream desulfurization process will be required when using sulfur-containing fossil fuels.

$\mathrm{CO}_{2}$ removal efficiencies of about $90 \%$ were achieved during the early stages of laboratoryscale fixed-bed and fluid-bed reactor tests. Complete carbonation of the sorbent was possible when the fixed-bed tests were carried out to completion. No deterioration in sorbent performance occurred in 15-cycle fixed-bed tests.

The calcination reaction, which regenerates the sorbent for reuse, has been confirmed to go to completion in laboratory-scale reactor systems. This endothermic reaction is responsible for most of the process energy requirements. While this heat requirement is fixed by the heat of 
reaction, the economic feasibility of the process will be improved by using the lowest quality heat available from the power plant.

Capital and operating costs will be strongly affected by the reactivity and attrition resistance of the sorbent. A faster and more complete carbonation will result in smaller and less expensive contacting equipment. Sorbents with greater attrition resistance will result in reduced sorbent loss and thus lower operating cost. Supported sorbent have been prepared in the laboratory with increased reactivity as well as increased attrition resistance. Scale up of these sorbents to large quantity is in progress. 


\section{CHAPTER 5}

\section{FUTURE WORK}

\subsection{MATHEMATICAL MODELING OF THE PROCESS}

Using ASPEN PLUS process simulation software, a model has been developed to represent a cyclic sodium carbonate sorbent-based, entrained-bed reactor process to capture and concentrate carbon dioxide from flue gas. This model will be refined to produce realistic material and energy balances, optimizing the use of heat from the power plant for sorbent regeneration. Ultimately, this model will be used to size equipment for a full-scale process. Capital and operating cost estimates will then be developed for the process.

\subsection{PILOT-SCALE TESTING}

Several multicycle tests will be conducted at a pilot-scale entrained-bed reactor facility. These tests will be conducted in single-loop mode with sorbent from the carbonation reaction collected and reloaded for calcination. The results of these tests will provide a good estimate of the rates that can be expected in a full-scale transport reactor system and will impact reactor sizing and economic feasibility analyses.

\subsection{SORBENT DEVELOPMENT}

Work will continue in the laboratory spray dryer system to produce active, attrition-resistant sorbents that can be scaled to large-quantity production. 


\section{CHAPTER 6}

\section{REFERENCES}

ASTM International, 1995. Method D5757-95: Standard Test Method for Determination of Attrition and Abrasion of Powdered Catalysts by Air Jets.

Berger, A., 2002, The Effect of Greenhouse Gases on Climate, Proceedings of the Conference on Future Energy Systems and Technology for CO2 Abatement, Antwerp, Belgium, Nov. 18-19, pp. 1-18.

Church and Dwight, Inc., 2000, personal communication.

Doctor, R., Molburg, J., Brockmeier, N., Manfredo, L., Gorokhov, VI, Ramezan, M., and Stiegal, G., 2001, Life-Cycle Analysis of A Shell Gasification-Based Multi-Product System with $\mathrm{CO}_{2}$ Recovery, Proceedings of the First Annual Conference on Carbon Sequestration, Washington, DC, May 14-17, http//:www.netl.gov/publications/proceedings/01/carbon_sq/4b1.pdf

Douglas, M., Zheng, L., Bulut, D., Tan, Y., Thambimuthu, K., Jamal, A., Berruti, A., McArthur, J., and Curran, K., 2003, Oxy-Combustion Field Demonstration Project, Proceedings of the Second Annual Conference on Carbon Sequestration, Alexandria, VA, May 5-8, http://www.carbonsq.com/papers.cfm

Falotico, A.J., "Dry Carbonation of Trona”, 1993. PCT Application No.: PCT/US92/06321 (WO 93/11010), assigned to Church and Dwight Co., Inc. June 10, 1993.

Hurst, P., Boden, J., Wilkinson, M., and Simmonds, M., 2003, Chemical Looping Combustion for $\mathrm{CO}_{2}$ Capture, Proceedings of the Second Annual Conference on Carbon Sequestration, Alexandria, VA, May 5-8, http://www.carbonsq.com/papers.cfm

Krieg, J.P., et al., "Dry Carbonation Process", 1984. U.S. Patent No.: 4,459,272, assigned to Church and Dwight Co., Inc. July 10

Reddy, S., Scherffius, J., Freguia, S., and Roberts, C., 2003, Fluor's Econamine FG Plus ${ }^{T M}$ Technology, Proceedings of the Second Annual Conference on Carbon Sequestration, Alexandria, VA, May 5-8, http://www.carbonsq.com/papers.cfm. 
Sarapata, J.S., et al., "Method for the Preparation of a Bicarbonate Sorbent in Flue Gas Desulfurization." 1987. U.S. Patent No.: 4,664,893, assigned to Church and Dwight Co., Inc. May 12

Yu, J., Corripio, A., Copeland, R., and Harrison, D., 2003, Analysis of the Sorbent Energy Transfer System (SETS) for Power Generation and $\mathrm{CO}_{2}$ Capture, Advances in Environmental Research, 7, 335-345.

Zhao, R., Goodwin, J.G., Jothimurugesan, K., Spivey, J.J., and Gangwal, S.K., "Comparison of Attrition Test Methods" ASTM Standard Fludized Bed vs Jet Cup", 2000. Ind. Eng. Chem. Res. 39, No. 5, p. 1155-1158. May 